
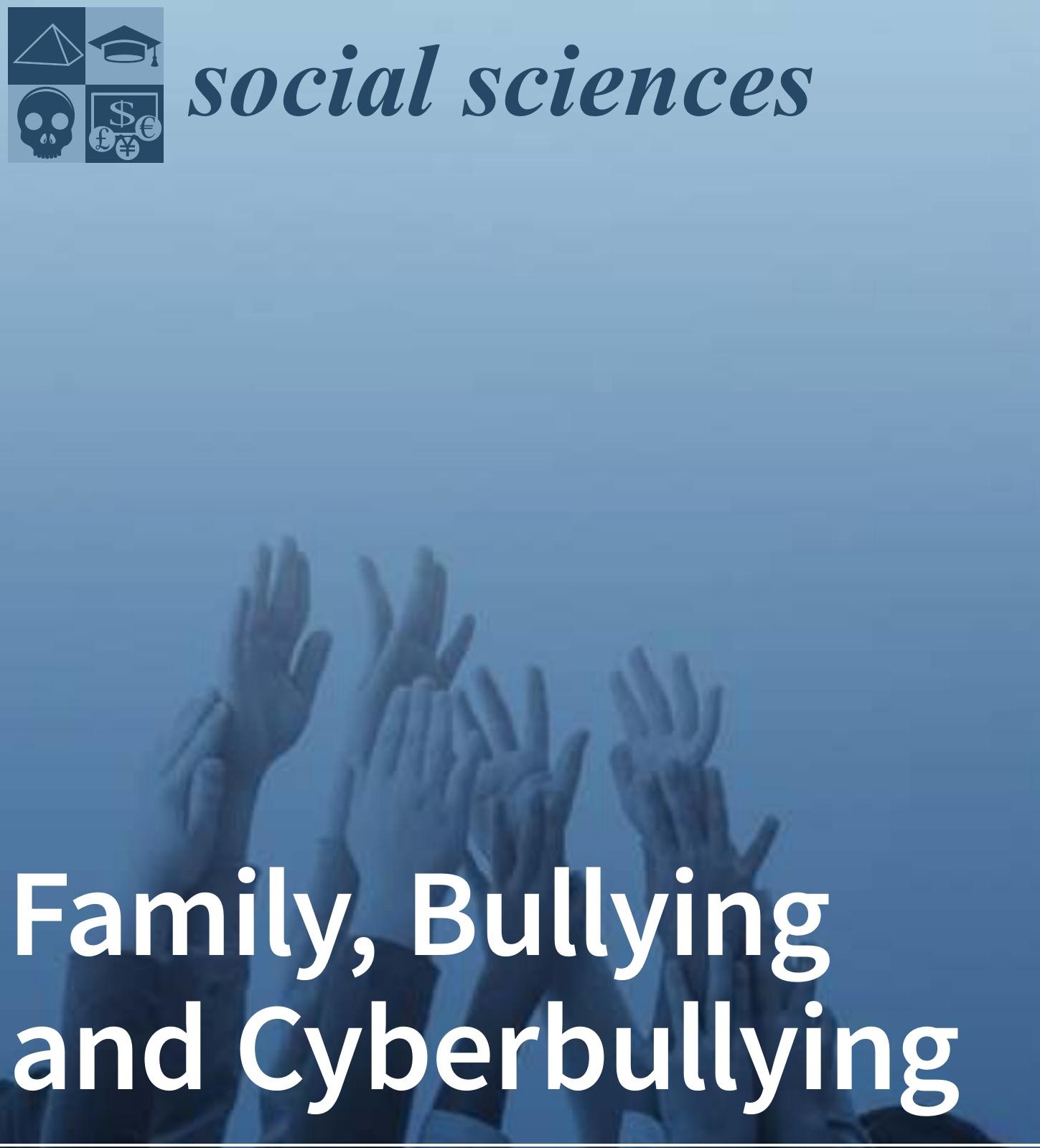

Edited by

Raul Navarro Olivas Printed Edition of the Special Issue Published in Social Sciences 
Family, Bullying and Cyberbullying 



\section{Family, Bullying and Cyberbullying}

Special Issue Editor

Raul Navarro Olivas 
Special Issue Editor

Raul Navarro Olivas

Universidad de Castilla-La Mancha

Spain

\section{Editorial Office}

MDPI

St. Alban-Anlage 66

4052 Basel, Switzerland

This is a reprint of articles from the Special Issue published online in the open access journal Social Sciences (ISSN 2076-0760) from 2018 to 2019 (available at: https:/ /www.mdpi.com/journal/ socsci/special_issues/family_bullying_and_cyberbullying)

For citation purposes, cite each article independently as indicated on the article page online and as indicated below:

LastName, A.A.; LastName, B.B.; LastName, C.C. Article Title. Journal Name Year, Article Number, Page Range.

ISBN 978-3-03921-080-0 (Pbk)

ISBN 978-3-03921-081-7 (PDF)

Cover image courtesy of freepik.com.

(C) 2019 by the authors. Articles in this book are Open Access and distributed under the Creative Commons Attribution (CC BY) license, which allows users to download, copy and build upon published articles, as long as the author and publisher are properly credited, which ensures maximum dissemination and a wider impact of our publications.

The book as a whole is distributed by MDPI under the terms and conditions of the Creative Commons license CC BY-NC-ND. 


\section{Contents}

About the Special Issue Editor $\ldots \ldots \ldots \ldots \ldots \ldots \ldots$ vii

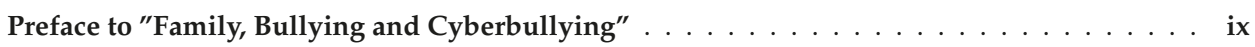

Leticia López-Castro and Diana Priegue

Influence of Family Variables on Cyberbullying Perpetration and Victimization: A Systematic

Literature Review

Reprinted from: Soc. Sci. 2019, 8, 98, doi:10.3390/socsci8030098 _ . . . . . . . . . . . . .

Olga Gómez-Ortiz, Carmen Apolinario, Eva M. Romera and Rosario Ortega-Ruiz

The Role of Family in Bullying and Cyberbullying Involvement: Examining a New Typology of Parental Education Management Based on Adolescents' View of Their Parents

Reprinted from: Soc. Sci. 2019, 8, 25, doi:10.3390/socsci8010025 . . . . . . . . . . . . . . 26

Jennifer L. Doty, Amy L. Gower, Renee E. Sieving, Shari L. Plowman and

Barbara J. McMorris

Cyberbullying Victimization and Perpetration, Connectedness, and Monitoring of Online

Activities: Protection from Parental Figures

Reprinted from: Soc. Sci. 2018, 7, 265, doi:10.3390/socsci7120265 . . . . . . . . . . . . . . .

Jessica Ortega Barón, Javier Postigo, Begoña Iranzo, Sofía Buelga and Laura Carrascosa

Parental Communication and Feelings of Affiliation in Adolescent Aggressors and Victims of Cyberbullying

Reprinted from: Soc. Sci. 2019, 8, 3, doi:10.3390/socsci8010003

Michelle F. Wright and Sebastian Wachs

Does Parental Mediation Moderate the Longitudinal Association among Bystanders and Perpetrators and Victims of Cyberbullying?

Reprinted from: Soc. Sci. 2018, 7, 231, doi:10.3390/socsci7110231 . . . . . . . . . . . . . . 66

Ana Romero-Abrio, Celeste León-Moreno, Daniel Musitu-Ferrer and

María Elena Villarreal-González

Family Functioning, Self-Concept and Cybervictimization: An Analysis Based on Gender

Reprinted from: Soc. Sci. 2019, 8, 69, doi:10.3390/socsci8020069 _ . . . . . . . . . . . . . 76

Carmen Yot-Domínguez, María Dolores Guzmán Franco and Ana Duarte Hueros

Trainee Teachers' Perceptions on Cyberbullying in Educational Contexts

Reprinted from: Soc. Sci. 2019, 8, 21, doi:10.3390/socsci8010021 . . . . . . . . . . . . . . 89

Hyun-jung Ju and Seung-ha Lee

Mothers' Perceptions of the Phenomenon of Bullying among Young Children in South Korea

Reprinted from: Soc. Sci. 2019, 8, 12, doi:10.3390/socsci8010012 . . . . . . . . . . . . . . . 107

Wanda Cassidy, Chantal Faucher and Margaret Jackson

What Parents Can Do to Prevent Cyberbullying: Students' and Educators' Perspectives

Reprinted from: Soc. Sci. 2018, 7, 251, doi:10.3390/socsci7120251 . . . . . . . . . . . . . . 125

Elisa Larrañaga, Santiago Yubero and Raúl Navarro

Parents' Responses to Coping with Bullying: Variations by Adolescents' Self-Reported Victimization and Parents' Awareness of Bullying Involvement

Reprinted from: Soc. Sci. 2018, 7, 121, doi:10.3390/socsci7080121 . . . . . . . . . . . . . . . 137 
Sofía Buelga, Belén Martínez-Ferrer, María-Jesús Cava and Jessica Ortega-Barón

Psychometric Properties of the CYBVICS Cyber-Victimization Scale and Its Relationship with Psychosocial Variables

Reprinted from: Soc. Sci. 2019, 8, 13, doi:10.3390/socsci8010013 . . . . . . . . . . . . . . . . . . 148

David Álvarez-García, Trinidad García and Zara Suárez-García

The Relationship between Parental Control and High-Risk Internet Behaviours in Adolescence Reprinted from: Soc. Sci. 2018, 7, 87, doi:10.3390/socsci7060087 


\section{About the Special Issue Editor}

Raul Navarro Olivas (PhD) is an Associate Professor at the University of Castilla-La Mancha in Spain. He has a PhD in psychology and a background in research on bullying and cyberbullying, specifically how bullying is related to gender identity. He is interested in trying to understand why people engage in aggressive behaviors and how we can prevent violence. 



\section{Preface to "Family, Bullying and Cyberbullying"}

A few years ago, one of my sisters asked me to talk to one of her friends whose son was being bullied by an older student. My sister told this friend that I had been studying bullying for years, and she believed that I could advise her on how to deal with this problem in the school and, also, on how to talk with her son. Although I had been investigating bullying for more than 10 years and I had published several studies analyzing this form of aggression in Spain, the truth is that I had not directly intervened in a bullying case beyond offering advice to different educational centers on how to study its prevalence and help in the design of some preventive activities. Indeed, although my formation in social psychology and my readings of studies, such as those conducted by Salmivalli and Voeten (2004) or Ojala and Nesdale (2004), helped me to understand that bullying is a social process involving individual and group factors, I had not paid special attention to family variables in my own research. Fortunately, I had read quite a lot of studies analyzing this relationship. Research by Espelage, Bosworth \& Simon (2000) or Cava, Musitu, Buelga \& Murgui (2010), among many others, has helped me, over the years, to comprehend the important role played by the family in the bullying dynamics. This knowledge, of course, did not make me an expert on the subject, but it did not make release me from the responsibility that I think academics and researchers have regarding the reality that we analyze. So, I met with my sister's friend to try to help her in whatever way I could or, in any case, guide her to seek more effective help than mine. When we met, I found a mother very concerned about her son's wellbeing. For a while, she had noticed he was more taciturn and reserved than usual. She tried to find out if something was happening to him, but he was not very communicative. Sometime later, he told her what was going on in the school. She experienced feelings of guilt and, also, anger. Luckily, these emotions had not led her to act impulsively. We know that when a boy or a girl finally decides to tell his family that he has been suffering bullying, adults should avoid playing down the facts that the child narrates, and also avoid blaming him/her for not defending themselves from the bullying. As this mother did, it is advisable not to make decisions in a "hot mood" or take actions without considering the opinion of the child. We must to take time to think about what is the best way to act. To begin with, it is almost certain that our son is reluctant to talk directly with the people in charge of the school. For example, he may fear that other peers will know about the bullying he/she is suffering. He may also fear possible retaliations from the perpetrator. At first, the family should help by listening attentively to what their child is telling them. It is important that family members make their child a participant regarding decisions about what to do, without it leading to inaction. In my opinion, this mother was doing great work listening to her son, and they agreed she would talk with the teachers at the school. When this time came, she happily met very receptive professionals who immediately began to inquire about the problem and were in constant communication with the parents about the steps they undertook to stop the bullying. Without going into detail, the effort made by the school staff was good, but the mother had internalized the guilt and she still felt unable to improve her son's wellbeing. I advised her regarding what the bullying research carried out in the last 40 years has discovered. Multiple studies have shown that family communication is key to detecting any type of problem that children and adolescents may be experiencing and to seek for solutions. Research has shown that families that spend time during the day engaged in dialogue with their members, for example, at meals or dinners, are able to detect possible situations of conflict more quickly (Elgar et al., 2014). In these spaces, parents must be interested in the things that young people have done during the day, especially 
in the school or when they are using information and communication technologies. Research has recommended that parents should encourage their children to talk about relationships with their friends, if they have had a specific problem with another student, or ask if there is someone they would like to invite home to know how his/her social life is going on. Although the existence of this communication, in itself, does not prevent that youth suffering from bullying, it does help to create a climate of trust in which the youth knows that his/her family members are there to help. In the case to which I am relating, finding moments to share the things that had happened during the day, finding spaces to play with their children, and being available when children wanted to talk strengthen the bond between the members of this family and enabled them to reconnect. Of course, this did not solve the problem on its own, but it did improve everyone's attitude in facing it and finding solutions. This mother's actions and the positive help of her son's teachers made the bullying stop, and his life in the center improved. Although single studies on bullying are not definitive enough from which we can draw universal clinical, practice, or policy implications, they could be helpful. In this sense, the aim of this book is to review and discuss the role that family plays on bullying behaviors during childhood and adolescence, with a special focus on electronic bullying or cyberbullying. It is my hope that the range of international and multidisciplinary perspectives brought together will serve to raise awareness of the importance of family in prevent bullying.

\section{References}

Cava, M. J., Musitu, G., Buelga, S., \& Murgui, S. 2010. The relationships of family and classroom environments with peer relational victimization: An analysis of their gender differences. The Spanish Journal of Psychology 13: 156-65.

Elgar, F. J., Napoletano, A., Saul, G., Dirks, M. A., Craig, W., Poteat, V. P. \& Koenig, B. W. 2014. Cyberbullying victimization and mental health in adolescents and the moderating role of family dinners. JAMA Pediatrics 168: 1015-22.

Espelage, D. L., Bosworth, K., \& Simon, T. R. 2000. Examining the social context of bullying behaviors in early adolescence. Journal of Counseling \& Development 78: 326-33.

Ojala, K., \& Nesdale, D. 2004. Bullying and social identity: The effects of group norms and distinctiveness threat on attitudes towards bullying. British Journal of Developmental Psychology 22: 19-35.

Salmivalli, C., \& Voeten, M. 2004. Connections between attitudes, group norms, and behaviour in bullying situations. International Journal of Behavioral Development 28; 246-58.

Raul Navarro Olivas

Special Issue Editor 




\title{
Influence of Family Variables on Cyberbullying Perpetration and Victimization: A Systematic Literature Review
}

\author{
Leticia López-Castro * and Diana Priegue \\ Department of Pedagogy and Didactics, University of Santiago de Compostela, 15782 Santiago de Compostela, \\ Spain; diana.priegue@usc.es \\ * Correspondence: leticia.lopez@usc.es
}

Received: 31 January 2019; Accepted: 11 March 2019; Published: 15 March 2019

\begin{abstract}
In recent years, the number of studies conducted on the influence of family variables on cyberbullying perpetration and victimization has increased, especially in terms of relational family processes. The present review investigates the role played by family variables on cyberbullying perpetration and victimization. A systematic literature review was conducted in five databases (ScienceDirect, Scopus, PubMed, ERIC, and Web of Science) from October 2016 to October 2018. During this brief period of time, the number of publications on family variables and cyberbullying, both perpetration and victimization, has significantly increased. We eventually reviewed 34 studies which rigorously met the selection criteria of our research. For the analysis of the results, we distinguish between two types of variables according to the following possibilities of pedagogical intervention: Structural (contextual family variables and individual parental processes), and dynamic (relational family processes). Our review found evidence that there is more controversy around structural variables than around dynamic variables. The most consistent variables are family communication and the quality of the family relationship. However, there is a perceived need for clarifying the influence that different structural variables, parental educational styles, and parental mediation exert on the prevention and consolidation of cyberbullying perpetration and cybervictimization.
\end{abstract}

Keywords: cyberbullying; cybervictimization; parent; family; systematic review

\section{Introduction}

Cyberbullying is an important phenomenon that may seriously affect anyone. Although a universal definition has not been agreed upon, a widely accepted one is proposed by Smith et al. (2008, p. 376), "an aggressive, intentional act carried out by a group or individual, using electronic forms of contact, repeatedly and over time against a victim who cannot easily defend him or herself". It is a complex phenomenon involving very different variables and factors. According to the socio-ecological approach applied to bullying, several factors interact, such as individual factors and those related to family, students, peer, and community reference groups, among others.

Given the above context, Espelage (2014) carried out a review of the protection and risk factors linked to each of these systems. It was found that parental monitoring, supervision, family conflict, family abuse, and family support are variables closely related to bullying. More recently, Nocentini et al. (2018) have conducted a systematic review of 154 articles published between 1970 and 2017 on the role played by contextual family processes, relational processes, and individual parental processes in bullying. This research shows the clear impact that family variables play in bullying, especially the contextual family variables and relational family variables and, to a lesser extent, the individual parental variables. More specifically, the variables with greater consistency and stability 
as predictors of the phenomenon are, on the one hand, domestic violence and parental mental health (contextual family variables), and on the other hand, child abuse, child neglect, and maladaptive parenting (relational family processes).

Kowalski et al. (2014) conducted an exhaustive meta-analysis research on cyberbullying among young people, including a critical review. Their work led to the conclusion that the children involved in cyberbullying situations had weaker emotional links with their parents, a higher level of parental discipline, and a lower frequency of parental monitoring. An inverse relationship between parental support and involvement as perpetration was also found, as well as between parental control and victimization. Görzig and Machackova (2015) also conducted a thorough analysis of the prevalence of the phenomenon from a socio-ecological perspective, using the data from the EU Kids Online research. They managed to recognize that the following variables: Parental concerns, parental Internet use, and restrictive parental mediation, were associated with cybervictimization. Finally, Elsaesser et al. (2017) analyzed the role of the parents in the prevention of cyberbullying and cybervictimization in adolescence through a systematic review until October 2016. The authors found that parental monitoring, as an integral part of a warm and supportive relationship, seems to be more closely related to a decreased involvement of children in cyberbullying, both as perpetrators and as victims. Definitively, these studies demonstrated the decisive role that family variables play in the prevention of this phenomenon (Elsaesser et al. 2017).

The main objective of our study is to carry out a systematic review of the literature, focusing on the role played by family variables in cyberbullying, both in terms of perpetration and victimization. The research covers a two-year period, between October 2016 and October 2018. The main reason for the selection of this period is the notable increase in the volume of publications on the phenomenon over the past three years. This can be seen through the search by title of the terms "cyberbullying OR cybervictim" in databases such as ScienceDirect, SCOPUS, PubMed, and Web of Science. The works published from 2016 to 2018 represent approximately 50\% of the total amount of publications with the same search criteria. Specifically, ScienceDirect found publications from 2007 to 2019, and the 2016-2018 period represents 52\%. In SCOPUS, we found such publications since 2010, with the 2016-2018 period corresponding to 51\%. In PubMed, taking into account publications from 2006 to 2019, the 2016-2018 period represents 49\%. Finally, Web of Science found publications since 2003 to 2019 , with the 2016-2018 period being equivalent to 50\%. Therefore, all of them attest to the increase in publications over the past three years. In addition, the systematic literature review carried out by Elsaesser et al. (2017) on family variables ended in October 2016. Although this research is not a continuation of their work, focusing on studies published between October 2016 and October 2018 allows us to cover a period of time that has not been previously analyzed.

For the analysis of the results, we integrated the socio-ecological approach (Bronfenbrenner 1977) into a typology that classifies the family variables as structural and dynamic, according to their possibilities of pedagogical intervention (Priegue 2016). The structural variables refer to the "family background" mentioned by Coleman et al. (1966, p. 22) and are generated from the interaction of multiple contextual variables, on which there is a lower possibility of pedagogical intervention. With regard to the socio-ecological theory, it could be understood that structural family variables are the product of the unidirectional interaction of the chronosystem, the macrosystem, the exosystem, and the mesosystem on the microsystem. Structural factors include contextual family variables and individual parental processes. The contextual family variables refer to family composition, socioeconomic status, parents' age, education level, mental health status, and violence between parents or siblings. The individual parental processes refer to the beliefs, knowledge, values, attitudes, and self-efficacy of parents. Second, the dynamic variables are the result of the multidirectional interaction between the microsystem and the other systems. In other words, the dynamic variables are derived from the interaction of the family and its structural variables (Ruiz 2001), which makes them more prone to pedagogical intervention. If we take the socio-ecological analysis of family variables conducted by Nocentini et al. (2018) as a reference point, the dynamic variables correspond to the relational family 
processes of their proposal. More specifically, dynamic factors include the interactions that occur in the family environment, such as the case of parental educational styles, communication, and family involvement and support.

\section{Method}

\subsection{Search Strategy}

The literature search was based on five different databases in order to collect the most relevant publications on the influence of family variables on cyberbullying, both in terms of perpetration and victimization. For the collection of the information, a manual coding system was used. We identified the family variables that had been studied in each research study, the type of sample, the type of behavior related to the phenomenon (cybervictimization and cyberbullying perpetration), as well as the main findings regarding the family variables studied.

In particular, we conducted a systematic search of the published studies on family variables and the phenomenon between October 2016 and October 2018, both inclusive. To this end, we followed the recommendations of Higgins and Green (2008), i.e., avoiding the search of many concepts separately, the use of "NOT", and the language restrictions in the search. In addition, we considered using synonyms and related terms combined with "AND" and "OR", as needed. The following databases were used: ScienceDirect, Scopus, PubMed, ERIC, and Web of Science. The search was conducted combining Abstract, Title, and Keywords where possible. ScienceDirect and Scopus allowed the search by Abstract, Title, and Keywords. PubMed and ERIC allowed the search by Abstract and Title. The Web of Science database allowed exclusively the search by Title. The search strategy, which was adapted according to the type of syntax, allowed in each database was the following: ("cyberbullying" OR "bullying" OR "cybervictim") AND ("family" OR "parent*") AND (pubyear: 2016-2018). To maximize the number of relevant results that may have been excluded, we used the following inclusive strategy: ("cyberbullying" OR “bullying" OR "cybervictim") AND (pubyear: 2016-2018).

\subsection{Study Exclusion Criteria}

For the search, we avoided the use of specific terms (e.g., control, mediation, communication, etc.), in an attempt to include all possible family-related variables. However, studies with the following characteristics were excluded: (1) Those focused on general aggression or violence and not on bullying; (2) those which addressed bullying, but did not include cyberbullying perpetration or cybervictimization; (3) those which addressed consequences associated with cyberbullying perpetration or cybervictimization (e.g., depression, stress, anxiety, etc.); (4) those which used family variables as moderators of psychological symptoms linked to cyberbullying perpetration or cybervictimization (e.g., family conflict and depression, mental distress and family support, etc.); (5) meta-analysis studies or systematic reviews of the literature; (6) those which used languages other than English; and (7) those that were not published in an article format.

\subsection{Data Extraction}

The general search in the five databases included 8802 articles. Starting from this initial search, we reviewed the Title of all the articles found, allowing us to exclude 8720 studies. The duplicated studies $(n=6025)$ and those whose Title did not fit the seven criteria of the study $(n=2695)$ were discarded. Thus, the number of articles evaluated for eligibility was 82 . Subsequently, we reviewed the Abstract and the full text of each of them to check whether the criteria were met, discarding a total of 48 (see Figure 1). Finally, there were 34 research studies that rigorously met the criteria of our study and were therefore included in this review. 


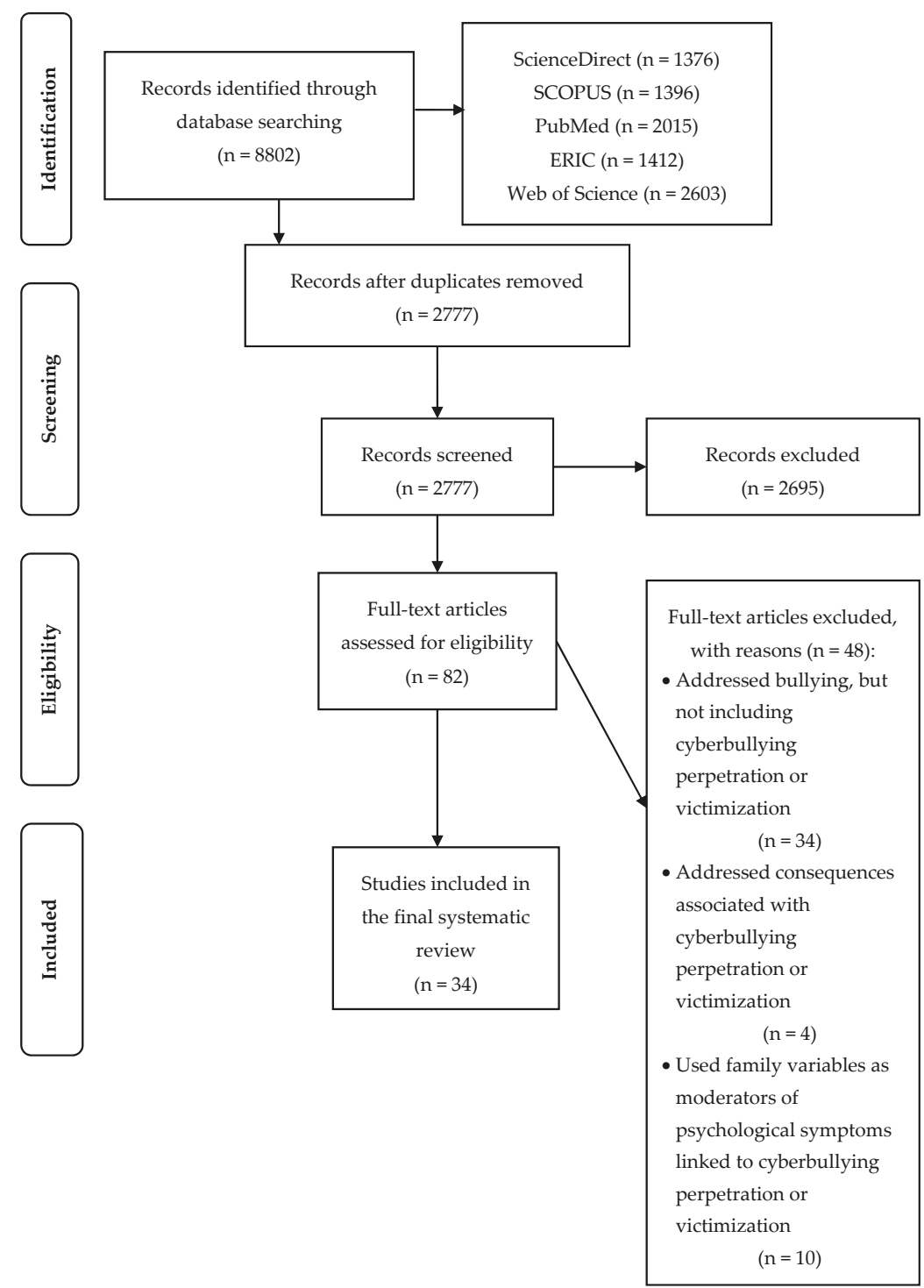

Figure 1. PRISMA Flow diagram of the systematic review process.

\section{Results}

There were 4 articles published from October to December 2016 (12\%), 18 in 2017 (53\%), and 12 from January to October 2018 (35\%). Of the 34 empirical studies included in this review, 29 are cross-sectional (85\%), and 5 are longitudinal (15\%). There are 33 quantitative studies, compared to a single qualitative study. The samples were mainly from Asia (47\%), Europe (32\%), and the United States (15\%), but a research study from Africa and another from Oceania were also included (see Table 1).

According to the quality of the 34 articles included in this review, $82 \%$ were published in a JCR journal, $9 \%$ in SCOPUS journal, and $9 \%$ in others $(6 \%$ were found from ERIC and 3\% from Web of 
Science). A total of $82 \%$ of journals are Open Access and $88 \%$ of the studies were evaluated through a peer-review process.

Table 1. Sample region and characteristics of the review.

\begin{tabular}{ccc}
\hline Sample Region & Country & $\begin{array}{c}\text { Frequency of Studies, } \\
\text { n (\%) }\end{array}$ \\
\hline \multirow{6}{*}{ Asia } & China & $1(3 \%)$ \\
& Iran & $1(3 \%)$ \\
& Israel & $2(7 \%)$ \\
& Jordan & $1(3 \%)$ \\
& Kuwait & $1(3 \%)$ \\
Malaysia & $1(3 \%)$ \\
& Singapore & $1(3 \%)$ \\
South Korea & $2(7 \%)$ \\
Africa & Turkey & $5(17 \%)$ \\
\multirow{2}{*}{ America } & Vietnam & $1(3 \%)$ \\
\hline \multirow{3}{*}{ Europe } & South Africa & $1(3 \%)$ \\
& Canada & $1(3 \%)$ \\
& United States & $4(14 \%)$ \\
\hline Oceania & Cyprus & $1(3 \%)$ \\
& Greece & $1(3 \%)$ \\
& Iceland & $1(3 \%)$ \\
Source: Systematic review conducted by the authors.
\end{tabular}

The type of instrument most commonly used in these research studies (15\%) was the Revised Olweus Bully/Victim Questionnaire (Olweus 1996). In most cases, the original version was used and, in other cases, the questionnaire was adapted by the authors. The use of adaptations of other instruments, such as those of Ybarra et al. (2007) and Hunt et al. (2012), both employed in 18\% of the studies, was also quite common. Finally, $6 \%$ opted for the adaptation of the instrument of Ang and Goh (2010) and another 6\% opted for the one developed by Patchin and Hinduja (2011).

Regarding the research topic, there were 8 studies $(24 \%)$ that focused on the structural variables as follow: There were $6(18 \%)$ on the contextual family variables and $2(6 \%)$ on the individual parental processes. There were 20 studies $(58 \%)$ which examined the dynamic family variables. The remaining 6 studies (18\%) analyzed different levels of family functioning (see Table 2).

\subsection{Structural Variables}

\subsubsection{Contextual Family Variables}

There were $6(18 \%)$ studies which focused only on contextual family variables (Abdulsalam et al. 2017; Çakır et al. 2016; Chen et al. 2018; Garmy et al. 2018; Marret and Choo 2017; Shaheen et al. 2018). However, there were 9 more studies (26\%) which took into account such variables (Bevilacqua et al. 2017; Beyazit et al. 2017; Buelga et al. 2017; Doty et al. 2017; Garaigordobil and Machimbarrena 2017; Gómez et al. 2017; Le et al. 2017; Shams et al. 2017; Uludasdemir and Kucuk 2018). The following variables were included: Family composition, family conflict, family's socioeconomic status, parents' education level, parental employment situation, family's home degree of rurality, parents' age, technological competence, stress, and parents' city of residence.

The composition of the household turned out to be a prominent factor, with a certain degree of consensus. Bevilacqua et al. (2017) found that students from single-parent households were more likely to be cyberbullied. Abdulsalam et al. (2017) found that children of divorced/widowed parents were more likely to be a cybervictim. Chen et al. (2018) discovered that parents' divorce and separation were associated with cyberbullying victimization. Garmy et al. (2018) found a correlation between children 
who did not live with their parents and higher frequencies of being bullied (cyber and traditional victimization was included). Finally, Le et al. (2017) identified the composition of the household as a predictor of perpetration behavior (cyber and traditional perpetration was included). However, the other research studies that took this variable into account did not find any relationship between the composition of the household and the probability of being a cybervictim or a cyberbullying perpetrator (Beyazit et al. 2017; Doty et al. 2017; Uludasdemir and Kucuk 2018).

There is also quite a consensus among the results derived from the research on family conflict. Buelga et al. (2017) found that the family conflict predicted the role of cyberbullies. Chen et al. (2018) detected a relationship between parental in-law conflict and intimate partner violence, with a higher possibility of children becoming cybervictims. Marret and Choo (2017) stated that students who experienced high levels of parental conflict were twice more likely to be cybervictims. Finally, Shams et al. (2017) discovered that children who had witnessed violence between their parents were more likely to show bullying behaviors (cyber and traditional perpetration and victimization was included). However, Le et al. (2017) found that witnessing violence between their parents was a significant predictor of cyberbullying perpetration, but not in case of victimization.

Regarding the socioeconomic status, the results are inconclusive. Bevilacqua et al. (2017) found that a low socioeconomic status was associated with a greater risk of being a cyberbullying victim or a perpetrator. In addition, Shaheen et al. (2018) found that children belonging to low-income families experienced bullying (cyber and traditional perpetration was included) more than those from moderate-income families. Chen et al. (2018) were able to associate the low family income with cybervictimization. On the other hand, Beyazit et al. (2017) found that a high family income was a significant factor, predictive of cyberbullying perpetration. On the contrary, Garmy et al. (2018) studied the socioeconomic status, identifying three groups according to the degree of affluence (low, medium, and high), and the results were not significant.

In relation to the parents' education level, the findings of the reviewed studies are contradictory. Çakır et al. (2016) discovered that students with parents possessing a low level of education were more likely to be cybervictims and cyberbullies. However, in the study conducted by Chen et al. (2018) only the mother's low level of education was associated with cyberbullying victimization. In addition, it was also found that parents with a high level of education increased the likelihood of cyberbullying perpetration and victimization (Uludasdemir and Kucuk 2018).

Regarding parental employment situation, Chen et al. (2018) discovered that father's unemployment was associated with cybervictimization. Shams et al. (2017) indicated that employed parents had less time to spend with their children and these students sought weaker peers to bully them. However, Shaheen et al. (2018) stated that the parents' job did not have an impact on the adolescents' bullying experience (cyber and traditional victimization was included). Finally, Uludasdemir and Kucuk (2018) also found no relationship between parental employment situations and cyberbullying perpetration or victimization.

Regarding the family's home degree of rurality, Garmy et al. (2018) reported that children who lived in rural areas were associated with higher frequencies of being bullied (cyber and traditional perpetration was included). Likewise, Gómez et al. (2017) found a significant relationship between environment and involvement in cyberbullying behaviors, perpetration, and victimization.

In addition to the previous variables, others were studied, which were included in a single research study. Beyazit et al. (2017) found that being a young father (under 40 years of age) was a significant predictor of cyberperpetration. Çakır et al. (2016) discovered that the parents' technological competence made no statistically significant difference to being a cyberbullying perpetrator or a cybervictim. The research carried out by Garaigordobil and Machimbarrena (2017) reported that cybervictims had parents with higher parental stress. Finally, Abdulsalam et al. (2017) indicated that students whose parents were not from the city of residence (non-Kuwaiti) were more likely to be involved in cyberbullying perpetration or victimization. 


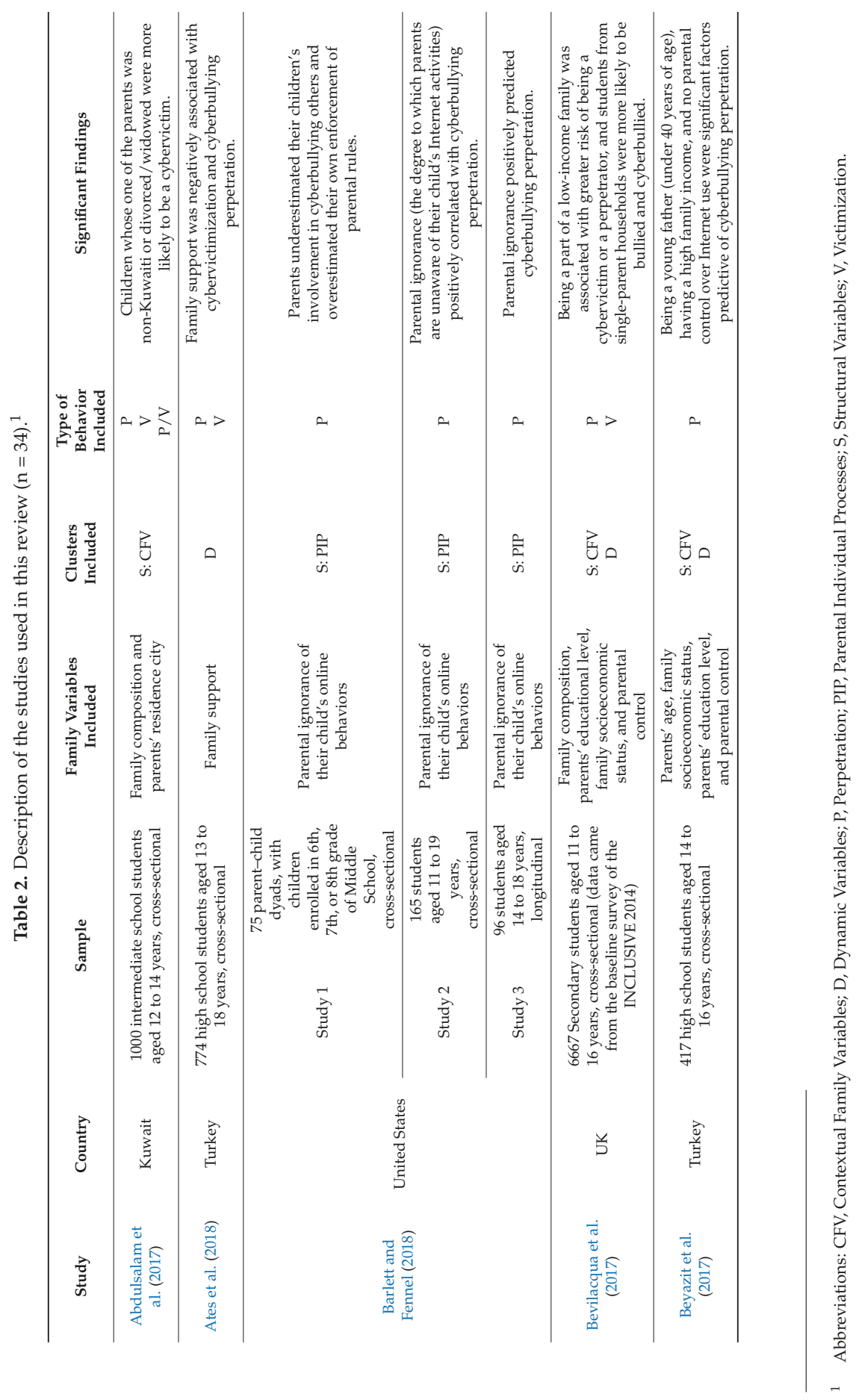




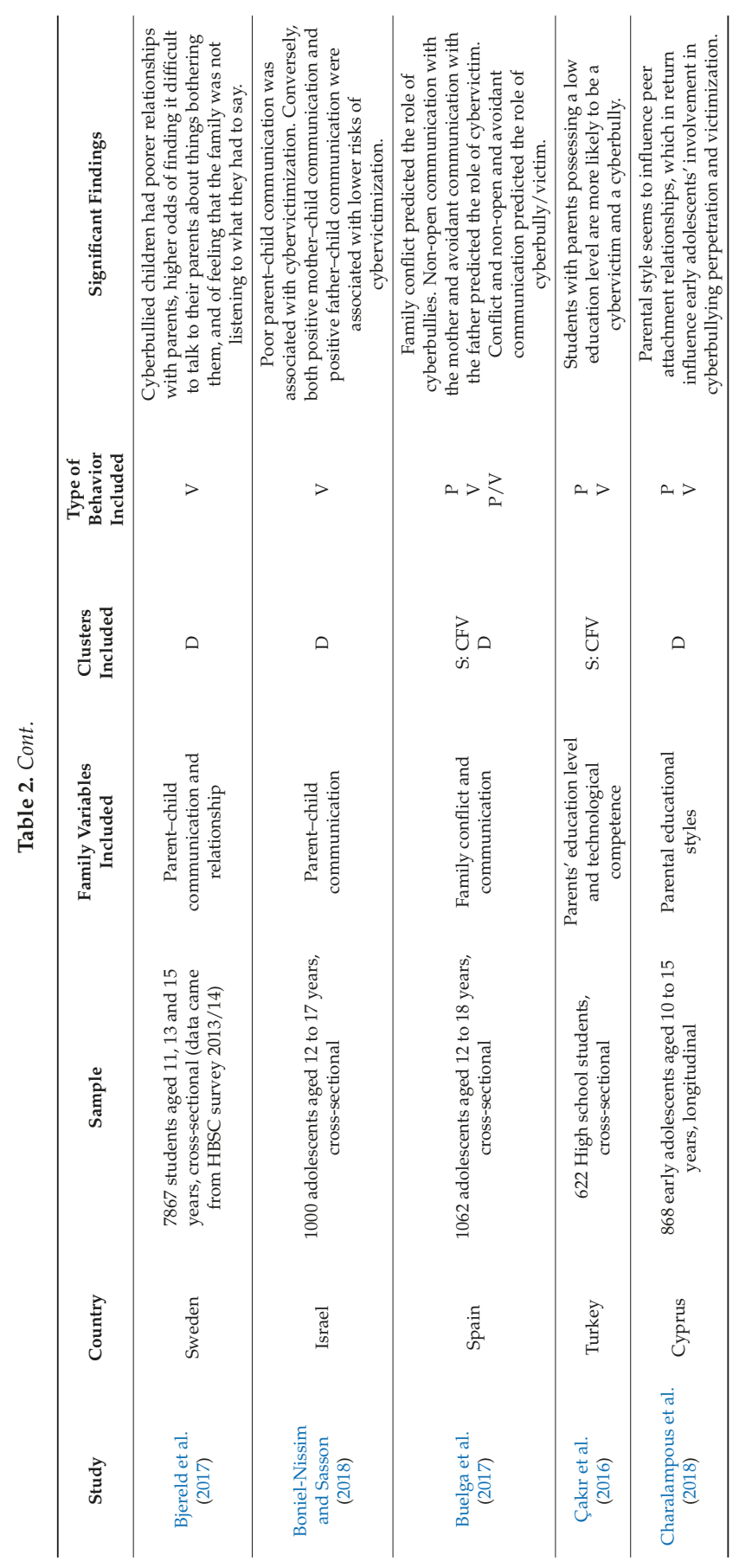




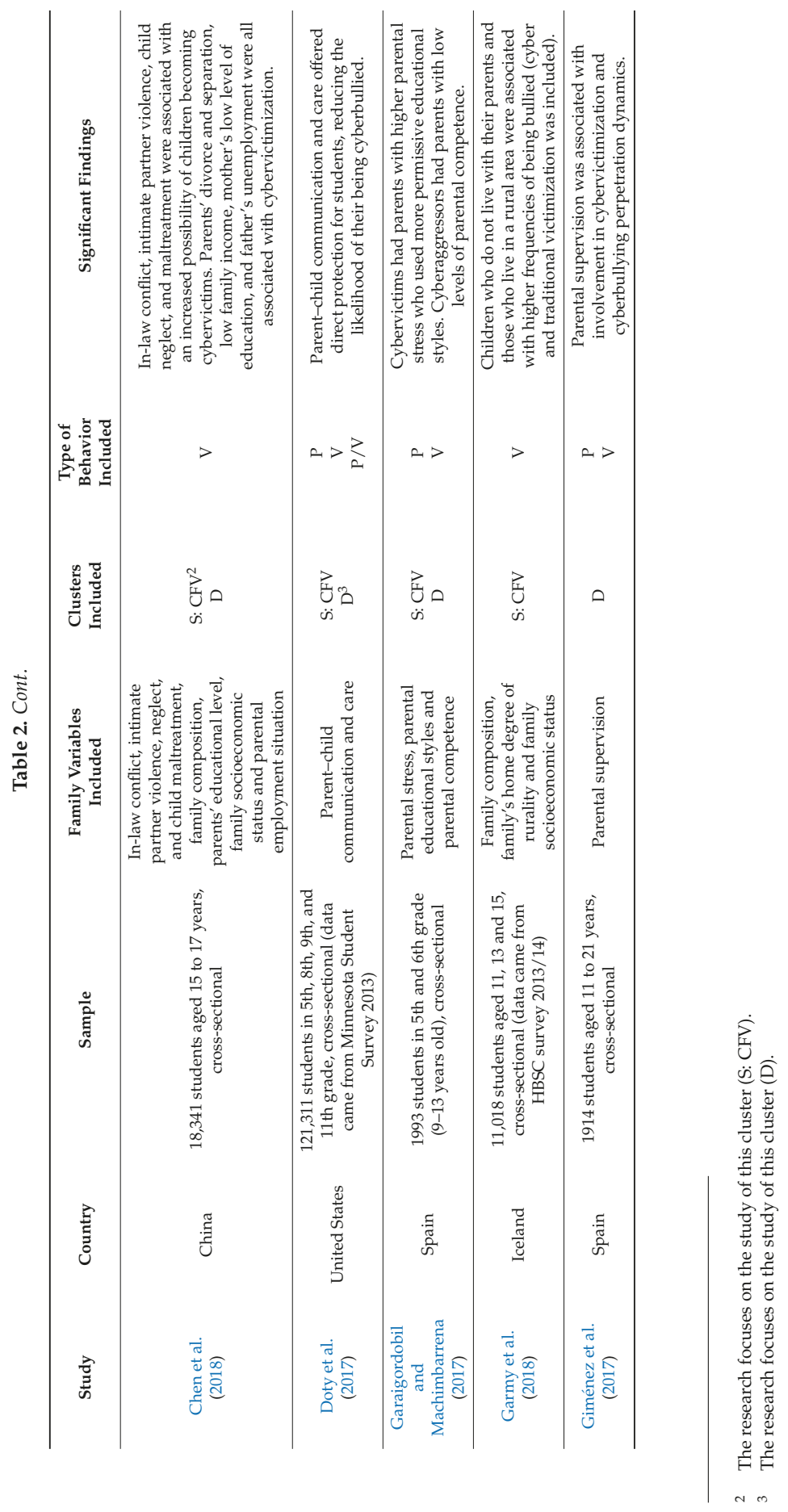




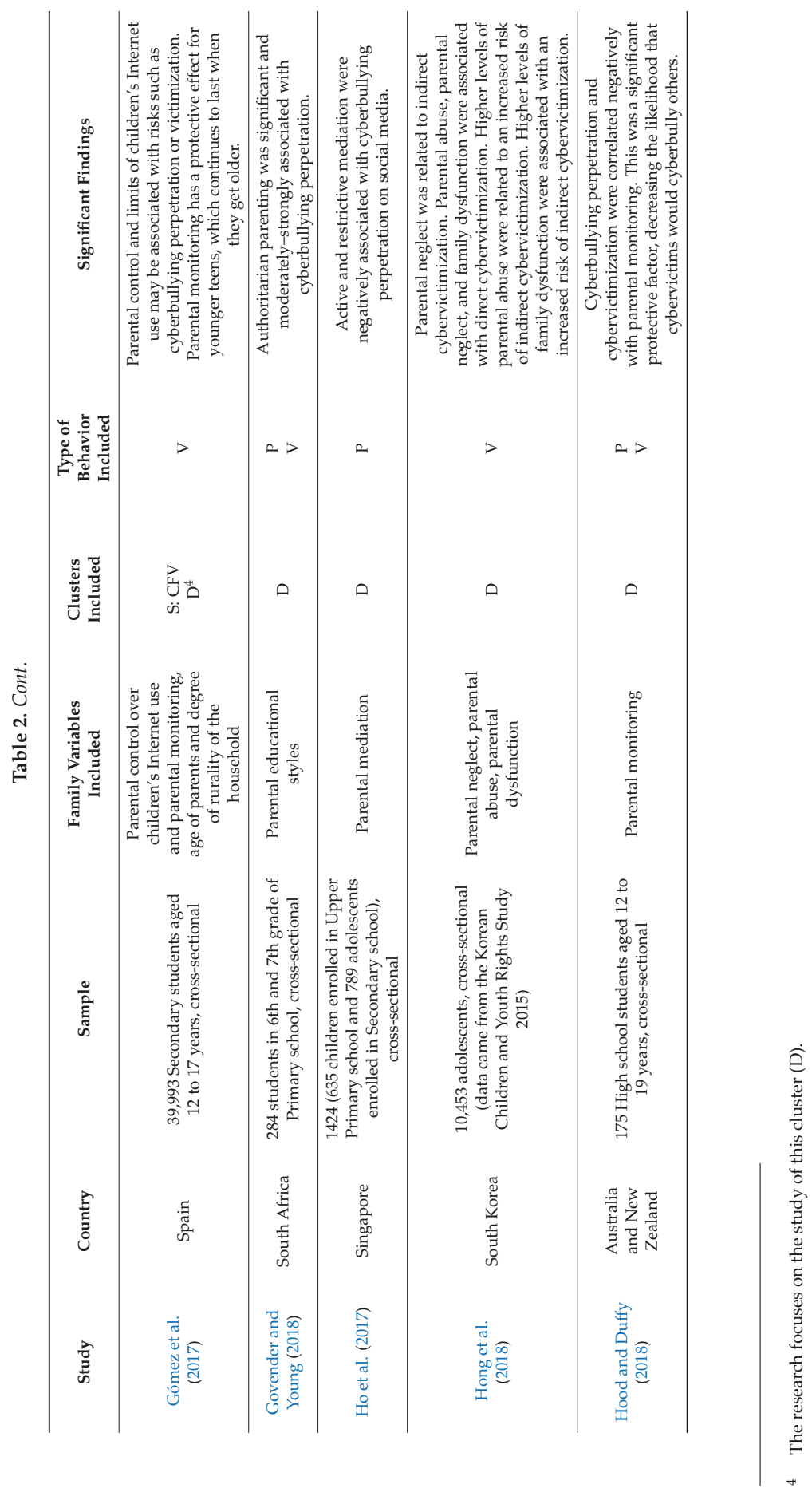




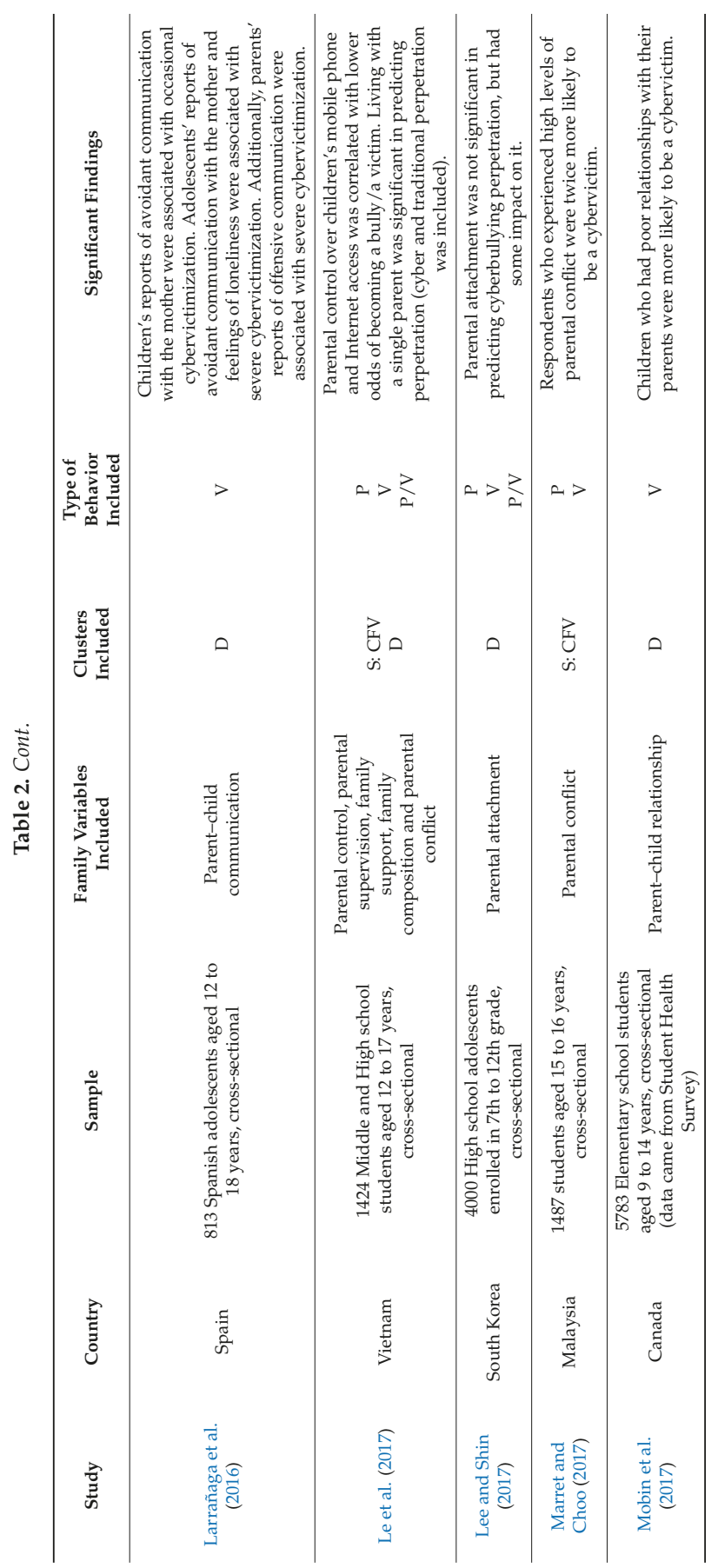




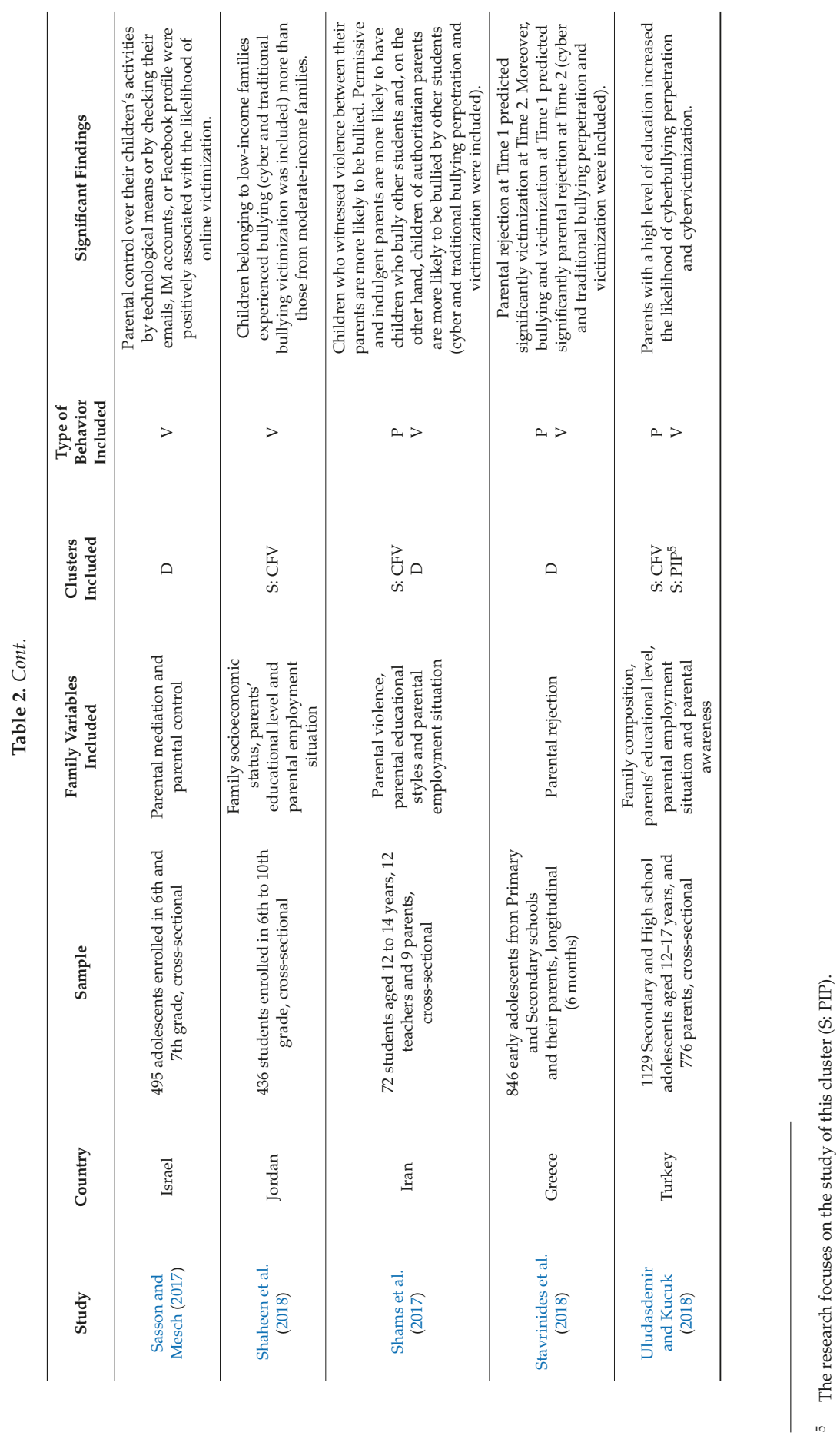




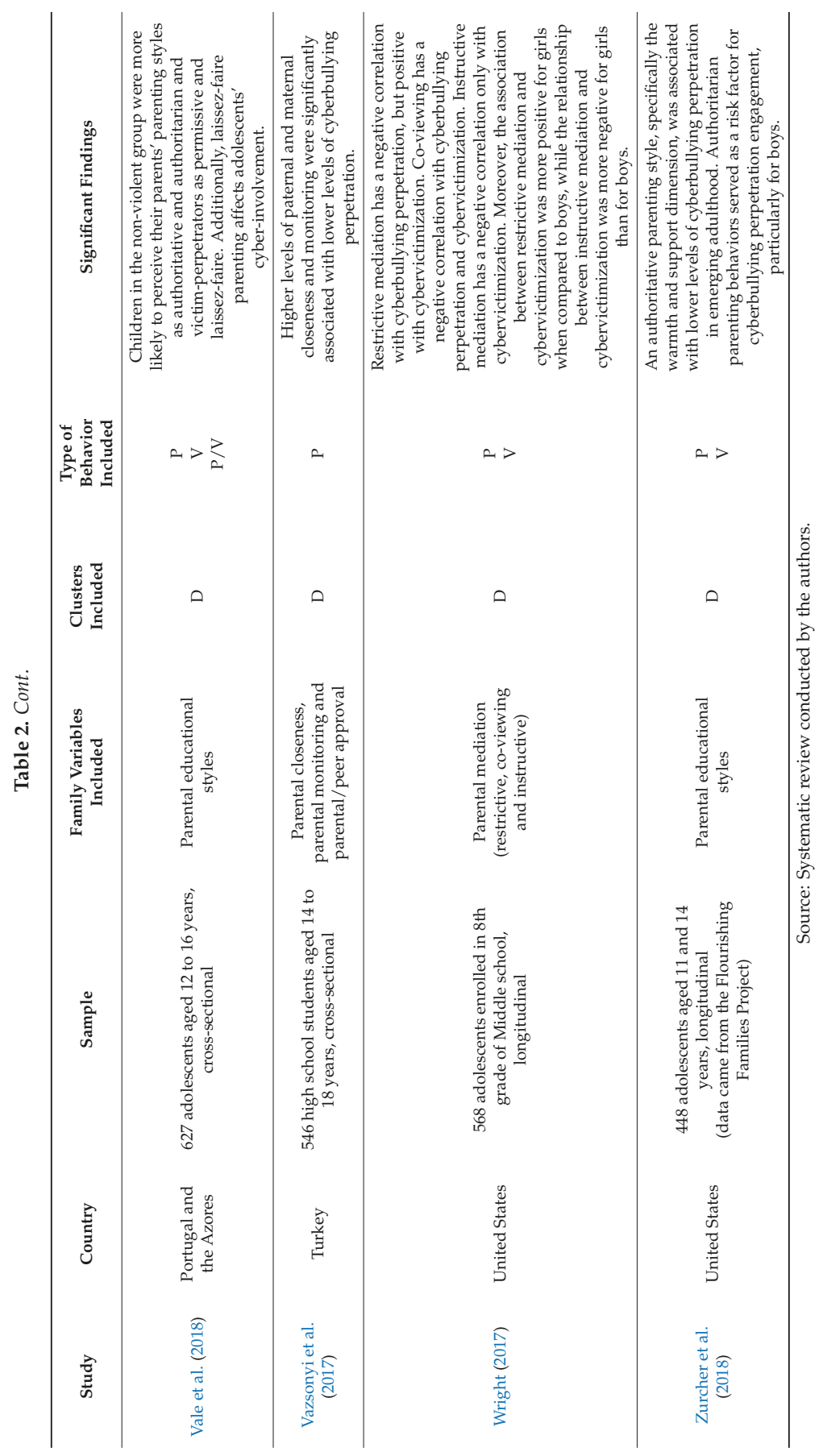




\subsubsection{Individual Parental Processes}

Only two research studies focused on individual parental processes. On the one hand, Barlett and Fennel (2018) studied parental ignorance of their children's online behaviors, which is understood as the degree to which parents are unaware of their children's Internet activities. It was found that parents underestimated their children's involvement in cyberbullying others and overestimated their own enforcement of parental rules. It was also confirmed that a positive correlation exists between parental ignorance and their children's cyberbullying behavior. Said ignorance is found to be a positive predictor of cyberbullying perpetration. On the other hand, Uludasdemir and Kucuk (2018) studied the parents' use of the Internet to monitor children's awareness of bullying/victimization. In this study, parents were found to be unaware of the cyberbullying and cybervictimization experienced by adolescents. More specifically, they were unaware of their children's social media account usage, which increases cyberbullying rates among adolescents by 5.5 times.

\subsection{Dynamic Variables}

There were 20 (58\%) studies which focused only on dynamic family variables (Bjereld et al. 2017; Boniel-Nissim and Sasson 2018; Charalampous et al. 2018; Chen et al. 2018; Doty et al. 2017; Giménez et al. 2017; Gómez et al. 2017; Govender and Young 2018; Ho et al. 2017; Hong et al. 2018; Hood and Duffy 2018; Larrañaga et al. 2016; Lee and Shin 2017; Mobin et al. 2017; Sasson and Mesch 2017; Stavrinides et al. 2018; Vale et al. 2018; Vazsonyi et al. 2017; Wright 2017; Zurcher et al. 2018). However, there were 6 more studies (17\%) which took into account dynamic variables (Bevilacqua et al. 2017; Beyazit et al. 2017; Buelga et al. 2017; Garaigordobil and Machimbarrena 2017; Le et al. 2017; Shams et al. 2017). The following variables are included: (a) Parental control over children's Internet use, monitoring and supervision, and mediation; (b) parent-child communication; (c) parental support, warmth, cohesion, closeness, care, and attachment; (d) parental educational styles; and (e) parental neglect, abuse and child maltreatment, parental dysfunction, rejection, and poor parent-child relationship.

\subsubsection{Parental Mediation}

Regarding parental mediation, Wright (2017) found that restrictive mediation had a negative correlation with cyberbullying perpetration and a positive correlation with cyberbullying victimization. Ho et al. (2017) agreed that restrictive and active mediation were negatively associated with cyberbullying perpetration on social media. In addition, Wright (2017) also found that co-viewing and instructive mediation had a negative correlation with cyberbullying perpetration and victimization. Despite the considerable number of studies which agree on the same results on parental mediation, Sasson and Mesch (2017) indicated that parental mediation through guidance or non-intervention was not statistically significant.

Regarding parental monitoring, there is fairly widespread agreement on its importance in the appearance of cyberbullying and cybervictimization, although with slight variations in terms of the role. Hood and Duffy (2018) discovered that cyberbullying perpetration and victimization were negatively correlated with parental monitoring. Moreover, it was a significant protective factor in preventing cybervictims from cyberbullying others. The results obtained by Gómez et al. (2017) indicated that parental monitoring had a protective effect, especially for younger adolescents, but also for the older ones. Moreover, Vazsonyi et al. (2017) also stated that higher levels of parental monitoring were significantly associated with lower levels of cyberbullying perpetration. Finally, Giménez et al. (2017) noted that parental supervision was associated with involvement in cyberbullying dynamics.

Regarding the parental control over children's Internet use, the findings of the three studies analyzing it agreed that it was a variable closely related to this phenomenon. Beyazit et al. (2017) discovered that it was a significant factor for predicting cyberbullying perpetration. Gómez et al. (2017) also indicated that the parental control and limitations over children's Internet use may be associated 
with cyberbullying perpetration and victimization. Le et al. (2017) detected a correlation between parental control and diminished odds of becoming a bully/a victim (cyber and traditional bullying perpetration and victimization were included). Finally, Sasson and Mesch (2017) found a positive correlation between the parental control over their children's activities by technological means or by checking their emails, IM accounts, or Facebook profile and the likelihood of online victimization.

\subsubsection{Parent-Child Communication}

Communication has been one of the most studied dynamic variables and there is a fairly high degree of agreement between the results, making it one of the most important variables. On the one hand, Boniel-Nissim and Sasson (2018) found that a poor parent-child communication was associated with cybervictimization. These findings coincide with the results of the research conducted by Buelga et al. (2017) who discovered that the variables, such as having non-open communication with the mother and avoidant communication with the father, predicted the role of cybervictim. In addition, Larrañaga et al. (2016) also found that children's reports of avoidant communication with the mother and parents' reports of offensive communication were both associated with cybervictimization. Finally, Bjereld et al. (2017) indicated that cyberbullied children had higher odds of finding it difficult to talk to their parents and of feeling that the family was not listening to them. On the other hand, both positive mother-child communication and father-child communication were associated with lower risks of cybervictimization (Boniel-Nissim and Sasson 2018). These results agree with the previous findings of the research conducted by Doty et al. (2017), who stated that parent-child communication offered direct protection for students, thus reducing the likelihood of their being cyberbullied.

\subsubsection{Parental Support, Warmth, Cohesion, Closeness, Care, and Attachment}

Research on parental support, warmth, cohesion, closeness, care, and attachment supports the importance of establishing a good relationship between parents and their children in order to prevent this phenomenon. According to Ates et al. (2018), family support was negatively associated with cybervictimization and cyberbullying perpetration. Vazsonyi et al. (2017) noted that higher levels of paternal and maternal closeness were significantly correlated with lower levels of cyberbullying perpetration. Doty et al. (2017) showed that care was directly protective for students, reducing the likelihood of being cyberbullied. Finally, Lee and Shin (2017) concluded that although the parental attachment variable failed to be significant in predicting cyberbullying perpetration, it did have some impact on it.

\subsubsection{Parental Educational Styles}

No consensus has yet been reached on the role of each of the parental educational styles in cyberbullying or cybervictimization, although their importance is unquestionable. Garaigordobil and Machimbarrena (2017) discovered that cybervictims had parents with higher parental stress, who used more permissive educational styles, whereas cyberaggressors had parents with lower levels of parental competence. Charalampous et al. (2018) indicated that parental style seemed to affect early adolescents' involvement in cyberbullying and victimization through their influence on peer attachment relationships. More specifically, Govender and Young (2018) noted that authoritarian parenting was significantly and moderately correlated with cyberbullying perpetration. These results agree with those obtained by Zurcher et al. (2018), who reported that authoritarian parenting behaviors served as a risk factor for cyberbullying perpetration, particularly for boys. They also coincide with the findings of the research conducted by Shams et al. (2017), who indicated that children of authoritarian parents were more likely to be bullied by other students (cyber and traditional victimization was included). From this study, it was also concluded that permissive and indulgent parents were more likely to have children who bully other students (cyber and traditional bullying perpetration was included). Vale et al. (2018) achieved results similar to those of the above-mentioned authors, stating that laissez-faire parenting affected adolescents' cyber-involvement. Their findings also indicated 
that children in the non-violent group were more likely to perceive their parents' style of parenting as authoritative and authoritarian, and victim-perpetrators as permissive and laissez-faire. Finally, Zurcher et al. (2018) also concluded that the authoritative parenting style, specifically the warmth and support dimension, was associated with lower levels of cyberbullying perpetration.

3.2.5. Parental Neglect, Child Abuse and Maltreatment, Parental Dysfunction, Rejection, and Poor Parent-Child Relationship

According to the research carried out by Hong et al. (2018), parental neglect was related to indirect cybervictimization. Higher levels of parental abuse and family dysfunction were associated with a higher risk of indirect cybervictimization. Moreover, parental abuse, parental neglect, and family dysfunction were associated with direct cybervictimization. These results coincide with those obtained by Chen et al. (2018) who claimed that child neglect and maltreatment were associated with a higher possibility of children becoming cybervictims.

Regarding parental rejection, the longitudinal research study conducted by Stavrinides et al. (2018) reported that parental rejection at Time 1 significantly predicted victimization at Time 2 . Parental rejection, however, was not a significant predictor of bullying. In addition, bullying and victimization at Time 1 significantly predicted parental rejection at Time 2 (cyber and traditional bullying perpetration and victimization were included).

Finally, Bjereld et al. (2017) concluded that cyberbullied children had poorer relationships with their parents. Similarly, the findings of Mobin et al. (2017) suggested that children who had a poor relationship with their parents were more likely to be cybervictims.

\section{Discussion}

\subsection{Structural Variables}

\subsubsection{Contextual Family Variables}

Research studies included in this review support the results of previous works regarding the importance of the following variables: Household composition (e.g., Fanti et al. 2012), family conflict (e.g., Baldry 2003; Beran and Violato 2004; Buelga and Chóliz 2013; Hawkins et al. 2000; Hemphill et al. 2015; Shields and Cicchetti 2001), family socioeconomic status (e.g., Görzig and Machackova 2015; Livingstone et al. 2011), and parents' education level (e.g., Makri-Botsari and Karagianni 2014), which we will discuss below.

Starting with the household composition, the discrepancy between the studies could be due to two factors as follows: The country of origin of the sample and the type of instrument used. Two of the research samples of the studies which did not find any relationship between the composition of the household and cyberbullying, perpetration, and victimization, came from Turkey (Beyazit et al. 2017; Uludasdemir and Kucuk 2018). In addition, these studies employed instruments less commonly used in research (e.g., Aricak et al. 2008; Topçu and Erdur-Baker 2010). Another study that did not find any relationship between the composition of the household and cyberbullying used the following single item to evaluate the phenomenon (Doty et al. 2017, p. 7): “How often have you been bullied through email, chat rooms, instant messaging, websites or texting?" The only research that found a relationship between the household composition and cyberbullying perpetration (Le et al. 2017) also employed an instrument less commonly used in research (Le et al. 2016). On the contrary, studies did find a relationship between the composition of the household and cybervictimization (Abdulsalam et al. 2017; Bevilacqua et al. 2017; Chen et al. 2018; Garmy et al. 2018) with instruments that have been extensively used in our study field (e.g., Olweus 1996) or items coming from research studies of recognized importance (e.g., Currie et al. 2014; Genta et al. 2009). Definitively, it could be concluded that the most reliable results point to a relationship between the household composition and cybervictimization. These results agree with previous research, such as the study conducted by 
Fanti et al. (2012) who found that adolescents living in single-parent households were more likely to be involved in cyberbullying victimization.

There is also a broad agreement among the results derived from studies on family conflict. Studies carried out in previous decades had already pointed out that the continued presence of violence and the use of ineffective strategies for the resolution of family conflicts led to violent behaviors and attitudes of children (Baldry 2003; Beran and Violato 2004; Hawkins et al. 2000; Shields and Cicchetti 2001). Subsequent studies, such as the work conducted by Hemphill et al. (2015), corroborated that family conflict was a predictive variable of bullying behaviors, which might be extended to cyberbullying and cybervictimization if we take into account that these patterns of violent behavior are generalized to other contexts, in both classroom and virtual environments (Buelga and Chóliz 2013). The relationship between family conflict and cybervictimization was also demonstrated by the studies analyzed in the present review (Buelga et al. 2017; Chen et al. 2018; Marret and Choo 2017) through instruments that have been extensively used in our study field (e.g., Currie et al. 2014; Ybarra et al. 2007). The only study that found no relationship between family conflict and cybervictimization, but did find it with cyberbullying perpetration (Le et al. 2017), employed an instrument less commonly used in research (Le et al. 2016). The only qualitative study included in this systematic review (Shams et al. 2017) agrees that there is a relationship between family conflict and involvement in bullying behaviors, although it does not mention what type. For all these reasons, we believe that family conflict has a significant influence on cybervictimization. However, further studies are needed to analyze in greater depth the possible relationship with cyberbullying perpetration.

Regarding the socioeconomic status, a higher level of consensus was found in previous research studies (e.g., Görzig and Machackova 2015; Livingstone et al. 2011). Livingstone et al. (2011) showed that the risk of becoming involved in the phenomenon was greater if the socioeconomic status was high. In the same vein, the findings of Görzig and Machackova (2015) pointed out a double relationship between the family socioeconomic status and participation in the phenomenon. On the one hand, between the role of victim and their low socioeconomic status and, on the other, between the role of aggressor and their high socioeconomic status. The research studies that we have considered for this systematic review differ more from each other. However, we could understand the differences according to the type of instrument used. The studies that agree on the influence of a low family socioeconomic status on the involvement in the phenomenon (Bevilacqua et al. 2017; Chen et al. 2018; Shaheen et al. 2018) do so through instruments that have been extensively used in our study field (e.g., Hunt et al. 2012; Genta et al. 2009). The only work that found a relationship between a high socioeconomic status and cyberbullying perpetration (Le et al. 2017) employed an instrument less commonly used in research (Le et al. 2016). In summary, the economic status seems to have an influence on cyberbullying perpetration and cybervictimization, but it is still an unclear variable, so further research may be necessary.

In relation to the parents' education level, the findings of the reviewed studies (Çakır et al. 2016; Chen et al. 2018; Uludasdemir and Kucuk 2018) are contradictory. Çakır et al. (2016) and Uludasdemir and Kucuk (2018) had different findings despite the fact that they had samples from the same country, Turkey, and of the same age group, high-school students. A possible explanation for their different findings could be the use of different instruments to assess the phenomenon (Ayas and Horzum 2010, respectively). A previous work which included the parents' education level variable is that conducted by Makri-Botsari and Karagianni (2014). Unlike the research contained in this study, they indicated that the educational level was not a significant differentiating factor of cyberbullying behavior. The role of the parents' education level variable on cyberbullying and victimization is still unclear, so further research may be necessary.

In relation to the parents' employment, the findings of the reviewed studies are contradictory. As in the case of the parents' education level, the same studies obtained different results (Çakır et al. 2016) in spite of the fact that they had samples from the same country, Turkey, and 
of the same age group, high-school students. The different findings could be due to the use of different instruments (Ayas and Horzum 2010; Topçu and Erdur-Baker 2010, respectively).

In addition to the previous variables, other variables that were analyzed by a single study, such as the degree of rurality, parents' age, parents' technological competence, parental stress, and the city of residence, should be studied in greater depth in the future.

\subsubsection{Parental Individual Processes}

Regarding previous research, the study of Canadian adolescents carried out by Hemphill et al. (2015) indicated that poor parental awareness of youth activities, when adolescents were 15 years of age, significantly predicted higher adolescent reports of past year cyberbullying perpetration four years later. The results of the work conducted by Uludasdemir and Kucuk (2018), which were analyzed in this systematic review, agree with those reached by that previous study. From the analysis of the parental individual processes we can conclude that the research should be extended, since the number of studies dealing with them is very limited and the influence they have on cybervictimization or cyberbullying perpetration is not clear. Therefore, studies on parents' knowledge of the phenomenon, their perception, as well as their beliefs, attitudes, and values would be of interest. Further research would allow us to compare the existing limited results and to draw the relevant conclusions.

\subsection{Dynamic Variables}

\subsubsection{Parental Mediation}

The works analyzed in this systematic review focused mainly on the study of parental monitoring, restrictive mediation, and control. On the one hand, the research studies that focused on parental monitoring (Gómez et al. 2017; Hood and Duffy 2018; Vazsonyi et al. 2017) agree that it is a strategy that has a negative influence on cyberbullying, both in terms of victimization and perpetration. These works used consolidated instruments to measure the phenomenon (e.g., Olweus 1996; Patchin and Hinduja 2011). On the other hand, studies that focused on restrictive mediation and control (Beyazit et al. 2017; Gómez et al. 2017; Ho et al. 2017; Le et al. 2017; Sasson and Mesch 2017; Wright 2017) also reached a certain consensus about the positive relationship that cyberbullying had with both victimization and perpetration. The most contradictory findings are those of Sasson and Mesch (2017), who indicated that they did not obtain significant results in terms of parental mediation through guidance or non-intervention. They showed that these actions had no effect on the odds of their children becoming online victims. However, these discrepancies can be explained by the type of sample used in the research, since they were the only ones who included children as young as ten years old. The other studies used samples of students aged from 12 to 14 years old. Another possible explanation for this discrepancy could be the type of instrument used since these authors are the only ones using a two-step method to measure cybervictimization. First, the children were asked if, in the last year, anyone had behaved toward him/her in an insulting or damaging manner. Subsequently, children who answered yes were then asked if this behavior happened online, face to face, or over the phone. Finally, the number of studies, included in this systematic review, that analyzed active mediation was very limited, since only Ho et al. (2017) showed a negative relationship with cyberbullying perpetration.

In the same way as indicated in the studies analyzed in this review, the scientific literature (e.g., D’Haenens et al. 2013; Duerager and Livingstone 2012; Navarro et al. 2013; Pfetsch 2018) supports mediation as an effective educational strategy in order to reduce the risks of Internet use by minors. However, there is no general agreement about what is the most effective type of mediation (Pfetsch 2018). More specifically, Navarro et al. (2013) stated that the monitoring software, the creation of rules governing the shared information, and the time minors spend online helped lessen the likelihood of becoming a cybervictim. Duerager and Livingstone (2012) showed that restrictive mediation was connected to lower online risks, such as involvement in cyberbullying behaviors. 
However, D'Haenens et al. (2013) reported a greater involvement in cyberbullying behaviors of children whose parents opted for the restrictive mediation of Internet use and who were less active in mediating Internet use. Lin and Chen (2016) found a significant and negative relationship between parental restriction and online risky behavior. In addition, their research discovered that parental monitoring was one of the strongest risk predictors. Finally, active parental mediation and co-use of media seem to be the most effective parental mediation strategies in relation to the prevention of cyberbullying perpetration and victimization, but further research is still needed (Pfetsch 2018). There is a clear need for continuing the research on parental mediation and, more specifically, on active mediation. This would allow comparing the results and understanding, in greater depth, the influence that parental mediation has on cyberbullying, both in terms of victimization and perpetration.

\subsubsection{Parent-Child Communication}

There is a fairly high degree of agreement between the results of the works studied (Bjereld et al. 2017; Boniel-Nissim and Sasson 2018; Buelga et al. 2017; Doty et al. 2017; Larrañaga et al. 2016), making parent-child communication one of the most important family variables. A poor quality of family communication, avoidant, not open, and with difficulties in general, is related to a greater probability of becoming a cybervictim. On the contrary, good communication works as a protective factor, reducing the risk of becoming a cybervictim. Several previous studies (e.g., Varela 2012; Yubero et al. 2014) found a greater possibility of becoming a victim of cyberbullying when there are, in general, communication problems in the family and, in particular, when we refer to the relationship with the mother. Therefore, the authors agree with Yubero et al. (2014, p. 344) on the importance of "improving family communication to protect children from harassment". Varela (2012) also confirmed, through her doctoral research, that young people who had relationships with their parents, characterized by open and fluid communication and by using, within the family, strategies of conflict resolution based on dialog and understanding, were not usually affected by situations that involve violence.

\subsubsection{Parental Cohesion}

The works studied analyzing family cohesion, support, care, attachment, and closeness (Ates et al. 2018; Doty et al. 2017; Lee and Shin 2017; Vazsonyi et al. 2017) agree that these are important variables to prevent cyberbullying, both in terms of victimization and perpetration. Family cohesion had also previously been pointed out as a protective factor of social adjustment during adolescence, which reduced the odds of experiencing cyberbullying perpetration (Navarro et al. 2013). Likewise, Ortega-Barón et al. (2016) indicated that severe cyberbullying victims, compared to non-victims, obtained significantly lower scores on family cohesion. In the same vein, Lin and Chen (2016) reflected a significant negative relationship between family cohesion and online risky behavior. In addition, Lin and Chen (2016) discovered that one of the strongest predictors for adolescents' risky online behavior was family cohesion.

\subsubsection{Parental Educational Styles}

The works studied analyzing the influence of parental educational styles on cyberbullying perpetration and victimization (Charalampous et al. 2018; Garaigordobil and Machimbarrena 2017; Govender and Young 2018; Shams et al. 2017; Vale et al. 2018; Zurcher et al. 2018) focused mainly on authoritarian and permissive styles. On the one hand, Govender and Young (2018), Shams et al. (2017), and Zurcher et al. (2018) agree that the authoritarian educational style has a positive relationship with cyberbullying perpetration. On the other hand, Garaigordobil and Machimbarrena (2017), Shams et al. (2017), and Vale et al. (2018) concur that there is a relationship between the permissive style and cybervictimization. A single study provided information on the authoritative style (Zurcher et al. 2018), which seems of great interest because of its negative relationship with the cyberbullying perpetration. 
The research studies addressing the relationship of parental educational styles and cyberbullying (e.g., Carson 2014; Dilmaç and Aydoğan 2010; Georgiou and Stavrinides 2013; Kokkinos et al. 2016; Makri-Botsari and Karagianni 2014) reached, in general terms, very similar conclusions, although we also detected certain discrepancies on specific issues, which we discuss below.

One of the first works that specifically addressed this issue was conducted by Dilmaç and Aydoğan (2010), who concluded that the most significant parental educational style, when predicting cyberbullying perpetration and victimization, was the authoritarian style. Makri-Botsari and Karagianni (2014) came to a similar conclusion, finding that the children of authoritative parents had the lowest rate of involvement, placing themselves at the other end of the scale compared to those educated under authoritarian guidelines. In addition, they indicated that parental educational styles could not be considered predictors of cybervictimization, but they were predictors of cyberperpetration.

Moreover, the doctoral research developed by Carson (2014) argued that there was a clear correlation between parental educational styles and involvement in cyberbullying situations. More specifically, the authoritative educational style was seen as a protective factor, predicting a low frequency of involvement in the phenomenon, and the permissive styles reached the highest risk levels. On the contrary, Kokkinos et al. (2016) pointed out that the neglecting educational style could be considered of the highest risk.

Definitively, it is clear that parental educational styles are closely related to cyberbullying perpetration and victimization, although it is not yet possible to establish an irrefutable correlation between different roles and styles. Despite this, it could be stated that a certain level of consensus has been reached by associating authoritarian and/or inconsistent styles with aggressive behaviors, overprotective styles with victimization behaviors, and authoritative styles as factors to protect the phenomenon for both roles. The fact is that parental educational styles are already recognized as determining factors in the child's behavior with information and communication technology (Kokkinos et al. 2016). Moreover, studying the influence of the authoritative educational style on cyberbullying perpetration and cybervictimization could provide a useful basis for further research.

\subsubsection{Poor Parent-Child Relationships}

The results of the analyzed studies on abuse, neglect, rejection, poor relationships, and family dysfunctions (Bjereld et al. 2017; Chen et al. 2018; Hong et al. 2018; Mobin et al. 2017; Stavrinides et al. 2018) achieved a significant level of agreement in their positive relationship with the involvement in cybervictimization. The findings of these studies on poor parent-child relationships are similar to previous outcomes (e.g., Gomes-Franco-Silva and Sendín-Gutiérrez 2014; Lereya et al. 2013). The meta-analysis performed by Lereya et al. (2013) demonstrated that the existence of a negative family climate made young people more vulnerable to being intimidated by their peers. More specifically, Gomes-Franco-Silva and Sendín-Gutiérrez (2014) noted that deteriorated family relationships resulted in children spending more time connected to the Internet, seeking to fill their gaps with interaction with other people online; it is well-known that this behavior involves numerous risks. Definitively, the quality of parent-child relationship has a clear relation with cybervictimization.

\section{Conclusions}

In recent years, the number of studies conducted on family variables has increased due to their evident repercussion on cyberbullying perpetration and victimization, especially works focused on dynamic variables. Our review found evidence that there is more controversy around structural variables than around dynamic variables. The most consistent variables are family communication and the quality of the family relationship. However, there is a perceived need for specifying the influence that different family structural variables, parental educational styles, and parental mediation exert on the prevention and consolidation of cyberbullying perpetration and cybervictimization. For all of these reasons, we believe that further steps should be taken to clarify the role that family variables perform on the phenomenon. Based on the large increase in publications over the past three years, systematic 
literature reviews carried out in a brief period could be very useful. This approach would allow us to examine the findings of further studies and draw conclusions regarding to the previous research.

\section{Limitations of the Study}

The main weakness is the lack of complementary sources, such as websites, theses, dissertations, snowballing literature, and gray literature. This deficiency is derived from excluding the studies which were not in an article format (exclusion criterion). Furthermore, our review lacks an in-depth analysis of the type of definition of cyberbullying used in each of these studies, in spite of being of special interest to the research of this topic. Finally, the quality of the empirical research used for this systematic review has not been conducted.

However, the present work focuses on clarifying the main findings on the hitherto little-explored influence exerted by family variables on both cyberbullying perpetration and cybervictimization. The reviewed studies were carried out over a finite period of time, in which there was a significant increase in the number of studies on family variables and cyberbullying perpetration and victimization.

Author Contributions: All authors have equally contributed to the paper.

Funding: This research received no external funding.

Conflicts of Interest: The authors declare no conflict of interest.

\section{References}

Abdulsalam, Ahmad J., Abdullah E. Al Daihani, and Konstantinos Francis. 2017. Prevalence and associated factors of peer victimization (bullying) among grades 7 and 8 middle school students in Kuwait. International Journal of Pediatrics 2017: 1-8. [CrossRef] [PubMed]

Ang, Rebecca P., and Dion H. Goh. 2010. Cyberbullying among adolescents: The role of affective and cognitive empathy, and gender. Child Psychiatry \& Human Development 41: 387-97. [CrossRef]

Aricak, Tolga, Sinem Siyahhan, Aysegul Uzunhasanoglu, Sevda Saribeyoglu, Songul Ciplak, Nesrin Yilmaz, and Cemil Memmedov. 2008. Cyberbullying among Turkish adolescents. Cyberpsychology \& Behavior 11: 253-61. [CrossRef]

Ates, Bünyamin, Alican Kaya, and Erhan Tunç. 2018. The Investigation of Predictors of Cyberbullying and Cyber Victimization in Adolescents. International Journal of Progressive Education 14: 103-18. [CrossRef]

Ayas, Tuncay, and Mehmet Barış Horzum. 2010. Cyber bully/victim scale development study. Akademik Bakıs 19: $1-17$.

Baldry, Anna C. 2003. Bullying in schools and exposure to domestic violence. Child abuse \& Neglect 27: 713-32. [CrossRef]

Barlett, Christopher P., and Miranda Fennel. 2018. Examining the relation between parental ignorance and youths' cyberbullying perpetration. Psychology of Popular Media Culture 7: 547-60. [CrossRef]

Beran, Tanya N., and Claudio Violato. 2004. A model of childhood perceived peer harassment: Analyses of the Canadian national longitudinal survey of children and youth data. The Journal of Psychology 138: 129-48. [CrossRef]

Bevilacqua, Leonardo, Nichola Shackleton, Daniel Hale, Elizabeth Allen, Lyndal Bond, Deborah Christie, Diana Elbourne, Natasha Fitzgerald-Yau, Adam Fletcher, Rebecca Jones, and et al. 2017. The role of family and school-level factors in bullying and cyberbullying: A cross-sectional study. BMC Pediatrics 17: 160-70. [CrossRef]

Beyazit, Utku, Şükran Şimşek, and Aynur Bütün Ayhan. 2017. An examination of the predictive factors of cyberbullying in adolescents. Social Behavior and Personality: An International Journal 45: 1511-22. [CrossRef]

Bjereld, Ylva, Kristian Daneback, and Max Petzold. 2017. Do bullied children have poor relationships with their parents and teachers? A cross-sectional study of Swedish children. Children and Youth Services Review 73: 347-51. [CrossRef]

Boniel-Nissim, Meyran, and Hagit Sasson. 2018. Bullying Victimization and Poor Relationships with Parents as Risk Factors of Problematic Internet Use in Adolescence. Computers in Human Behavior 88: 176-83. [CrossRef] 
Bronfenbrenner, Urie. 1977. Toward an experimental ecology of human development. American Psychologist 32: 513-31. [CrossRef]

Buelga, Sofía, and Mariano Chóliz. 2013. El adolescente frente a las nuevas tecnologías de la información y de la comunicación. In Adolescencia y Familia: Nuevos Retos en el Siglo XXI, 1st ed. Edited by Gonzalo Musitu. México: Trillas, pp. 209-28.

Buelga, Sofía, Belén Martínez-Ferrer, and María-Jesús Cava. 2017. Differences in family climate and family communication among cyberbullies, cybervictims, and cyber bully-victims in adolescents. Computers in Human Behavior 76: 164-73. [CrossRef]

Çakır, Özlem, Deniz Mertkan Gezgin, and Tuncay Ayas. 2016. The Analysis of the Relationship between Being a Cyberbully and Cybervictim among Adolescents in Terms of Different Variables. International Journal of Progressive Education 12: 134-54. Available online: http:/ /www.inased.org/v12n3/ijpev12n3.pdf (accessed on 20 December 2018).

Carson, Rosemary. 2014. Adolescent Cyberbullying in New Zealand and the Implications of Parenting Styles. Master's thesis, University of Canterbury, Canterbury, New Zealand. Available online: https: / /ir.canterbury. ac.nz/bitstream/handle/10092/9917/thesis_fulltext.pdf;sequence=1 (accessed on 6 December 2018).

Charalampous, Kyriakos, Constantina Demetrioua, Loukia Trichab, Myria Ioannoua, Stelios Georgioua, Militsa Nikiforoub, and Panayiotis Stavrinides. 2018. The effect of parental style on bullying and cyber bullying behaviors and the mediating role of peer attachment relationships: A longitudinal study. Journal of Adolescence 64: 109-23. [CrossRef]

Chen, Qiqi, Lo Camilla K. M, Zhu Yuhongc, Cheung Anned, Chan Ko Linga, and Ip Patricke. 2018. Family poly-victimization and cyberbullying among adolescents in a Chinese school sample. Child Abuse $\mathcal{E}$ Neglect 77: 180-87. [CrossRef]

Coleman, James Samuel, Elihu Katz, and Herbert Menzel. 1966. Medical Innovation: A diffusion Study. Indianapolis: The Bobbs-Merrill Company.

Currie, Candace, Jo Inchley, Michal Molcho, Michaela Lenzi, Zuzana Veselska, and Felicity Wild. 2014. Health Behaviour in School-Aged Children (HBSC) Study Protocol: Background, Methodology and Mandatory Items for the 2013/2014 Survey. St. Andrews: Child and Adolescent Health Research Unit (Cahru).

D’Haenens, Leen, Sofie Vandoninck, and Verónica Donoso. 2013. How to Cope and Build Online Resilience? London: London School of Economics and Political Science.

Dilmaç, Bülent, and Didem Aydoğan. 2010. Parental attitudes as a predictor of cyber bullying among primary school children. World Academy of Science, Engineering and Technology 67: 167-71. Available online: http: //waset.org/publications/3406 (accessed on 13 December 2018).

Doty, Jennifer L., Amy L. Gower, Jessie H. Rudi, Barbara J. McMorris, and Iris W. Borowsky. 2017. Patterns of bullying and sexual harassment: Connections with parents and teachers as direct protective factors. Journal of Youth and Adolescence 46: 2289-304. [CrossRef]

Duerager, Andrea, and Sonia Livingstone. 2012. How Can Parents Support Children's Internet Safety? London: London School of Economics and Political Science.

Elsaesser, Caitlin, Beth Russell, Christine McCauley Ohannessian, and Desmond Pattond. 2017. Parenting in a digital age: A review of parents' role in preventing adolescent cyberbullying. Aggression and Violent Behavior 35: 62-72. [CrossRef]

Espelage, Dorothy L. 2014. Ecological theory: Preventing youth bullying, aggression, and victimization. Theory into Practice 53: 257-64. [CrossRef]

Fanti, Kostas A., Andreas G. Demetriou, and Veronica V. Hawa. 2012. A longitudinal study of cyberbullying: Examining risk and protective factors. European Journal of Developmental Psychology 9: 168-81. [CrossRef]

Garaigordobil, Maite, and Juan Manuel Machimbarrena. 2017. Stress, competence, and parental educational styles in victims and aggressors of bullying and cyberbullying. Psicothema 29: 335-40. [CrossRef] [PubMed]

Garmy, Pernilla, Rúnar Vilhjálmsson, and Guðrún Kristjánsdóttir. 2018. Bullying in school-aged children in Iceland: A cross-sectional study. Journal of Pediatric Nursing 38: 30-4. [CrossRef] [PubMed]

Genta, Maria Luisa, Antonella Brighi, and Annalisa Guarini. 2009. European project on bullying and cyberbullying granted by Daphne II programme. Zeitschrift für Psychologie/Journal of Psychology 217: 233.

Georgiou, Stelios N., and Panayiotis Stavrinides. 2013. Parenting at home and bullying at school. Social Psychology of Education 16: 165-79. [CrossRef] 
Giménez, Ana $\mathrm{M}^{\mathrm{a}}$, José A. Luengo, and $\mathrm{M}^{\mathrm{a}}$ Bartrina. 2017. What are young people doing on Internet? Use of ICT, parental supervision strategies and exposure to risks. Electronic Journal of Research in Educational Psychology 15: 533-52. [CrossRef]

Gomes-Franco-Silva, Flávia, and José Carlos Sendín-Gutiérrez. 2014. Internet as a Haven and Social Shield. Problematic Uses of the Network by Young Spaniards/Internet como refugio y escudo social: Usos problemáticos de la Red por jóvenes españoles. Comunicar 22: 45-53. [CrossRef]

Gómez, Patricia, Sion Kim Harris, Carmen Barreiro, Manuel Isorna, and Antonio Rial. 2017. Profiles of Internet use and parental involvement, and rates of online risks and problematic Internet use among Spanish adolescents. Computers in Human Behavior 75: 826-33. [CrossRef]

Görzig, Anke, and Hana Machackova. 2015. Cyberbullying from a Socio-Ecological Perspective: A Contemporary Synthesis of Findings from EU Kids Online. London: London School of Economics and Political Science.

Govender, Catherine, and Kelly Young. 2018. A comparison of gender, age, grade, and experiences of authoritarian parenting amongst traditional and cyberbullying perpetrators. South African Journal of Education 38: 1-11. [CrossRef]

Hawkins, J. David, Todd I. Herrenkohl, David P. Farrington, Devon Brewer, Richard F. Catalano, Tracy W. Harachi, and Lynn Cothern. 2000. Predictors of Youth Violence. Juvenil Justice Bulletin 1: 1-12. Available online: https:/ / www.ncjrs.gov/pdffiles1/ojjdp/179065.pdf (accessed on 14 December 2018).

Hemphill, Sheryl A., Michelle Tollit, Aneta Kotevski, and Jessica A. Heerde. 2015. Predictors of traditional and cyber-bullying victimization: A longitudinal study of Australian secondary school students. Journal of Interpersonal Violence 30: 2567-90. [CrossRef]

Higgins, Julian P. T., and Sally Green. 2008. Cochrane Handbook for Systematic Reviews of Interventions. West Sussex: The Cochrane Collaboration and John Wiley \& Sons Ltd.

Ho, Shirley S., Liang Chen, and Angelica P. Y. Ng. 2017. Comparing cyberbullying perpetration on social media between primary and secondary school students. Computers \& Education 109: 74-84. [CrossRef]

Hong, Jun Sung, Dong Ha Kim, Robert Thornberg, Jun Hyeok Kang, and Julie Toth Morgan. 2018. Correlates of direct and indirect forms of cyberbullying victimization involving South Korean adolescents: An ecological perspective. Computers in Human Behavior 87: 327-36. [CrossRef]

Hood, Michelle, and Amanda L. Duffy. 2018. Understanding the relationship between cyber-victimisation and cyber-bullying on Social Network Sites: The role of moderating factors. Personality and Individual Differences 133: 103-8. [CrossRef]

Hunt, Caroline, Lorna Peters, and Ronald M. Rapee. 2012. Development of a measure of the experience of being bullied in youth. Psychological Assessment 24: 156-65. [CrossRef]

Kokkinos, Constantinos M., Nafsika Antoniadou, Angeliki Asdre, and Kyriaki Voulgaridou. 2016. Parenting and Internet behavior predictors of cyber-bullying and cyber-victimization among preadolescents. Deviant Behavior 37: 439-55. [CrossRef]

Kowalski, Robin M., Gary W. Giumetti, Amber N. Schroeder, and Micah R. Lattanner. 2014. Bullying in the digital age: A critical review and meta-analysis of cyberbullying research among youth. Psychological bulletin 140: 1073-137. [CrossRef]

Larrañaga, Elisa, Santiago Yubero, Anastasio Ovejero, and Raúl Navarro. 2016. Loneliness, parent-child communication and cyberbullying victimization among Spanish youths. Computers in Human Behavior 65: 1-8. [CrossRef]

Le, Ha Hai Thi, Nguyen Thanh Huong, Tien Truong Quang, Marilyn Campbell, Michelle Gatton, and Michael Dunne. 2016. Validity and reliability of traditional and cyberbullying victimisation scale: Findings from a school-based survey in urban areas of Hanoi and Hai Duong. Vietnam Journal of Public Health 40: 198-204. Available online: http://www.vjph.vn/index.php/tapchiytcc/article/view/118/91 (accessed on 19 December 2018).

Le, Ha Thi Hai, Michael P. Dunne, Marilyn A. Campbell, Michelle L. Gatton, Huong Thanh Nguyen, and Nam T. Tran. 2017. Temporal patterns and predictors of bullying roles among adolescents in Vietnam: A school-based cohort study. Psychology, Health \& Medicine 22: 107-21. [CrossRef]

Lee, Changho, and Namin Shin. 2017. Prevalence of cyberbullying and predictors of cyberbullying perpetration among Korean adolescents. Computers in Human Behavior 68: 352-58. [CrossRef]

Lereya, Suzet T., Muthanna Samara, and Dieter Wolke. 2013. Parenting behavior and the risk of becoming a victim and a bully/victim: A meta-analysis study. Child Abuse \& Neglect 37: 1091-108. [CrossRef] 
Lin, Han-Tang, and Huey-Jiuan Chen. 2016. Relationships Between Parental Internet Intervention, School Engagement, and Risky Online Behaviors Among Adolescents: The Moderatoring Role of Family Cohesion. Journal of Research in Education Sciences 61: 205-42. [CrossRef]

Livingstone, Sonia, Leslie Haddon, Anke Görzig, and Kjartan Ólafsson. 2011. Risks and Safety on the Internet: The Perspective of European Children: Full Findings and Policy Implications from the EU Kids Online Survey of 9-16 Year Olds and Their Parents in 25 Countries. London: EU Kids Online Network.

Makri-Botsari, Evanthia, and Georgia Karagianni. 2014. Cyberbullying in Greek adolescents: The role of parents. Procedia-Social and Behavioral Sciences 116: 3241-53. [CrossRef]

Marret, Mary J., and Wan Yuen Choo. 2017. Factors associated with online victimisation among Malaysian adolescents who use social networking sites: A cross-sectional study. BMJ Open 7: 1-11. [CrossRef]

Mobin, Ahmad, Cindy Xin Feng, and Cory Neudorf. 2017. Cybervictimization among preadolescents in a community-based sample in Canada: Prevalence and predictors. Canadian Journal of Public Health 108: 475-81. [CrossRef]

Navarro, Raúl, Cristina Serna, Verónica Martínez, and Roberto Ruiz-Oliva. 2013. The role of Internet use and parental mediation on cyberbullying victimization among Spanish children from rural public schools. European Journal of Psychology of Education 28: 725-45. [CrossRef]

Nocentini, Annalaura, Giada Fiorentini, Ludovica Di Paola, and Ersilia Menesini. 2018. Aggression and Violent Behavior 1-10. [CrossRef]

Olweus, Dan. 1996. The Revised Olweus Bully/Victim Questionnaire. Bergen: Research Center for Health Promotion, University of Bergen.

Ortega-Barón, Jessica, Sofía Buelga-Vasquez, and María Jesús Cava-Caballero. 2016. The Influence of School Climate and Family Climate among Adolescents Victims of Cyberbullying= Influencia del clima escolar y familiar en adolescentes, víctimas de ciberacoso. Comunicar 24: 57-65. [CrossRef]

Patchin, Justin W., and Sameer Hinduja. 2011. Traditional and nontraditional bullying among youth: A test of general strain theory. Youth $\mathcal{E}$ Society 43: 727-51. [CrossRef]

Pfetsch, Jan. 2018. Adolescent Use of Digital Media and Parental Mediation-A Research Review. Praxis der Kinderpsychologie und Kinderpsychiatrie 67: 110-33. [CrossRef]

Priegue, Diana. 2016. Familia, inmigración y rendimiento académico: Construir alianzas estratégicas. In El poder de la Familia en la Educación. Edited by Miguel Ángel Santos Rego. Madrid: Síntesis, pp. 145-63.

Ruiz, Covadonga. 2001. Factores familiares vinculados al bajo rendimiento. Revista Complutense de Educación 12: 81-113. Available online: https:// core.ac.uk/download/pdf/38820954.pdf (accessed on 1 December 2018).

Sasson, Hagit, and Gustavo Mesch. 2017. The role of parental mediation and peer norms on the likelihood of cyberbullying. The Journal of Genetic Psychology 178: 15-27. [CrossRef]

Shaheen, Abeer M., Sawsan Hammad, Eman M. Haourani, and Omayyah S. Nassar. 2018. Factors Affecting Jordanian School Adolescents' Experience of Being Bullied. Journal of Pediatric Nursing 38: 66-71. [CrossRef]

Shams, Hedayatallah, Gholamreza Garmaroudi, and Saharnaz Nedjat. 2017. Factors related to bullying: A qualitative study of early adolescent students. Iranian Red Crescent Medical Journal 19: 1-11. [CrossRef]

Shields, Ann, and Dante Cicchetti. 2001. Parental maltreatment and emotion dysregulation as risk factors for bullying and victimization in middle childhood. Journal of Clinical Child Psychology 30: 349-63. [CrossRef]

Smith, Peter K., Jess Mahdavi, Manuel Carvalho, Sonja Fisher, Shanette Russell, and Neil Tippett. 2008. Cyberbullying: Its nature and impact in secondary school pupils. Journal of Child Psychology and Psychiatry 49: 376-85. [CrossRef]

Stavrinides, Panayiotis, Spyridon Tantaros, Stelios Georgiou, and Loukia Tricha. 2018. Longitudinal associations between parental rejection and bullying/victimization. Emotional and Behavioural Difficulties 23: 203-12. [CrossRef]

Topçu, Çiğdem, and Özgür Erdur-Baker. 2010. The revised cyber bullying inventory (RCBI): Validity and reliability studies. Procedia-Social and Behavioral Sciences 5: 660-4. [CrossRef]

Uludasdemir, Dilek, and Sibel Kucuk. 2018. Cyber Bullying Experiences of Adolescents and Parental Awareness: Turkish Example. Journal of Pediatric Nursing 44: 84-90. [CrossRef]

Vale, Arminda, Filipa Pereira, Mariana Gonçalves, and Marlene Matos. 2018. Cyber-aggression in adolescence and Internet parenting styles: A study with victims, perpetrators and victim-perpetrators. Children and Youth Services Review 93: 88-99. [CrossRef] 
Varela, Rosa María. 2012. Violencia victimización y cyberbullying en adolescentes escolarizados/as: Una perspectiva desde el trabajo social. Ph.D. dissertation, Universidad Pablo de Olavide, Sevilla, Spain. Available online: https://rio.upo.es/xmlui/bitstream/handle/10433/4127/varela-garay-tesis-11-12.pdf (accessed on 4 December 2018).

Vazsonyi, Alexander T., Gabriela Ksinan Jiskrova, Yalçın Özdemir, and Marcia Malone Bell. 2017. Bullying and cyberbullying in Turkish adolescents: Direct and indirect effects of parenting processes. Journal of Cross-Cultural Psychology 48: 1153-71. [CrossRef]

Wright, Michelle F. 2017. Parental mediation, cyberbullying, and cybertrolling: The role of gender. Computers in Human Behavior 71: 189-95. [CrossRef]

Ybarra, Michele L., Marie Diener-West, and Philip J. Leaf. 2007. Examining the overlap in Internet harassment and school bullying: Implications for school intervention. Journal of Adolescent Health 41: 42-50. [CrossRef] [PubMed]

Yubero, Santiago, Elisa Larrañaga, and Raúl Navarro. 2014. Comunicación familiar en la victimización del bullying y del cyberbullying. International Journal of Developmental and Educational Psychology 6: 343-50. [CrossRef]

Zurcher, Jessica D., Hailey G. Holmgren, Sarah M. Coyne, Christopher P. Barlett, and Chongming Yang. 2018. Parenting and cyberbullying across adolescence. Cyberpsychology, Behavior, and Social Networking 21: 294-303. [CrossRef] [PubMed]

(C) 2019 by the authors. Licensee MDPI, Basel, Switzerland. This article is an open access article distributed under the terms and conditions of the Creative Commons Attribution (CC BY) license (http:/ / creativecommons.org/licenses/by/4.0/). 


\title{
The Role of Family in Bullying and Cyberbullying Involvement: Examining a New Typology of Parental Education Management Based on Adolescents' View of Their Parents
}

\author{
Olga Gómez-Ortiz ${ }^{1, *}$, Carmen Apolinario ${ }^{1}$, Eva M. Romera ${ }^{1}$ and Rosario Ortega-Ruiz ${ }^{1,2}$ \\ 1 Departamento de Psicología, Facultad de Ciencias de la Educación, 14004 Córdoba, Spain; \\ z72appoc@uco.es (C.A.); eva.romera@uco.es (E.M.R.); ortegaruiz@uco.es (R.O.-R.) \\ 2 Department of Psychology, Social Work and Counselling, Faculty of Education and Health, University of \\ Greenwich, London SE10, UK \\ * Correspondence: olga.gomez@uco.es; Tel.: +34-957-21-2603
}

Received: 17 November 2018; Accepted: 4 January 2019; Published: 15 January 2019

\begin{abstract}
The influence of the family in children's involvement in bullying and cyberbullying has been well documented. However, previous research into this relationship seems to have overlooked recent social changes, which have affected the family context. The aim of this study is to put forward a categorization of the current educational management of Spanish parents and examine how this is linked to their children's involvement in bullying and cyberbullying. To achieve this, 2060 schoolchildren from the South of Spain $(47.9 \%$ girls with mean age $=14.34)$ answered four questionnaires including the Scale for the Assessment of the Parenting Styles of Adolescents' Mothers and Fathers, the Discipline Dimensions Inventory, the European Bullying Intervention Project Questionnaire, and the European Cyberbullying Intervention Project Questionnaire. The Cluster Analysis results revealed a typology containing six styles: permissive, authoritarian, strict, normative democratic, indulgent democratic, and punitive democratic. Lower levels of victimization and aggression in bullying and cyberbullying were found to be linked to the indulgent democratic or normative democratic styles and higher levels to the authoritarian and strict styles. The value of parents' educational practices and how they are combined in general styles, since these are elements that can predispose or prevent adolescent's involvement in bullying and cyberbullying, is discussed.
\end{abstract}

Keywords: parenting; socialization; violence; victimization; teenagers

\section{Introduction}

Despite the fact that a considerable body of scientific evidence has accumulated on the nature and prevalence of bullying and cyberbullying, there are still many gaps in our knowledge. For this reason, further studies are needed into ways to prevent both of these phenomena.

Bullying is a group phenomenon, occurring within more or less complex networks of relationships, in which a single pupil or a group of schoolchildren pick on another intentionally and without provocation. The aggression often takes place regularly over time and the victim finds it extremely difficult to defend themselves against their aggressor or aggressors, given the imbalance of power that exists between them (Smith 2016; Olweus 1999). The aggression is generally made worse by two processes, which form a part of the group's micro-culture. First, the law of silence, which prevents those involved and specially bystanders from reporting the unfair aggression, makes it difficult that it is reported to adults and, hence, stopped. The submissive domain scheme also transforms the usual horizontality that characterizes relations between equals into a kind of perverse verticality. 
The aggression involved in bullying can be verbal, physical, sexual, psychological, or relational (Ortega and Mora-Merchán 2008).

Currently, the advent of information and communication technology has opened up new opportunities for social aggression, which gives rise to a parallel phenomenon closely connected to bullying known as cyberbullying. Although there is a degree of controversy over the exact definition of cyberbullying, initial approaches have defined it as repeated, aggressive behavior conducted through electronic devices with the intention of hurting or intimidating the recipient (Hinduja and Patchin 2008; Tokunaga 2010). Cyberbullying is characterized by sending aggressive messages or humiliating images, making intimidating telephone calls, impersonating the victim's identity, or recording and then sharing videos in which the victim is ridiculed or attacked. Since it was demonstrated that there is a considerable overlap between both violent phenomena, a number of authors have agreed to label cyberbullying as a sub-category of bullying (Waasdorp and Bradshaw 2015). We will examine both of these problems of interpersonal violence in this work.

Interpersonal violence between peers exists as a phenomenon in all schools (Craig et al. 2009). In fact, Modecki et al. (2014), in their meta-analysis, which included 80 studies from all around the world, found that cyberbullying is less frequent than conventional bullying, with a prevalence of $15 \%$ when compared to $35 \%$ for bullying.

The need to prevent these phenomena by addressing all the relevant factors of both protection and risk is, therefore, becoming more and more urgent. Most research has centered on individual aspects in an attempt to delimit the factors associated with these forms of interpersonal violence, which include social competence, emotional intelligence, empathy, judgment, and moral sensitivity. The relevant research shows that schoolchildren involved in bullying have lower levels of socio-moral competence than those who have not been affected (Del Rey et al. 2016; Romera et al. 2018; Gómez-Ortiz et al. 2017; Elipe et al. 2015).

In addition to this, research has also focused on studying the connection between the family context and involvement in bullying or cyberbullying, and this idea has been linked to the parenting styles of the parents. The research seems to point out where the problem may be originating from, but it is still rather imprecise (Nocentini et al. 2018).

Traditionally, most research on parental styles followed the theoretical model originally proposed by Baumrind (1968) and concluded by Maccoby and Martin (1983). The empirical and practical validity of this model has been widely accepted, whereby four categories of parenting were established, based on the dimensions of involvement and control or coercion. The categories include: (a) democratic (high levels of both factors), (b) permissive (high involvement and low coercion), (c) authoritarian (low involvement and high coercion), and (d) negligent (low levels of both factors). Other authors have also accepted this categorical approach, and other typologies have been proposed to classify the behavior and attitudes of parents toward their children and to study the children's adjustment such as that proposed by Musitu and García (2005).

According to this typological approach, the democratic and the indulgent styles are those that seem to best prevent children from getting involved in bullying and cyberbullying (Baldry and Farrington 2005; Gómez-Ortiz et al. 2015; Martínez et al. 2019). On the other hand, the authoritarian style, especially when accompanied by the use of physical punishment and excessive parental control, is closely linked to the likelihood of becoming a bully or victim in these two areas (Dehue et al. 2012; Garaigordobil and Machimbarrena 2017; Low and Espelage 2013; Ybarra and Mitchell 2004). The negligent style is also a risk factor linked to children showing aggressive behavior towards their peers (Cerezo et al. 2018).

Nevertheless, the 'parenting style' construct has recently acquired new dimensions and has been described with greater precision, which enables us to attempt to outline the possible contribution of parents and, in general, of the educational climate in the family to the risk of getting involved in bullying and cyberbullying. The perspective in which the educational style is analyzed is known as a dimensional perspective. It involves studying various facets of the parent-child relationship, 
which, as well as affection and communication, include a sense of humor, mutual enjoyment between parents and children (Oliva et al. 2007), and the encouragement of autonomy. In other words, this gives children the opportunity to make their own decisions or choose certain behavior (Lewis 1981). Moreover, from this dimensional perspective, the factor of control is examined in a detailed way and the attitudinal and behavioral strategies that are linked to this dimension are diversified. A distinction is, therefore, made between behavioral control, characterized by establishing rules and the supervision of young people's behavior (Gray and Steinberg 1999), and psychological control, meaning the use of manipulative and intrusive strategies, such as generating guilt or the withdrawal of affection when children display undesirable behavior (Silk et al. 2003). In addition, filial disclosure, which refers to the information that young people voluntarily share with their parents about aspects of their private or school life, enables the parents to know more about their child and monitor them (Kerr et al. 1999).

The dimensional approach has also shown that both the use of psychological control and the lack of supervision by parents are risk factors that increase the likelihood of children bullying their peers or being victimized by them (Gómez-Ortiz et al. 2016; Samper-García et al. 2015; Holt et al. 2008; Hong et al. 2017). As for disclosure, it has been found that children who voluntarily confide in their parents and enjoy good communication with them, as well as those that grow up in a positive, warm, loving environment in which the child's autonomy is encouraged, are less likely to get involved in bullying and cyberbullying (Gómez-Ortiz et al. 2014; Larrañaga et al. 2016; Murphy et al. 2017; Offrey and Rinaldi 2017; Stavrinides et al. 2015; Fousiani et al. 2016; Low and Espelage 2013).

The steps that parents take to manage their children's discipline at home constitute a set of parental educational practices closely linked to parenting style. Strauss and Fauchier (2007) identified four procedures related to the exercise of parental discipline. This includes: (a) physical and psychological punishment, including the use of force and even physical or psychological aggression in order to correct a child's behavior, (b) response cost, which involves the withdrawal of privileges and the imposition of other compensatory behavior, (c) inductive discipline, consisting of giving explanations about the right way of doing things, reinforcing the child's correct behavior, and trying to divert their attention from unacceptable behavior, and, lastly, (d) direct supervision, including strategies aimed at checking whether the child is behaving correctly or not and ignoring negative behavior with the aim of suppressing it.

There has also been some research into the link between managing discipline and children becoming involved in bullying even though this has not gone into the subject in much depth. Most studies have focused on the link between punitive discipline and bullying, and have found that parents who exercise punitive discipline at home make it more likely that their children will also become bullies or victims of bullying (Hong et al. 2017; Lansford et al. 2014; Gómez-Ortiz et al. 2016; Lereya et al. 2013). Other risk factors also include disciplinary methods, which involve psychological aggression (Zottis et al. 2014). The relationship between cyberbullying involvement and parental discipline management has been unexplored.

A review of the literature shows that current research is attempting to establish the relationship between parenting practices and their exercise of corrective discipline as well as children's involvement in bullying and cyberbullying. However, the results produced by most of these studies are extremely segmented, focusing on one particular educational practice at the expense of others. This is especially true in the case of discipline, where there are significant gaps in our knowledge regarding everything related to non-punitive discipline, which is still very much uncharted territory, not only in relation to bullying and cyberbullying, but also in the area of competition and the psychosocial adjustment of schoolchildren in general. The original idea of this research was, therefore, to propose categories of parenting styles, which include not only practices linked to the dimension of warm or control, but also others, which have a strong influence over children's psycho-social adjustment, such as the encouragement of autonomy or the parents' sense of humor (Gómez-Ortiz et al. 2015) as well as different disciplinary methods. To the best of our knowledge, no classification of parental educational management styles exists that contains these characteristics and includes all these variables, as well as explores both maternal and paternal behavior. 
Some authors, however, do seem to have reflected this need, and have proposed alternative classifications to the classic typology devised by Maccoby and Martin (1983), notably Torío et al. (2009), Oliva et al. (2008), and Gómez-Ortiz et al. (2015). In fact, even Baumrind (1991), some years after her initial proposal, proposed an alternative typology, which included special features, which typify parent-child relationships in adolescence. In any case, almost all these classifications focus on studying the educational style and do not specifically address discipline management. In addition, they only analyze the individual behavior of each parent rather than the interaction of both, when, in real life, parental coherence has been shown to be an important element in influencing a child's adjustment (Gómez-Ortiz et al. 2015; Oliva et al. 2008). Furthermore, apart from the classification by Gómez-Ortiz et al. (2015), the other classifications differ very little from the classic typologies proposed over 40 years ago. For this reason, we need to reflect the fact that family life has moved on significantly since that time and that the different features of education and parental discipline management may well have expanded and diversified.

The main aim of this research was, therefore, to discover the behavioral patterns displayed by parents while bringing up their children and how this affects the child's adjustment. We assessed this adjustment through their involvement in bullying and cyberbullying, two violent phenomena, which arouse considerable concern in society, given their common occurrence and severe repercussions.

This general objective can be broken down into two specific objectives:

1. To explore the educational profile of the parents of adolescents, analyzing specific parenting practices they use with their children, evaluated from the children's point of view.

2. To distinguish any possible differences in the degree of involvement in bullying and cyberbullying linked to the parents' educational profile.

The approach and implementation of our research was based on two hypotheses:

1. We expected to find diverse profiles of parental education, in which the factor of democratic mothers and fathers is attenuated by different styles of discipline management, communication, sense of humor, and other relational patterns (Gómez-Ortiz et al. 2015).

2. We expected to find that the parents with documented higher levels of affection, sense of humor, promotion of autonomy, and in whom their children spontaneously confide their feelings and ideas (disclosure) and who avoid punitive discipline would show a lower involvement of their children in bullying and cyberbullying (Fousiani et al. 2016; Gómez-Ortiz et al. 2014; Zottis et al. 2014).

\section{Materials and Methods}

\subsection{Participants}

The sample consisted of 2060 students from the Compulsory Secondary Education (ESO, in Spanish) whose ages ranged between 12 and $19\left(\mathrm{x}^{\perp-}=14.34\right.$; o $\left.=1.34\right)$, of which $52.1 \%$ were boys and $47.9 \%$ girls. Furthermore, $28.4 \%$ were in their first year of secondary school, $28.4 \%$ in the second year, $22.1 \%$ in their third year, and $21.1 \%$ in the fourth year. The students were chosen from public and private schools from different areas around Andalusia.

The sample was considered representative of the population of schoolchildren enrolled in Compulsory Secondary Education (ESO) in Andalusia, and was selected by randomized, single-stage, stratified, random sampling using conglomerates and with proportional affixation. The strata were identified as the geographical area of Andalusia (Eastern or Western Andalusia), the type of school (public or private), and the population of the town/city (under 10,000 inhabitants, between 10,001 and 100,000 inhabitants, and more than 100,000 inhabitants). All the categories of the strata are indexes, which are relevant in Spain.

This study was carried out in accordance with the Helsinki declaration and, before collecting the data, the parents provided informed consent for their sons and daughters to take part in the study. The Ethics Committee of the University of Córdoba authorized the study. 


\subsection{Instruments}

The European Bullying Intervention Project Questionnaire (EBIP-Q) was used to evaluate the level of involvement in bullying (Ortega-Ruiz et al. 2016). This self-report is made up of 14 Likert-type items with five response options ('No,' 'Yes, once or twice,' 'Yes, once or twice a month,' 'Yes, about once a week,' and 'Yes, more than once a week'), of which 7 items are related to bullying and the other 7 to victimization. The questionnaire covers aspects of verbal, physical, relational, direct, and indirect harassment. The time interval used to evaluate the frequency was the academic year the pupils were in at the time of answering the questionnaires. The reliability of this scale is adequate ( $\alpha$ victimization $=0.80, \alpha$ bullying $=0.76$, total $\alpha=0.83$ ).

Cyberbullying was evaluated using the European Cyberbullying Intervention Project Questionnaire (ECIPQ) (Del Rey et al. 2015), which is made up of 22 Likert-type items, including five response options ('No', 'Yes, once or twice,' 'Yes, once or twice a month,' 'Yes, about once a week,' and 'Yes, more than once a week'). This self-report contains two dimensions: cyber-victimization and cyberbullying, with a suitable Cronbach's Alpha score $(\alpha$ cyber-victimization $=0.76, \alpha$ cyberbullying $=$ $0.68, \alpha$ total $=0.81$ ). The time interval used to evaluate the frequency was the academic year the pupils were in at the time of answering the questionnaires.

The dimensions of the parenting style were evaluated through the scale for evaluating the parenting style of fathers and mothers of adolescents designed by Oliva et al. (2007). This instrument is composed of 41 items related to the child's perception of the mother's parenting style and another 41 linked to the paternal style. It has a Likert-type response format with 6 response options ( 1 = totally disagree, 6 = totally agree) and the items measure six parental dimensions: (1) affection and communication (8 items), (2) behavioral control (6 items), (3) psychological control (8 items), (4) promotion of autonomy (8 items), (5) sense of humor (6 items), and (6) self-disclosure (5 items). This scale has good reliability indices $(\alpha$ total $=0.93, \alpha 1$ mother $=0.90), \alpha 1$ father $=0.92, \alpha 2$ mother $=$ $0.80, \alpha 2$ father $=0.83, \alpha 3$ mother $=0.83, \alpha 3$ father $=0.83, \alpha 4$ mother $=0.8), \alpha 4$ father $=0.87, \alpha 5$ mother $=$ $0.88, \alpha 5$ father $=0.89, \alpha 6$ mother $=0.82$, and $\alpha 6$ father $=0.85$ ).

Lastly, discipline was measured using the Inventory of Disciplinary Dimensions (IDD) designed by Strauss and Fauchier (2007) and validated in a Spanish adolescent population by Calvete et al. (2010). This scale consists of a total of 52 items, of which 26 refer to the mother's discipline methods and the other 26 to the father's. The scale has a Likert-type response format with 10 response options ranging from 0 (never) to 9 (twice or more times a day). This instrument measures four factors referring to various disciplinary procedures: Physical and psychological punishment (PPP: psychological aggression and physical punishment), Response Cost (RC: withdrawal of privileges, compensation), Inductive Discipline (ID: distraction, explanation and reward), and Supervision (SUP: ignoring and control). The internal consistency was acceptable for higher order factors: $\alpha$ IDmother $=0.73, \alpha \mathrm{IDf}$ ather $=0.74, \alpha$ SUPmaterial $=0.74, \alpha$ SUPfather $=0.69, \alpha$ PPPmother $=0.87, \alpha$ PPPfather $=0.88, \alpha$ RCmother $=$ $0.82, \alpha$ RCfather $=0.82$, and total $\alpha=96$.

\subsection{Procedure}

After permission was obtained from the parents and school management, we went out to the schools to conduct the survey. The children had previously been informed that the surveys were anonymous and confidential and that they could take part on a voluntary basis. Students filled the questionnaire on the paper. The questionnaires took 45 min maximum to complete.

\subsection{Data Analysis}

There was observed randomness in missing data including a MCAR (missing completely at random) pattern (Little's MCAR test: $6105.86(6026) ; p=0.23)$. Therefore, we decided to perform the analysis without such data (Bennett 2001). As such, the data included 1096 students who answered all the questions of the survey. $\mathrm{N}$ was specified in all analyses. 
First, a hierarchical conglomerate analysis was performed on the variables connected with the mother's and father's educational styles, in order to establish the right number of clusters. To achieve this, both the dendogram scores and the distance between clusters observed in the clustering history were taken into account. In the latter case, the cluster was defined by the gaps between the successive values of the agglomeration coefficient, on the basis that adding the next case to the conglomerate would lead to a loss of its homogeneity. Next, a K-media cluster was performed to identify the parents' possible educational profile based on their children's perception of their educational practices and their use of disciplinary procedures.

The factors were then subjected to an analysis of variance (ANOVA) to evaluate the link between the parents' educational profile and the child's involvement in situations of aggression and victimization with their peers either on the Internet (cyberbullying) or in real life (conventional bullying). In this way, the groups defined by the conglomerates were considered as factors and the variables measuring the extent of the (cyber) aggression or (cyber) victimization were taken as dependent variables. Lastly, a Games-Howell post hoc test was carried out to check the difference in means between the groups when each was compared with the other five. The significant differences obtained with the ANOVA were contrasted with the results produced from measuring the size of the effect (Cohen's D). A value below or equal to 0.20 in this index would indicate a minimal effect, while values of more than 0.20 and up to 0.50 would indicate a moderate effect and over 0.80 would indicate a strong effect (Cohen 1992). All the data coding and analyses were carried out using the SPSS statistical package (version 19.0).

\section{Results}

\subsection{Classification of Parental Educational Management}

The results of the hierarchical cluster analysis revealed that the solutions from clusters 5, 6, 7, and 8 would be the most suitable. After performing the K-means cluster analysis, it was decided to create six groups, as this appeared to be the most coherent solution and met the objective of providing a classification, which reflected the wide possible variability of the construct, while, at the same time, allowed maximum intra-group homogeneity and inter-group heterogeneity. The 5-cluster solution proved less informative since it reduced the diversification of parental profiles, and solutions with 7 and 8 conglomerates produced groups, which were overly similar to each other, and, therefore, showed little inter-group heterogeneity.

The schoolchildren from group 1 revealed a moderate level of behavioral control by their parents, and this group obtained the lowest means for that dimension. The scores for psychological control were slightly lower, while those for disclosure were about the same. On the other hand, higher scores were produced for items related to affection and communication, as well as the promotion of autonomy and parental sense of humor. Similarly, these students revealed that the use of all types of discipline by their parents was infrequent (this group, in particular, reflected the lowest use of inductive discipline by their parents). It was agreed to label the parents of these pupils as permissive. Group 2 was the group that produced the lowest scores for the dimensions of affection and communication, promotion of autonomy, sense of humor, and disclosure. However, they showed a high level of behavioral, and, above all, psychological control. In addition, the use of all types of discipline by both parents was frequent, and this group obtained the highest scores for physical and psychological punishment. These parents were labeled as authoritarians. The pupils in group 3 had high scores for all the dimensions related to the educational style, except for psychological control, where the scores were moderate. Regarding disciplinary strategies, they showed a frequent use of inductive discipline, while other disciplinary procedures were used much less frequently. Given their frequent use of behavioral control, it was agreed that the most suitable label for this group was normative democratic parents. The boys and girls in group 4 described their parents in a very similar way to the children in group 2, while they revealed a less frequent use of all the disciplinary strategies and slightly higher levels of affection and promotion of autonomy. However, these levels were still low compared 
with the other groups. These parents were labeled as strict. The parents of the schoolchildren in group 5 produced the highest scores for affection and communication, promotion of autonomy, and sense of humor compared with the other groups. They also revealed the highest levels of disclosure. The scores for behavioral control were also high, but not the highest. The parents of the children of this group stood out for their low scores in coercion. They also obtained the lowest scores for psychological control and for the use of all types of discipline, with the exception of inductive discipline, for which group 1 had the lowest scores. These parents were labeled as indulgent democratic. Lastly, the pupils from group 6 described their parents as affectionate and open to communication, and stressed their tendency to promote their autonomy and have a good sense of humor. However, they also pointed out that these parents commonly used behavioral and psychological control and used the discipline techniques evaluated in this scenario very frequently (this group was the one that scored highest for behavioral and psychological control, inductive discipline, response cost, and supervision). This latter group was labeled punitive democratic parents (see Tables 1 and 2).

Table 1. Final areas of conglomerates of groups defined according to the scores on parenting practices.

\begin{tabular}{lcccccc}
\hline & $\mathbf{1}$ & $\mathbf{2}$ & $\mathbf{3}$ & $\mathbf{4}$ & $\mathbf{5}$ & $\mathbf{6}$ \\
\hline Affect \& communication: mother & 4.87 & 3.85 & 5.58 & 4.02 & 5.70 & 5.57 \\
Affect \& communication: father & 4.06 & 3.34 & 5.18 & 3.80 & 5.46 & 5.25 \\
Behavioral control: mother & 3.82 & 4.38 & 5.09 & 4.39 & 5.02 & 5.38 \\
Behavioral control: father & 3.35 & 4.02 & 4.87 & 3.87 & 4.85 & 5.09 \\
Psychological control: mother & 2.71 & 4.01 & 3.11 & 4.12 & 2.46 & 4.17 \\
Psychological control: father & 2.60 & 4.12 & 3.11 & 3.56 & 2.41 & 4.15 \\
Promotion of autonomy: mother & 4.40 & 3.14 & 5.23 & 3.46 & 5.29 & 5.08 \\
Promotion of autonomy: father & 4.03 & 3.24 & 5.10 & 3.57 & 5.19 & 4.89 \\
Humor: mother & 4.54 & 3.37 & 5.25 & 3.37 & 5.37 & 5.24 \\
Humor: father & 4.54 & 3.37 & 5.25 & 3.37 & 5.37 & 5.24 \\
Disclosure: mother & 3.48 & 2.83 & 4.96 & 3.08 & 5.22 & 4.81 \\
Disclosure: father & 2.60 & 2.44 & 4.40 & 2.69 & 4.80 & 4.38 \\
Inductive discipline: mother & 2.28 & 4.85 & 4.63 & 3.80 & 2.41 & 6.34 \\
Inductive discipline: father & 1.95 & 4.87 & 4.57 & 3.37 & 2.36 & 6.18 \\
Physical/psychological punishment: mother & 1.19 & 4.94 & 1.38 & 3.31 & 0.51 & 4.50 \\
Physical/psychological punishment: father & 1.15 & 5.11 & 1.41 & 2.75 & 0.47 & 4.47 \\
Response cost: mother & 1.17 & 4.69 & 2.63 & 3.37 & 0.87 & 5.73 \\
Response cost: father & 1.03 & 4.88 & 2.58 & 2.79 & 0.82 & 5.54 \\
Supervision: mother & 0.87 & 5.30 & 2.12 & 2.72 & 0.61 & 5.69 \\
Supervision: father & 0.71 & 5.49 & 2.04 & 2.39 & 0.58 & 5.46 \\
n & 222 & 38 & 284 & 114 & 388 & 81 \\
\hline
\end{tabular}




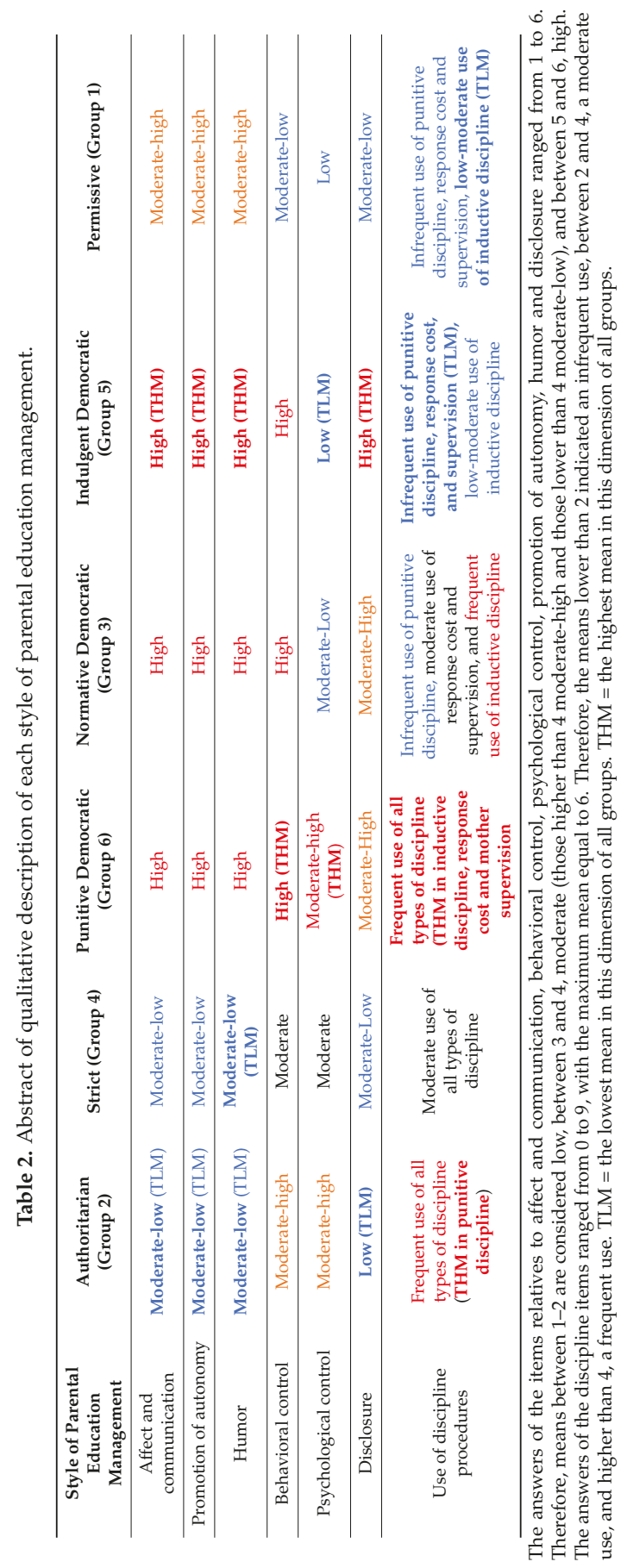




\subsection{Parental Educational Profile and Involvement in Bullying and Cyberbullying}

When analyzing the relationship between the parental educational profile and the aggression and victimization in bullying and cyberbullying, the results of the ANOVA test (see Table 3) showed statistically significant differences between the groups.

The Games-Howell post-hoc test (see Table 2) showed that, in the dimension of victimization in bullying, it was the youngsters with authoritarian parents who obtained the highest scores, which differed significantly, with a moderate effect size, from those whose parents from the indulgent democratic style, which reflected the lowest scores. The latter group also differed significantly in their levels of victimization among peers from the group of schoolchildren with parents from the strict and punitive democratic categories, with a moderate, low effect size. On the other hand, the group of schoolchildren with strict parents also stood out for their levels of victimization, and came second after the children of authoritarian parents. They also differed, therefore, from the children of permissive and normative democratic parents, with a moderate and low effect, respectively.

Table 3. Differences in involvement in bullying and cyberbullying, according to the parents' educational profile.

\begin{tabular}{|c|c|c|c|c|c|c|c|c|c|}
\hline & Groups & n & Mean & S. D. & $F$ & GL & Sig. & Post Hoc & Cohen's D \\
\hline Bullying: Victim. & $\begin{array}{l}\text { PA } \\
\text { ND } \\
S \\
\text { ID } \\
\text { PD }\end{array}$ & \begin{tabular}{l|}
221 \\
38 \\
284 \\
113 \\
386 \\
70
\end{tabular} & $\begin{array}{l}0.578 \\
0.947 \\
0.542 \\
0.879 \\
0.453 \\
0.645\end{array}$ & $\begin{array}{l}0.519 \\
0.863 \\
0.517 \\
0.730 \\
0.579 \\
0.491\end{array}$ & 13.30 & 1111 & 0.000 & $\begin{array}{l}\mathrm{P} \neq \mathrm{S} \\
\mathrm{ND} \neq \mathrm{S} \\
\mathrm{ID} \neq \mathrm{S} \\
\mathrm{ID} \neq \mathrm{A} \\
\mathrm{ID} \neq \mathrm{PD}\end{array}$ & $\begin{array}{l}-0.48 \\
-0.53 \\
0.65 \\
-0.67 \\
-0.35\end{array}$ \\
\hline $\begin{array}{l}\text { Bullying: } \\
\text { Aggression }\end{array}$ & $\begin{array}{l}\mathrm{P} \\
\mathrm{A} \\
\mathrm{ND} \\
\mathrm{S} \\
\mathrm{ID} \\
\mathrm{PD}\end{array}$ & \begin{tabular}{l|l}
219 \\
37 \\
282 \\
114 \\
386 \\
71
\end{tabular} & $\begin{array}{l}0.383 \\
0.803 \\
0.316 \\
0.627 \\
0.206 \\
0.465\end{array}$ & $\begin{array}{l}0.430 \\
0.777 \\
0.323 \\
0.516 \\
0.247 \\
0.393\end{array}$ & 36.53 & 1108 & 0.000 & $\begin{array}{l}\mathrm{P} \neq \mathrm{S} \\
\mathrm{P} \neq \mathrm{ID} \\
\mathrm{A} \neq \mathrm{ND} \\
\mathrm{A} \neq \mathrm{ID} \\
\mathrm{ND} \neq \mathrm{S} \\
\mathrm{ND} \neq \mathrm{ID} \\
\mathrm{S} \neq \mathrm{ID} \\
\mathrm{ID} \neq \mathrm{PD} \\
\mathrm{ND} \neq \mathrm{PD} \\
\mathrm{P} \neq \mathrm{A}\end{array}$ & $\begin{array}{l}-0.51 \\
0.51 \\
0.82 \\
1.04 \\
-0.72 \\
0.38 \\
1.04 \\
-0.79 \\
-0.41 \\
-0.66\end{array}$ \\
\hline $\begin{array}{l}\text { Cyber-bullying: } \\
\text { Victim. }\end{array}$ & $\begin{array}{l}\mathrm{P} \\
\mathrm{A} \\
\mathrm{ND} \\
\mathrm{S} \\
\mathrm{ID} \\
\mathrm{PD}\end{array}$ & $\begin{array}{l}220 \\
38 \\
283 \\
113 \\
387 \\
71\end{array}$ & $\begin{array}{l}0.139 \\
0.355 \\
0.147 \\
0.279 \\
0.113 \\
0.236\end{array}$ & $\begin{array}{l}0.220 \\
0.519 \\
0.231 \\
0.319 \\
0.246 \\
0.361\end{array}$ & 12.39 & 1111 & 0.000 & $\begin{array}{l}\mathrm{P} \neq \mathrm{S} \\
\mathrm{ND} \neq \mathrm{S} \\
\mathrm{ID} \neq \mathrm{S}\end{array}$ & $\begin{array}{l}-0.51 \\
-0.47 \\
0.58\end{array}$ \\
\hline $\begin{array}{l}\text { Cyber-bullying: } \\
\text { Aggression }\end{array}$ & $\begin{array}{l}\mathrm{P} \\
\mathrm{A} \\
\mathrm{ND} \\
\mathrm{S} \\
\mathrm{ID} \\
\mathrm{PD}\end{array}$ & \begin{tabular}{l|l}
221 \\
37 \\
282 \\
113 \\
388 \\
71
\end{tabular} & $\begin{array}{l}0.116 \\
0.345 \\
0.106 \\
0.224 \\
0.055 \\
0.190\end{array}$ & $\begin{array}{l}0.182 \\
0.488 \\
0.171 \\
0.269 \\
0.096 \\
0.246\end{array}$ & 28.21 & 1111 & 0.000 & $\begin{array}{l}\mathrm{P} \neq \mathrm{S} \\
\mathrm{P} \neq \mathrm{DI} \\
\mathrm{A} \neq \mathrm{DI} \\
\mathrm{ND} \neq \mathrm{S} \\
\mathrm{ND} \neq \mathrm{ID} \\
\mathrm{S} \neq \mathrm{ID} \\
\mathrm{ID} \neq \mathrm{PD}\end{array}$ & $\begin{array}{l}-0.47 \\
0.42 \\
0.82 \\
-0.52 \\
0.37 \\
0.84 \\
-0.72\end{array}$ \\
\hline
\end{tabular}

$\mathrm{P}=$ Permissive parents. $\mathrm{A}=$ Authoritarian parents. $\mathrm{ND}=$ Normative democratic parents. $\mathrm{S}=\mathrm{Strict}$ parents. ID $=$ Indulgent democratic parents. $\mathrm{PD}=$ punitive democratic parents. Victim. = Victimization.

Similarly, the children of authoritarian and strict parents also scored higher in the dimension of aggression in bullying. These two groups differed significantly from those with parents in the normative democratic (high and moderate effect size, respectively), indulgent democratic (high effect size in both cases), and permissive categories (moderate effect size in both comparisons). Differences were also found between the groups of children with parents in the democratic category, 
with the highest scores in this dimension given by the children of punitive democratics, who differed from the children of the normative democratic and indulgent democratic parents (low and moderate effect size, respectively). It was the latter who obtained the lowest scores in this dimension, with moderate differences between them and the children of permissive parents and low differences with the children whose parents are in the normative democratic category.

Regarding victimization in cyberbullying, differences were revealed between the group of schoolchildren with strict parents (second highest scores, after the group with parents in the authoritarian category) and those with permissive, indulgent democratic and normative democratic parents. The effect size of these differences was moderate in the former two cases and low in the latter.

As for cyberbullying aggression, the groups that reflected the highest scores were the pupils with parents in the authoritarian and strict categories. This latter group, in fact, differed significantly from those with parents classified as permissive or normative democratic (low and moderate effect size, respectively). In contrast, the lowest scores for this dimension were found in the group of children with indulgent democratic parents. This group differed from the group of schoolchildren with parents in the permissive, democratic, normative, strict, democratic, punitive, and authoritarian categories (low size effect for the differences in the first two cases, moderate in the third and fourth cases, and high in the last).

\section{Discussion}

The main aim of this research was to examine the relationship between the parents' educational profile and likelihood of their children becoming involved in the phenomena of bullying and cyberbullying, as well as to reassess the profiles of parents' educational styles to include the way parents use and handle discipline strategies as part of this relationship.

With regard to parenting styles, in agreement with the information in the first hypothesis, including the use and management of parental discipline techniques, levels of affection and communication, behavioral and psychological control, promotion of autonomy, children disclosure, and sense of humor shown by both parents, the overall picture of parental educational styles has become more diverse and it is clear that a more accurate description of parents' educational practices is required to reflect this wider variability. The results obtained produced a typology, which distinguishes six styles of parental educational management, which have been labeled: (1) permissive, (2) authoritarian, (3) normative democratic, (4) strict, (5) indulgent democratic, and (6) punitive democratic. The three styles we have termed 'democratic' were consistent with the traditional description of this style, and obtained high scores for the dimensions of affection and communication, behavioral control, promotion of autonomy, sense of humor, and disclosure (Gómez-Ortiz et al. 2015; Maccoby and Martin 1983; Musitu and García 2005; Oliva et al. 2008). However, it became evident that there were major differences between them regarding the use of discipline and psychological control. Thus, while indulgent democratic parents used psychological control and most disciplinary methods less frequently (except inductive discipline, where permissive parents obtained the lowest scores), the punitive democratic profile, as its name suggests, stood out for obtaining the highest scores in the use of most disciplinary and psychological control strategies. Normative democratic parents, on the other hand, fell halfway between these two styles, showing a moderate use of psychological control and non-punitive discipline techniques, while resorting fairly often to punitive measures, although to a lesser extent than the other groups (except indulgent democratic and permissive parents). Their main persuasive tool, therefore, was behavioral control, which entailed obtaining information by which they could control their children and establish rules (hence, the term 'normative'). In another dimension, there are two parental prototypes, which seem to tie in consistently with the characteristics of the fathers and mothers described in the classic typologies (Maccoby and Martin 1983; Baumrind 1968). The permissive parents group scored lower for affection and communication, promotion of autonomy, sense of humor, and disclosure than the democratic parents, and they differed considerably from the latter, especially in their infrequent use of behavioral control, and, in general, of all methods of 
coercion and discipline. The authoritarian parents group obtained the lowest scores for the dimensions linked to personal involvement (affection and communication, sense of humor) and for promoting filial autonomy, while they scored the highest for physical and psychological punishment. These parents also reflected high levels of psychological control. In other words, they were described by their children as punitive, coercive, and with a personal involvement, which fell short of their expectations, as described in the classification by Baumrind (1968) and Maccoby and Martin (1983). Lastly, the parents we termed 'strict' were, in fact, a moderate version of the previous style, although their profile included slightly higher (although not excessive) levels of involvement (affection, communication, and sense of humor). The profile also included a more moderate use of harsh disciplinary procedures such as physical and psychological punishment, which is why the label is given (previously used in the study by Oliva et al. (2008). In all cases, strict parents and authoritarian parents also shared the fact that they were the ones who least encouraged, and, therefore, least obtained, disclosure from their children. This fact may have its own particular relevance and logic. Since these types of parents put emphasis on controlling their children behaviorally and psychologically, one would expect that they do not gain the mutual trust that children need to take part in processes such as disclosure, telling their parents about their daily affairs or feelings, and so on. Disclosure, as well as a feeling of security in the affection, seems to require warm, receptive communicative styles, which are not often evident in these types of parents (Kerr et al. 1999).

The second main aim of this research was to explore the possible differences in the degree of involvement in bullying and cyberbullying of adolescents depending on their parents' educational profile. The results obtained seem to confirm clearly that children with authoritarian and strict parents are those who tend to admit that they are involved in the phenomena of bullying and cyberbullying, both in situations of aggression and victimization. Similarly, the group of schoolchildren with punitive democratic parents is also linked to high levels of involvement in both phenomena, although to a rather lesser degree than the previous groups. At the opposite extreme, schoolchildren who describe their parents as permissive, normative democratic, or indulgent democratic are the ones who showed less involvement in bullying. In particular, the group with the lowest levels of involvement in the dynamics of bullying and cyberbullying in any of its manifestations or behavior is that of the schoolchildren with parents with an indulgent democratic profile.

These results confirm our second hypothesis, and appear to imply that adolescents who have a negative perception of their family environment recognize implicitly that they have less ability and resources to face up to common social problems, of which bullying and cyberbullying are among the most frequent. In particular, the greatest risk seems to be found in the combination of parenting, which overuses coercion and offers little involvement with their children. Both the authoritarian and strict parenting styles lead to rigid, restrictive parent-child dynamics in terms of the freedom and autonomy needed by the adolescent, combined with attitudes that offer very little emotional warmth. Likewise, these profiles tend to make an excessive use of punishments and psychological and behavioral restrictions that do nothing to stimulate the child's sense of security and maturity: on the contrary, they make them more socially vulnerable (Baumrind 1968; Maccoby and Martin 1983; Oliva et al. 2008). All this, together with social conditions that directly affect them (interpersonal peer relationships, managing the balance of power in the group, teachers who supervise children's social life and peaceful coexistence, etc.) may affect the adolescent's ability to face up to these conflicts and increase the tendency to become victims or cyber-victims as well as bullies or cyberbullies of their peers (Dehue et al. 2012; Garaigordobil and Machimbarrena 2017; Low and Espelage 2013).

On the other hand, when a family atmosphere breeds affection and a warm, fluid communication where the child can talk freely to their parents about their feelings, mentioning both their successes and their failures or problems, a greater stimulus is given to security and social competence. This enables the child to acquire the behavioral and attitudinal resources, which may reduce the possibility of becoming victims of bullying and cyberbullying or of using aggression and harassment against their peers (Larrañaga et al. 2016; Martínez et al. 2019; Fousiani et al. 2016; Gómez-Ortiz et al. 2014). As our results 
show, this pattern of close involvement is especially effective when accompanied by a positive, sensible management of discipline issues, in which induction and reasoning are preferred as a way of guiding the child's behavior. Punishments that use humiliation and manipulation to re-conduct the child's behaviour are avoided, as reflected in the profiles of indulgent democratic and normative democratic parents. This fact highlights how useful it is to have a parental typology, which looks in detail at the patterns of parent-child interaction and not just at general notions of involvement or coercion. It is clear that the classic generalized profile of the 'democratic' parent does not convey sufficient information: our study has shown different levels of involvement in bullying and cyberbullying depending on the sub-category analyzed. In any case, the impact of unsuitable discipline management on the child's involvement in these violent phenomena (Gómez-Ortiz et al. 2016; Zottis et al. 2014) seems to be attenuated when warm, affectionate attitudes and behavior are shown by parents, which promote a healthy degree of autonomy and independence in the child, as evidenced by previous studies (Gámez-Guadix et al. 2010; Ma et al. 2012). For this reason, the levels of involvement of children with punitive democratic parents are lower than those with authoritarian or strict parents. However, to draw a clearer conclusion about these tendencies, more research is needed into educational profiles and their impact on involvement in bullying and cyberbullying in children.

This study has certain limitations, such as the use of self-report measurements to collect the data. Self-report surveys tend to elicit subjective and somewhat spontaneous answers from the respondents, which means we must be rather cautious and reserved when drawing our conclusions. Furthermore, parents have not been included as participants, taking only into account the teenagers' perception about parenting styles. In addition, the cross-sectional design of the study prevents us from establishing causal relationships. Future research should conduct further longitudinal studies into showing the sustainability or changes in the filial perception of family education, as well as the inclusion of other variables related to other individuals and contextual factors linked to the phenomena of bullying and cyberbullying. Moreover, it could be interesting to include the parental reporting about their own parenting styles to compare with that of the adolescents.

\section{Conclusions}

This research confirms the major role that parenting play in their children's involvement in bullying and cyberbullying. Abusive practices by the parents, such as physical punishment and psychological aggression, accompanied by a lack of affection and poor communication, little promotion of autonomy, and excessive behavioral control, which all combine to increase their children's vulnerability and make them more prone to victimization or bullying at school or behind a screen (Gómez-Ortiz et al. 2015). These findings highlight the importance to include parents as a key element of intervention and prevention programs not only to increase their awareness about their role in the development of these violent phenomena and improve their parenting skills, but also to teach them the best way to help their children cope with bullying and cyberbullying involvement (Larrañaga et al. 2018). In this sense, the intervention should guide parents to become in "indulgent democratics," which means to promote affect, communication, and autonomy showing also a positive humor. Parents should also be able to fix fair and enough rules and to monitor children behavior avoiding manipulative strategies such as those included in psychological control. Regarding discipline, the best seems to be to use inductive procedures based on explanations, rewards, and the use of attention to avoid children's misbehavior. In any case, these practices should be accompanied by positive and close attitudes that allow parents to be empathetic with their children while they are also able to make them understand that they have to respect parents (as parents respect them) and that their behavior has consequences. However, this study only includes the assessment of parental practices and not attitudes, as seen in most parenting studies. This is because the most of the parenting scales are focused on practices and ignore values and attitudes, which are important aspects of the parenting styles (Darling and Laurence 1993). Therefore, it would be necessary to design instruments 
that assess all aspects of parenting to offer a more complete description of the best parenting style regarding children and adolescent psychosocial adjustment.

Author Contributions: Conceptualization, O.G.-O. and C.A. Formal analysis, O.G.-O. and C.A; Funding acquisition, O.G.-O., E.M.R. and R.O.-R. Methodology, O.G.-O. Project administration, O.G.-O. and R.O.-R.; Supervision, O.G.-O.; Writing —original draft, C.A. Writing—review \& editing-, O.G.-O., E.M.R. and R.O.-R.

Funding: This research was funded by the Government of Spain-R+D plan—grant number "PSI2016-74871-R" and "PSI2015-64114-R", and by the European Research Council (H2020 grant number 755175).

Conflicts of Interest: The authors declare no conflict of interest.

\section{References}

Baldry, Anna C., and David P. Farrington. 2005. Protective Factors as Moderators of Risk Factors in Adolescence Bullying. Social Psychology of Education 8: 263-84. [CrossRef]

Baumrind, Diana. 1968. Authoritarian vs. Authoritative parental control. Adolescence 3: 255-72.

Baumrind, Diana. 1991. The Influence of Parenting Style on Adolescent Competence and Substance Use. The Journal of Early Adolescence 11: 56-95. [CrossRef]

Bennett, Derrick A. 2001. How can I deal with missing data in my study? Australian and New Zealand Journal of Public Health 25: 464-69. [CrossRef] [PubMed]

Calvete, Esther, Manuel Gámez Guadix, and Izaskun Orue. 2010. The Dimensions of Discipline Inventory (DDI)-Child and adolescent version: Analysis of parental discipline from a gender perspective. Anales de Psicología/Annals of Psychology 26: 410-18.

Cerezo, Fuensanta, Cecilia Ruiz-Esteban, Consuelo Sánchez Lacasa, and Julián J. Arense Gonzalo. 2018. Dimensions of Parenting Styles, Social Climate, and Bullying Victims in Primary and Secondary Education. Psicothema 30: 59-65. [CrossRef]

Cohen, Jacob. 1992. A Power Primer. Psychological Bulletin 112: 155-59. [CrossRef]

Craig, Wendy, Yossi Harel-Fisch, Haya Fogel-Grinvald, Suzanne Dostaler, Jorn Hetland, Bruce Simons-Morton, Michal Molcho, Margarida Gaspar de Mato, Mary Overpeck, Pernille Due, and et al. 2009. A cross-national profile of bullying and victimization among adolescents in 40 countries. International Journal of Public Health 54: 216-24. [CrossRef]

Darling, Nancy, and Steinberg Laurence. 1993. Parenting style as context: An integrative model. Psychological Bulletin 113: 487-96. [CrossRef]

Dehue, Francine, Catherine Bolman, Trijntje Vollink, and Mieneke Pouwelse. 2012. Cyberbullying and traditional bullying in relation to adolescents' perception of parenting. Journal of Cybertherapy and Rehabilitation 5: 25-34.

Del Rey, Rosario, José A. Casas, Rosario Ortega-Ruiz, Anja Schultze-Krumbholz, Herbert Scheithauer, Peter Smith, Fran Thompson, Vassilis Barkoukisf, Haralambos Tsorbatzoudisf, Antonella Brighi, and et al. 2015. Structural validation and cross-cultural robustness of the European Cyberbullying Intervention Project Questionnaire. Computers in Human Behavior 50: 141-47. [CrossRef]

Del Rey, Rosario, Lambros Lazuras, José A. Casas, Vassilis Barkoukis, Rosario Ortega-Ruiz, and Haralambos Tsorbatzoudis. 2016. Does empathy predict (cyber) bullying perpetration, and how do age, gender and nationality affect this relationship? Learning and Individual Differences 45: 275-81. [CrossRef]

Elipe, Paz, Joaquín A. Mora-Merchán, Rosario Ortega-Ruiz, and José A. Casas. 2015. Perceived emotional intelligence as a moderator variable between cybervictimization and its emotional impact. Frontiers in Psychology 6: 486. [CrossRef] [PubMed]

Fousiani, Kyriaki, Panagiota Dimitropoulou, Michalis P. Michaelides, and Stijn Van Petegem. 2016. Perceived Parenting and Adolescent Cyber-Bullying: Examining the Intervening Role of Autonomy and Relatedness Need Satisfaction, Empathic Concern and Recognition of Humanness. Journal of Child and Family Studies 25: 2120-29. [CrossRef]

Gámez-Guadix, Manuel, Izaskun Orue, Esther Calvete, José A. Carrobles, Marina Muñoz-Rivas, and Carmen Almendros. 2010. Propiedades psicométricas de la versión española del Inventario de Dimensiones de Disciplina (DDI) en universitarios. Psicothema 22: 151-56.

Garaigordobil, Maite, and Juan M. Machimbarrena. 2017. Stress, Competence, and Parental Educational Styles in Victims and Aggressors of Bullying and Cyberbullying. Psicothema 29: 335-340. [CrossRef] [PubMed] 
Gómez-Ortiz, Olga, Rosario Del Rey, José-Antonio Casas, and Rosario Ortega-Ruiz. 2014. Parenting Styles and Bullying Involvement/Estilos Parentales E Implicación En Bullying. Cultura Y Educación 26: 132-58. [CrossRef]

Gómez-Ortiz, Olga, Eva M. Romera, and Rosario Ortega-Ruiz. 2015. Parenting Styles and Bullying. The Mediating Role of Parental Psychological Aggression and Physical Punishment. Child Abuse E Neglect 51: 132-43. [CrossRef]

Gómez-Ortiz, Olga, Rosario Del Rey, Eva M. Romera, and Rosario Ortega-Ruiz. 2016. Los estilos educativos paternos y maternos en la adolescencia y su relación con la resiliencia, el apego y la implicación en acoso escolar. Anales de Psicología 31: 979. [CrossRef]

Gómez-Ortiz, Olga, Eva M. Romera, and Rosario Ortega-Ruiz. 2017. Multidimensionality of Social Competence: Measurement of the Construct and its Relationship with Bullying Roles. Revista de Psicodidáctica (English ed.) 22: 37-44. [CrossRef]

Gray, Marjory Roberts, and Laurence Steinberg. 1999. Unpacking authoritative parenting: Reassessing a multidimensional construct. Journal of Marriage and the Family 61: 574-87. [CrossRef]

Hinduja, Sameer, and Justin W. Patchin. 2008. Cyberbullying: An Exploratory Analysis of Factors Related to Offending and Victimization. Deviant Behavior 29: 129-56. [CrossRef]

Holt, Melissa K., Glenda Kaufman Kantor, and David Finkelhor. 2008. Parent/Child Concordance about Bullying Involvement and Family Characteristics Related to Bullying and Peer Victimization. Journal of School Violence 8: 42-63. [CrossRef]

Hong, Jun Sung, Dong Ha Kim, and Alex R. Piquero. 2017. Assessing the Links between Punitive Parenting, Peer Deviance, Social Isolation and Bullying Perpetration and Victimization in South Korean Adolescents. Child Abuse \& Neglect 73: 63-70. [CrossRef]

Kerr, Margaret, Hakan Stattin, and Kari Trost. 1999. To know you is to trust you: parents' trust is rooted in child disclosure of information. Journal of Adolescence 22: 737-52. [CrossRef] [PubMed]

Lansford, Jennifer E., Chinmayi Sharma, Patrick S. Malone, Darren Woodlief, Kenneth A. Dodge, Paul Oburu, Concetta Pastorelli, Ann T. Skinner, Emma Sorbring, Sombat Tapanya, and et al. 2014. Corporal Punishment, Maternal Warmth, and Child Adjustment: A Longitudinal Study in Eight Countries. Journal of Clinical Child and Adolescent Psychology 43: 670-85. [CrossRef]

Larrañaga, Elisa, Santiago Yubero, Anastasio Ovejero, and Raúl Navarro. 2016. Loneliness, parent-child communication and cyberbullying victimization among Spanish youths. Computers in Human Behavior 65: 1-8. [CrossRef]

Larrañaga, Elisa, Santiago Yubero, and Raúl Navarro. 2018. Parents' Responses to Coping with Bullying: Variations by Adolescents' Self-Reported Victimization and Parents' Awareness of Bullying Involvement. Social Sciences 7: 121. [CrossRef]

Lereya, Suzet Tanya, Muthanna Samara, and Dieter Wolke. 2013. Parenting Behavior and the Risk of Becoming a Victim and a Bully/Victim: A Meta-Analysis Study. Child Abuse E Neglect 37: 1091-108. [CrossRef]

Lewis, Catherine C. 1981. The effects of parental firm control: A reinterpretation of findings. Psychological Bulletin 90: 547-63. [CrossRef]

Low, Sabina, and Dorothy Espelage. 2013. Differentiating cyber bullying perpetration from non-physical bullying: Commonalities across race, individual, and family predictors. Psychology of Violence 3: 39-52. [CrossRef]

Ma, Julie, Yoonsun Han, Andrew Grogan-Kaylor, Jorge Delva, and Marcela Castillo. 2012. Corporal Punishment and Youth Externalizing Behavior in Santiago, Chile. Child Abuse E Neglect 36: 481-90. [CrossRef]

Maccoby, Eleanor E., and J. A. Martin. 1983. Socialization in the context of the family: Parent-child interaction. In Handbook of Child Psychology, 4th ed. Volume 4, Socialization, Personality and Social Development. P. H. Mussen (Series Ed.) \& E. M. Hetherington (Vol. Ed.). New York: Wiley, pp. 1-101.

Martínez, Isabel, Sergio Murgui, Oscar F. García, and Fernando García. 2019. Parenting in the digital era: Protective and risk parenting styles for traditional bullying and cyberbullying victimization. Computers in Human Behavior 90: 84-92. [CrossRef]

Modecki, Kathryn L., Jeannie Minchin, Allen G. Harbaugh, Nancy G. Guerra, and Kevin C. Runions. 2014. Bullying Prevalence across Contexts: A Meta-Analysis Measuring Cyber and Traditional Bullying. Journal of Adolescent Health 55: 602-11. [CrossRef] [PubMed]

Murphy, Tia Panfile, Deborah Laible, and Mairin Augustine. 2017. The Influences of Parent and Peer Attachment on Bullying. Journal of Child and Family Studies 26: 1388-97. [CrossRef] 
Musitu, Gonzalo, and José Fernando García. 2005. Consequences of Family Socialization in the Spanish Culture. Psychology in Spain 9: 34-40.

Nocentini, Annalaura, Giada Fiorentini, Ludovica Di Paola, and Ersilia Menesini. 2018. Parents, family characteristics and bullying behavior: A systematic review. Aggression and Violent Behavior. [CrossRef]

Offrey, Laura D., and Christina M. Rinaldi. 2017. Parent-child communication and adolescents' problem-solving strategies in hypothetical bullying situations. International Journal of Adolescence and Youth 22: 251-67. [CrossRef]

Oliva, Alfredo, Águeda Parra, Inmaculada Sánchez-Queija, and Francisca López. 2007. Estilos educativos materno y paterno: Evaluación y relación con el ajuste adolescente. Anales de Psicología 23: 49-56.

Oliva, Alfredo, Águeda Parra, and Enrique Arranz. 2008. Estilos relacionales parentales y ajuste adolescente. Infancia y Aprendizaje: Journal for the Study of Education and Development 31: 93-106. [CrossRef]

Olweus, Dan. 1999. Sweden. In The Nature of School Bullying: A Cross National Perspective. Edited by Peter K. Smith, Yohji Morita, Josine Jurgen-Tas, Dan Olweus, Richard Catalano and Philip Slee. Londres: Routledge.

Ortega-Ruiz, Rosario, Del Rey Rosario, and José A. Casas. 2016. Evaluar el bullying y el cyberbullying validación española del EBIP-Q y del ECIP-Q. Psicología Educativa 22: 71-79. [CrossRef]

Ortega, Rosario, and Joaquín A. Mora-Merchán. 2008. Las redes de iguales y el fenómeno del acoso escolar: explorando el esquema dominio-sumisión. Infancia y Aprendizaje 31: 515-28. [CrossRef]

Romera, Eva M., Jose A. Casas, Olga Gómez-Ortiz, and Rosario Ortega-Ruiz. 2018. Moral domain as a risk and protective factor against bullying. An integrating perspective review on the complexity of morality. Aggression and Violent Behavior. [CrossRef]

Samper-García, Paula, Vicenta Mestre-Escrivá, Elisabet Malonda, and Belén Mesurado. 2015. Victimización en la escuela: Relación de la crianza y variables funcionales-disfuncionales del desarrollo. Anales de Psicología 31: 849-58. [CrossRef]

Silk, Jennifer S., Amanda S. Morris, Tomoe Kanaya, and Laurence Steinberg. 2003. Psychological Control and Autonomy Granting: Opposite Ends of a Continuum or Distinct Constructs? Journal of Research on Adolescence 13: 113-28. [CrossRef]

Smith, Peter K. 2016. Bullying: Definition, Types, Causes, Consequences and Intervention. Social and Personality Psychology Compass 10: 519-32. [CrossRef]

Stavrinides, Panayiotis, Militsa Nikiforou, and Stelios Georgiou. 2015. Do Mothers Know? Longitudinal Associations between Parental Knowledge, Bullying, and Victimization. Journal of Social and Personal Relationships 32: 180-96. [CrossRef]

Strauss, Murray A., and Angèle Fauchier. 2007. Manual for the Dimensions of Discipline Inventory (DDI). Durham: Family Research Laboratory, University of New Hampshire.

Tokunaga, Robert S. 2010. Following You Home from School: A Critical Review and Synthesis of Research on Cyberbullying Victimization. Computers in Human Behavior 26: 277-87. [CrossRef]

Torío, Susana, José Vicente Peña, and María del Carmen Rodríguez. 2009. Estilos educativos parentales: revisión bibliográfica y reformulación teórica. Teoría de la Educación. Revista Interuniversitaria 20. Available online: http:/ / revistas.usal.es/index.php/1130-3743/article/view/988 (accessed on 15 November 2018).

Waasdorp, Tracy E., and Catherine P. Bradshaw. 2015. The Overlap between Cyberbullying and Traditional Bullying. The Journal of Adolescent Health: Official Publication of the Society for Adolescent Medicine 56: 483-88. [CrossRef]

Ybarra, Michele L., and Kimberly J. Mitchell. 2004. Online Aggressor/Targets, Aggressors, and Targets: A Comparison of Associated Youth Characteristics. Journal of Child Psychology and Psychiatry 45: 1308-16. [CrossRef] [PubMed]

Zottis, Graziela A. H., Giovanni A. Salum, Luciano R. Isolan, Gisele G. Manfro, and Elizeth Heldt. 2014. Associations between Child Disciplinary Practices and Bullying Behavior in Adolescents. Jornal De Pediatria 90: 408-14. [CrossRef] [PubMed]

(C) 2019 by the authors. Licensee MDPI, Basel, Switzerland. This article is an open access article distributed under the terms and conditions of the Creative Commons Attribution (CC BY) license (http:/ / creativecommons.org/licenses/by/4.0/). 


\title{
Article \\ Cyberbullying Victimization and Perpetration, Connectedness, and Monitoring of Online Activities: Protection from Parental Figures
}

\author{
Jennifer L. Doty ${ }^{1, *}$, Amy L. Gower ${ }^{2}$, Renee E. Sieving ${ }^{2,3}$, Shari L. Plowman ${ }^{2}$ and \\ Barbara J. McMorris ${ }^{2,3}$ \\ 1 Department of Family, Youth and Community Sciences, University of Florida, Gainesville, FL 32611, USA \\ 2 Healthy Youth Development-Prevention Research Center, University of Minnesota, Minneapolis, MN 55454, \\ USA; gowe0009@umn.edu (A.L.G.); sievi001@umn.edu (R.E.S.); plow0014@umn.edu (S.L.P.); \\ mcmo0023@umn.edu (B.J.M.) \\ 3 School of Nursing, University of Minnesota, Minneapolis, MN 55455, USA \\ * Correspondence: jennifer.doty@ufl.edu
}

Received: 29 October 2018; Accepted: 5 December 2018; Published: 12 December 2018

\begin{abstract}
Cyberbullying victimization and perpetration are associated with poor mental health outcomes for adolescents, including depressive symptoms, anxiety, and suicide ideation. Although most cyberbullying occurs at home, few interventions have been developed for parents of adolescents. We examined parental connectedness and parental online monitoring in relation to cyberbullying victimization and perpetration, with the goal of understanding how parents buffer young teens from involvement in cyberbullying. We leveraged data from an existing study involving three racially and ethnically diverse middle schools in a metropolitan area in the Midwest of the U.S. $(n=570)$. In the spring of sixth grade, students reported on cyberbullying involvement, parental connectedness, and parental monitoring. Greater parental connectedness was related to a lower likelihood of cyberbullying victimization and perpetration in logistic regression models. Parental monitoring of online activities was not related to cyberbullying victimization but was marginally related to a lower likelihood of cyberbullying perpetration. Results suggest that cyberbullying prevention programs should consider ways to foster parent/youth connectedness.
\end{abstract}

Keywords: cyberbullying; parenting; adolescence; parental monitoring

\section{Introduction}

Cyberbullying victimization and perpetration are associated with internalizing behaviors such as anxiety, depression, and suicidal ideation (Campbell et al. 2013; Hinduja and Patchin 2010; Kim et al. 2018; Kowalski and Limber 2013). Although most cyberbullying occurs while youth are at home, little is known about parent-based prevention of cyberbullying (National Academies of Sciences, Engineering, and Medicine 2016). Emerging research has found that warm parent-child relationships and parental monitoring are associated with decreased risk of cyberbullying (Elsaesser et al. 2017). Few studies have examined parent-child connectedness and monitoring concurrently with respect to cyberbullying. Our goal was to understand how parents buffer young teens from involvement in cyberbullying by examining concurrent associations between cyberbullying victimization, perpetration, and potential protective parenting factors in a diverse sample of middle school youth.

\subsection{Cyberbullying Perpetration and Victimization among Youth}

Cyberbullying refers to repeated hostile or aggressive communication via technology or digital means such as texting, social media, mobile applications, or video games (Tokunaga 2010; National 
Academies of Sciences, Engineering, and Medicine 2016). A challenge in defining cyberbullying is the difficulty of determining hostile intent online, where social and emotional clues are lacking (National Academies of Sciences, Engineering, and Medicine 2016). In a recent study on youth perception of cyberbullying, adolescents most often included the following components from the Centers for Disease and Control and Prevention (CDC) definition of bullying in their description of cyberbullying: aggressive, peer-to-peer behavior online that inflicts harm (Moreno et al. 2018). Kowalski and Limber (2013) argue that cyberbullying poses unique risks - reaching farther and spreading faster online than traditional bullying, and often providing anonymity to perpetrators (see also Kowalski et al. 2018).

The prevalence of cyberbullying victimization and perpetration varies widely. In national surveys, involvement in cyberbullying behavior ranged from 6.9 to $14.8 \%$ of U.S. youth aged 10 to 18 years (National Academies of Sciences, Engineering, and Medicine 2016). The CDC's nationwide Youth Behavior Risk Survey indicator of cyberbullying victimization ranged from $10.1 \%$ to $21.2 \%$ across states, which suggests that environmental factors contribute to cyberbullying (Centers for Disease Control and Prevention 2017). In recent reviews of the literature, cyberbullying perpetration among youth ranged from $1 \%$ to $41 \%$, and cyberbullying victimization ranged from 3\% to 72\% (Borges Bottino et al. 2015; Selkie et al. 2016), reflecting variation in definitions, populations, and measurements.

Whereas traditional bullying peaks in middle school (National Academies of Sciences, Engineering, and Medicine 2016; Graham and Bellmore 2007), evidence from national data in the U.S. suggests that cyberbullying may continue to increase during high school as youth increase their online presence (National Academies of Sciences, Engineering, and Medicine 2016). Middle school may be an ideal time to prevent cyberbullying because many youth increase their cell phone use going into middle school (Rideout et al. 2010) — the average age for children in the U.S. to receive a smart phone is 10.3 years (Influence Central 2016). Relatedly, the average age for U.S. children to open social media accounts is 11.4 years, which for most students is during their sixth grade year or first year of middle school (Influence Central 2016). Finally, addressing cyberbullying early is important because online harassment may also follow students back into school environments and interrupt learning (Waasdorp and Bradshaw 2015).

\subsection{Parenting as Protective of Cyberbullying}

Although bullying and cyberbullying often co-occur (Waasdorp and Bradshaw 2015), the context of cyberbullying differs from face-to-face bullying: $70 \%$ of cyberbullying occurs at home (Kowalski et al. 2012). Furthermore, bullying that starts at school can now follow students home via texting, internet, and social media use (Tokunaga 2010) and vice versa. This suggests a growing need for parents to be included in bullying prevention.

Warm and firm parenting protects against several youth risk behaviors, including bullying (Elsaesser et al. 2017; Fletcher et al. 2004). In this paper, we use the term "parenting" to refer to the behaviors and skills of caregivers raising adolescents, regardless of whether those caregivers are biological parents. In other words, parenting may be done by grandparents, foster parents, or others. In an increasingly digital environment, parenting may be complicated by adolescents' proclivity for online activities because adolescents often have greater skills and greater online activity than parents realize (Cassidy et al. 2012). However, research confirms that nurturing a warm and caring relationship between parents and children as well as monitoring are effective parenting skills that support positive youth development in a digital age (Elsaesser et al. 2017).

\subsection{Parent-Adolescent Relationships and Youth Cyberbullying Prevention}

Research across several countries has consistently indicated that parental support and parental warmth have negative associations with cyberbullying (Accordino and Accordino 2011; Elsaesser et al. 2017; Hong et al. 2016). Parental support-measured by four items about helping, loving, understanding, and comforting-was related to lower levels of cyberbullying victimization and perpetration in a national sample of U.S. teens (Wang et al. 2009). Although these studies have largely been 
cross-sectional, one found that family support was negatively related to cyberbullying victimization and perpetration one year later (Fanti et al. 2012). In a meta-analysis that examined parenting with respect to cyberbullying victimization and perpetration, Kowalski et al. (2014) reported five studies that found that parental warmth was negatively associated with cyberbullying victimization and perpetration, though effect sizes for these associations were small in magnitude given the small number of studies. Few studies have examined the role of youth gender in the relationship between parent connectedness and cyberbullying, and examinations of moderation effects by gender are needed (Navarro 2016).

One study on cyberbullying in the Netherlands used Baumrind's original conceptualization of parenting styles to identify authoritarian (controlling), authoritative (both controlling and warm), permissive (warmth but low control), and neglectful parents (neither controlling nor warm; Dehue Francine et al. 2012). As they transitioned into secondary school, youth were the least likely to report cyberbullying victimization or perpetration if they had authoritative compared to other parenting types. In other studies, authoritarian parenting was positively related to cyberbullying perpetration but not victimization (Floros et al. 2013a; Makri-Botsari and Karagianni 2014).

This research into parental warmth, support, and parenting style establishes that relationships exist between aspects of parenting and youth cyberbullying. However, these studies did not examine other important parental factors such as monitoring or attempts to control an online environment.

\subsection{Parental Monitoring}

Few studies focus on the effects of parental monitoring with respect to cyberbullying (Elsaesser et al. 2017). Although some studies caution that adolescents may have a negative reaction to parental monitoring (Hessel et al. 2017; Laird et al. 2018), emerging studies suggest a negative relationship between parental monitoring and cyberbullying victimization/perpetration (Chang et al. 2015; Hemphill and Heerde 2014; Hong et al. 2016; Khurana et al. 2015). Hong et al. (2016) found that parental monitoring-measured by parental knowledge of youth's friends, free time, and activities-was negatively related to both face-to-face bullying and cyberbullying. In a longitudinal Australian study, parents' awareness of their adolescents' activities was linked to lower levels of reported cyberbullying harassment four years later (Hemphill and Heerde 2014). However, adolescents may view some forms of parental monitoring as snooping or invasion of privacy (e.g., Hawk et al. 2008). Although there are several forms of monitoring (see Laird et al. (2018) for an excellent discussion), in the current paper, monitoring generally refers to parents' behaviors (e.g., asking questions about child behaviors).

Monitoring specifically in the online environment—often referred to as parental mediation—may be particularly important to parents who are concerned about cyberbullying (Cassidy et al. 2012; American Psychological Association 2017). In a mixed-methods study of 312 parents of sixth- to ninth-graders in Canada, most parents emphasized the need for the prevention of cyberbullying — starting at home (Cassidy et al. 2012). Although parents voiced some concern about online risks and cyberbullying, parents underestimated the amount of cyberbullying children experienced (compared with child reports) and the amount of time that their children spent online. Over two-thirds of parents reported monitoring their children at least somewhat, and $41 \%$ believed that restrictive monitoring was the best way to prevent cyberbullying. Still, more than half of parents emphasized the need for communication, support when cyberbullying occurred, and more education on how to respond to cyberbullying.

Parents also described the need to become more aware of their child's social media use, but others felt that parents generally do not have the energy to guide children's use (Cassidy et al. 2012). Similarly, in the Stress in America report (American Psychological Association 2017), 48\% of parents reported that monitoring online activity was a constant battle, $45 \%$ felt that technology interrupted family connectedness, and 58\% worried that their children were attached to their electronic devices. In a study of middle school students in Taiwan, Chang et al. (2015) found that parents' restriction of online activity was related to lower cyberbullying victimization and perpetration. According to 
Martins et al. (2017), family rules, including rules regarding digital technology, may be a deterrent to cyberbullying. These studies underscore the need to involve parents in cyberbullying prevention, a theme echoed in qualitative studies with parents about face-to-face bullying (Harcourt et al. 2014).

Many parental monitoring studies have examined parental control of online activity. In a study of youth aged 12-17 years who participated in the Pew Internet and American Life project, Mesch (2009) examined both parental restriction of adolescents' online activities as well as family rules about information sharing and websites. Rule-setting implied that parents and adolescents had talked about these issues. Having rules in place about websites was the only type of online monitoring that was associated with lower levels of bullying victimization. In another study of the Pew data, Wisniewski et al. (2015) found that restrictive, direct parental control such as setting limits of screen time and access to passwords was related to low adolescent risky behavior online (including cyberbullying). However, parental control also may have discouraged teens from engaging online or correcting their online misjudgments (e.g., deleting their own posts). In contrast, active discussion and parental monitoring that included online interaction was related to engagement with others online and correcting their online misjudgments. In one cross-sectional study, primarily restrictive parental monitoring of online behavior was positively related to cyberbullying, which in turn was positively associated with offline bullying (Meter and Bauman 2018). Similarly, in a longitudinal study of Midwestern students (aged 13-15 years) in the U.S., restrictive parental monitoring of social networking activity was associated with greater cyberbullying victimization at the same time point and greater depressive symptoms one year later. However, parental co-viewing and instruction was associated with lower cyberbullying victimization at the same time point, and lower depressive symptoms one year later (Wright 2018).

These studies provide emerging evidence that active parent-teen communication about online activities and involved parental monitoring may be key leverage points for reducing risk of the negative health outcomes associated with cyberbullying. In the current study, we focus on the discussion of online activities as another form of parental monitoring that may include asking youth about what they have been doing in online contexts.

\subsection{Examining Parent-Child Relationships and Monitoring Concurrently}

Despite consistent evidence of the protective association of positive parenting and low cyberbullying involvement (Elsaesser et al. 2017), a gap in the literature remains: the examination of parent-child relationships and monitoring together as they relate to cyberbullying involvement. In one of the few exceptions, Chang et al. (2015) found that a strong parent-adolescent relationship and restrictive parental monitoring of online activity were associated with lower likelihood of both cyberbullying victimization and perpetration in a sample of youth from Taiwan. Other types of parental monitoring -including active discussion, safety instruction, monitoring of activity, or technical help-were not significantly related to cyberbullying involvement. Another study of U.S. students found that a poor parent-adolescent relationship and low parental monitoring were both associated with greater cyberbullying perpetration (Ybarra and Mitchell 2004). However, a study of students in Greece found that parental safety practices online-including restrictive monitoring - were related to lower cyberbullying victimization, but parental bonding was not related to either type of cyberbullying involvement (Floros et al. 2013b). Given these sparse and contradictory findings, further joint examination of parent-child relationships and monitoring is warranted. We address this shortcoming in the current study.

\subsection{The Current Study}

Consistent with Baumrind's assertion that parenting warmth and control combine for the most effective parenting (Baumrind 1991), caring parent-child relationships and parental monitoring have been found to be deterrents of cyberbullying victimization and perpetration (e.g., Hemphill and Heerde 2014). In addition, parental monitoring of adolescents' online activities has been shown 
to be effective in reducing online risk when it includes collaboration and discussion rather than control or restriction (e.g., Wisniewski et al. 2015). However, few researchers have examined caring parent-child relationships and parental monitoring of adolescents' online activities concurrently. A warm parent-child relationship has been shown to dampen and moderate children's negative reactions to parental monitoring (LaFleur et al. 2016). Therefore, by accounting for the effects of parental connectedness, we can examine under what circumstances parental monitoring of online activities may be related to low cyberbullying involvement.

In the current secondary data analysis, we addressed this gap by examining both parental connectedness and parental monitoring of online activities. We expected that youth report of parental caring would be negatively related to both cyberbullying victimization and perpetration. We also hypothesized that parental monitoring of online activities would be negatively related to both cyberbullying victimization and perpetration, controlling for connectedness and demographics. We explored potential moderating effects of youth gender, answering a recent call to understand differential effects of gender with respect to cyberbullying (Navarro 2016). We also explored potential moderating effects of parental connectedness on the relationship between parental monitoring of online activities and both forms of cyberbullying.

\section{Methods}

\subsection{Participants}

Data were collected from 570 sixth grade students participating in the Partnering for Healthy Student Outcomes (PHSO) study, a longitudinal study of school-based prevention programs in three middle schools in the Minneapolis/St. Paul metropolitan area in the spring of 2015. Participants were $48.7 \%$ female; $1.9 \%$ reported being American Indian, 13.7\% Asian, 20.2\% Black, 20.4\% Latino, $22.7 \%$ White, and $21.1 \%$ multiracial. Nearly two-thirds (65.7\%) qualified for free/reduced-price lunch (see Table 1).

Table 1. Descriptive statistics of the sixth grade sample: youth report of key variables.

\begin{tabular}{ll}
\hline & Full Sample $(n=570)$ \\
\cline { 2 - 2 } & $\%$ or $M(S D)$ \\
\hline Demographics & \\
Female & $47.8 \%$ \\
Race/ethnicity & \\
$\quad$ American Indian & $1.9 \%$ \\
Asian/South Pacific & $13.7 \%$ \\
Black & $20.2 \%$ \\
Latino/a & $20.4 \%$ \\
Multi-racial & $21.1 \%$ \\
White & $22.6 \%$ \\
Lives with two biological parents & $68.0 \%$ \\
Receipt of free/reduced-priced lunch & $65.7 \%$ \\
\hline Key Variables & \\
Cyberbullying victimization & $16.7 \%$ \\
Cyberbullying perpetration & $8.4 \%$ \\
Parental connectedness & $3.20(0.76)$ \\
Parental online monitoring & $2.81(1.11)$ \\
\hline
\end{tabular}

\subsection{Procedure}

Three schools were assigned to one of three conditions: (1) an evidence-based social emotional skill-building curriculum; (2) a year-long teacher professional development program aimed at improving teacher-student relationships, student engagement, and teacher classroom management and inclusion practices; and (3) both the social emotional skill building and the teacher professional 
development program. Schools were recruited for two reasons. First, they served students from diverse racial/ethnic and socioeconomic backgrounds (i.e., high percentage of students eligible to receive free/reduced-price lunch). Second, they were experiencing challenges in terms of academic risk (i.e., lower percentages of students meeting proficiency on standardized tests), in comparison to overall state statistics.

All students in sixth grade at the three schools were eligible to participate in the study. In the fall of sixth grade, we attempted to obtain parental consent from $n=789$ enrolled students by approaching parents at an information night before the school year started, sending home written notes to each student's parents, and by calling families who had not returned the written form. In the spring of sixth grade, 48 additional students had enrolled, and parents received information mailed to their home describing the study and follow-up phone calls, as needed, to obtain parental consent. Written forms were made available in English, Spanish, Hmong, and Somali based on the preferences of the family as documented by the school. Verbal consent was also offered in English, Spanish, and Hmong. Of the 837 eligible across both time points, 649 parents provided consent (77.5\%). At the spring assessment, 615 students were still enrolled at the school and had parental consent. Of those, 571 (92.8\%) students provided written assent and participated in the survey. One student had missing data on all variables of interest; therefore, the current secondary data analysis utilizes data from 570 students. Intervention effects were not tested or expected at this early interim time point. The Institutional Review Board at the University of Minnesota approved this study.

\subsection{Measures}

Cyberbullying victimization and perpetration were measured by asking, "During the last 30 days, how often have you [been bullied/bullied others] online through social media, email, texting, websites, video games, photos/videos, or instant messaging?" (California Department of Education 2015). Five frequency response options were dichotomized to "never" versus "ever" reporting cyberbullying victimization and perpetration in the past 30 days based on past research that has found a substantial difference in the experiences of those who have never been involved in bullying and those who have been even once or twice in the last month (Gower and Borowsky 2013).

Parental connectedness was measured by a three-item Caring Relationships at Home Scale. Items include "In my home, there is a parent or some other adult who listens to me when I have something to say," "... who is interested in my schoolwork," and "... who talks with me about my problems" (responses ranged from $1=$ not at all true to $4=$ very true; $\alpha=0.73$; California Department of Education 2015). Online parental monitoring was measured by one item: "In my home, there is a parent or some other adult who asks me about things I do online (through social media, email, texting, websites, video games, photos/videos, or instant messaging)" ( $1=$ not at all true; $4=$ very true).

Several socio-demographic variables were included. Students indicated their family structure (two biological parents versus other configurations) on the survey; gender and qualification for free/reduced-price lunch were obtained from school records. Finally, a composite variable for race/ethnicity was created in which self-reports were prioritized first at baseline, then at the second assessment. If race/ethnicity was missing from these two self-reports, school records were used to provide data. We also controlled for school context by including dummy-coded variables and contrasting two of the schools to the third school as the referent.

\subsection{Analysis Plan}

First, we examined descriptive statistics of the variables of interest and correlations, and we tested for differences between those who reported cyberbullying victimization or perpetration and those who reported no cyberbullying involvement via $t$-tests and cross tabulation analyses. Then, we conducted a series of multivariable logistic regression analyses to estimate the relationship of parenting connectedness and parental monitoring with cyberbullying victimization and perpetration, controlling for socio-demographic variables and school. Next, to test whether the relationships between parenting 
variables and cyberbullying involvement were moderated by gender and whether the relationship between monitoring of online activities and cyberbullying involvement was moderated by parental connectedness, we added interaction terms to the models. A spreadsheet containing the variables used in these analyses is available in the Supplementary Materials.

Missing data for each variable amounted to less than $5 \%$. For example, only $1.9 \%$ of students were missing data on either of the cyberbullying victimization and perpetration variables. However, when all variables were considered together, $17 \%$ of cases had some missing data. We conducted cross tabulation analyses to examine missingness on the dependent variables. No significant differences were found by gender, race, or receipt of free/reduced-price lunch. However, students who did not live with two biological parents were more likely to be missing data on cyberbullying victimization and perpetration variables. To account for missing data, we used 25 iterations of multiple imputation in all models, including socio-demographic variables to inform the imputation (Johnson and Young 2011).

\section{Results}

Descriptive statistics are found in Table 1. In the spring of their sixth-grade year, $16.7 \%$ of students reported cyberbullying victimization, and $8.4 \%$ reported cyberbullying perpetration in the past 30 days. Unadjusted bivariate analyses indicated that parental connectedness was significantly lower among adolescents who reported cyberbullying victimization $(M=2.96 ; S D=0.83)$ compared to adolescents not involved in cyberbullying victimization $(M=3.24 ; S D=0.74 ; t(548)=-3.28, p=0.001)$. Parental connectedness was also significantly lower among adolescents who reported cyberbullying perpetration $(M=2.90 ; S D=0.83)$ compared to adolescents not involved in cyberbullying perpetration $(M=3.22 ; S D=0.75 ; t(548)=-2.78, p=0.006)$. Online parental monitoring was significantly lower among adolescents who reported cyberbullying perpetration $(M=2.48 ; S D=1.24)$ compared to adolescents not involved in cyberbullying perpetration $(M=2.84 ; S D=1.09 ; t(542)=-2.12, p=0.035)$. A similar, marginally significant pattern of differences in online parental monitoring was noted for youth who reported cyberbullying victimization $(M=2.61 ; S D=1.10$ versus $M=2.85 ; S D=1.11 ; t(542)=-1.89$, $p=0.060)$. We also examined the correlation between the two parenting practice measures. Parental connectedness was significantly correlated with parental online monitoring $(r=0.47, p<0.000)$.

Results of the logistic regression models are found in three columns in Table 2. In Model 1 analyses, each one-unit increase in connectedness to a parent/parental figure was associated with a $35 \%$ reduction in likelihood of cyberbullying victimization and a $46 \%$ reduction in likelihood of cyberbullying perpetration. Adjusted associations with parental monitoring are shown in Model 2. Student report of parental online monitoring was associated with a $34 \%$ reduction in the likelihood of cyberbullying perpetration per unit of parental online monitoring. When both parental connectedness and parental online monitoring were included in Model 3, only parental connectedness was significantly associated with a lower likelihood of cyberbullying victimization and cyberbullying perpetration ( $24 \%$ and $36 \%$ lower per unit of parent connectedness, respectively). To illustrate the magnitude of effects in the non-linear models, we plotted the predicted probabilities of cyberbullying victimization and perpetration for each unit of parental connectedness (see Figure 1). Although online parental monitoring was associated with a $36 \%$ lower likelihood of cyberbullying perpetration, this effect was marginally significant $(p=0.090)$. Finally, no significant interaction effects were detected, indicating that gender did not moderate the main effects; nor did parental connectedness moderate the relationships between online parental monitoring and cyberbullying victimization/perpetration. 
Table 2. Results of multivariable logistic regression models of parental connectedness and monitoring of online activities on cyberbullying victimization and perpetration $(n=570)$.

\begin{tabular}{|c|c|c|c|c|c|c|c|c|c|c|c|}
\hline & \multicolumn{3}{|c|}{ Model 1} & \multicolumn{4}{|c|}{ Model 2} & \multicolumn{4}{|c|}{ Model 3} \\
\hline & \multirow[t]{2}{*}{$\mathrm{OR}^{\mathrm{a}}$} & \multirow[t]{2}{*}{$\mathrm{SE}^{\mathrm{b}}$} & $95 \% \mathrm{CI}^{\mathrm{c}}$ & \multirow{2}{*}{ OR } & \multirow{2}{*}{$\frac{\text { SE }}{\text { nizati }}$} & \multicolumn{2}{|c|}{$95 \% \mathrm{CI}$} & \multirow[t]{2}{*}{ OR } & \multirow[t]{2}{*}{ SE } & \multicolumn{2}{|c|}{$95 \% \mathrm{CI}$} \\
\hline \multicolumn{6}{|c|}{ Cyberbullying Victimization } & & & & & & \\
\hline Connectedness & $0.65^{* *}$ & 0.10 & 0.46 & & & & & $0.76^{*}$ & 0.08 & 0.49 & 0.94 \\
\hline Online Monitoring & & & & $0.82^{+}$ & 0.09 & 0.67 & 1.01 & 0.76 & 0.12 & 0.55 & 1.17 \\
\hline Constant & 0.21 & 0.11 & & 0.62 & 0.41 & & & 0.64 & 0.43 & & \\
\hline \multicolumn{12}{|c|}{ Cyberbullying Perpetration } \\
\hline Connectedness & $0.54 * *$ & 0.11 & 0.37 & & & & & $0.64^{*}$ & 0.14 & 0.42 & 0.99 \\
\hline Online Monitoring & & & & $0.66^{* *}$ & 0.10 & 0.50 & 0.88 & $0.76^{+}$ & 0.12 & 0.56 & 1.03 \\
\hline Constant & 0.03 & 0.03 & & 0.06 & 0.08 & & & 1.02 & 0.95 & & \\
\hline
\end{tabular}

Note. ${ }^{\mathrm{a}} \mathrm{OR}=$ Odds Ratio. ${ }^{\mathrm{b}} \mathrm{SE}=$ Standard Error. ${ }^{\mathrm{c}} \mathrm{CI}=$ Confidence Interval. All models control for gender, race/ethnicity, family structure, receipt of free or reduced-price lunch, and school. $+p<0.10$; ${ }^{*} p<0.05$; $* *<0.001$.

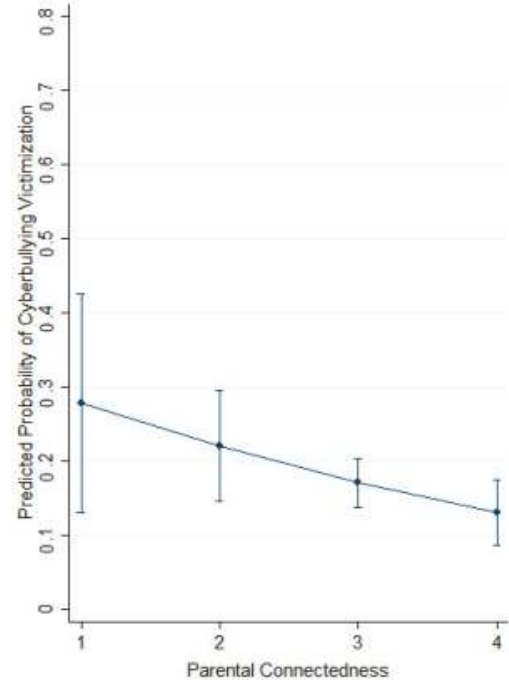

(a)

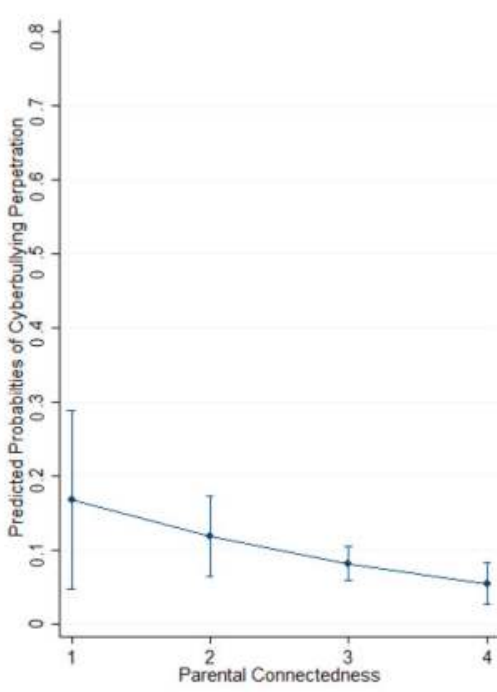

(b)

Figure 1. Marginal effects of parental connectedness on the predicted probabilities of (a) cyberbullying victimization and (b) cyberbullying perpetration.

\section{Discussion}

The current paper extends past research by examining both parental connectedness and monitoring with respect to cyberbullying victimization and perpetration. More specifically, we examined parental connectedness in concert with parental monitoring of online activities through discussion. We found that parental connectedness was negatively associated with the likelihood of both cyberbullying victimization and perpetration, accounting for the effects of parental monitoring. Parental monitoring of online activities was negatively associated with cyberbullying perpetration, though this association was only marginally significant when parental connectedness was included in the model. Study results suggest that parental connectedness may be more salient than parental monitoring of online activities to deter cyberbullying involvement.

Findings from this study contribute to a body of literature that has found that parent-adolescent connectedness is linked to positive youth health outcomes (Sieving et al. 2017) and is associated with lower risk of cyberbullying involvement (Kowalski et al. 2014; Wang et al. 2009). Strong parent-adolescent 
relationships may encourage youth disclosure of online risk and enable parents to guide youth in online environments. Youth disclosure of online activities and risk-taking has been found to be more important than parental monitoring of information (Shapka and Law 2013). Additionally, parent-adolescent connectedness may provide a safe learning environment for adolescents to take online risks and correct mistakes (Wisniewski et al. 2015), ultimately protecting youth against cyberbullying involvement. For example, youth may be more willing to post creative videos or apologize for a failed attempt at online sarcasm if they feel the support of parents. These explanations merit further investigation.

Our findings are consistent with past research that has found that parental monitoring may deter cyberbullying perpetration. Past research has primarily focused on restrictive monitoring (Chang et al. 2015; Martins et al. 2017). However, we examined whether adolescents report that their parents ask them about what they do online, suggesting a type of active discussion. Although parental monitoring of online activities was marginally related to lower cyberbullying perpetration, parental connectedness was significantly related to both perpetration and victimization. This finding is in line with previous studies that suggest caution should be taken before recommending a strategy of asking adolescents what they are doing online. Older adolescents, in particular, may resent a perceived invasion of privacy (e.g., Hawk et al. 2008), and at least one study found that parental requests for information about youth activities via technology was related to higher rates of youth depressive symptoms rather than face-to-face conversations (Hessel et al. 2017). However, parental online monitoring may be an important deterrent in other areas of online safety.

These findings have implications for parent-based prevention of cyberbullying and online risk. Public opinion seems to indicate that parents want more options for monitoring and controlling online use. For example, a recent open letter to Apple on behalf of parents called for improvements in online monitoring, and Apple responded in kind with parental controls in their iPhone operating system (JANA Partners LLC and the California State Teachers' Retirement System 2018). Some monitoring of online activities may be appropriate for new users of technology-mediated activities such as social media use and reducing online risk in other areas. However, the current research suggests that parent-child relationships remain an important component in the prevention of cyberbullying (Elsaesser et al. 2017).

Parent-based programs for the prevention of cyberbullying may be especially effective because adolescents often use technology and experience cyberbullying at home (Kowalski et al. 2012). Also, parent-based programs have been shown to strengthen parent-child relationships (Sandler et al. 2011) and may serve as a buffer to cyberbullying (Low and Espelage 2014). Students who have experienced family dysfunction are at high risk for bullying involvement (Forster et al. 2017) and may benefit from programming that strengthens parent-adolescent relationships, which in turn could reduce the likelihood of cyberbullying.

\section{Strengths and Limitations}

The strengths of this study include the examination of youth reports of both parental connectedness and parental online monitoring, the diversity of the sample, and the inclusion of parental online monitoring via discussion as opposed to restrictive monitoring. However, limitations must be acknowledged. Cyberbullying victimization and perpetration were measured with a single item, which may not capture all potential cyberbullying situations and may underestimate results. Ideally, a stronger variable would consist of multiple items. In the current study, we did not examine parent connectedness and parental monitoring among youth who experience both cyberbullying victimization and perpetration because their numbers were so few $(n=21)$. Future analyses should also consider examining multiple parenting variables among youth involved in both cyberbullying victimization and perpetration. Also, parental online monitoring was a single item measure, and other aspects of parental monitoring behavior such as rule-setting were not captured. 
The sample was local and may not generalize beyond the Midwest metropolitan area where the study took place. Replication is warranted. Finally, because this study was based on a cross-sectional analysis, temporal order was not established. It may be that cyberbullying involvement causes parents to be more protective of their children, which may manifest in greater connectedness and monitoring. Therefore, longitudinal studies examining the relationship of parenting practices with cyberbullying involvement are needed (Elsaesser et al. 2017).

\section{Conclusions}

Young adolescents involved in cyberbullying, whether as a victim or a bully, reported lower levels of parental connectedness and parental online monitoring in unadjusted analyses. Rates of cyberbullying experiences were similar to other studies of middle school students. Because large national data sets have found trends suggesting that cyberbullying increases across adolescence in the U.S., early prevention is key (National Academies of Sciences, Engineering, and Medicine 2016). In multivariable analyses, we found that that greater levels of parental connectedness, and to a lesser extent parental online monitoring, were associated with lower odds of cyberbullying involvement in a diverse sample of sixth graders. Our findings offer preliminary support for parent-involved prevention or intervention programs that focus on teaching both parents and their children strategies to strengthen their relationships, in addition to providing practical content about online contexts. Such programming might be delivered in a variety of settings—-through schools, communities, or clinics. As most young adolescents will increase their engagement in online spaces as they grow older, nurturing strong parent-adolescent relationships will continue to be a primary protective factor for a digitally-focused generation. Research is needed to test whether parent-based interventions and digital training can deter cyberbullying involvement among middle school students.

Supplementary Materials: The following are available online at http:/ www.mdpi.com/2076-0760/7/12/265/s1, Spreadsheet 1. Study data.

Author Contributions: Authors contributed to the manuscript as follows: conceptualization, J.L.D., A.L.G., B.J.M., S.L.P., and R.E.S.; methodology, J.L.D., A.L.G., and B.J.M.; software, J.L.D.; validation, A.L.G.; formal analysis, J.L.D.; investigation, J.L.D., A.L.G., B.J.M., S.L.P. ; resources, A.L.G., B.J.M., S.L.P., R.E.S.; data curation, A.L.G., S.L.P.; writing-original draft preparation, J.L.D., A.L.G.; writing-review and editing, J.L.D., A.L.G., B.J.M., and R.E.S.; visualization, J.L.D.; supervision, B.J.M., R.E.S.; project administration, S.L.P., B.J.M.; funding acquisition, B.J.M., R.E.S.

Funding: This study was funded by Cooperative Agreement Number U48DP005011 (PI: Sieving) from the Centers for Disease Control and Prevention. J.D. was supported by the Health Resources and Services Administration (HRSA) of the U.S. Department of Health and Human Services (HHS) under National Research Service Award (NRSA) in Primary Medical Care, grant no. T32HP22239 (PI: Borowsky). This information or content and conclusions are those of the authors and should not be construed as the official position or policy of, nor should any endorsements be inferred by the CDC, HRSA, HHS, or the U.S. Government.

Conflicts of Interest: The authors declare no conflict of interest.

\section{References}

Accordino, Denise B., and Michael P. Accordino. 2011. An Exploratory Study of Face-to-Face and Cyberbullying in Sixth Grade Students. American Secondary Education 40: 14-30. Available online: https:/ /www.jstor.org/ stable/23100411 (accessed on 8 July 2018).

American Psychological Association. 2017. Stress in America: Coping with Change. Stress in America ${ }^{T M}$ Survey. Available online: https://www.apa.org/news/press/releases/stress/2017/technology-social-media.PDF (accessed on 14 May 2018).

Baumrind, Diana. 1991. The Influence of Parenting Style on Adolescent Competence and Substance Use. The Journal of Early Adolescence 11: 56-95. [CrossRef]

Borges Bottino, Sara Mota, Cássio Bottino, Caroline Gomez Regina, Aline Villa Lobo Correia, and Wagner Silva Ribeiro. 2015. Cyberbullying and Adolescent Mental Health: Systematic review. Cadernos de Saude Publica 31: 463-75. [CrossRef] 
California Department of Education. 2015. California Healthy Kids Survey, Student Well-Being in California, 2013-2015: Statewide Elementary Results. San Francisco: WestEd Health and Human Development Program for the California Department of Education. Available online: http:/ / surveydata.wested.org/resources/Biennial_ State_1315.pdf (accessed on 14 May 2018).

Campbell, Marilyn A., Phillip T. Slee, Barbara Spears, Des Butler, and Sally Kift. 2013. Do Cyberbullies Suffer Too? Cyberbullies' Perceptions of the Harm They Cause to Others and to Their Own Mental Health. School Psychology International 34: 613-29. [CrossRef]

Cassidy, Wanda, Karen Brown, and Margaret Jackson. 2012. 'Making Kind Cool': Parents' Suggestions for Preventing Cyber Bullying and Fostering Cyber Kindness. Journal of Educational Computing Research 46: 415-36. [CrossRef]

Centers for Disease Control and Prevention. 2017. Youth Risk Report Survey: Data Summary and Trends Report 2007-2017. Available online: https:/ /www.cdc.gov/healthyyouth/data/yrbs/index.htm?s_cid=tw-zaza1171 (accessed on 6 July 2018).

Chang, Fong-Ching, Chiung-Hui Chiu, Nae-Fang Miao, Ping-Hung Chen, Ching-Mei Lee, Jeng-Tung Chiang, and Ying-Chun Pan. 2015. The Relationship between Parental Mediation and Internet Addiction among Adolescents, and the Association with Cyberbullying and Depression. Comprehensive Psychiatry 57: 21-28. [CrossRef]

Dehue Francine, Catherine Bolman, Trijntje Vollink, and Mieneke Pouwelse. 2012. Cyberbullying and Traditional Bullying in Relation to Adolescents' Perception of Parenting. Journal of Cybertherapy \& Rehabilitation 5: 25-34.

Elsaesser, Caitlin, Beth Russell, Christine McCauley Ohannessian, and Desmond Patton. 2017. Parenting in a Digital Age: A Review of Parents' Role in Preventing Adolescent Cyberbullying. Aggression and Violent Behavior 35: 62-72. [CrossRef]

Fanti, Kostas A., Andreas G. Demetriou, and Veronica V. Hawa. 2012. A Longitudinal Study of Cyberbullying: Examining Risk and Protective Factors. European Journal of Developmental Psychology 9: 168-81. [CrossRef]

Fletcher, Anne C., Laurence Steinberg, and Meeshay Williams-Wheeler. 2004. Parental Influences on Adolescent Problem Behavior: Revisiting Stattin and Kerr. Child Development 75: 781-96. [CrossRef]

Floros, Georgios, Anna Paradeisioti, Michalis Hadjimarcou, Demetrios G. Mappouras, Olga Kalakouta, Penelope Avagianou, and Konstantinos Siomos. 2013a. Cyberbullying In Cyprus-Associated Parenting Style and Psychopathology. Studies in Health Technology and Informatics 191: 85-89. [CrossRef]

Floros, Georgios D., Konstantinos E. Siomos, Virginia Fisoun, Evaggelia Dafouli, and Dimitrios Geroukalis. 2013b. Adolescent Online Cyberbullying in Greece: The Impact of Parental Online Security Practices, Bonding, and Online Impulsiveness. Journal of School Health 83: 445-53. [CrossRef] [PubMed]

Forster, Myriam, Amy L. Gower, Barbara J. McMorris, and Iris W. Borowsky. 2017. Adverse Childhood Experiences and School-Based Victimization and Perpetration. Journal of Interpersonal Violence. [CrossRef]

Gower, Amy L., and Iris W. Borowsky. 2013. Associations between Frequency of Bullying Involvement and Adjustment in Adolescence. Academic Pediatrics 13: 214-21. [CrossRef] [PubMed]

Graham, Sandra, and Amy D. Bellmore. 2007. Peer Victimization and Mental Health during Early Adolescence. Theory into Practice 46: 138-46. [CrossRef]

Harcourt, Susan, Marieke Jasperse, and Vanessa A. Green. 2014. "We were Sad and We were Angry": A Systematic Review of Parents' Perspectives on Bullying. Child \& Youth Care Forum 43: 373-91. [CrossRef]

Hawk, Skyler T., William W. Hale III, Quinten A. W. Raaijmakers, and Wim Meeus. 2008. Adolescents' Perceptions of Privacy Invasion in Reaction to Parental Solicitation and Control. The Journal of Early Adolescence 28: 583-608. [CrossRef]

Hemphill, Sheryl A., and Jessica A. Heerde. 2014. Adolescent Predictors of Young Adult Cyberbullying Perpetration and Victimization among Australian Youth. Journal of Adolescent Health 55: 580-87. [CrossRef] [PubMed]

Hessel, Heather, Yaliu He, and Jodi Dworkin. 2017. Paternal Monitoring: The Relationship between Online and In-person Solicitation and Youth Outcomes. Journal of Youth and Adolescence 46: 288-99. [CrossRef]

Hinduja, Sameer, and Justin W. Patchin. 2010. Bullying, Cyberbullying, and Suicide. Archives of Suicide Research 14: 206-21. [CrossRef]

Hong, Jun Sung, Jungup Lee, Dorothy L. Espelage, Simon C. Hunter, Desmond Upton Patton, and Tyrone Rivers Jr. 2016. Understanding the Correlates of Face-to-face and Cyberbullying Victimization among US Adolescents: A Social-ecological Analysis. Violence and Victims 31: 638-63. [CrossRef] 
Influence Central. 2016. Kids \& Tech: The Evolution of Today's Digital Natives. Available online: http:/ /influencecentral.com/kids-tech-the-evolution-of-todays-digital-natives / (accessed on 13 May 2018).

JANA Partners LLC and the California State Teachers' Retirement System. 2018. Open Letter from JANA Partners and CALSTRS to Apple, Inc. Available online: https: / / thinkdifferentlyaboutkids.com/letter/?acc=1 (accessed on 18 July 2018).

Johnson, David R., and Rebekah Young. 2011. Toward Best Practices in Analyzing Datasets with Missing Data: Comparisons and Recommendations. Journal of Marriage and Family 73: 926-45. [CrossRef]

Khurana, Atika, Amy Bleakley, Amy B. Jordan, and Daniel Romer. 2015. The Protective Effects of Parental Monitoring and Internet Restriction on Adolescents' Risk of Online Harassment. Journal of Youth and Adolescence 44: 1039-47. [CrossRef] [PubMed]

Kim, Soyeon, Scott R. Colwell, Anna Kata, Michael H. Boyle, and Katholiki Georgiades. 2018. Cyberbullying Victimization and Adolescent Mental Health: Evidence of Differential Effects by Sex and Mental Health Problem Type. Journal of Youth and Adolescence 47: 661-72. [CrossRef] [PubMed]

Kowalski, Robin M., and Susan P. Limber. 2013. Psychological, Physical, and Academic Correlates of Cyberbullying and Traditional Bullying. Journal of Adolescent Health 53: S13-S20. [CrossRef] [PubMed]

Kowalski, Robin M., Susan P. Limber, Sue Limber, and Patricia W. Agatston. 2012. Cyberbullying: Bullying in the Digital Age. Hoboken: John Wiley \& Sons.

Kowalski, Robin M., Gary W. Giumetti, Amber N. Schroeder, and Micah R. Lattanner. 2014. Bullying in the Digital Age: A Critical Review and Meta-analysis of Cyberbullying Research among Youth. Psychological Bulletin 140: 1073-37. [CrossRef] [PubMed]

Kowalski, Robin, Susan P. Limber, and Annie McCord. 2018. A Developmental Approach to Cyberbullying: Prevalence and Protective Factors. Aggression and Violent Behavior. [CrossRef]

LaFleur, Laura K., Yinan Zhao, Megan M. Zeringue, and Robert D. Laird. 2016. Warmth and Legitimacy Beliefs Contextualize Adolescents' Negative Reactions to Parental Monitoring. Journal of Adolescence 51: 58-67. [CrossRef] [PubMed]

Laird, Robert D., Megan M. Zeringue, and Emily S. Lambert. 2018. Negative Reactions to Monitoring: Do They Nndermine the Ability of Monitoring to Protect Adolescents? Journal of Adolescence 63: 75-84. [CrossRef]

Low, Sabina, and Dorothy Espelage. 2014. Conduits from Community Violence Exposure to Peer Aggression and Victimization: Contributions of Parental Monitoring, Impulsivity, and Deviancy. Journal of Counseling Psychology 61: 221. [CrossRef]

Makri-Botsari, Evi, and G. Karagianni. 2014. Cyberbullying in Greek Adolescents: The Role of Parents. Procedia-Social and Behavioral Sciences 116: 3241-53. [CrossRef]

Martins, Maria José D., Ana Margarida Veiga Simão, Isabel Freire, Ana Paula Caetano, and Armanda Matos. 2017. Cyber-victimization and cyber-aggression among Portuguese adolescents: The relation to family support and family rules. In Violence and Society: Breakthroughs in Research and Practice. Hershey: IGI Global, pp. 134-49. [CrossRef]

Mesch, Gustavo S. 2009. Parental Mediation, Online Activities, and Cyberbullying. CyberPsychology E Behavior 12: 387-93. [CrossRef]

Meter, Diana J., and Sheri Bauman. 2018. Moral Disengagement about Cyberbullying and Parental Monitoring: Effects on Traditional Bullying and Victimization Via Cyberbullying Involvement. The Journal of Early Adolescence 38: 303-26. [CrossRef]

Moreno, Megan A., Nina Suthamjariya, and Ellen Selkie. 2018. Stakeholder Perceptions of Cyberbullying Cases: Application of the Uniform Definition of Bullying. Journal of Adolescent Health 62: 444-49. [CrossRef] [PubMed]

National Academies of Sciences, Engineering, and Medicine. 2016. Preventing Bullying through Science, Policy, and Practice. Washington: National Academies Press. [CrossRef]

Navarro, Raúl. 2016. Gender issues and cyberbullying in children and adolescents: From gender differences to gender identity measures. In Cyberbullying across the Globe. Cham: Springer, pp. 35-61. [CrossRef]

Rideout, Victoria J., Ulla G. Foehr, and Donald F. Roberts. 2010. Generation M 2: Media in the Lives of 8-to 18-Year-Olds. Henry J. Kaiser Family Foundation. Available online: https://www.kff.org/other/event/ generation-m2-media-in-the-lives-of/ (accessed on 21 July 2018). 
Sandler, Irwin N., Erin N. Schoenfelder, Sharlene A. Wolchik, and David P. MacKinnon. 2011. Long-term Impact of Prevention Programs to Promote Effective Parenting: Lasting Effects but Uncertain Processes. Annual Review of Psychology 62: 299-329. [CrossRef] [PubMed]

Selkie, Ellen M., Jessica L. Fales, and Megan A. Moreno. 2016. Cyberbullying Prevalence among US middle and High School-aged Adolescents: A systematic Review and Quality Assessment. Journal of Adolescent Health 58: 125-33. [CrossRef] [PubMed]

Shapka, Jennifer D., and Danielle M. Law. 2013. Does One Size Fit All? Ethnic Differences in Parenting Behaviors and Motivations for Adolescent Engagement in Cyberbullying. Journal of Youth and Adolescence 42: 723-38. [CrossRef] [PubMed]

Sieving, Renee E., Annie-Laurie McRee, Barbara J. McMorris, Rebecca J. Shlafer, Amy L. Gower, Hillary M. Kapa, Kara J. Beckman, Jennifer L. Doty, Shari L. Plowman, and Michael D. Resnick. 2017. Youth-adult Connectedness: A Key Protective Factor for Adolescent Health. American Journal of Preventive Medicine 52: S275-78. [CrossRef] [PubMed]

Tokunaga, Robert S. 2010. Following You Home from School: A Critical Review and Synthesis of Research on Cyberbullying Victimization. Computers in Human Behavior 26: 277-87. [CrossRef]

Waasdorp, Tracy E., and Catherine P. Bradshaw. 2015. The Overlap between Cyberbullying and Traditional Bullying. Journal of Adolescent Health 56: 483-88. [CrossRef] [PubMed]

Wang, Jing, Ronald J. Iannotti, and Tonja R. Nansel. 2009. School Bullying among Adolescents in the United States: Physical, Verbal, Relational, and Cyber. Journal of Adolescent Health 45: 368-75. [CrossRef]

Wisniewski, Pamela, Haiyan Jia, Heng Xu, Mary Beth Rosson, and John M. Carroll. 2015. Preventative vs. Reactive: How Parental Mediation Influences Teens' Social Media Privacy Behaviors. Paper presented at the 18th ACM Conference on Computer Supported Cooperative Work \& Social Computing, Vancouver, BC, Canada, March 14-18, pp. 302-316. [CrossRef]

Wright, Michelle. 2018. Cyberbullying Victimization through Social Networking Sites and Adjustment Difficulties: The Role of Parental Mediation. Journal of the Association for Information Systems 19: 113-23. [CrossRef]

Ybarra, Michele L., and Kimberly J. Mitchell. 2004. Youth Engaging in Online Harassment: Associations with Caregiver-child Relationships, Internet Use, and Personal Characteristics. Journal of Adolescence 27: 319-36. [CrossRef]

(c) 2018 by the authors. Licensee MDPI, Basel, Switzerland. This article is an open access article distributed under the terms and conditions of the Creative Commons Attribution (CC BY) license (http:/ / creativecommons.org/licenses/by/4.0/). 
Article

\title{
Parental Communication and Feelings of Affiliation in Adolescent Aggressors and Victims of Cyberbullying
}

\author{
Jessica Ortega Barón ${ }^{1, *}$, Javier Postigo ${ }^{2}$, Begoña Iranzo ${ }^{3}$, Sofía Buelga ${ }^{4}$ and Laura Carrascosa ${ }^{4}$ \\ 1 Department of Psychology of Education and Psychobiology, Faculty of Education, \\ International University of la Rioja (UNIR), 26006 Logroño, Spain \\ 2 Department of Social Psychology, Faculty of Psychology, University of Málaga, 29071 Málaga, Spain; \\ javier_postigo@msn.com \\ 3 Department of Health Sciences, Valencian International University, 46002 Valencia, Spain; \\ begona.iranzo@campusviu.es \\ 4 Department of Social Psychology, Faculty of Psychology, University of Valencia, 46010 Valencia, Spain; \\ sofia.buelga@uv.es (S.B.); laura.carrascosa@uv.es (L.C.) \\ * Correspondence: jessica.ortega@unir.net
}

Received: 12 November 2018; Accepted: 22 December 2018; Published: 25 December 2018

\begin{abstract}
Cyberbullying is an increasingly frequent problem among adolescents, and it produces considerable social concern. Using a cross-sectional and quantitative methodology, the main objective of this study was to analyze the differences among students involved in the perpetration and victimization of cyberbullying (non-involved, occasional, and severe), in their parental communication, and feelings of affiliation with classmates. The sample consisted of 849 adolescents ( $51.7 \%$ boys and $48.3 \%$ girls) from 12 to 18 years old $(M=14.5$; $S D=1.62)$. Three comparison groups of aggressors and victims of cyberbullying were formed, depending on the intensity of the intimidation: non-involved, occasional, and severe. The results of the analysis of variance indicated that adolescents involved in cyberbullying as perpetrators or victims have less open and more avoidant communication with their parents than adolescents who are not involved in cyberbullying. Additionally, victims of cyberbullying perceive lower feelings of affiliation with their classmates, whereas cyberbullies show no differences between the groups on this variable. These new results provide insight into the important role of family and peers in the prevention and eradication of the growing problem of cyberbullying.
\end{abstract}

Keywords: cyberbullying; perpetration; victimization; parental communication; affiliation; peers

\section{Introduction}

The growing use of a wide variety of technologies has created new forms of possible interaction and communication among adolescents (Betts and Spenser 2017; Goodyear and Armour 2018). Information and communication technologies (ICTs) provide many advantages for young people. However, the use of electronic devices at increasingly young ages also encourages their inappropriate use (Campbell and Bauman 2018; Garaigordobil 2017). Cyberbullying is defined as an intentional and aggressive behavior that is repeated frequently over a period of time through the use (by an individual or group) of electronic devices against a victim who cannot easily defend him/herself (Smith et al. 2008, p. 376). Today, this is the most common form of digital bullying among peers in adolescence (Watkins et al. 2016).

Cyberbullying is a serious and growing problem that affects more children and adolescents every day in all developed countries. In fact, most researchers coincide in pointing out that the prevalence of cyberbullying has increased considerably in recent years (Kowalski et al. 2014; Machimbarrena and 
Garaigordobil 2018; Watts et al. 2017). In the case of cybervictims, these authors have mentioned a $6.5 \%$ prevalence of cyberbullying victims in their study (Ybarra and Mitchell 2004). Almost ten years later, Floros et al. (2013) observed a cybervictim prevalence of $28.3 \%$. Regarding cyberbullies, an increase in their prevalence has also been reported over the years. In 2008, Slonje and Smith (2008) found a $10.3 \%$ prevalence of cyberbullies in their study. Almost a decade later, Lee and Shin (2017) noted a $34 \%$ prevalence of cyberbullies. Different studies reveal that there is a greater percentage of occasional cyberbullies and cybervictims than severe ones (Buelga et al. 2015; Palermiti et al. 2017). In spite of the studies mentioned above, one problem occurring in the scientific literature on the prevalence of cyberbullying is the lack of consensus with respect to its definition and the methodologies used for measuring cyberbullying and cybervictimization (Baldry et al. 2018; Hinduja and Patchin 2014). This divergence greatly complicates the comparison of research, both within countries as well as between different countries and cultures.

In addition, cyberbullying has negative consequences for the psychosocial wellbeing of adolescents involved in this problem. Cybervictims sometimes present depression, anxiety, suicide ideation, fear, nervousness, irritability, somatizations, sleep disorders, and difficulties in concentrating (Garaigordobil 2011; Navarro et al. 2015). Although the most pronounced effects are found in victims, cyberbullying also has negative consequences for cyberbullies. Some studies indicate that cyberbullies' behavior can be a precursor to criminal behavior (Buelga et al. 2015; Juvonen and Graham 2014). Moreover, Cerezo (2006) also observed a lack of empathy and moral comprehension in the bullies that keeps them from establishing normal social relationships and affects their psychological and social development.

In this context, given the seriousness of cyberbullying, different studies emphasize the important role of families in educating and preventing it (Taiariol 2010; Tsiplakides 2018). With regard to family climate, on the one hand, different studies point out that family cohesion acts as a protective factor against both cyberaggression and cybervictimization (Elsaesser et al. 2017; Sasson and Mesch 2017). On the other hand, family conflict is conceived as a risk factor that increases the probability that an adolescent will become involved in cyberbullying (Kowalski et al. 2014; Ortega-Baron et al. 2016). In this regard, Ybarra and Mitchell (2004) found that a poor family relationship, characterized by low supervision, lack of emotional ties, and severe discipline, is associated with a greater probability of becoming a victim or aggressor through technologies.

Another family variable related to the appearance and continuity of violent behaviors in adolescence is the adolescent's communication with his/her parents. In fact, the quality of the family atmosphere depends largely on the communication among the members of the family (Galvin et al. 2015). Regarding the issue of bullying, different studies show that bullies and victims have less open and more avoidant and offensive communication than adolescents who are not involved in this problem (Carrascosa et al. 2016; Ledwell and King 2015). With regard to cyberbullying, the study by Dehue et al. (2008) showed that more difficulties in family communication were observed in both cyberbullies and cybervictims. In addition, Larrañaga et al. (2016) found that cybervictims have more avoidant communication, which contributes to prolonging the duration of the cybervictimization.

The negative or not very fluid communication between parents and adolescents makes it difficult for parents to detect their children's cyberbullying. Various studies indicate that up to $50 \%$ of victims do not tell anyone about the bullying they are experiencing, or they do so rarely because they are afraid of being cyberbullied again (Ang and Goh 2010; García-Maldonado et al. 2011). Furthermore, according to the study by $\mathrm{Li}$ (2007), one-third of adolescents believe that even if adults know that there is a cyberbullying problem, they will not be able to help them. Other studies have shown that, in general, the first people victims go to for help are their peers (Aricak et al. 2008; Brooks et al. 2012).

The quality and support of peer relationships is another important variable in adolescents' wellbeing (Trejos-Herrera et al. 2018). Odac1 and Kalkan (2010) demonstrated that victims of cyberbullying experience greater isolation and social rejection from their peers. Moreover, different studies revealed that cyberbullies are popular and respected for their use of cyberviolence 
(Buelga et al. 2015; Povedano et al. 2012). This lack of help and the reinforcement of the aggressor by peers are variables that, together with family variables, also influence the occurrence and continuity of cyberbullying over time (Wegge et al. 2016; Calvete et al. 2010).

In short, different studies have proven the important role of family and peers to prevent intimidation among peers (Sasson and Mesch 2017; Price and Dalgleish 2010). According to Cava (2011), victims with positive family communication and who feel that they can identify with their peer group have a better psychological adjustment. According to this study, it is essential that the victim has a climate of trust and support in their environment to be able to communicate the situation experienced and overcome the problem of harassment.

Taking these antecedents into account, and in addition to the importance of parents and peers in preventing and reducing cyberbullying, the objectives of this study are: (1) To determine the extent of the relationship between cyberbullying (perpetration and victimization) and the variables in this study: Open communication (mother, father), avoidant communication (mother, father), and feeling of affiliation (peers); (2) analyze the prevalence of cybervictims and cyberbullies based on the intensity (occasional and severe); (3) analyze whether there are significant differences among the three groups of aggressors (non-cyberbullies, occasional cyberbullies, and severe cyberbullies) on the variables: Open communication (mother, father), avoidant communication (mother, father), and feeling of affiliation (peers); and (4) analyze whether there are significant differences among the three groups of victims (non-cybervictims, occasional cybervictims, and severe cybervictims) on the target variables. In short, this study contributes to broadening the knowledge about the differences between victims and aggressors of cyberbullying in the family communication and perception of feeling of affiliation with peers.

\section{Method}

\subsection{Participants}

In this cross-sectional study, participant selection was carried out by means of a non-probabilistic sampling for convenience due to their accessibility and prior interest in participating in the present study. The strata were established according to the grade level in high school (1st, 2nd, 3rd, and 4th course) of Compulsory Secondary Education (ESO) and the sociodemographic equivalence between the schools. The sample size of adolescents corresponding to the student group size in compulsory secondary education (ESO) in the Valencian Community, with a sampling error of $\pm 3.5 \%$, a confidence level of $95 \%$, and $p=q=0.5,(n=190.872)$, was estimated at 781 students.

The sample was composed of 849 high school students between 12 and 18 years old $(M=14.09$; $S D=1.37$ ) who attended four public high schools in the Valencian Community (Spain). Sex distribution of participants in this study was similar: $51.7 \%(n=439)$ were boys, and $48.3 \%$ were girls $(n=410)$. Regarding distribution by grade level, $22.4 \%(n=190)$ of participants were in the first course of ESO, (grade 7), 30.7\% $(n=261)$ were in the second course (grade 8$), 22.6 \%(n=192)$ were in the third course (grade 9$)$, and $24.3 \%(n=206)$ were in the fourth course (grade 10).

\subsection{Measures}

Adolescent victimization through the mobile phone and Internet scale (CYBVIC; Buelga et al. 2010, 2012). This scale consists of 18 items, which are rated on a Likert-type scale from 1 to 4 (never, seldom, often, and always). The items evaluate the bullying experienced through the mobile phone and the Internet in the past year. Mobile phone victimization is composed of 8 items (for example, "I have been insulted or ridiculed through messages or calls"), and Internet victimization is evaluated with the same items and 2 other items related to identity theft (for example, "They stole my identity to say or do bad things on the Internet"). In this study, Cronbach's alpha reliability coefficient for the scale was 0.88 and the coefficient omega was 0.86 . 
Adolescent aggression through the mobile phone and Internet scale (CYB-AG; Buelga and Pons 2012). This scale consists of 10 items with a response range from 1 to 5 (never, rarely, sometimes, frequently, quite often). The items evaluate the frequency with which the person has participated in aggressive behaviors through new technologies in the past year (for example, "I have used a peer's identity to do bad things on the Internet or on the phone" or "I have told lies or rumors to annoy a classmate over the Internet or on the phone"). In this study, Cronbach's alpha reliability coefficient for the scale was 0.82 and the coefficient omega was 0.80 .

Parent-adolescent communication scale (PACS; Barnes and Olson 1982). This scale is divided into two subscales (the adolescent's communication with the mother and the adolescent's communication with the father), each containing 16 items, which are rated from 1 (never) to 5 (always). For the purposes of this study, the dimensions of open communication and avoidance communication were used. Open communication evaluates the degree of positive communication based on understanding and the free exchange of information (for example, "In my family we express our opinions frequently and spontaneously"). Avoidant communication evaluates the degree of lack of communication, based on distancing and avoidance (for example, "In my family, we almost never openly show our anger"). In this study, Cronbach's alpha reliability coefficients for the open communication dimension were 0.72 (mother) and 0.69 (father). Cronbach's alpha reliability coefficients for the avoidance communication dimensions were 0.73 (mother) and 0.61 (father). The Omega coefficients for open communication dimension were 0.70 (mother) and 0.67 (father) and for the avoidance communication dimensions 0.71 (mother) and 0.60 (father).

Feeling of affiliation with peers subscale (Fernández-Ballesteros and Sierra 1989). For the purposes of this study, the subscale of the classroom environment scale (CES; Spanish adaptation by Fernández-Ballesteros and Sierra 1989) was used. This scale consists of 10 true-false items that evaluate the adolescent's perception of affiliation: Friendship and help among students (for example, "Students like to help each other"). In this study, Cronbach's alpha reliability coefficient for the subscale was 0.74 and the coefficient omega was 0.72 .

\subsection{Procedure}

Various informative meetings were held with the schools selected to explain the study aims. The selection of the high schools was carried out through non-probabilistic convenience sampling, based on their accessibility and prior interest in participating in this study. After obtaining the schools' permission and informed consent from the parents, the instruments were applied during school hours by previously trained researchers. Throughout the study, adolescents were informed that their participation was voluntary and anonymous. The participants' privacy was guaranteed, and none of the students refused to answer. The present study follows the ethical values required for research on humans, in accordance with the 1964 Declaration of Helsinki and its later amendments. Further, this study was approved by the Ethics Committee of the University of Valencia, Spain (Project identification code: H1456762885511).

\subsection{Data Analysis}

All data were analyzed with the SPSS statistical package (version 23). First, a Pearson correlation analysis was carried out to determine the relations between cyberbullying (perpetration and victimization) and the variables being studied open communication (mother, father), avoidance communication (mother, father), and feeling of affiliation (peers).

Second, subjects' scores on the scales of aggression and victimization through the mobile phone and Internet were used to classify students into three groups: (a) adolescent non-cyberbullies and adolescent non-cybervictims; (b) occasional cyberbullies and occasional cybervictims; (c) severe cyberbullies and severe cybervictims. The cut-off point used to assign the subjects to the group of severe cyberbullies and cybervictims was 1 standard deviation (+1 SD) above the mean. These data were $M=1.23, S D=0.34$ for the scale of cyberbullying (minimum score 10 , maximum 50 ), and $M=2.46$, 
$S D=0.60$ for the scale of cybervictimization (minimum score 18 , maximum 72 ). The adolescents who scored 1 ("never") on all items on these scales were placed in the non-cyberbully and non-cybervictim groups. The remaining adolescents were assigned to the groups of occasional cyberbullies and occasional cybervictims.

Third, the prevalence of cyberbullies and cybervictims based on the intensity (non-involved, occasional, and severe) was calculated.

Finally, a one-factor ANOVA was performed to analyze differences among the three comparison groups (non-cyberbullies, occasional cyberbullies, and severe cyberbullies and non-cybervictims, occasional cybervictims, and severe cybervictims) on the variables: open communication (mother, father), avoidance communication (mother, father), and feeling of affiliation (peers). Post-hoc Games-Howell tests were applied when there were significant differences between the comparison groups on the variables studied.

\section{Results}

The Pearson correlation analysis reveals statistically significant correlations between cyberbullying (perpetration and victimization) and almost all the variables analyzed in this study (Table 1). The only variable that did not present statistically significant correlations with cyberbullying (perpetration) is the feeling of affiliation with peers $(p=-0.013)$.

Table 1. Pearson correlations between cyberbullying (perpetration and victimization) and the study variables.

\begin{tabular}{ccc}
\hline Variables & Cyberbullying Perpetration & Cyberbullying Victimization \\
\hline Cyberbullying perpetration & - & $0.443^{* *}$ \\
Cyberbullying victimization & $0.443^{* *}$ & - \\
Open communication (mother) & $-0.174^{* *}$ & $-0.178^{* *}$ \\
Open communication (father) & $-0.125^{* *}$ & $-0.123^{* *}$ \\
Avoidant communication (mother) & $0.097^{* *}$ & $0.161^{* *}$ \\
Avoidant communication (father) & $0.077^{*}$ & $0.147^{* *}$ \\
Feeling of affiliation (peers) & -0.013 & $-0.051^{*}$ \\
\hline
\end{tabular}

Note: ${ }^{*} p<0.05,{ }^{* *} p<0.01$.

Cyberbullying perpetration correlated positively at $p<0.01$ with cyberbullying victimization and avoidant communication with the mother. A positive significant correlation between cyberbullying at $p<0.05$ and avoidant communication with the father was also observed. Further, cyberbullying perpetration correlated negatively at $p<0.01$ with open communication with both the mother and father.

In relation to cyberbullying victimization, findings showed that this variable correlated positively at $p<0.01$ with cyberbullying perpetration, avoidant communication with the mother, and avoidant communication with the father. In addition, cyberbullying victimization correlated negatively at $p<0.01$ with open communication with both the mother and father.

Regarding the prevalence of cybervictimization, results indicated that $73.5 \%(n=624)$ of adolescents participating in this study have never been victimized through the Internet or the mobile phone, whereas $26.5 \%(n=225)$ have been victims of cyberbullying in the past year. In this scale (range score $18-72)$, from these victims, $22.4 \%(n=190)$ were cyberbullied occasionally with a mean score of $24.01(S D=4.68)$, and $4.1 \%(n=35)$ severely with a mean score of $31.97(S D=7.20)$.

For the prevalence of cyberbullying (range score 10-50), findings indicated that $53.7 \%(n=456)$ of adolescents in this study have never bullied their peers through the Internet or mobile phone, whereas $46.3 \%(n=393)$ have been cyberbullies in the past year. Of these aggressors, $35.5 \%(n=301)$ cyberbullied their peers occasionally, with a mean score of $13.01(S D=1.01)$, and $10.8 \%(n=92)$ severely, with a mean score on the cyberbullying scale of $20.08(S D=4.08)$.

With regard to the analysis of variance between cyberbully groups, results showed (Table 2) that on the variables of open communication with the mother and with the father, the non-cyberbully 
adolescents presented significantly higher scores than the cyberbullies, with no significant differences between the occasional cyberbullies and the severe ones (open communication with the mother: $F=11.87, p<0.001$; open communication with the father: $F=10.87, p<0.001)$. Furthermore, results indicated (Table 2) that on the variables of avoidant communication with the mother and with the father, the non-cyberbully group presented significantly lower scores than cyberbullies, with no significant differences found between occasional and severe cyberbullies (avoidant communication with the mother: $F=5.69, p=0.003$; avoidant communication with the father: $F=5.47, p=0.004$ ). In relation to the feeling of affiliation with peers, no significant differences were observed between the comparison groups $(F=0.53, p=0.589)$.

Table 2. Mean (Standard Deviation), ANOVA of differences between cyberbully groups in variables family communication and feeling of affiliation.

\begin{tabular}{cccccc}
\hline Variables & Non-Cyberbullies & $\begin{array}{c}\text { Occasional } \\
\text { Cyberbullies }\end{array}$ & $\begin{array}{c}\text { Severe } \\
\text { Cyberbullies }\end{array}$ & $F$ & $\eta^{2}$ \\
\hline Open communication (mother) & $3.86^{\mathrm{a}}(0.94)$ & $3.64^{\mathrm{b}}(0.91)$ & $3.39^{\mathrm{b}}(0.98)$ & $11.87^{* * *}$ & 0.027 \\
\hline Open communication (father) & $3.58^{\mathrm{a}}(0.93)$ & $3.36^{\mathrm{b}}(0.86)$ & $3.16^{\mathrm{b}}(0.87)$ & $10.87^{* * *}$ & 0.013 \\
\hline Avoidant communication (mother) & $2.83^{\mathrm{b}}(0.75)$ & $2.98^{\mathrm{a}}(0.69)$ & $3.03^{\mathrm{a}}(0.76)$ & $5.69^{* *}$ & 0.025 \\
\hline Avoidant communication (father) & $2.90^{\mathrm{b}}(0.75)$ & $3.06^{\mathrm{a}}(0.68)$ & $3.07^{\mathrm{a}}(0.67)$ & $5.47^{* *}$ & 0.013 \\
\hline Feeling of affiliation (peers) & $1.45(0.24)$ & $1.46(0.25)$ & $1.47(0.21)$ & 0.53 & 0.001 \\
\hline Note: $F=$ Welch; $\alpha=0.05,{ }^{* *} p<0.01,{ }^{* * *} p<0.001$; Games-Howell Test, a $>\mathrm{b} ;$ small effect size: $\eta^{2} \leq 0.06$.
\end{tabular}

Regarding differences between cybervictim groups, findings indicated (Table 3) that on the open communication with the mother variable, non-cybervictim adolescents presented significantly higher scores than cybervictims, with no significant differences between cybervictim groups depending on the intensity (open communication with the mother: $F=22.45, p<0.001$ ). However, on the open communication with the father variable, the group of severe cybervictims presented significantly lower scores than the occasional cybervictims, who, in turn, presented lower scores than the non-cybervictims (open communication with the father: $F=13.25, p<0.001$ ).

Table 3. Mean (Standard Deviation), ANOVA of differences between cybervictim groups in variables family communication and feeling of affiliation.

\begin{tabular}{|c|c|c|c|c|c|}
\hline Variables & Non-Cybervictims & $\begin{array}{c}\text { Occasional } \\
\text { Cybervictims }\end{array}$ & $\begin{array}{c}\text { Severe } \\
\text { Cybervictims }\end{array}$ & $F$ & $\eta^{2}$ \\
\hline Open communication (mother) & $3.85^{\mathrm{a}}(0.88)$ & $3.42^{\mathrm{b}}(1.05)$ & $3.18^{\mathrm{b}}(1.02)$ & $22.45^{* * *}$ & 0.050 \\
\hline Open communication (father) & $3.54^{\mathrm{a}}(0.92)$ & $3.29^{\mathrm{b}}(0.78)$ & $2.88^{c}(1.01)$ & $13.25 * * *$ & 0.011 \\
\hline Avoidant communication (mother) & $2.86^{\mathrm{b}}(0.74)$ & $3.02^{\mathrm{a}}(0.68)$ & $3.09^{\mathrm{a}}(0.69)$ & $4.76^{* *}$ & 0.030 \\
\hline Avoidant communication (father) & $2.92^{b}(0.74)$ & $3.11^{\mathrm{a}}(0.63)$ & $3.25^{\mathrm{a}}(0.81)$ & $7.94^{* * *}$ & 0.018 \\
\hline Feeling of affiliation (peers) & $1.46^{\mathrm{a}}(0.24)$ & $1.45^{\mathrm{a}}(0.23)$ & $1.33^{\mathrm{b}}(0.21)$ & $4.75^{* *}$ & 0.011 \\
\hline
\end{tabular}

Further, on the variables avoidant communication with the mother and with the father, as in the cyberbullies, the results indicated (Table 3) that the non-cybervictim group presented significantly lower scores than cybervictims, with no significant differences between occasional and severe cybervictims (avoidant communication with the mother: $F=4.76, p=0.009$; avoidant communication with the father: $F=7.94, p<0.001)$. Regarding the feeling of affiliation with peers, significant differences were observed $(F=4.75, p=0.009)$. Specifically, severe cybervictims had a lower feeling of affiliation than non-cybervictims and occasional cybervictims.

\section{Discussion}

The main objective of this study was to analyze possible differences in family communication and the feeling of affiliation amongst adolescents involved in perpetration and victimization of cyberbullying. These two groups, cyberbullies and cybervictims, were classified and analyzed 
according to the frequency of intimidation: Severe, occasional and non-involved; the differences between open and avoidant communication with both the mother and father; and in the feeling of affiliation with peer companions. Prior to carrying out this main purpose, the relationship between the study variables was determined, as well as the prevalence of cybervictimization and cyberbullying (severe, occasional, and non-involved).

Thus, regarding relationships between variables, the existence of a positive association between cybervictimization and cyberbullying has been demonstrated in accordance with previous literature. This result seems to indicate that some adolescents involved in cyberbullying behaviors could also be victims of cyberbullying and vice versa, suggesting the idea of the double role of cyberbully-victim. In this regard, several authors suggest that this double role is more common in the virtual world than in traditional bullying (Buelga et al. 2017; Mishna et al. 2012), because adolescents can hide their identity online (Aboujaoude et al. 2015; Betts and Spenser 2017; Baldry et al. 2018). On the other hand, our work has shown that cyberbullying and cybervictimization are positively related to avoidant communication with the mother and father, and negatively with open communication with both parents. The quality of family communication proves to be, therefore, as highlighted in the literature, a protective or risk factor for children's involvement in cyberbullying and cybervictimization behaviors (Larrañaga et al. 2016; Navarro et al. 2013; Buelga et al. 2017). In addition, we have confirmed that the feeling of affiliation with the peer group does not correlate significantly with cyberbullying, but it does have a relationship with cybervictimization, although weak. With regard to cyberbullying, among peers, social self-concept, popularity or social reputation are more important variables than the feeling of affiliation, as highlighted in research (Buelga et al. 2015; Garaigordobil 2017; Wegge et al. 2016).

Regarding the findings related to the prevalence of cyberbullying and cybervictimization, our data indicated that approximately more than a quarter of adolescents have been victims of cyberbullying (22.4\% occasional and $4.1 \%$ severe). This incidence of cybervictimization coincides with the results found by Zych et al. (2016) in their systematic review of prevalence of cyberbullying, which showed an average prevalence of $24.4 \%$ of cybervictimization. With respect to aggressors, our data demonstrated a much higher prevalence; almost half of adolescents have been cyberbullies (35.5\% occasional and $10.8 \%$ severe cyberbullies). This high prevalence of cyberbullies was also found in Spain by other authors, such as Calvete et al. (2010), who reported a 44 percent of cyberbullying. One possible reason for this high incidence of cyberbullying in Spain may be due to the fact that 98\% of 14-year-old Spanish adolescents have a smartphone (Ditrendia Digital Marketing Trends 2016). This widespread use of smartphones by adolescents is combined with the fact that the virtual world has specific characteristics that seem to contribute to a greater expression of violent behaviors (Kowalski et al. 2014; Ortega-Baron et al. 2017). With regard to cyberbullying severity, previous studies also noted that the prevalence of occasional cyberbullying is much more frequent than severe cyberbullying (Larrañaga et al. 2016; Sorrentino et al. 2018).

Regarding the main purpose of our study, our results indicated the importance of the quality of family communication in children's adjustment when dealing with both cybervictimization and cyberbullying. Significant differences between cyberbullies (severe and occasional) with respect to adolescents not involved in cyberbullying have been confirmed. Thus, cyberbullies have obtained lower scores in open communication and higher scores in avoidant communication, both with the mother and father. These findings coincided with the vast amount of research that reports that positive, open, and fluid communication is related to a lower involvement in aggressive behavior in the child, both in traditional bullying (Galvin et al. 2015; Ledwell and King 2015) as in cyberbullying (Appel et al. 2014; Buelga et al. 2017). On the contrary, communication that is not very fluid or negative with parents is associated with a greater participation by children in antisocial and violent behavior (Braithwaite et al. 2017; Carrascosa et al. 2016; Estévez and Emler 2010). In this regard, in a study conducted by Buelga et al. (2015), it was observed that cyberbullies presented inadequate patterns of family communication, characterized by offensive communication, full of negative and unclear messages. In this line, Solecki (2016) also noted that cyberbullies show negative communication with 
their parents, in addition to receiving little parental supervision of their online behavior. Many parents do not supervise or have a dialogue with their children about their Internet browsing, so they do not know the behavior they have in the online environment and if they are cyberbullies or cybervictims (Elsaesser et al. 2017; Livingstone et al. 2011).

Indeed, our work has also demonstrated that cybervictims, like cyberbullies, perceive less open communication and more avoidant communication with both parents compared to adolescents not involved in cyberbullying. This result is consistent with previous studies that also detect a greater deterioration in family communication in victims of cyberbullying (Appel et al. 2014; Larrañaga et al. 2018). Likewise, studies on traditional bullying have discovered that poor quality in the family climate, and especially parent-child communication, is a risk factor for school victimization (Cava 2011; Cerezo 2006). Inadequate patterns in family communication, as occurs with bullying, are closely linked to the perception of poor parental support (Hinduja and Patchin 2014). This negative family climate consequently increases the persistence in the dynamics of cybervictimization (Cuesta Medina et al. 2018; Royne et al. 2017). Frequently, children try to resort to peers to get out of the situation of harassment, but often they do not find the expected help because peers lack the necessary resources to resolve this situation (Brooks et al. 2012; Varela et al. 2013), or because they do not have a network of friends to turn to (Ortega-Baron et al. 2016; Wegge et al. 2016).

In this regard, in this study, we have verified that cybervictims obtain lower scores in the feeling of affiliation (friendship and help) than adolescents not involved in cyberbullying. These findings coincide with studies that suggest that victims experience loneliness, social isolation, and rejection by their peers (Olenik-Shemesh et al. 2012; Şahin 2012). This situation does not seem to occur with cyberbullies who are perceived by their peers as important figures in their group (Barlińska et al. 2013). Cyberbullies are popular and accepted among their peers (Pellegrini and Bartini 2000). Thus, our results have revealed that, unlike the situation with cybervictims, there is no difference in feelings of affiliation between cyberbullies and adolescents not involved in cyberbullying, which seems to confirm that cyberbullies do indeed belong and feel they can identify with a group of friends (Buelga et al. 2015).

Finally, this study has some limitations. The cross-sectional design does not allow us to see relationship changes between the variables over time. Future longitudinal studies can help to understand how the variables in the cyberbullying problem influence each other over the years. In addition, adolescents answered self-reports, which can present certain social desirability effects. On this matter, Flisher et al. (2004) confirmed that the use of self-reports to investigate violent behaviors in adolescence is acceptable. Regarding the instruments used, the reliability obtained in the avoidant communication scale is limited; it has been demonstrated that by eliminating an item from the scale, the internal consistency of the instrument increases significantly. This weakness will be reviewed in future research. Finally, in this study, only adolescents participated. Future studies should include the point of view of parents and peers.

Despite its limitations, this study contributes to a greater understanding of the role of family communication in cyberbullying perpetration and victimization. The fact that in both roles, these adolescent groups perceive family communication patterns as less open and more avoidant with parents proves the relevance of this variable to prevent children's online risk behaviors (Elsaesser et al. 2017; Sasson and Mesch 2017). Encouraging open and fluid dialogue in the family is certainly one of the strategies that helps children to perceive that their parents are a source of support they can count on when they have problems. Therefore, talking about the benefits and risks of the Internet in a positive environment increases the capacity of parents to support their children emotionally and psychologically when cybervictimization situations occur (Buelga et al. 2017; Navarro et al. 2013). This is, without a doubt, one of the biggest challenges for parents, because victims often avoid talking to their parents about their negative experiences online. 


\section{Conclusions}

This study shows the differences among students involved in the perpetration and victimization of cyberbullying (non-involved, occasional, and severe) in their parental communication and feelings of affiliation with classmates.

The results showed that adolescent cyberbullies and cybervictims have less open and more avoidant communication with their parents than adolescents who are not involved in cyberbullying. Regarding the feeling of affiliation with peers, cybervictims felt less affiliation with this group of friends. However, no significant differences were observed in the perception of affiliation with peers in the perpetrators of cyberbullying.

In summary, this study contributes to a greater understanding of the role of parental communication and the perception of peer support in cyberbullying perpetration and victimization.

Author Contributions: J.O.B. designed, conducted this study, drafted the manuscript and processed feedback from the author, reviewers, and editor; J.P. administrated the instruments, introduced and realized the data curation, drafted the manuscript; B.I. realized and reviewed the references, realized formal analysis, and provided constructive feedback on drafts of the manuscript; S.B. calculated the statistical results of the study, drafted the manuscript, and processed feedback from the author, reviewers, and editor; L.C. reviewed the manuscript and provided constructive feedback on drafts of the manuscript. All authors read and approved the final manuscript.

Funding: This research was financed by the project ACIF/2014/110 "Prevention of the harassment in adolescents through the New Technologies of Information and Communication: Prev Program@cib", funded by Consellería de Educació, Cultura i Esport (Generalitat Valenciana, Programa VALi+d).

Acknowledgments: We thank the students, professors, and directors of the participating schools.

Conflicts of Interest: The authors declare no conflict of interest.

\section{References}

Aboujaoude, Elias, Mathew Savage, Vladan Starcevic, and Wael Salame. 2015. Cyberbullying: Review of an old problem gone viral. Journal of Adolescent Health 57: 10-18. [CrossRef] [PubMed]

Ang, Rebecca P., and Dion Goh. 2010. Cyberbullying among Adolescents: The role of affective and cognitive empathy, and gender. Child Psychiatry \& Human Development 41: 387-97. [CrossRef]

Appel, Markus, Barbara Stiglbauer, Bernad Batinic, and Peter Holtz. 2014. Internet use and verbal aggression: The moderating role of parents and peers. Computers in Human Behavior 33: 235-41. [CrossRef]

Aricak, Tolga, Sinem Siyahhan, Aysegul Uzunhasanoglu, Sevda Saribeyoglu, Songul Ciplak, Nesrin Yilmaz, and Cemil Memmedov. 2008. Cyberbullying among Turkish sdolescents. Cyberpsychology \& Behavior 11: 253-61. [CrossRef]

Baldry, Anna Costanza, Catherine Blaya, and David P. Farrington, eds. 2018. International Perspectives on Cyberbullying: Prevalence, Risk Factors and Interventions. Berlin: Springer, ISBN 978-3-319-73263-3.

Barlińska, Julia, Anna Szuster, and Mikołaj Winiewski. 2013. Cyberbullying among adolescent bystanders: Role of the communication medium, form of violence, and empathy. Journal of Community \& Applied Social Psychology 23: 37-51. [CrossRef]

Barnes, Howard, and David H. Olson. 1982. Parent-Adolescent Communication Scale. In Family Inventories: Inventories Used in a National Survey of Families across the Family Life Cycle. Edited by David H. Olson. St. Paul: Family Social Science, University of Minnesota, pp. 33-48.

Betts, Lucy R., and Karin A. Spenser. 2017. "People think it's a harmless joke": Young people's understanding of the impact of technology, digital vulnerability and cyberbullying in the United Kingdom. Journal of Children and Media 11: 20-35. [CrossRef]

Braithwaite, Dawn O., Elizabeth A. Suter, and Kory Floyd. 2017. Engaging Theories in Family Communication: Multiple Perspectives. Abingdon: Routledge.

Brooks, Fiona M., Josefine Magnusson, Neil Spencer, and Antony Morgan. 2012. Adolescent multiple risk behaviour: An asset approach to the role of family, school and community. Journal of Public Health 34: i48-i56. [CrossRef]

Buelga, Sofía, and Javier Pons. 2012. Agresiones entre adolescentes a través del teléfono móvil y de Internet. Psychosocial Intervention 21: 91-101. [CrossRef] 
Buelga, Sofía, María Jesús Cava, and Gonzalo Musitu. 2010. Cyberbullying: Victimización entre adolescentes a través del teléfono móvil y de Internet. Psicothema 22: 784-789.

Buelga, Sofía, María Jesús Cava, and Gonzalo Musitu. 2012. Validación de la escala de victimización entre adolescentes a través del teléfono móvil y de Internet. Revista Panamericana de Salud Pública 32: 36-42. [CrossRef]

Buelga, Sofía, Begoña Iranzo, María-Jesús Cava, and Eva Torralba. 2015. Psychological profile of adolescent cyberbullying aggressors. Revista de Psicología Social 30: 382-406. [CrossRef]

Buelga, Sofía, Belén Martínez-Ferrer, and María-Jesús Cava. 2017. Differences in family climate and family communication among cyberbullies, cybervictims, and cyber bully-victims in adolescents. Computers in Human Behavior 76: 164-73. [CrossRef]

Calvete, Esther, Izaskun Orue, Ana Estévez, Lourdes Villardón, and Patricia Padilla. 2010. Cyberbullying in adolescents: Modalities and aggressors' profile. Computers in Human Behavior 26: 1128-35. [CrossRef]

Campbell, Marilyn, and Sheri Bauman. 2018. Reducing Cyberbullying in Schools: International Evidence-Based Best Practices. Cambridge: Academic Press, ISBN 978-0-12-811423-0.

Carrascosa, Laura, María Jesús Cava, Sofía Buelga, and Jessica Ortega. 2016. Relationships between family communication and different roles of bully-victim in school violence. In Psicología y Educación: Presente y Futuro. Coordinated by Juan Luis Castejón Costa. Alicante (España): ACIPE- Asociación Científica de Psicología y Educación, pp. 1454-62.

Cava, María Jesús. 2011. Family, teachers and peers: Keys to support victims of bullying. Psychosocial Intervention 20: 183-92. [CrossRef]

Cerezo, Fuensanta. 2006. Violencia y victimización entre escolares. El bullying: Estrategias de identificación y elementos para la intervención a través del Test Bull-S. Electronic Journal of Research in Educational Psychology 4: 333-51. [CrossRef]

Cuesta Medina, Liliana, Cristina Hennig Manzuoli, Lady Adriana Duque, and Sayana Malfasi. 2018. Cyberbullying: Tackling the silent enemy. International Journal of Inclusive Education 1: 1-12. [CrossRef]

Dehue, Francine, Catherine Bolman, and Trijntje Völlink. 2008. Cyberbullying: youngsters' experiences and parental perception. CyberPsychology \& Behavior 11: 217-23. [CrossRef]

Ditrendia Digital Marketing Trends. 2016. Informe Mobile en España y en el Mundo 2015. Available online: https:/ / ditrendia.es/wp-content/uploads/2015/07/Ditrendia-Informe-Mobile-en-Espa\%C3\%B1ay-en-el-Mundo-2015.pdf (accessed on 20 August 2018).

Elsaesser, Caitlin, Beth Russell, Christine McCauley Ohannessian, and Desmond Patton. 2017. Parenting in a digital age: A review of parents' role in preventing adolescent cyberbullying. Aggression and Violent Behavior 35: 62-72. [CrossRef]

Estévez, Estefanía, and Nicholas Emler. 2010. A structural modelling approach to predict adolescent offending behaviour from family, school and community factors. European Journal on Criminal Policy and Research 16: 207-20. [CrossRef]

Fernández-Ballesteros, Rocío, and Benjamín Sierra. 1989. Escalas de Clima Social FES, WES, CIES, CES. Madrid: TEA Ediciones.

Flisher, Alan J., Janet Evans, Martie Muller, and Carl Lombard. 2004. Brief report: Test-retest reliability of self-reported adolescent risk behaviour. Journal of Adolescence 27: 207-12. [CrossRef]

Floros, Georgios D., Konstantinos E. Siomos, Virginia Fisoun, Evaggelia Dafouli, and Dimitrios Geroukalis. 2013. Adolescent Online Cyberbullying in Greece: The impact of parental online security practices, bonding, and online impulsiveness. Journal of School Health 83: 445-53. [CrossRef] [PubMed]

Galvin, Kathleen M., Dawn O. Braithwaite, and Carma L. Bylund. 2015. Family Communication: Cohesion and Change. Abingdon: Routledge, ISBN 978-0-205-94523-8.

Garaigordobil, Maite. 2011. Prevalencia y consecuencias del cyberbullying: Una revisión. International Journal of Psychology and Psychological Therapy 11: 233-54.

Garaigordobil, Maite. 2017. Antisocial Behavior: Connection with Bullying/Cyberbullying and Conflict Resolution. Psychosocial Intervention 26: 47-54. [CrossRef]

García-Maldonado, Gerardo, Víctor Manuel Joffre-Velázquez, Gerardo Jesús Martínez-Salazar, and Arturo Llanes-Castillo. 2011. Cyberbullying: A virtual way of bullying. Revista Colombiana de Psiquiatría 40: 115-30. [CrossRef] 
Goodyear, Victoria, and Kathleen Armour. 2018. Young people's perspectives on and experiences of health-related social media, Apps, and wearable health devices. Social Sciences 7: 137. [CrossRef]

Hinduja, Sameer, and Justin W. Patchin. 2014. Bullying beyond the Schoolyard: Preventing and Responding to Cyberbullying. Thousand Oaks: Corwin Press, ISBN 978-1-4833-4993-0.

Juvonen, Jaana, and Sandra Graham. 2014. Bullying in schools: The power of bullies and the plight of victims. Annual Review of Psychology 65: 159-85. [CrossRef] [PubMed]

Kowalski, Robin M., Gary W. Giumetti, Amber N. Schroeder, and Micah R. Lattanner. 2014. Bullying in the digital age: A critical review and meta-analysis of cyberbullying research among youth. Psychological Bulletin 140: 1073-137. [CrossRef]

Larrañaga, Elisa, Santiago Yubero, Anastasio Ovejero, and Raúl Navarro. 2016. Loneliness, parent-child communication and cyberbullying victimization among Spanish youths. Computers in Human Behavior 65: 1-8. [CrossRef]

Larrañaga, Elisa, Santiago Yubero, and Raúl Navarro. 2018. Parents' responses to coping with bullying: Variations by adolescents' self-reported victimization and parents' awareness of bullying involvement. Social Sciences 7: 121. [CrossRef]

Ledwell, Maggie, and Valarie King. 2015. Bullying and internalizing problems: Gender differences and the buffering role of parental communication. Journal of Family Issues 36: 543-66. [CrossRef]

Lee, Changho, and Namin Shin. 2017. Prevalence of cyberbullying and predictors of cyberbullying perpetration among korean adolescents. Computers in Human Behavior 68: 352-58. [CrossRef]

Li, Qing. 2007. New bottle but old wine: A research of cyberbullying in schools. Computers in Human Behavior 23: 1777-91. [CrossRef]

Livingstone, Sonia, Leslie Haddon, Anke Görzig, and Kjartan Ólafsson. 2011. Risks and Safety on the Internet: The Perspective of European Children. Full Findings. London: LSE, EU Kids Online.

Machimbarrena, Juan Manuel, and Maite Garaigordobil. 2018. Prevalence of bullying and cyberbullying in the last stage of primary education in the Basque Country. The Spanish Journal of Psychology 21: E48. [CrossRef] [PubMed]

Mishna, Faye, Mona Khoury-Kassabri, Tahany Gadalla, and Joanne Daciuk. 2012. Risk factors for involvement in cyberbullying: Victims, bullies and bully-victims. Children and Youth Services Review 34: 63-70. [CrossRef]

Navarro, Raúl, Cristina Serna, Verónica Martínez, and Roberto Ruiz-Oliva. 2013. The role of Internet use and parental mediation on cyberbullying victimization among Spanish children from rural public schools. European Journal of Psychology of Education 28: 725-45. [CrossRef]

Navarro, Raúl, Santiago Yubero, and Elisa Larrañaga. 2015. Psychosocial risk factors for involvement in bullying behaviors: Empirical comparison between cyberbullying and social bullying victims and bullies. School Mental Health 7: 235-48. [CrossRef]

Odac1, Hatice, and Melek Kalkan. 2010. Problematic Internet use, loneliness and dating anxiety among young adult university students. Computers $\mathcal{E}$ Education 55: 1091-97. [CrossRef]

Olenik-Shemesh, Dorit, Tali Heiman, and Sigal Eden. 2012. Cyberbullying victimisation in adolescence: Relationships with loneliness and depressive mood. Emotional and Behavioural Difficulties 17: 361-74. [CrossRef]

Ortega-Baron, Jessica, Sofía Buelga, and María Jesús Cava. 2016. The influence of school climate and family climate among adolescents victims of cyberbullying. Comunicar 24: 57-65. [CrossRef]

Ortega-Baron, Jessica, Sofía Buelga, María Jesús Cava, and Eva Torralba. 2017. School violence and attitude toward authority of student perpetrators of cyberbullying. Journal of Psychodidactics 22: 14-23. [CrossRef]

Palermiti, Anna Lisa, Rocco Servidio, Maria Giuseppina Bartolo, and Angela Costabile. 2017. Cyberbullying and self-Esteem: An Italian study. Computers in Human Behavior 69: 136-41. [CrossRef]

Pellegrini, Anne, and María Bartini. 2000. A longitudinal study of bullying, victimization, and peer affiliation during the transition from primary school to middle school. American Educational Research Journal 37: 699-725. [CrossRef]

Povedano, Amapola, Estefanía Estévez, Belén Martínez, and María-Carmen Monreal. 2012. Un perfil psicosocial de adolescentes agresores y víctimas en la escuela: análisis de las diferencias de género. Revista de Psicología Social 27: 169-82. [CrossRef]

Price, Megan, and John Dalgleish. 2010. Cyberbullying: Experiences, impacts and coping strategies as described by Australian young people. Youth Studies Australia 29: 51-59. 
Royne, Marla B., Claudia Rademaker, and Gerard E. Kelly. 2017. Powerful bullies and silent victims in cyber space: The darkness of social media. In The Dark Side of Social Media. Abingdon: Routledge, pp. 57-72. ISBN 978-1-351-6838-14.

Şahin, Mustafa. 2012. The Relationship between the cyberbullying/cybervictmization and loneliness among adolescents. Children and Youth Services Review 34: 834-37. [CrossRef]

Sasson, Hagit, and Gustavo Mesch. 2017. The role of parental mediation and peer norms on the likelihood of cyberbullying. The Journal of Genetic Psychology 178: 15-27. [CrossRef] [PubMed]

Slonje, Robert, and Peter Smith. 2008. Cyberbullying: Another main type of bullying? Scandinavian Journal of Psychology 49: 147-54. [CrossRef] [PubMed]

Smith, Peter K., Jess Mahdavi, Manuel Carvalho, Sonja Fisher, Shanette Russell, and Neil Tippett. 2008. Cyberbullying: Its nature and impact in secondary school pupils. Journal of Child Psychology and Psychiatry 49: 376-85. [CrossRef]

Solecki, Susan M. 2016. An Exploratory Study on Parental Monitoring of Adolescent Cell Phone Use. Ph.D. Thesis, Drexel University, Philadelphia, PA, USA.

Sorrentino, Anna, Anna Costanza Baldry, and Sonya Cacace. 2018. Cyberbullying in Italy. In International Perspectives on Cyberbullying. Berlin: Springer, pp. 231-49. ISBN 978-3-319-73262-6.

Taiariol, Jennifer. 2010. Cyberbullying: The Role of Family and School. Ph.D. Thesis, Wayne State University, Detroit, MI, USA; p. 118.

Trejos-Herrera, Ana M., Marly J. Bahamón, Yolima Alarcón-Vásquez, Jorge I. Vélez, and Stefano Vinaccia. 2018. Validity and Reliability of the Multidimensional Scale of Perceived Social Support in Colombian Adolescents. Psychosocial Intervention 27: 56-63. [CrossRef]

Tsiplakides, Iakovos. 2018. Differentiation in higher education: The impact of parental education. Social Sciences 7: 28. [CrossRef]

Varela, Rosa, María Elena Ávila, and Belén Martínez. 2013. Violencia escolar: Un análisis desde los diferentes contextos de interacción. Psychosocial Intervention 22: 25-32. [CrossRef]

Watkins, Laura E., Rosalita C. Maldonado, and David DiLillo. 2016. The cyber aggression in relationships scale: A new multidimensional measure of technology-based intimate partner aggression. Assessment 25: 608-26. [CrossRef] [PubMed]

Watts, Lynette K., Jessyca Wagner, Benito Velasquez, and Phyllis Behrens. 2017. Cyberbullying in higher education: A literature review. Computers in Human Behavior 69: 268-74. [CrossRef]

Wegge, Denis, Heidi Vandebosch, Steven Eggermont, and Sarah Pabian. 2016. Popularity through online harm: The longitudinal associations between cyberbullying and sociometric status in early adolescence. The Journal of Early Adolescence 36: 86-107. [CrossRef]

Ybarra, Michele L., and Kimberly Mitchell. 2004. Online aggressor/targets, aggressors, and targets: A comparison of associated youth characteristics. Journal of child Psychology and Psychiatry 45: 1308-16. [CrossRef] [PubMed]

Zych, Izabela, Rosario Ortega-Ruiz, and Inmaculada Marín-López. 2016. Cyberbullying: A systematic review of research, its prevalence and assessment issues in Spanish studies. Psicología Educativa 22: 5-18. [CrossRef]

(C) 2018 by the authors. Licensee MDPI, Basel, Switzerland. This article is an open access article distributed under the terms and conditions of the Creative Commons Attribution (CC BY) license (http:/ / creativecommons.org/licenses/by/4.0/). 
Article

\title{
Does Parental Mediation Moderate the Longitudinal Association among Bystanders and Perpetrators and Victims of Cyberbullying?
}

\author{
Michelle F. Wright ${ }^{1,2, *}$ and Sebastian Wachs ${ }^{3}$ \\ 1 Department of Psychology, Penn State University, University Park, PA 16802, USA \\ 2 Institute for Research on Children, Youth, and Family, Masaryk University, 60200 Brno, the Czech Republic \\ 3 Department of Education, University of Potsdam, 14476 Potsdam, Germany; wachs@uni-potsdam.de \\ * Correspondence: mfw5215@psu.edu
}

Received: 4 October 2018; Accepted: 6 November 2018; Published: 11 November 2018

\begin{abstract}
The purpose of the present study was to examine the moderation of parental mediation in the longitudinal association between being a bystander of cyberbullying and cyberbullying perpetration and cyberbullying victimization. Participants were 1067 th and 8th graders between 12 and 15 years old ( $51 \%$ female) from six middle schools in predominantly middle-class neighborhoods in the Midwestern United States. Increases in being bystanders of cyberbullying was related positively to restrictive and instructive parental mediation. Restrictive parental mediation was related positively to Time 2 (T2) cyberbullying victimization, while instructive parental mediation was negatively related to T2 cyberbullying perpetration and victimization. Restrictive parental mediation was a moderator in the association between bystanders of cyberbullying and T2 cyberbullying victimization. Increases in restrictive parental mediation strengthened the positive relationship between these variables. In addition, instructive mediation moderated the association between bystanders of cyberbullying and T2 cyberbullying victimization such that increases in this form of parental mediation strategy weakened the association between bystanders of cyberbullying and T2 cyberbullying victimization. The current findings indicate a need for parents to be aware of how they can impact adolescents' involvement in cyberbullying as bullies and victims. In addition, greater attention should be given to developing parental intervention programs that focus on the role of parents in helping to mitigate adolescents' likelihood of cyberbullying involvement.
\end{abstract}

Keywords: cyberbullying; bystander; bystanding; victimization; perpetration; bully; parental mediation

\section{Introduction}

Cyberbullying is often conceptualized as a dyadic conflict between the perpetrator and victim, although adolescents can have other roles (e.g., defender, bystander) in these conflicts. Research on bystanders of cyberbullying is increasing, especially because toxic stress can result from witnessing cyberbullying (Rivers et al. 2009). Such toxic stress might reduce bystanders' use of effective coping strategies, leading to their involvement in cyberbullying. Researchers have focused on factors that might reduce adolescents' involvement in cyberbullying (Hinduja and Patchin 2008; Rivers et al. 2009). One such factor is parental mediation, and it influences adolescents' cyberbullying involvement (Livingstone and Helsper 2008; Navarro et al. 2013; Sasson and Mesch 2017; Wright 2018), although it is unclear how parental mediation might impact the likelihood of being a bystander of cyberbullying. It is also unknown whether parental mediation might diminish the likelihood of bystanders of cyberbullying becoming cyberbullying perpetrators or cyberbullying victims. The purpose of the present study was to examine the moderation of parental mediation in the longitudinal associations 
among being a cyberbullying bystander, perpetrator, and victim. The findings of this study contribute to the field of cyberbullying by explaining the role of parental mediation in cyberbullying bystanding, perpetration, and victimization.

\subsection{Cyberbullying: Perpetrators, Victims, and Bystanders}

Defined as the deliberate and repetitive infliction of harm through digital technologies (e.g., email, online gaming, gaming consoles, mobile devices, instant messenger, social networking websites), cyberbullying involves an imbalance of power (Hinduja and Patchin 2008). Cyberbullying includes embarrassing, intimidating, harassing, outing, and social exclusionary behaviors (Ferdon and Hertz 2007; Grigg 2010; Kowalski and Limber 2007; Topcu et al. 2008; Walker et al. 2011; Wolak et al. 2007; Ybarra et al. 2007). Through digital technologies, cyberbullies are able to victimize others at almost any time without concern for the consequences of their actions (Wright and Li 2013; Wright 2014). Anonymity of the online environment can trigger adolescents' inability to constrain or restrain their behaviors, which makes them susceptible to cyberbullying perpetration and victimization (Suler 2004; Udris 2014; Wright 2014).

A bystander of cyberbullying is defined as an adolescent who sees/witnesses the behavior occurring between the cyberbully(ies) and cybervictims(s), but decides not to get involved in the situation (Wachs 2012). Witnessing cyberbullying as a bystander is one of the most common ways to experience cyberbullying. Rates of witnessing cyberbullying in adolescent samples ranges from 30\% to 60\% (Huang and Chou 2010; Van Cleemput et al. 2014; Vandebosch and Van Cleemput 2009); variations in these rates most likely reflect different sampling and measurement techniques. Bystanders of cyberbullying are less likely to report cyberbullying to adults than bystanders of offline bullying (Smith et al. 2008). Such a finding is especially concerning as the online world of adolescents includes fewer adults than their offline world, adolescents may or may not know the cyberbully(ies) or cybervictim(s), and that cyberbullying can include an infinite number of bystanders. These features of the online world of adolescents might reduce the likelihood of them reporting the situation.

Understanding more about bystanders of cyberbullying is important as the purpose of bullying is often to diminish victims' social standing among their peer group as a means of exerting dominance and gaining status in the peer group (Wright 2015). Sometimes the intent of cyberbullying behaviors is to not only target the victim directly, but to also influence bystanders to eventually become involved in an effort to further humiliate and prolong the attack. The reasons adolescents do not intervene in cyberbullying are complex. Many adolescents might not feel responsible for the bullying behavior, fear unfavorable judgement by peers for intervening, not realize that the situation is perceived as uncomfortable, and they might lack the skills to intervene (Wachs et al. 2015). When bystanders remain passive, they are giving the impression that they indirectly and silently support bullying, which could normalize cyberbullying and increase these behaviors. Although research has been conducted on the factors that determine the likelihood of being bystanders of cyberbullying, parents' roles in bystanders' involvement in cyberbullying are unknown.

\subsection{Parental Mediation}

Parents utilize different parental mediation strategies to manage their children's relationship with digital technologies (Livingstone and Helsper 2008). One strategy that parents utilize is to set time limits on their children's digital media use and specifies the type of content that their children views on the internet (Dehue et al. 2008). Oftentimes parents set rules regarding technology use, but do not provide guidelines for appropriate online behavior. Parental mediation strategies involve restrictive, co-viewing, and instructive strategies (Arrizabalaga-Crespo et al. 2010). Restrictive mediation is defined as parents' use of strategies that prevent their children from accessing specific online content. Co-viewing mediation involves parents and their children accessing online content together. However, parents who co-view content with their children do not always discuss the content with their children. 
Instructive mediation is defined as parents engaging in active discussion with their children regarding online content.

Parents' use of mediation strategies has an impact of their children's behaviors when using digital technologies. Research on parental mediation of technology use and cyberbullying revealed that parental mediation of technology use reduces adolescents' vulnerability to cyberbullying (Dehue et al. 2008; Livingstone and Helsper 2008; Mesch 2009; Van Den Eijnden et al. 2008). Mesch (2009) found that parental mediation of technology use reduced their children's risk of experiencing cyberbullying, especially when parents monitored internet use and set rules regarding the websites their children were allowed to visit. Parents' use of monitoring software and the creation of rules about the amount of time adolescents could interact with digital technologies reduced the likelihood of adolescents sharing personal information online, diminishing adolescents' cyberbullying involvement (Navarro et al. 2013). Co-viewing mediation and instructive mediation were related negatively to cyberbullying victimization while restrictive mediation was associated positively with cyberbullying perpetration and victimization, as well as cybertrolling (Wright 2016, 2017). It is unclear how parental mediation strategies relate to being bystanders of cyberbullying, and how these strategies might moderate the associations between being bystanders and cyberbullying involvement as bullies and victims. Considering that parental mediation strategies are associated with cyberbullying involvement, it might be likely that similar patterns are found for bystanders of cyberbullying, given that bystanding is also related to cyberbullying perpetration and victimization (Vandebosch and Van Cleemput 2009).

\subsection{Present Study}

Gaps exist in the literature concerning the role of parental mediation of technology use as a moderator in the association between bystanders of cyberbullying and cyberbullying involvement. The aim of the present study was to examine the one-year longitudinal buffering effect of Time 1 (6th or 7th grade) parental mediation of technology use (i.e., restrictive, co-viewing, instructive) in the relationship between Time 1 cyberbullying bystanding and Time 2 ( 1 year later) cyberbullying perpetration and victimization. We controlled for Time 1 cyberbullying perpetration and victimization, and Time 1 face-to-face bullying perpetration and victimization. The following research questions and hypotheses were examined:

(1) What is the relationship between bystanders of cyberbullying and parental mediation strategies (i.e., restrictive, co-viewing, instructive)?

a Hypothesis 1: We hypothesized that the restrictive mediation strategy will be associated with being bystanders of cyberbullying.

b Hypothesis 2: We hypothesized that instructive and co-viewing mediation strategies will be associated negatively with being bystanders of cyberbullying.

(2) What, if any, moderating effect does parental mediation strategies (i.e., restrictive, co-viewing, instructive) have on the longitudinal associations between cyberbullying involvement (i.e., perpetration, victimization) and bystanders of cyberbullying?

\section{Methods}

\subsection{Participants}

There were 1067 th and 8th graders between the ages of 12 and 15 years included in this study. They were recruited from six middle schools in the Midwestern United States from predominantly middle-class neighborhoods. Adolescents self-identified as Caucasian (55.6\%), followed by Latino/a (27.8\%), Black/African American (8.8\%), Asian (7.2\%), and Native Hawaiian (0.6\%). Family income and educational background for parents/guardians were not collected. Among all students at the six schools, $31 \%$ to $53 \%$ qualified for free or reduced cost lunch. 


\subsection{Procedures}

Before contacting schools, ethics approval was obtained for this study from the first author's previous university. A list of 10 middle schools in the Midwestern United States was randomly selected from a list of 165 schools in the area. Recruitment letters were emailed to the principals from the 10 schools. Two principals never replied to the recruitment email, two indicated that they were committed to other research, and six agreed to have their students participate. Meetings were conducted between the researcher, principals, and teachers to introduce them to the study, explain adolescents' privacy, and what adolescents would do if they participated. Classroom announcements were made to 6th and 7th grade classrooms to inform adolescents about how they could participate, what they would do if they participated, and their rights as participants. There were approximately 1293 parental permission slips sent home with 6th and 7th grade students. There were 103 parental permission slips that were never returned, 79 declining participation, and 1111 parents/guardians agreed to allow their child to participate in the study. Two days were allocated for data collection for all six schools, for a total of 12 days for data collection. On the first day of data collection, 13 students were absent, with 10 of those students participating on the second day of data collection and three never participating in the study. Prior to data collection, adolescents provided their assent, and 11 declined to participate. During the fall of 6th or 7th grade (Time 1; T1), data was collected from 1090 adolescents. They completed questionnaires on cyberbullying bystanding, cyberbullying perpetration, cyberbullying victimization, and parental mediation strategies.

During the fall of 7th or 8th grade (Time 2; T2), a letter was sent home with adolescents reminding their parents/guardians about the study the year prior and informing parents/guardians that their child would be asked to fill out two questionnaires. Parents/guardians were instructed that if they did not want their child to participate again then they should write their child's first and last name on the letter and then return the letter to their child's teacher. Two letters were returned to the school. Of the 1090 adolescents from T1, 15 had moved away and eight declined to participate. The final total of adolescents at T2 was 1067. During T2, adolescents completed questionnaires on cyberbullying perpetration and victimization.

\subsection{Measures}

\subsubsection{Cyberbullying Bystanding}

The items on this questionnaire were modified from Wright and Li's (2013) questionnaire on cyberbullying perpetration and victimization to reflect adolescents witnessing cyberbullying. Adolescents rated six items, using the following scale: 1 (never), 2 (almost never), 3 (sometimes), 4 (almost all the time), and 5 (all the time). Sample items included: Witnessed someone being insulted online and witnessed someone being called mean names online. Items were averaged to form a final score for bystander of cyberbullying. This questionnaire was administered at T1 only. Cronbach's alpha was 0.82 .

\subsubsection{Cyberbullying Perpetration and Victimization}

Adolescents were asked to indicate how often they experienced and perpetrated cyberbullying (Wright and Li 2013). There were six items for cyberbullying victimization and six items for cyberbullying perpetration; each item was rated on the following scale: 1 (never), 2 (almost never), 3 (sometimes), 4 (almost all the time), and 5 (all the time). For cyberbullying victimization, sample items included: Was insulted online by someone, called mean names online, were the target of gossip online, and had a rumor spread about themselves online. For cyberbullying perpetration, sample items included: Insulted someone online, called someone mean names online, and gossiped about someone online. The items were averaged to form separate scores for cyberbullying victimization and cyberbullying perpetration. This questionnaire was administered at T1 and T2. Cronbach's alphas were 0.89 for cyberbullying victimization at both $\mathrm{T} 1$ and $\mathrm{T} 2$ and 0.88 for cyberbullying perpetration at $\mathrm{T} 1$ and 0.87 for $\mathrm{T} 2$. 


\subsubsection{Parental Mediation}

This questionnaire asked adolescents how much they agree that their parents are involved in their technology use (Arrizabalaga-Crespo et al. 2010). The questionnaire includes three subscales: Restrictive mediation (4 items; e.g., My parents impose a time limit on the amount of the time that I surf the Internet), co-viewing mediation (3 items; e.g., My parents surf the internet with me), and instructive mediation ( 2 items; e.g., My parents show me how to use the internet and warn me about its risks). Nine items were rated on a scale of 1 (completely disagree) to 5 (completely agree). The items for each of the subscales were averaged to form measures of restrictive mediation, co-viewing mediation, and instructive mediation. This questionnaire was administered at T1 only. Cronbach's alphas were 0.89 for restrictive mediation, 0.87 for co-viewing mediation, and 0.83 for instructive mediation.

\subsection{Analytic Plan}

Means and standard deviations were performed for all the study's variables. Correlations were conducted between each of the variables as well. A structure regression model was conducted to investigate the study's purpose. Paths were specified from bystanders of cyberbullying to all three parental mediation strategies (i.e., restrictive, co-viewing, instructive) and T2 cyberbullying perpetration and cyberbullying victimization, as well as specified from the three parental mediation strategies to T2 cyberbullying perpetration and cyberbullying victimization. To control for T1 cyberbullying perpetration and cyberbullying victimization, T1 cyberbullying perpetration was specified to predict T2 cyberbullying perpetration, and T1 cyberbullying victimization was specified to predict $\mathrm{T} 2$ cyberbullying victimization. T1 cyberbullying perpetration and cyberbullying victimization were further controlled by having these variables predict bystanders of cyberbullying, T2 cyberbullying perpetration, and T2 cyberbullying victimization. Two-way interactions were also included between bystanders of cyberbullying and the three parental mediation strategies. To probe significant interactions, the Interaction program was used. This program provides the significance of the unstandardized simple regression slopes and displays graphical illustration of the simple slopes at $+1 S D$, the mean, and $-1 S D$. Concerning our analyses, the program provided the simple slopes at $+1 S D$, the mean, and $-1 S D$ for each of the three parental mediation strategies.

\section{Results}

Means and standard deviations are included in Table 1. Table 1 also includes correlations among the study's variables. Findings revealed that bystander of cyberbullying was correlated positively with restrictive medication, instructive mediation, and T1 and T2 cyberbullying victimization and perpetration. Parental mediation strategies were unrelated to each other. Restrictive mediation was related positively to $\mathrm{T} 1$ and $\mathrm{T} 2$ cyberbullying perpetration and victimization. Instructive mediation was associated negatively with $\mathrm{T} 1$ and $\mathrm{T} 2$ cyberbullying perpetration and victimization. Co-viewing mediation was related negatively to $\mathrm{T} 1$ and $\mathrm{T} 2$ cyberbullying perpetration. $\mathrm{T} 1$ and $\mathrm{T} 2$ cyberbullying perpetration and victimization were each related to each other.

Table 1. Means, standard deviations, and correlations among variables.

\begin{tabular}{|c|c|c|c|c|c|c|c|c|}
\hline & 1 & 2 & 3 & 4 & 5 & 6 & 7 & 8 \\
\hline 1. Bystanders of Cyberbullying & - & & & & & & & \\
\hline 2. Restrictive Mediation & $0.26^{* *}$ & - & & & & & & \\
\hline 3. Co-Viewing Mediation & 0.09 & 0.03 & - & & & & & \\
\hline 4. Instructive Mediation & 0.18 * & -0.10 & 0.11 & - & & & & \\
\hline 5. T1 Cyberbullying Perpetration & $0.26^{* *}$ & $0.29 * * *$ & $-0.27^{* *}$ & $-0.26 * *$ & - & & & \\
\hline 6. T1 Cyberbullying Victimization & $0.33^{* * *}$ & $0.26 * *$ & -0.10 & $-0.29 * * *$ & 0.30 *** & - & & \\
\hline 7. T2 Cyberbullying Perpetration & $0.25 *$ & $0.28 * *$ & $-0.27 * *$ & $-0.25 * *$ & $0.29 * * *$ & $0.32 * * *$ & - & \\
\hline 8. T2 Cyberbullying Victimization & $0.31^{* * *}$ & 0.28 ** & -0.09 & $-0.29 * * *$ & $0.31 * * *$ & $0.30 * * *$ & $0.30 * *$ & - \\
\hline$M$ & 3.67 & 3.00 & 2.91 & 3.13 & 2.79 & 3.03 & 2.83 & 3.14 \\
\hline$S D$ & (1.03) & $(0.91)$ & $(0.80)$ & (1.01) & $(0.69)$ & $(0.81)$ & $(0.73)$ & $(0.79)$ \\
\hline
\end{tabular}


The measurement model was examined using CFA in Mplus 6.12. The model fit was adequate, $x^{2}=765.03, d f=703, p=n . s ., C F I=0.99, T L I=0.97, R M S E A=0.04, S R M R=0.04$; all standardized factor loadings were significant, $p s<0.001$. Items for each questionnaire served as indicators for the latent variables in the structural regression model. The results revealed that the structural model fit the data adequately, $x^{2}=816.73, d f=789, p=n . S ., C F I=0.99, T L I=0.98, R M S E A=0.04, S R M R=0.04$ (see Figure 1). Increases in being bystanders of cyberbullying was related positively to restrictive parental mediation $(\beta=0.24, p<0.01)$ and instructive parental mediation $(\beta=0.14, p<0.05)$. Bystanders of cyberbullying was related positively to T2 cyberbullying perpetration $(\beta=0.28, p<0.01)$ and T2 cyberbullying victimization $(\beta=0.27, p<0.01)$. Restrictive parental mediation was related positively to T2 cyberbullying victimization $(\beta=0.30, p<0.001)$, while instructive parental mediation was negatively related to T2 cyberbullying perpetration $(\beta=-0.18, p<0.05)$ and T2 cyberbullying victimization $(\beta=-0.16, p<0.05)$. Restrictive mediation was unrelated to T2 cyberbullying perpetration $(\beta=0.06$, $p=n$. .s.). Co-viewing mediation was unrelated to bystander of cyberbullying $(\beta=0.03, p=n$.s. $)$, but it was related negatively to T2 cyberbullying perpetration $(\beta=-0.16, p<0.05)$ and T2 cyberbullying victimization $(\beta=-0.17, p<0.05)$.

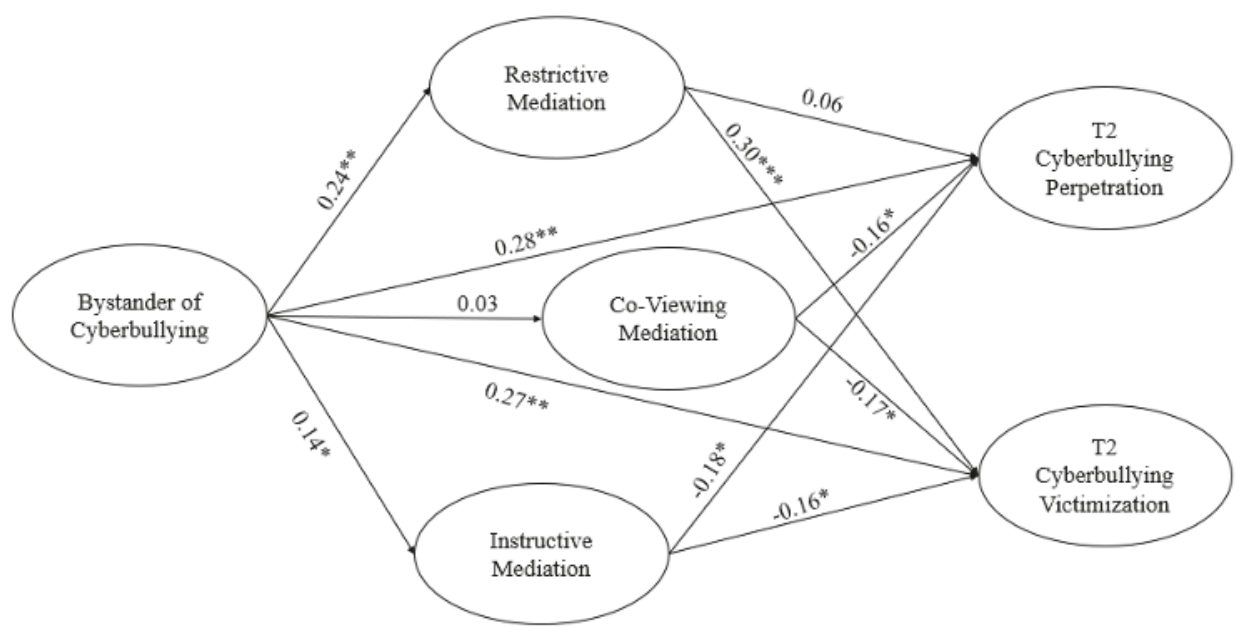

Figure 1. Graphical representation of the structural regression model. Note: T2 = Time 2. T1 cyberbullying perpetration and victimization were both controlled for by letting both variables predict T2 cyberbullying perpetration and victimization. T1 cyberbullying perpetration was related positively to T2 cyberbullying perpetration $(\beta=0.20, p<0.05)$. T1 cyber victimization was related positively to T2 cyberbullying victimization $(\beta=0.19, p<0.05)$. ${ }^{*} p<0.05 .{ }^{* *} p<0.01 .{ }^{* *} p<0.001$.

Restrictive parental mediation was a moderator in the association between bystanders of cyberbullying and T2 cyberbullying victimization. Increases in restrictive parental mediation strengthened the positive relationship between these variables $(B=0.13, S E=0.05, p=0.01$ at the $+1 S D$; $B=0.04, S E=0.02, p=n$.s. at means; $B=0.02, S E=0.02, p=n . s$. at $-1 S D)$. In addition, instructive mediation moderated the association between bystanders of cyberbullying and T2 cyberbullying victimization such that increases in instructive mediation weakened the association between bystanders of cyberbullying and T2 cyberbullying victimization $(B=0.04, S E=0.01, p=n$. s. at the $+1 \mathrm{SD} ; B=0.03$, $S E=0.02, p=n$. . at means; $B=0.12, S E=0.04, p=0.01$ at $-1 S D)$.

\section{Discussion}

The aim of the present study was to investigate the relationship between bystanders of cyberbullying and parental mediation strategies (i.e., instructive, co-viewing, restrictive). Another 
purpose of this one-year longitudinal study was to examine the moderating effects of parental mediation strategies on the relationship between bystanders of cyberbullying and cyberbullying perpetration and victimization.

Parental mediation of technology use might function as a type of social support. This proposal is possible as parents' use of mediation strategies affords opportunities to discuss online experiences with their children (Livingstone et al. 2011). These discussions might involve parents discussing strategies with their children on ways to mitigate or reduce exposure to online risks as well as how to deal with these risks (Wright 2015, 2018). Having parents to talk to might help adolescents feel like what happens to them matters, leading them to seek out support and guidance from their parents concerning online experiences (Wright 2018). Adolescents whose parents maintain an open dialogue about online experiences might seek social support from parents when they experience technical problems or uncomfortable situations while using digital technologies (Nikken and de Haan 2015; Talves and Kalmus 2015; Wright 2017). The benefit of parental mediation of technology use is that it encourages continuous communication between parents and their children regarding online experiences.

Bystanders of cyberbullying was related positively to restrictive mediation, providing support for Hypothesis 1. Instructive mediation was also positively associated with bystanders of cyberbullying, and co-viewing mediation was unrelated to bystanders of cyberbullying. These findings fail to support Hypothesis 2, as both parental mediation strategies were expected to relate negatively to witnessing cyberbullying. These findings suggest that adolescents might witness cyberbullying regardless of whether they believe their parent utilizes restrictive mediation or instructive mediation. Given that $30 \%$ to $60 \%$ of adolescents witness cyberbullying, it might be likely that this is a common experience for adolescents, unrelated to their parents' use of restrictive mediation or instructive mediation (Huang and Chou 2010; Van Cleemput et al. 2014; Vandebosch and Van Cleemput 2009). Consequently, our findings suggest that the association between restrictive and instructive parental mediation strategies and witnessing cyberbullying do not follow similar patterns as those found in previous studies linking parental mediation strategies to cyberbullying perpetration and victimization (Vandebosch and Van Cleemput 2009; Wright 2018).

We found that increases in restrictive parental mediation strengthened the positive relationship between bystanders of cyberbullying and Time 2 cyberbullying victimization. The finding regarding restrictive mediation is consistent with the literature (Wright 2015). Restrictive mediation involves elements of an overprotective parenting style in which children do not have opportunities to develop problem-solving skills and social skills (Clarke et al. 2013; Lereya et al. 2013). The use of restrictive mediation does not allow adolescents to develop strategies for dealing with online risks, which might increase their exposure to risk situations, such as cyberbullying (Smahel and Wright 2014). Because these adolescents do not learn problem-solving skills, they might be unable to avoid situations that might increase their likelihood of experiencing cyberbullying victimization.

The relationships between bystanders and Time 2 cyberbullying victimization were weakened at higher levels of the instructive mediation strategy. These findings are consistent with the literature, suggesting that this form of parental mediation reduces the risk of cyberbullying victimization (Mesch 2009; Navarro et al. 2013; Wright 2015). Through the use of instructive parental mediation, parents are able to provide social support through ongoing discussions with their children, which provides opportunities for adolescents to learn about strategies for avoiding cyberbullying involvement (Mesch 2009; Nikken and de Haan 2015; Talves and Kalmus 2015). Such discussion might involve teaching adolescents about technical and social support coping strategies that reduce adolescents' exposure to cyberbullying perpetration and victimization. These adolescents might also avoid situations that could lead to being involved in cyberbullying.

Co-viewing mediation did not moderate the associations between bystanders of cyberbullying and cyberbullying perpetration or victimization. Although parents who utilize co-viewing strategies might not necessarily discuss content with their children, there might be some minimal amount of discussion on appropriate content and ways to deal with negative online situations (Arrizabalaga-Crespo et al. 2010). 
Wright (2015) found that co-viewing parental mediation was negatively associated with cyberbullying victimization. More research attention should be given to the nuances of the different parental mediation strategies, particularly the co-viewing strategy, to understand the mechanisms behind these strategies and how they mitigate online risks.

\section{Limitations and Future Directions}

This study contributes valuable knowledge to the literature on the buffering effects of the instructive parental mediation strategy on the associations between bystanders of cyberbullying and cyberbullying victimization and perpetration, as well as how restrictive mediation increases these associations. There are a few limitations of this research that needs to be acknowledged. The first limitation is that the study relied on self-reports for all variables, making the findings susceptible to self-report biases. It is important for follow-up research to implement multiple informants, such as assessing parents' own perceptions of mediation strategies. Including peer-reports might also be helpful for providing more objective assessments of cyberbullying involvement. Such a methodological improvement might reduce the biases associated with self-reports. It is also important for researchers to further investigate the characteristics of the three parental mediational strategies utilized in this study. This follow-up research will make it possible to better understand the unique associations of the parental mediation strategies to the different roles adolescents can have in cyberbullying involvement. Another limitation is that parental mediation strategies and bystanders of cyberbullying were assessed at one time point only. Future research should investigate these variables at additional time points as well. This improvement will make it possible to determine the temporal ordering of the variables and the moderation effects examined in this study. Despite the large sample size included in this study, the sample cannot be considered representative, given that a small number of schools were recruited. Consequently, it is important for researchers to conduct studies with representatives to increase the generalizability of this research. It is also necessary for researchers to include diverse samples.

\section{Conclusions}

An important finding from this study is that adolescents are at risk for witnessing cyberbullying, regardless of whether they believe their parents utilize restrictive mediation or instructive mediation. Parental mediation strategies have important implications on bystanders' involvement in cyberbullying one year later. Therefore, the current findings indicate a need for parents to be aware of how they can impact their children's involvement in cyberbullying as victims and bullies.

Greater attention should be given to developing parental intervention programs that focus on the role of parents in helping to mitigate their children's likelihood of cyberbullying involvement. Parents might also be important for helping adolescents develop effective coping strategies for witnessing bullying; such coping strategies might empower adolescents to actually use these strategies to help the victim. Being able to cope with the unpleasant feelings associated with witnessing cyberbullying and helping the victim might help bystanders overcome the potential of engaging in cyberbullying and reduce their risk of cyberbullying victimization. Empowering bystanders to intervene might help to reduce negative feelings that could trigger cyberbullying perpetration. Parents/guardians should be educated on how they can support adolescents who report witnessing cyberbullying. Awareness among parents/guardians regarding the impact of witnessing cyberbullying might be possible through the use of social media advertisements designed to spread knowledge about cyberbullying and the role they have in reducing adolescents' risk.

Author Contributions: M.F.W. was the Principal Investigator, designed, and conducted this study. She performed the statistical analyses and drafted the manuscript. S.W. provided constructive feedback on drafts of the manuscript. M.F.W. processed feedback from the author, reviewers, and editor. All authors read and approved the final manuscript.

Funding: This research received no external funding.

Acknowledgments: We would like to thank the adolescents who participated in this research. 
Conflicts of Interest: The authors declare no conflict of interest.

\section{References}

Arrizabalaga-Crespo, C., A. Aierbe-Barandiaran, and C. Medrano-Samaniego. 2010. Internet uses and parental mediation in adolescents with ADHD. Revista Latina de Comunicación 65: 561-71. [CrossRef]

Clarke, K., P. Cooper, and C. Creswell. 2013. The Parental Overprotection Scale: Associations with child and parental anxiety. Journal of Affective Disorders 151: 618-24. [CrossRef] [PubMed]

Dehue, F., C. Bolman, and T. Völlink. 2008. Cyberbullying: Youngsters' experiences and parental perception. Cyberpsychology \& Behavior 11: 217-23. [CrossRef]

Ferdon, C. D., and M. F. Hertz. 2007. Electronic media, violence, and adolescents: An emerging public health problem. Journal of Adolescent Health 41. [CrossRef]

Grigg, D. W. 2010. Cyber-aggression: Definition and concept of cyberbullying. Australian Journal of Guidance and Counselling 20: 143-56. [CrossRef]

Hinduja, S., and J. W. Patchin. 2008. Cyberbullying: An exploratory analysis of factors related to offending and victimization. Deviant Behavior 29: 129-56. [CrossRef]

Huang, Y., and C. Chou. 2010. An analysis of multiple factors of cyberbullying among junior high school students in Taiwan. Computers in Human Behavior 26: 1581-90. [CrossRef]

Kowalski, R. M., and S. P. Limber. 2007. Electronic bullying among middle school students. Journal of Adolescent Health 41: S22-30. [CrossRef] [PubMed]

Lereya, S. T., M. Samara, and D. Wolke. 2013. Parenting behavior and the risk of becoming a victim and a bully/victim: A meta-analysis study. Child Abuse and Neglect 37: 1091-103. [CrossRef] [PubMed]

Livingstone, S., and E. J. Helsper. 2008. Parental mediation of children's internet use. Journal of Broadcasting $\mathcal{E}$ Electronic Media 52: 581-99. [CrossRef]

Livingstone, S., L. Haddon, A. Görzig, and K. Ólafsson. 2011. Risks and Safety on the Internet: The Perspective of European Children. London: EU Kids Online, London School of Economics and Political Science.

Mesch, G. S. 2009. Parental mediation, online activities, and cyberbullying. CyberPsychology \& Behavior 12: 387-93. [CrossRef]

Navarro, R., C. Serna, V. Martínez, and R. Ruiz-Oliva. 2013. The role of internet use and parental mediation on cyberbullying victimization among Spanish children from rural public schools. European Journal of Psychology of Education 28: 725-45. [CrossRef]

Nikken, P., and J. de Haan. 2015. Guiding young children's internet use at home: Problems that parents experience in their parental mediation and the need for parenting support. Cyberpsychology. Journal of Psychosocial Research on Cyberspace 9. [CrossRef]

Rivers, I., V. P. Poteat, N. Noret, and N. Ashurst. 2009. Observing bullying at school: The mental health implications of witness status. School Psychology Quarterly 24: 211-23. [CrossRef]

Sasson, H., and G. Mesch. 2017. The role of parental mediation and peer norms on the likelihood of cyberbullying. The Journal of Genetic Psychology: Research and Theory on Human Development 178: 15-27. [CrossRef] [PubMed]

Smahel, D., and M. F. Wright. 2014. The Meaning of Online Problematic Situations for Children: Results of Qualitative Cross-Cultural Investigation in Nine European Countries. London: EU Kids Online, London School of Economics and Political Science.

Smith, P. K., J. Mahdavi, M. Carvalho, S. Fisher, S. Russell, and N. Tippett. 2008. Cyberbullying: Its nature and impact in secondary school pupils. Journal of Child Psychology and Psychiatry 49: 376-85. [CrossRef] [PubMed]

Suler, J. 2004. The online disinhibition effect. CyberPsychology \& Behavior 7: 321-26.

Talves, K., and V. Kalmus. 2015. Gendered mediation of children's internet use: A keyhole for looking into changing socialization practices. Cyberpsychology: Journal of Psychosocial Research on Cyberspace 9. [CrossRef]

Topcu, C., O. Erdur-Baker, and Y. Capa-Aydin. 2008. Examination of cyber-bullying experiences among Turkish students from different school types. CyberPsychology \& Behavior 11: 644-48. [CrossRef]

Udris, R. 2014. Cyberbullying among high school students in Japan: Development and validation of the Online Disinhibition Scale. Computers in Human Behavior 41: 253-61. [CrossRef]

Van Cleemput, K., H. Vandebosch, and S. Pabian. 2014. Personal characteristics and contextual factors that determine "Helping," "Joining In," and "Doing Nothing" when witnessing cyberbullying. Aggressive Behavior 40: 383-96. [CrossRef] [PubMed] 
Van Den Eijnden, R., G. Meerkerk, A. Vermulst, R. Spijkerman, and R. C. M. E. Engels. 2008. Online communication, compulsive internet use, and psychosocial well-being among adolescents: A longitudinal study. Developmental Psychology 44: 655-65. [CrossRef] [PubMed]

Vandebosch, H., and K. Van Cleemput. 2009. Cyberbullying among youngsters: Profiles of bullies and victims. New Media \& Society 11: 1349-71.

Wachs, S. 2012. Moral disengagement and emotional and social difficulties in bullying and cyberbullying: Differences by participant role. Emotional and Behavioural Difficulties 17: 347-60. [CrossRef]

Wachs, S., M. Junger, and R. Sittichai. 2015. Traditional, cyber and combined bullying roles: Differences in risky online and offline activities. Societies 5: 109-35. [CrossRef]

Walker, C., B. Sockman, and S. Koehn. 2011. An exploratory study of cyberbullying with undergraduate university students. Tech Trends 55: 31-38. [CrossRef]

Wolak, J., K. Mitchell, and D. Finkelhor. 2007. Does online harassment constitute bullying? An exploration of online harassment by known peers and online-only Cybervictimization and Substance Use among Adolescents. Journal of Adolescent Health 41. [CrossRef] [PubMed]

Wright, M. F. 2014. Predictors of anonymous cyber aggression: The role of adolescents' beliefs about anonymity, aggression, and the permanency of digital content. CyberPsychology, Behavior, and Social Networking 17: 431-38. [CrossRef] [PubMed]

Wright, M. F. 2015. Cyber victimization and adjustment difficulties: The mediation of Chinese and American adolescents' digital technology usage. CyberPsychology: Journal of Psychosocial Research in Cyberspace 9. [CrossRef]

Wright, M. F. 2016. Cybervictimization and substance use among adolescents: The moderation of perceived social support. Journal of Social Work Practice in the Addictions 16: 93-112. [CrossRef]

Wright, M. F. 2017. Parental mediation, cyberbullying, and cybertrolling: The role of gender. Computers in Human Behavior 71: 189-95. [CrossRef]

Wright, M. F. 2018. Cyberbullying Victimization through Social Networking Sites and Adjustment Difficulties: The Role of Parental Mediation. Journal of the Association for Information Systems 19. Available online: https://aisel.aisnet.org/jais/vol19/iss2/1 (accessed on 10 September 2018). [CrossRef]

Wright, M. F., and Y. Li. 2013. The association between cyber victimization and subsequent cyber aggression: The moderating effect of peer rejection. Journal of Youth $\mathcal{E}$ Adolescence 42: 662-74. [CrossRef]

Ybarra, M. L., M. Diener-West, and P. J. Leaf. 2007. Examining the overlap in internet harassment and school bullying: Implications for school intervention. Journal of Adolescent Health 41. [CrossRef] [PubMed]

(C) 2018 by the authors. Licensee MDPI, Basel, Switzerland. This article is an open access article distributed under the terms and conditions of the Creative Commons Attribution (CC BY) license (http://creativecommons.org/licenses/by/4.0/). 
Article

\title{
Family Functioning, Self-Concept and Cybervictimization: An Analysis Based on Gender
}

\author{
Ana Romero-Abrio ${ }^{1, *}$, Celeste León-Moreno ${ }^{1}$, Daniel Musitu-Ferrer ${ }^{1}$ and \\ María Elena Villarreal-González ${ }^{2}$ \\ 1 Department of Education and Social Psychology, Pablo Olavide University, 41013 Seville, Spain; \\ cmleomor@upo.es (C.L.-M.); dmusfer@alu.upo.es (D.M.-F.) \\ 2 Faculty of Psychology, Autonomus University of Nuevo Leon, Monterrey 64460, Nuevo Leon, Mexico; \\ maria.villarrealgl@uanl.edu.mx \\ * Correspondence: aromabr@upo.es; Tel.: +34-954-977-959
}

Received: 23 December 2018; Accepted: 18 February 2019; Published: 21 February 2019

\begin{abstract}
The aim of this study was to analyze the relationships between cybervictimization, family functioning, and self-concept in adolescents, while taking the gender perspective into account. A study was conducted with a sample of 8115 adolescents, aged between 11 and 16 years $(M=13.34$; $S D=1.04)$ from the State of Nuevo Leon, Mexico. A MANOVA $3 \times 2$ was performed to analyze the data. The results showed that family functioning, family self-concept, and academic self-concept were higher when cybervictimization was low. It was also observed that, in situations of cybervictimization, the girls had lower family self-concept, lower academic self-concept, and lower family functioning than the boys. The results that were obtained and their implications are discussed in the final section.
\end{abstract}

Keywords: cyberbullying; cybervictimization; family functioning; self-concept; adolescence

\section{Introduction}

In recent decades, advances in Information and Communication Technologies (ICT) have very rapidly changed the way people interact and communicate with each other. For adolescents, smartphones-mobile phones with Internet access-virtual social media, and instant messaging, are part of their daily lives and they provide them with a connected environment for development and socialization (Livingstone et al. 2011; Wachs et al. 2016). However, this incursion of ICT in the day-to-day lives of adolescents also has many negative effects, such as, for example, Internet addiction and behaviors that are associated with cyberbullying (Aricak and Ozbay 2016; Martínez-Ferrer et al. 2018). Recent studies have revealed the alarming increase in cyberbullying in all developed countries, which has raised great concern in social and educational spheres (De Santisteban and Gámez-Guadix 2017; Garaigordobil 2017; Kowalski et al. 2014; Ortega-Barón et al. 2016).

Cyberbullying is defined as any behavior performed by individuals or groups through electronic or digital means, which involves repeatedly sending hostile or aggressive messages with the intention of causing harm or discomfort to others (Tokunaga 2010; Wachs et al. 2016). Despite the similarities between bullying and cyberbullying, such as intentionality, persistence, and imbalance of power (Buelga et al. 2016), cyberbullying has some very particular characteristics that do not occur in bullying, such as the following: the anonymity of the aggressor; the scope and amplitude of spectators; the impossibility of fleeing from aggression in cyberspace; and, the indefinite reproduction of cyber aggression by observers (Aricak and Ozbay 2016; Buelga et al. 2010). Moreover, one specific characteristic of cyberbullying is the higher prevalence of aggressive cybervictims, since the Internet provides victims with tools to defend themselves and counterattack, displaying behaviors that they would not dare to express in face-to-face bullying situations (Antoniadou and Kokkinos 2015; Buelga et al. 2017). 
In recent years, there has been a notable increase in the amount of research that is focused on the behavior of cyber-aggressors (Giménez Gualdo et al. 2015; Hosseinmardi et al. 2015; Watts et al. 2017). Moreover, numerous authors have analyzed the profile of cyber-victims and their relationship with psychosocial adjustment variables (Ak et al. 2015; Buelga et al. 2017; Stoll and Block 2015).

As regards the effects of cybervictimization on the psychosocial adjustment of adolescents, previous studies have made reference to different socialization scenarios. Thus, at the community level, the relationship between integration variables and community participation and victimization has been analyzed (Martínez Ferrer et al. 2011). In terms of the school context, recent review studies have highlighted the relationship between cybervictimization and learning difficulties (Garaigordobil 2017) and problems of low academic performance (Tokunaga 2010). In the same line, a meta-analysis that as carried out by Kowalski et al. (2014) reported that the adolescents who suffer cybervictimization have a negative perception of the school and little confidence in teachers. Additionally, a study by Ortega-Barón et al. (2016) has analyzed the relationship between cybervictimization and a negative perception of peer relationships.

Previous studies have highlighted that positive family communication favors the self-concept of adolescents within the family, representing a protective factor against cybervictimization, as occurs with family support and parental affection. In contrast, previous studies have highlighted the relationship between family functioning and cybervictimization (Brighi et al. 2012; Sasson et al. 2015). In this respect, some of the authors have reported that deterioration in family functioning contributes to greater victim vulnerability and the longer duration of cyberbullying due, in part, to the lack of family support to deal with problems (Buelga et al. 2016; Navarro et al. 2015).

In relation to personal and behavioral characteristics, in a review paper by Chan and Wong (2015), it has been observed that adolescents who are cybervictimized also suffer problems of low self-control. Additionally, in other studies, cybervictimization has been related to depression (Calvete et al. 2016), anxiety (Litwiller and Brausch 2013), problems of anger and hostility (Aymerich et al. 2018), loneliness and low empathy (Brewer and Kerslake 2015), and suicidal ideation and low self-concept (Brewer and Kerslake 2015; Extremera et al. 2018). As regards self-concept, defined as the perception that individuals have of themselves as physical, social, and spiritual beings (García and Musitu 1999), the authors of this study believe that attention should be drawn to the important role that it plays in the development of adolescent identity. This study was performed using the hierarchical and multidimensional self-concept model (Shavelson et al. 1976) in order to obtain a more sensitive, adjusted, and specific analysis of the measurements (Fuentes et al. 2011). Previous studies have reported that adolescents with high self-concept have higher levels of psychosocial adjustment, such as greater satisfaction with life and less loneliness (Moreno et al. 2009) and lower levels of depression and anxiety than adolescents with low self-concept (Garaigordobil and Durá 2006). In contrast, other authors have associated low self-concept with victimization (Kowalski and Limber 2013) and cybervictimization (Brewer and Kerslake 2015; Extremera et al. 2018; Wachs et al. 2016).

Lastly, regarding the prevalence of cybervictimization according to gender, there is still no consensus among researchers. Certain previous studies have reported that cybervictimization may be more frequent in boys (Durán-Segura and Martínez-Pecino 2015), or no gender differences have been observed (Katzer et al. 2009). Additionally, a meta-analysis by Kowalski et al. (2014) indicated an increased frequency of cybervictimization in girls. In relation to self-concept, in a meta-analysis that was carried out with 32,486 individuals through 115 studies, no gender differences were observed in the familiar and academic dimensions of self-concept (Gentile et al. 2009).

\section{The Current Study}

In the family environment, studies have been carried out on cybervictimization from the perspective of family communication (Buelga et al. 2017), parenting styles (Chou et al. 2016; Fuentes et al. 2015), and family atmosphere (Moral Jiménez and Bernal 2013), as well as from the intercultural standpoint (Estévez et al. 2016). However, very few studies have analyzed 
cybervictimization from the point of view of family functioning (Buelga et al. 2016). There is also extensive literature regarding the relationship between self-concept and cybervictimization, but from the multidimensional perspective of self-concept (Brewer and Kerslake 2015; Buelga and Musitu 2006). In this study, a two-dimensional perspective was chosen, which focused exclusively on the two potentially most significant contexts in the adolescent's life, namely family and school. Thus, consideration was given to the dimensions of family and academic self-concept dimensions, which previous studies have related to low levels of aggressive behavior in school, high academic performance, and better school achievement (Estévez et al. 2006), as well as with other adjustment factors in adolescents, such as substance use (Musitu et al. 2007) and criminal behavior (Cava et al. 2008). In particular, some of the authors have related the family self-concept with high levels of family socialization (Fuentes et al. 2011). In terms of gender, as mentioned previously, no conclusive results have been reached in previous studies regarding the differences between boys and girls in cybervictimization in relation to those variables, namely self-concept and family functioning.

Against this background, the general objective of this study is to analyze the relationship between family functioning, family self-concept, academic self-concept, and cybervictimization in school-aged adolescents based on gender. The expected outcomes are as follows:

Hypothesis 1 (H1). Family functioning would be greater the lower the cybervictimization.

Hypothesis 2 (H2). Academic and family self-concept would be higher in adolescents with low cybervictimization.

Hypothesis 3 (H3). In situations of high cybervictimization, girls would display lower family functioning, lower academic self-concept and lower family self-concept than boys.

\section{Method}

\subsection{Participants}

Proportional stratified sampling was carried out according to urban and rural educational centers (universe of 984 centers), in the State of Nuevo Leon (Mexico) (confidence level 90\%, alpha 0.05). 8,115 adolescents participated (51.5\% boys and $48.5 \%$ girls) from 118 centers (62 urban and 56 rural), of which $62.3 \%$ studied in urban schools and $62.3 \%$ studied in rural schools. Their ages ranged between $11-13$ years old $(54.0 \%)$ and $14-16$ years old $(46.0 \%)$.

\subsection{Instruments}

Family Functioning Scale-APGAR—(Smilkstein et al. 1982). It consisted of five items with three possible answers $(0=$ almost never, $1=$ sometimes, and $2=$ almost always $)$. It evaluates the cohesion and adaptability of family functioning (e.g., "Are you satisfied with the time you and your family spend together?"). Cronbach's alpha was 0.80 . Confirmatory factorial analysis (CFA) using the Maximum Likelihood Model showed good fit of the model to the data $\left[\mathrm{SB} \chi^{2}=40.41, \mathrm{gl}=4, p<0.001\right.$, CFI $=0.996$, RMSEA $=0.033(0.025,0.043)]$.

Self-Concept Form-5 Scale-AF-5-(García and Musitu 1999). This consisted of 30 items, with a response range of $1=$ very little according to $99=$ agree strongly. It measured five dimensions of self-concept: academic self-concept (e.g., "I do schoolwork well"), social self-concept (e.g., "I make friends easily"), emotional self-concept (e.g., "I'm afraid of some things"), family self-concept (e.g., "At home they criticize me a lot"), and physical self-concept (e.g., "I take care of myself physically"). Cronbach's alpha was 0.81 . Its internal consistency for each of its dimensions-academic self-concept and family self-concept-was 0.88 and 0.77 , respectively. The CFA using the Maximum Likelihood model presented an acceptable fit to the data $\left[\mathrm{SB} \chi^{2}=6892.5998, \mathrm{gl}=337, p<0.001\right.$, CFI $=0.958$, RMSEA $=0.050(0.049,0.051)]$.

Scale of Victimization via Mobile Phone and Internet_CYB-VIC—(Buelga et al. 2012). It consisted of 18 items with four Likert response options (from 1 = never to 4 = always). The scale measured 
the adolescent's experience as a victim of cyberbullying via mobile phone and Internet in the last 12 months. It consisted of two sub-scales: mobile phone victimization (e.g., "I've been insulted or ridiculed with messages or calls"); and, Internet victimization (e.g., "They've gotten into my messenger or private account without being able to do anything"). Cronbach's alpha was 0.89 . The CFA using the Maximum Likelihood Model confirmed the good fit of the model to the data: $\left[\mathrm{SB} \chi^{2}=238.90, \mathrm{df}=124\right.$, $p<0.001, \mathrm{CFI}=0.93, \mathrm{NNFI}=0.91, \mathrm{RMSEA}=0.03(0.024,0.035)]$.

\subsection{Procedure}

The Autonomous University of Nuevo Leon and the Secretariat for Education, of the same state, planned and developed the project. This Secretariat convened the inspectors of the different state regions to inform them of the start of this research and for the latter to, in turn, inform their directors about the interest and relevance of the project in order to grant access to university researchers for the administration of the instruments. PhD students from the Faculty of Psychology $(\mathrm{N}=19)$ received training on all aspects related to the development of the research (administration, attitudes, and behaviour in the process with respect to students and teachers). Once they had been informed and had given their permission, the instruments were administered at the selected centres following the obtainment of permission from the parents and students. For transport purposes, participants living long distances from the centres were provided with a bus service by the Faculty of Psychology. The number of researchers and $\mathrm{PhD}$ students who used this service was $\mathrm{N}=25$. In classrooms where there were children with reading and comprehension problems, administration was performed on an individual basis by trained staff. Additionally, all of the students were informed that their participation was voluntary and anonymous and that they could refuse to participate whenever they wished. A total of 19 students $(21 \%)$ refused to participate in the project. The study complied with the ethical values required in research with human beings, respecting the fundamental principles that were included in the Helsinki Declaration (World Medical Association 2013), its amendments and regulations in force (regulating informed consent and right to information, personal data protection and guarantees of confidentiality, non-discrimination, freedom, and the option of abandoning the study in any of its phases).

\subsection{Data Analysis}

First, two cluster analyses were carried out with the two dimensions of cybervictimization that are measured on the scale (mobile phone victimization and Internet victimization), in order to determine the maximum intergroup variability and minimum intragroup variability. Firstly, a two-stage analysis was carried out to obtain the optimal number of groups, followed by a k-means analysis to assign the individuals to each group. The result was that three cybervictimization groups (high, moderate, and low) were obtained, with good fits. The average score was used to determine the prevalence of cybervictimization, resulting in three conglomerates that were compared in accordance with the evaluation of this variable (Closas et al. 2013). Based on the mean, the values were classified, as follows: values between 1 and 1.60 were considered to be low cybervictimization; values between 1.70 and 2.60, moderate cybervictimization; and, values between 2.70 and 5, high cybervictimization. Subsequently, a multivariate factorial design (MANOVA, $3 \times 2$ ) was performed to analyze any interaction effects. The fixed factors were cybervictimization (high, moderate, and low) and gender (boy and girl) and the dependent variables were family functioning and self-concept (family self-concept and academic self-concept). Lost data by scales or sub-scales, provided that they did not exceed $15 \%$, were processed using the multiple linear regression imputation model (Cuesta et al. 2013). Univariate atypical data were detected by the exploration of standardized scores) (Hair et al. 1999). SPSS (edition 25) software was used. 


\section{Results}

\subsection{Descriptive Analysis}

The distribution of adolescents according to gender, cybervictimization, family functioning, and self-concept is shown in Table 1. The percentage of boys and girls, as a function of cybervictimization, was similar in all of the variables.

Table 1. Sociodemographic variables.

\begin{tabular}{|c|c|c|c|c|c|}
\hline \multirow[b]{2}{*}{ Variables } & \multirow[b]{2}{*}{$\begin{array}{c}\text { Total Sample } \\
\quad(\mathrm{N}=8115)\end{array}$} & \multicolumn{3}{|c|}{ Cybervictimization } & \multirow[b]{2}{*}{$x^{2}$} \\
\hline & & $\begin{array}{c}\text { Low } \\
(\mathrm{N}=6525)\end{array}$ & $\begin{array}{l}\text { Moderate } \\
(\mathrm{N}=1328)\end{array}$ & $\begin{array}{c}\text { High } \\
(\mathrm{N}=262)\end{array}$ & \\
\hline Gender & & & & & $28.216^{* * *}$ \\
\hline Boys & 4177 (51.5\%) & $3449(52.9 \%)$ & $620(46.7 \%)$ & $108(41.2 \%)$ & \\
\hline Girls & $3938(49.5 \%)$ & $3076(47.1 \%)$ & $708(53.3 \%)$ & $154(58.8 \%)$ & \\
\hline
\end{tabular}

\subsection{Multivariate Analysis}

A MANOVA was performed and statistically significant differences were obtained in the main effects of cybervictimization $\left(\Lambda=0.965, F(6,16,214)=47.89, p<0.001, \eta^{2}=0.017\right)$, and gender $\left(\Lambda=0.995, F(3,8107)=14.85, p<0.001, \eta^{2}=0.005\right)$. A statistically significant interaction effect between cybervictimization and gender was also observed $\left(\Lambda=0.995, F(6,16,214)=6.86, p<0.001, \eta^{2}=0.003\right)$.

As regards cybervictimization, the ANOVA results showed statistically significant differences in family functioning $\left(F(2,1882)=58.859, p<0.001, \eta^{2}=.014\right)$, family self-concept $(F(2,8112)=156.653$, $\left.p<0.001, \eta^{2}=0.037\right)$, and academic self-concept $\left(F(2,8112)=30.281, p<0.001, \eta^{2}=0.007\right)$ (see Table 2). The Bonferroni test $(\alpha=0.05)$ indicated that family functioning, family self-concept and academic self-concept were higher in adolescents with low cybervictimization than in those with high cybervictimization. The effect sizes detected were medium-low, from 0.007 to 0.037 .

Table 2. Means, Standard Deviation (SD) and results ANOVA between cybervictimization and family functionning, family self-concept, and academic self-concept.

\begin{tabular}{cccccc}
\hline \multirow{2}{*}{ Variables } & \multicolumn{3}{c}{ Cybervictimization } & \multicolumn{1}{c}{$\boldsymbol{F}$} & $\eta^{2}$ \\
\cline { 2 - 6 } & Low & Moderate & High & $\boldsymbol{F ( 2 , 8 1 1 2 )}$ \\
\hline FF & $2.484(0.545)^{\mathrm{a}}$ & $2.374(0.545)^{\mathrm{b}}$ & $2.173(0.621)^{\mathrm{c}}$ & $58.859^{* * *}$ & 0.014 \\
ASC & $81.574(18.558)^{\mathrm{a}}$ & $74.548(21.902)^{\mathrm{b}}$ & $64.636(24.373)^{\mathrm{c}}$ & $156.653^{* * *}$ & 0.037 \\
FSC & $71.339(21.090)^{\mathrm{a}}$ & $67.867(21.802)^{\mathrm{b}}$ & $63.302(22.710)^{\mathrm{c}}$ & $30.281^{* * *}$ & 0.007 \\
\hline
\end{tabular}

FF: Family functioning; FSC: Family Self-Concept; ASC: Academic Self-Concept; Bonferroni Test $\alpha=0.05$; a $>\mathrm{b}>\mathrm{c}$; ${ }^{* * *} p<0.001 ; \eta^{2}=0.01-0.06$ (small effect), $>0.06-0.14$ (medium effect), $>0.14$ (high effect).

In relation to gender, significant differences were obtained in family self-concept $\left(F(1,8113)=18.774, p<0.001, \eta^{2}=0.002\right)$ and in academic self-concept $(F(1,8113)=37.149, p<0.001$, $\left.\eta^{2}=0.005\right)$. As shown in Table 3 , girls showed greater academic self-concept, while boys showed greater family self-concept.

Table 3. Means, Standard Deviation (SD) and results ANOVA between gender and family functioning, family self-concept and academic self-concept.

\begin{tabular}{ccccc}
\hline \multirow{2}{*}{ Variables } & \multicolumn{2}{c}{ Gender } & $\boldsymbol{F}$ & $\eta^{\mathbf{2}}$ \\
\cline { 2 - 5 } & Boy & Girl & $\boldsymbol{F ( 1 , 8 1 1 3 )}$ \\
\hline FF & $2.468(0.561)$ & $2.444(0.541)$ & 3.797 & 0.000 \\
FSC & $80.797(18.334)$ & $78.901(21.052)$ & $18.774^{* * *}$ & 0.002 \\
ASC & $69.113(20.713)$ & $71.995(21.887)$ & $37.149^{* * *}$ & 0.005 \\
\hline
\end{tabular}

FF: Family functionning; FSC: Family Self-concept; ASC: Academic Self-Concept; ${ }^{* * *} p<0.001 ; \eta^{2}=0.01-0.06$ (small effect), $>0.06-0.14$ (médium effect), >0.14 (high effect). 


\subsection{Univariate Analyses of Interaction Effects}

Three interaction effects were obtained. The first interaction was between cybervictimization, gender, and family functioning $\left(F(5,8109)=28.732, p<0.001, \eta^{2}=0.017\right)$. The post-hoc contrast results from the Bonferroni test $(\alpha=0.05$ ) indicated that, when cybervictimization was high and moderate, girls perceived worse family functioning, while, when cybervictimization was low, boys and girls similarly perceived high family functioning (Figure 1).

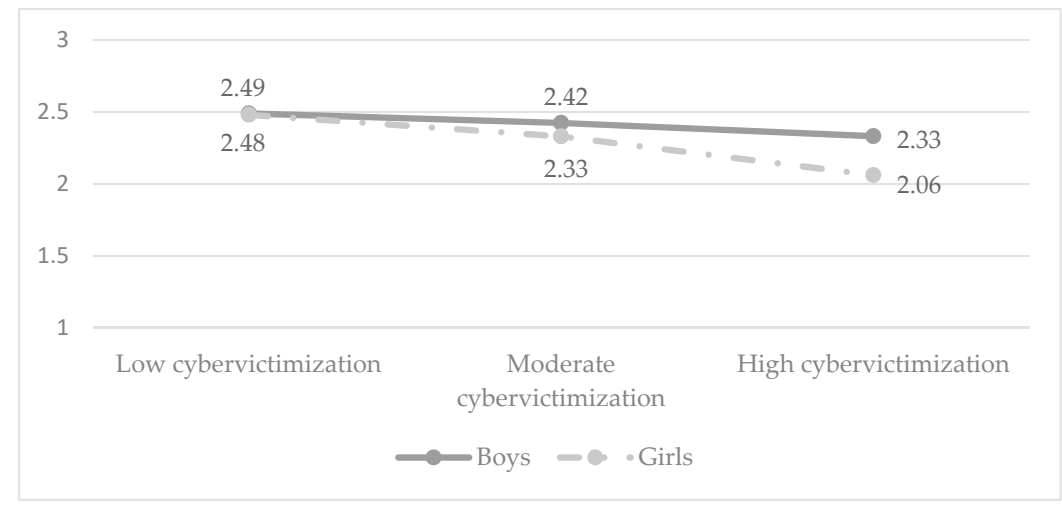

Figure 1. Cybervictimization, family functioning and gender.

The second interaction was between cybervictimization, gender, and family functioning $\left(F(5,8109)=70.654, p<0.001, \eta^{2}=0.042\right)$. Post-hoc contrast results from the Bonferroni test $(\alpha=0.05)$ (Figure 2) indicated that when cybervictimization was moderate and high girls showed lower family self-concept, while, when cybervictimization was low, boys and girls similarly perceived high family functioning.

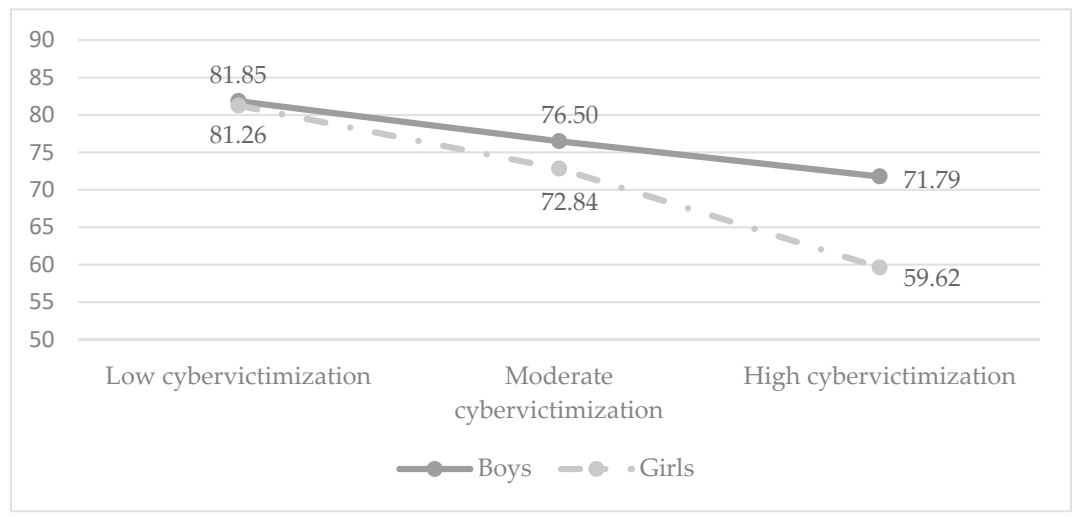

Figure 2. Cybervictimization, family self-concept and gender.

The third interaction was between cybervictimization, gender, and academic self-concept $\left(F(5,8109)=24.889, p<0.001, \eta^{2}=0.015\right)$. As can be seen from the results (Figure 3), when cybervictimization was high, girls showed lower academic self-concept, while, when cybervictimization was low, girls showed higher academic self-concept. Only in the condition of moderate victimization did the boys and girls show similar academic self-concept. 


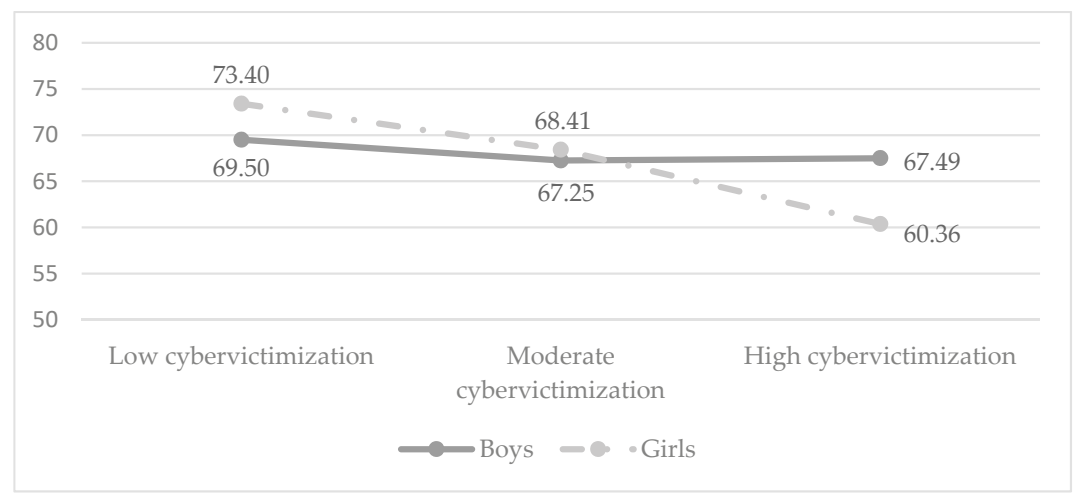

Figure 3. Cybervictimization, academic self-concept, and gender.

\section{Discussion}

This study aimed to analyze the relationships between cybervictimization, family functioning, and academic and family self-concept in school-aged adolescents, while taking into account the gender perspective. The results showed that family functioning, family self-concept, and academic self-concept were significantly related with cybervictimization. Significant differences were observed between boys and girls in these variables in the three conditions of cybervictimization that were analyzed in this study.

As regards family functioning, the results showed that it was the adolescents with low cybervictimization who perceived better family functioning and that higher cybervictimization was associated with lower perception of good family functioning, allowing us to confirm the first hypothesis. These results were consistent with those that were obtained by other authors in the field of family functioning, with variables, such as family communication (Navarro et al. 2015), parenting styles (Fuentes et al. 2015; Huang et al. 2010) and family climate (Ortega-Barón et al. 2016). These findings are also considered to be fundamentally interesting because they provide a new dimension—family functioning — that is considered to bring together the other variables in the family context (Castilla et al. 2014; Martínez-Ferrer et al. 2003; Musitu et al. 2007). Family functioning was also observed to be related with cybervictimization. More specifically, our results show that adolescents with good family functioning are less cyber-victimized than those with poor family functioning. In the same line, previous studies have highlighted that the likelihood of adolescents being cyber-victimized is related to protection variables that are related to family structure and functioning, such as parental affection and family support (Elsaesser et al. 2017; Fanti et al. 2012; Martins et al. 2016).

In relation to self-concept, it was observed that adolescents with low cyber-victimization status reported greater family and academic self-concept, allowing for us to confirm the second hypothesis. These results are consistent with those that were reported in previous studies, which have highlighted that self-concept, together with family functioning, is also a protection factor against cybervictimization (Kowalski et al. 2018). However, this study included the two dimensions of self-concept that are related to family and school, thus enriching the results that were reported previously, insofar as cybervictimization has a reference in both the school and family contexts. Recently, it has also been observed that the relationship between self-concept and cybervictimization may be moderated by positive relationships between parents and adolescent children. More specifically, frequent communication between parents and children is related to high levels of self-concept in adolescents (Özdemir 2014).

As regards gender, and as expected (third hypothesis), the relationships between cybervictimization, family functioning, family self-concept, and academic self-concept differed between boys and girls. Firstly, it was observed that girls with high cybervictimization reported poorer family 
functioning than boys. However, when cybervictimization was low, no gender differences in family functioning were observed. This result is related to the notion that girls are more sensitive to poor family functioning than boys, which could explain more emotional problems and, consequently, reveal greater difficulty in dealing with problems in the family sphere and in other contexts, such as school. These negative experiences linked to emotional resources would explain the victimization (Buelga et al. 2017; Hinduja and Patchin 2012). In this connection, previous studies have reported that girls are better in identifying and expressing emotions than boys in contexts of family violence, such as in cases of child-to-parent violence (Levant et al. 2009; Martínez-Ferrer et al. 2018). Although this is one potential explanation, the downside is that it is a borderline explanation in the sense that poor family functioning is not necessarily related to violence. In the authors' opinion, these results are very interesting and they should therefore be explored further.

Secondly, and as regards family self-concept, it was observed that the effect of interaction with cybervictimization and gender followed the same trend as in the case of family functioning. The results showed that the boys presented higher scores than the girls when cybervictimization was high, but in situations of low cybervictimization, girls and boys had a high and similar family self-concept. This result is related to one extremely important fact, which appeared at the beginning of the last century with symbolic interactionists (Brown and Lohr 1987; Pons Diez 2010; Serpe and Stryker 2011; Shalin 2015), and it continues today with the theory of empowerment (Cattaneo and Goodman 2015; Musitu and Buelga 2004; Peterson 2014; Song 2012), namely that parenting styles and other dimensions of the family environment, such as family communication, are considered to be processes that have certain outcomes or resources, and one of the results of these processes is self-concept (Collins 2011). This study infers that these processes are weaker in the cases of adolescent cyber-bullying victims. To summarize, the fact that cyber-victimized adolescents presented a lower family self-concept is related to the idea that family socialization processes are intimately linked to family functioning, as are parenting styles when family functioning is negative, having a negative effect on the self-concept of adolescents. It is important to emphasize that self-concept has been identified as an important predictor of criminal behavior (Barry et al. 2007), violent behavior (Babore et al. 2017; Estévez et al. 2006), and substance use (Musitu et al. 2007).

Finally, and in relation to the academic self-concept, the results showed that, when cybervictimization was low and moderate, boys and girls showed significant differences, which were greater in the girls in both cases. When cybervictimization was high, boys and girls showed the lowest scores of the three groups, but it was the girls who presented the lowest levels. Our results revealed gender differences in academic self-concept, which is consistent with findings that were reported in previous studies (Jansen et al. 2014), and supports the idea that, when girls are victimized, their academic self-concept diminishes, a situation that does not occur in boys. Previous studies have described the relationship between academic self-concept and adjustment variables, such as anxiety, intrinsic motivation, and academic performance (Khalaila 2015). In turn, these variables have been observed to be significantly related to cyberbullying and cybervictimization (Litwiller and Brausch 2013). This result seems significant, especially since it was observed that poor family functioning not only influences this environment internally, but it also extends to another very important scenario in this period of adolescence, namely school. It is important to note that the results obtained in this study showed that boys and girls seem to differ in the way that they interpret complex situations with high emotional content. In this sense, other authors have reported that girls interpret emotions better (Levant et al. 2009), and have better emotional self-concept than boys (Ortega-Barón et al. 2016), which could explain its greater sensitivity and permeability in situations of cybervictimization. As regards academic self-concept, performance, and academic adjustment (Jansen et al. 2014; Khalaila 2015), it has also been observed that girls present higher levels and adjustment than boys in non-violent or peaceful situations. These results may be explained by gender schemes that are acquired through socialization processes and they result in the learning of 
behaviors that are considered to be socially appropriate for men and women (Santoro et al. 2018; Yubero Jimenez and Olivas 2010).

Finally, we believe that this study provides suggestive and relevant observations regarding certain variables that are involved in cybervictimization. However, it is important to note that the results obtained in this study must be interpreted with caution, due to its transversal and correlational nature, which, as is well known, does not allow causal relationships to be established between the variables. A longitudinal study with measurements at different times would help to clarify the relationships that were observed here.

Despite these limitations, the authors believe that this study provides interesting and valuable results regarding the relationship between cyberbullying and the emotional variables of psychological distress and, above all, suicidal ideation, as well as the fundamental role that is played by family as a protection context. These findings highlight the importance of the role of family and gender in the strengthening of resources, such as self-concept, which have a protective effect on the interaction of adolescents with their peers at school and on virtual social media.

Author Contributions: All the authors of the manuscript contributed equally to the research and writing of the present study.

Funding: This study was funded by the project "Bullying in adolescence: individual and family variables", and subsidised by Support Scientific and Technological Research Programme (PAYCIT) by the Autonomous University of Nuevo Leon (UNAL) (Mexico).

Conflicts of Interest: The authors declare no conflict of interest.

\section{References}

Ak, Şerife, Yalçin Özdemir, and Yaşar Kuzucu. 2015. Cybervictimization and Cyberbullying: The Mediating Role of Anger, Don't Anger Me! Computers in Human Behavior 49: 437-43. [CrossRef]

Antoniadou, Nafsika, and Constantinos M. Kokkinos. 2015. Cyber and School Bullying: Same or Different Phenomena? Aggression and Violent Behavior 25: 363-72. [CrossRef]

Aricak, Osman Tolga, and Ahmet Ozbay. 2016. Investigation of the Relationship between Cyberbullying, Cybervictimization, Alexithymia and Anger Expression Styles among Adolescents. Computers in Human Behavior 55: 278-85. [CrossRef]

Aymerich, María del Milagro, Gonzalo Musitu, and Francisco Palmero. 2018. Family Socialisation Styles and Hostility in the Adolescent Population. Sustainability 10: 2962. [CrossRef]

Babore, Alessandra, Leonardo Carlucci, Fedele Cataldi, Vicky Phares, and Carmen Trumello. 2017. Aggressive Behaviour in Adolescence: Links with Self-Esteem and Parental Emotional Availability. Social Development 26: 704-42. [CrossRef]

Barry, Christopher T., Sarah J. Grafeman, Kristy K. Adler, and Jessica D. Pickard. 2007. The Relations among Narcissism, Self-Esteem, and Delinquency in a Sample of at-Risk Adolescents. Journal of Adolescence. [CrossRef]

Brewer, Gayle, and Jade Kerslake. 2015. Cyberbullying, Self-Esteem, Empathy and Loneliness. Computers in Human Behavior 48: 255-60. [CrossRef]

Brighi, Antonella, Annalisa Guarini, Giannino Melotti, Silvia Galli, and Maria Luisa Genta. 2012. Predictors of Victimisation across Direct Bullying, Indirect Bullying and Cyberbullying. Emotional and Behavioural Difficulties 17: 375-88. [CrossRef]

Brown, B. Bradford, and Mary Jane Lohr. 1987. Peer-Group Affiliation and Adolescent Self-Esteem: An Integration of Ego-Identity and Symbolic-Interaction Theories. Journal of Personality and Social Psychology 52: 47-55. [CrossRef] [PubMed]

Buelga, Sofía, and Gonzalo Musitu. 2006. Famille et Adolescence: Prévention de Conduites à Risque [Family and Adolescence: Preventions of Risk Behaviour]. In Adolescences d'aujourd'hui. Edited by Denis Jacquet and Marc Zabalia. Rennes: PUF, pp. 17-35.

Buelga, Sofía, María Jesús Cava, and Gonzalo Musitu. 2010. Cyberbullying: Victimizacion Entre Adolescentes a Través Del Teléfono Movil y de Internet [Cyberbullying: Victimization among Adolescents through Mobile Phone and Internet]. Psicothema 22: 784-89. [CrossRef] [PubMed] 
Buelga, Sofía, María Jesús Cava, and Gonzalo Musitu. 2012. Validation of the Adolescent Victimization through Mobile Phone and Internet Scale. Revista Panamericana de Salud Pública = Pan American Journal of Public Health 32: 36-42. [CrossRef] [PubMed]

Buelga, Sofía, Belén Martínez-Ferrer, and Gonzalo Musitu. 2016. Family Relationships and Cyberbullying. In Cyberbullying Across the Globe: Gender, Family, and Mental Health. Edited by Raúl Navarro, Santiago Yubero and Elisa Larrañaga. España: Springer, pp. 99-114. [CrossRef]

Buelga, Sofía, Belén Martínez-Ferrer, and María Jesús Cava. 2017. Differences in Family Climate and Family Communication among Cyberbullies, Cybervictims, and Cyber Bully-victims in Adolescents. Computers in Human Behavior 76: 164-73. [CrossRef]

Calvete, Esther, Izaskun Orue, and Manuel Gámez-Guadix. 2016. Cyberbullying Victimization and Depression in Adolescents: The Mediating Role of Body Image and Cognitive Schemas in a One-Year Prospective Study. European Journal on Criminal Policy and Research. [CrossRef]

Castilla, Humberto A., Tomas P. Caycho, Midori Shimabukuro, and Amalia A. Valdivia. 2014. Percepción Del Funcionamiento Familiar: Análisis Psicométrico de La Escala APGAR-Familiar En Adolescentes de Lima [Perception of Family Functioning: Psychometric Analysis of the APGAR-Family Scale in Adolescents in Lima]. Propósitos y Representaciones 2: 49-58. [CrossRef]

Cattaneo, Lauren Bennett, and Lisa A. Goodman. 2015. What Is Empowerment Anyway? A Model for Domestic Violence Practice, Research, and Evaluation. Psychology of Violence 5: 84-94. [CrossRef]

Cava, María Jesús, Sergio Murgui, and Gonzalo Musitu. 2008. Diferencias En Factores de Protección Del Consumo de Sustancias En La Adolescencia Temprana y Media [Differences in Protective Factors for Substance Use in Early and Middle Adolescence]. Psicothema 20: 389-95. [PubMed]

Chan, Heng Choon Oliver, and Dennis S.W. Wong. 2015. Traditional school bullying and cyberbullying in Chinese societies: Prevalence and a review of the whole-school intervention approach. Aggression and Violent Behavior 23: 98-108. [CrossRef]

Chou, Hui Lien, Chien Chou, and Chao Hsiu Chen. 2016. The Moderating Effects of Parenting Styles on the Relation between the Internet Attitudes and Internet Behaviors of High-School Students in Taiwan. Computers and Education 94: 204-14. [CrossRef]

Closas, Antonio Humberto, Edgardo Alberto Arriola, Cristina Isabel Kuc, Rosana Amarilla, and Ethel Carina Jovanovich. 2013. Análisis Multivariante, Conceptos y Aplicaciones En Psicología Educativa y Psicometría [Multivariate Analysis, Concepts and Applications in Educational Psychology and Psychometry]. Enfoques XXV: 65-92.

Collins, Randall. 2011. Wiley's Contribution to Symbolic Interactionist Theory. American Sociologist 42: 156-67. [CrossRef]

Cuesta, Marcelino, Eduardo Fonseca-Pedrero, Guillermo Vallejo, and José Muñiz. 2013. Datos Perdidos y Propiedades Psicométricas En Los Tests de Personalidad [Lost Data and Psychometric Properties in Personality Test]. Anales de Psicologia 29: 285-92. [CrossRef]

De Santisteban, Patricia, and Manuel Gámez-Guadix. 2017. Estrategias de persuasión en grooming online de menores: Un análisis cualitativo con agresores en prisión [Persuasion strategies in online grooming of young people: A qualitative analysis with aggressors in prison]. Psychosocial Intervention 26: 139-46. [CrossRef]

Durán-Segura, Mercedes, and Roberto Martínez-Pecino. 2015. Ciberacoso Mediante Teléfono Móvil e Internet En Las Relaciones de Noviazgo Entre Jóvenes [Cyberbullying Trough Mobile Phone and the Internet in Dating Relationships on Youth]. Comunicar. Revista Científica de Comunicación y Educación 22: 159. [CrossRef]

Elsaesser, Caitlin, Beth Russell, Christine McCauley Ohannessian, and Desmond Patton. 2017. Parenting in a Digital Age: A Review of Parents' Role in Preventing Adolescent Cyberbullying. Aggression and Violent Behavior. [CrossRef]

Estévez, Estefanía, Belén Martínez, and Gonzalo Musitu. 2006. La Autoestima En Adolescentes Agresores y Víctimas En La Escuela: La Perspectiva Multidimensional [Self-Esteem in Adolescent Aggressors and Victims in School: The Multidimensional Perspective]. Psychosocial Intervention 15: 223-32.

Estévez, Estefanía, Teresa I. Jiménez, and María Jesús Cava. 2016. A Cross-Cultural Study in Spain and Mexico on School Aggression in Adolescence: Examining the Role of Individual, Family, and School Variables. Cross-Cultural Research 50: 123-53. [CrossRef] 
Extremera, Natalio, Cirenia Quintana-Orts, Sergio Mérida-López, and Lourdes Rey. 2018. Cyberbullying Victimization, Self-Esteem and Suicidal Ideation in Adolescence: Does Emotional Intelligence Play a Buffering Role? Frontiers in Psychology 9: 367. [CrossRef] [PubMed]

Fanti, Kostas A., Andreas G. Demetriou, and Veronica V. Hawa. 2012. A Longitudinal Study of Cyberbullying: Examining Risk and Protective Factors. European Journal of Developmental Psychology 9: 168-81. [CrossRef]

Fuentes, María C., José Fernando García, Enrique Gracia, and Marisol Lila. 2011. Autoconcepto y Ajuste Psicosocial En La Adolescencia [Self-Concept and Psychosocial Adjustment in Adolescence]. Psicothema 23: 7-12. [PubMed]

Fuentes, Maria C., Fernando García, Enrique Gracia, and Antonio Alarcon. 2015. Parental Socialization Styles and Psychological Adjustment. A Study in Spanish Adolescents. Revista de Psicodidáctica 27: 1-32. [CrossRef]

Garaigordobil, Maite. 2017. Conducta Antisocial: Conexión Con Bullying/Cyberbullying y Estrategias de Resolución de Conflictos [Antisocial Behaviour: Connection to Bullying/Cyberbullying and Conflict Resolution Strategies]. Psychosocial Intervention 26: 47-54. [CrossRef]

Garaigordobil, Maite, and Ainhoa Durá. 2006. Relaciones Del Autoconcepto y La Autoestima Con La Sociabilidad, Estabilidad Emocional y Responsabilidad En Adolescentes de 14 a 17 Años [Relationships of Self-Concept and Self-Esteem with Sociability, Emotional Stability and Responsibility in Adolescent]. Análisis y Modificación de Conducta 32: 37-64.

García, Fernando, and Gonzalo Musitu. 1999. AF5: Autoconcepto Forma 5 [SF5: Self-Concept Form 5]. Madrid: TEA Ediciones.

Gentile, Brittany, Shelly Grabe, Brenda Dolan-Pascoe, Jean M. Twenge, Brooke E. Wells, and Alissa Maitino. 2009. Gender Differences in Domain-Specific Self-Esteem: A Meta-Analysis. Review of General Psychology 13: 34-45. [CrossRef]

Giménez Gualdo, Ana M., Simon C. Hunter, Kevin Durkin, Pilar Arnaiz, and Javier J. Maquilón. 2015. The Emotional Impact of Cyberbullying: Differences in Perceptions and Experiences as a Function of Role. Computers \& Education 82: 228-35. [CrossRef]

Hair, Joseph F., Rolph E. Anderson, Ronald L. Tatham, and William C. Black. 1999. Análisis Multivariante [Multivariate Analysis], 4th ed. España: Prentice Hall.

Hinduja, Sameer, and Justin W. Patchin. 2012. Cyberbullying: Neither an Epidemic nor a Rarity. European Journal of Developmental Psychology 9: 539-43. [CrossRef]

Hosseinmardi, Homa, Sabrina Arredondo Mattson, Rahat Ibn Rafiq, Richard Han, Qin Lv, and Shivakant Mishra. 2015. Analyzing Labeled Cyberbullying Incidents on the Instagram Social Network. In Lecture Notes in Computer Science (Including Subseries Lecture Notes in Artificial Intelligence and Lecture Notes in Bioinformatics). Cham: Springer, vol. 9471, pp. 49-66. [CrossRef]

Huang, Xiuqin, Huimin Zhang, Mengchen Li, Jinan Wang, Ying Zhang, and Ran Tao. 2010. Mental Health, Personality, and Parental Rearing Styles of Adolescents with Internet Addiction Disorder. Cyberpsychology, Behavior, and Social Networking 13: 401-6. [CrossRef]

Jansen, Malte, Ulrich Schroeders, and Oliver Lüdtke. 2014. Academic Self-Concept in Science: Multidimensionality, Relations to Achievement Measures, and Gender Differences. Learning and Individual Differences 30: 11-21. [CrossRef]

Katzer, Catarina, Detlef Fetchenhauer, and Frank Belschak. 2009. Cyberbullying: Who Are the Victims? A Comparison of Victimization in Internet Chatrooms and Victimization in School. Journal of Media Psychology 21: 25-36. [CrossRef]

Khalaila, Rabia. 2015. The Relationship between Academic Self-Concept, Intrinsic Motivation, Test Anxiety, and Academic Achievement among Nursing Students: Mediating and Moderating Effects. Nurse Education Today 35: 432-38. [CrossRef] [PubMed]

Kowalski, Robin M., and Susan P. Limber. 2013. Psychological, Physical, and Academic Correlates of Cyberbullying and Traditional Bullying. Journal of Adolescent Health 53: 20. [CrossRef] [PubMed]

Kowalski, Robin M., Gary W. Giumetti, Amber N. Schroeder, and Micah R. Lattanner. 2014. Bullying in the Digital Age: A Critical Review and Meta-Analysis of Cyberbullying Research among Youth. Psychological Bulletin 140: 1073. [CrossRef] [PubMed]

Kowalski, Robin M., Susan P. Limber, and Annie McCord. 2018. A Developmental Approach to Cyberbullying: Prevalence and Protective Factors. Aggression and Violent Behavior. [CrossRef] 
Levant, Ronald F., Rosalie J. Hall, Christine M. Williams, and Nadia T. Hasan. 2009. Gender Differences in Alexithymia. Psychology of Men and Masculinity 10: 190. [CrossRef]

Litwiller, Brett J., and Amy M. Brausch. 2013. Cyber Bullying and Physical Bullying in Adolescent Suicide: The Role of Violent Behavior and Substance Use. Journal of Youth and Adolescence 42: 675-84. [CrossRef] [PubMed]

Livingstone, Sonia, Leslie Haddon, and Anke Görzig. 2011. Risks and Safety on the Internet: The Perspective of European Children: Full Findings and Policy Implications from the EU Kids Online Survey of 9-16 Year Olds and Their Parents in 25 Countries. EU Kids Online Network. London: LSE.

Martínez-Ferrer, Belén, Estefanía Estévez-López, and Teresa I Jiménez-Gutiérrez. 2003. Influencia Del Funcionamiento Familiar En La Conducta Disruptiva En Adolescentes [The Influence of Familily System in Adolescents' Disruptive Behaviour]. Encuentros En Psicología Social 1: 64-67.

Martínez Ferrer, Belén, David Moreno Ruiz, Luis Vicente Amador, and Jim Oxford. 2011. Victimización Escolar En Adolescentes. Un Análisis Desde La Perspectiva Ecológica [School Victimization Among Adolescents. An Analysis from an Ecological Perspective]. Psychosocial Intervention 20: 149-60. [CrossRef]

Martínez-Ferrer, Belén, David Moreno, and Gonzalo Musitu. 2018. Are Adolescents Engaged in the Problematic Use of Social Networking Sites More Involved in Peer Aggression and Victimization? Frontiers in Psychology. [CrossRef]

Martins, Maria José D., Ana Margarida Veiga Simão, Isabel Freire, Ana Paula Caetano, and Armanda Matos. 2016. Cyber-Victimization and Cyber- Aggression among Portuguese Adolescents: The Relation to Family Support and Family Rules. International Journal of Cyber Behavior, Psychology and Learning 6: 65-68. [CrossRef]

Moral Jiménez, María de la Villa, and Anastasio Ovejero Bernal. 2013. Percepción Del Clima Social Familiar y Actitudes Ante El Acoso Escolar En Adolescentes [Perception of Family Social Climate and Attitudes to Bullying in Adolescents]. European Journal of Investigation in Health, Psychology and Education 3: 149-60. [CrossRef]

Moreno, David, Estefanía Estévez, Sergio Murgui, and Gonzalo Musitu. 2009. Reputación Social y Violencia Relacional En Adolescentes: El Rol de La Soledad, La Autoestima y La Satisfacción Vital [Social Reputation and Relational Aggression in Adolescence. The Role of Loneliness, Self-Esteem and Life Satisfaction]. Psicothema 21: 537-42.

Musitu, Gonzalo, and Sofía Buelga. 2004. Desarrollo Comunitario y Potenciación (Empowerment) [Community Development and Empowerment]. In Introducción a La Psicologia Comunitaria. Edited by G. Musitu Ochoa, J. Herrero Olaizola, Leonor M. Cantera and Marisela Montenegro Martínez. Barcelona: UOC, pp. 167-95.

Musitu, Gonzalo, Teresa I. Jiménez, and Sergio Murgui. 2007. Funcionamiento Familiar, Autoestima y Consumo de Sustancias En Adolescentes: Un Modelo de Mediación [Family Functioning, Self-Esteem and Substance Use in Adolescents: A Model of Mediation]. Salud Publica de Mexico 49: 3-10. [CrossRef] [PubMed]

Navarro, Raúl, Santiago Yubero, and Elisa Larrañaga. 2015. Psychosocial Risk Factors for Involvement in Bullying Behaviors: Empirical Comparison Between Cyberbullying and Social Bullying Victims and Bullies. School Mental Health. [CrossRef]

Ortega-Barón, Jessica, Sofía Buelga, and María-Jesús Cava. 2016. The Influence of School Climate and Family Climate among Adolescents Victims of Cyberbullying. Comunicar 46: 57-65. [CrossRef]

Özdemir, Yalçin. 2014. Cyber Victimization and Adolescent Self-Esteem: The Role of Communication with Parents. Asian Journal of Social Psychology 17: 255-63. [CrossRef]

Peterson, N. Andrew. 2014. Empowerment Theory: Clarifying the Nature of Higher-Order Multidimensional Constructs. American Journal of Community Psychology 53: 96-108. [CrossRef] [PubMed]

Pons Diez, Xavier. 2010. La Aportación a La Psicología Social Del Interaccionismo Simbólico: Una Revisión Histórica [The Contribution of Symbolic Interactionism to Social Psychology: A Historical Review]. EduPsykhé 9: 23-41.

Santoro, Chiara, Belén Martínez-Ferrer, Carmen Monreal Gimeno, and Gonzalo Musitu. 2018. New Directions for Preventing Dating Violence in Adolescence: The Study of Gender Models. Frontiers in Psychology. [CrossRef]

Sasson, Hagit, Gustavo Mesch, Donna Cross, Amy Barnes, Alana Papageorgiou, Kate Hadwen, Lydia Hearn, and Leanne Lester. 2015. A Social-Ecological Framework for Understanding and Reducing Cyberbullying Behaviours. Aggression and Violent Behavior 23: 109-17. [CrossRef]

Serpe, Richard T., and Sheldon Stryker. 2011. The Symbolic Interactionist Perspective and Identity Theory. In Handbook of Identity Theory and Research. New York: Springer, pp. 225-48. [CrossRef] 
Shalin, Dmitri N. 2015. Making the Sociological Canon: The Battle over George Herbert Mead's Legacy. The American Sociologist 46: 313-40. [CrossRef]

Shavelson, Richard J., Judith J. Hubner, and George C. Stanton. 1976. Self-Concept: Validation of Construct Interpretations. Review of Educational Research 46: 407-41. [CrossRef]

Smilkstein, Gabriel, Clark Ashworth, and Dan Montano. 1982. Validity and Reliability of the Family APGAR as a Test of Family Function. The Journal of Family Practice 15: 303-11. [PubMed]

Song, Liyu. 2012. Service Utilization, Perceived Changes of Self, and Life Satisfaction Among Women Who Experienced Intimate Partner Abuse: The Mediation Effect of Empowerment. Journal of Interpersonal Violence 27: 1112-36. [CrossRef] [PubMed]

Stoll, Laurie Cooper, and Ray Block. 2015. Intersectionality and Cyberbullying: A Study of Cybervictimization in a Midwestern High School. Computers in Human Behavior 52: 387-97. [CrossRef]

Tokunaga, Robert S. 2010. Following You Home from School: A Critical Review and Synthesis of Research on Cyberbullying Victimization. Computers in Human Behavior 26: 277-87. [CrossRef]

Wachs, Sebastian, Gabriela Ksinan Jiskrova, Alexander T. Vazsonyi, Karsten D. Wolf, and Marianne Junger. 2016. A Cross-National Study of Direct and Indirect Effects of Cyberbullying on Cybergrooming Victimization via Self-Esteem. Psicología Educativa 22: 61-70. [CrossRef]

Watts, Lynette K., Jessyca Wagner, Benito Velasquez, and Phyllis I. Behrens. 2017. Cyberbullying in Higher Education: A Literature Review. Computers in Human Behavior. [CrossRef]

World Medical Association. 2013. Declaration of Helsinki World Medical Association Declaration of Helsinki Ethical Principles for Medical Research Involving Human Subjects. The Journal of the American Medical Association. [CrossRef]

Yubero Jimenez, Santiago, and Raúl Navarro Olivas. 2010. Socialización de Género [Gender Socialization]. In Intervención Social y Género. Madrid: Narcea, pp. 43-72.

(C) 2019 by the authors. Licensee MDPI, Basel, Switzerland. This article is an open access article distributed under the terms and conditions of the Creative Commons Attribution (CC BY) license (http:/ / creativecommons.org/licenses/by/4.0/). 


\title{
Article \\ Trainee Teachers' Perceptions on Cyberbullying in Educational Contexts
}

\author{
Carmen Yot-Domínguez ${ }^{1}$, María Dolores Guzmán Franco ${ }^{2}$ and Ana Duarte Hueros ${ }^{2, *}$ \\ 1 Department of Didactic and School Organization, Faculty of Education, University of Seville, C/Pirotecnia, \\ s/n, 41013 Sevilla, Spain; carmenyot@us.es \\ 2 Department of Pedagogy, Faculty of Education, Psychology and Sports Sciences, Avda. Tres de Marzo s/n, \\ University of Huelva, 21007 Huelva, Spain; maria.guzman@dedu.uhu.es \\ * Correspondence: duarte@uhu.es
}

Received: 31 October 2018; Accepted: 8 January 2019; Published: 11 January 2019

\begin{abstract}
This paper analyzes the perceptions of teachers in training regarding cyberbullying in schools. The objectives of the study were: to ascertain their perceptions regarding their concern and their commitment to cyberbullying, their agreement with the measures to address it in educational contexts, as well as the assessment of their capabilities to act and the training they have received and they would like to receive; to determine if the perceptions differ according to gender, age and degree pursued and if there are relationships between the perceptions; and, to define pre-service teachers' profiles based on perceptions. With a survey research design, 408 students from different undergraduate and graduate education-related degree programs at Spanish public universities participated. Findings highlight the coexistence of three different teacher in training profiles. All profiles exhibit a high level of concern and recognize cyberbullying as a problem. They strongly agree with all the proposed prevention and management measures. Two of the three profiles perceive themselves as highly confident and willing to respond. On the contrary, participants in the third profile do not feel confident enough to act and consider their training insufficient, coinciding with the second profile. The need to approach this issue in the initial training of future education professionals is a main conclusion.
\end{abstract}

Keywords: school coexistence; cyberbullying; education; family; victims; prevention; management; training; perceptions; pre-service teachers; teacher education

\section{Introduction}

Although bullying is a phenomenon that has always existed to a greater or lesser extent in schools, it currently casts a shadow over numerous children and adolescents whose health (in terms of social welfare, but also their psychological, physical and emotional well-being) and academic performance, among other basic aspects of their lives, are affected. The consequences of this problem may extend to later stages of life and development. As Musalem and Castro (2015) point out, adults seem to perceive bullying as a transitory problem, but this is not real since it is persistent and linked to other problems in children's lives, both in the short and long term.

The widespread use of ICTs among young people from a very early age is favoring the manifestation of new forms of risk behaviors in digital scenarios such as cyberbullying (Giménez Gualdo et al. 2018; Larrañaga et al. 2018). Cyberbullying has been defined as "willful and repeated harm inflicted through the use of computers, cell phones and other electronic devices" (Hinduja and Patchin 2009, p. 5). It has been considered a new form of traditional bullying, but with its own characteristics (Álvarez et al. 2011). Cyberbullying is not confined to a specific space. It expands easily and rapidly. It can occur in anonymity. In addition, victims are easily accessible while the possibility of empathy on the part of the aggressors towards them is unlikely. 
In the last decades, the progressive increase in cyberbullying cases has been evidenced in every country of the world (Garaigordobil 2011; Finkelhor et al. 2010). At the same time, interest and concern for the problem, not only in society but also in the academic community, has increased significantly.

Participation in traditional harassment as victims or as perpetrators is the most clearly predicting factor for cyberbullying and cybervictimization (Athanasiades et al. 2016). Cyberbullying is often an extension of traditional bullying, with bullying victims also facing this risk (Notar et al. 2013). In fact, as noted Kowalski et al. (2014), cyberbullying and traditional bullying overlap.

There are no totally defined motives for harassing or being harassed. Although in the scientific literature it has been mentioned a number of elements that could be understood as facilitators (Muñoz 2016). Navarro et al. $(2012,2018)$ highlight as risk factors the interpersonal difficulties people display in social interactions. Cappadocia et al. (2013) point to the higher levels of antisocial behaviors and fewer prosocial peer influences as two of the risks associated with cyberbullying. Cyberbullies show low adaptive psychosocial profiles (Buelga et al. 2015).

Regarding its consequences, Sourander et al. (2010) indicate that similar to children and young people affected by traditional bullying, all those involved in cyberbullying are likely to face challenges on multiple areas such as psychosomatic symptoms (headaches, abdominal pain, and sleeping difficulties), emotional and peer problems, and feelings of insecurity and non-cared by teachers. Giménez Gualdo et al. (2015) draw attention to the anguish that young people feel when they are harassed in traditional contexts and on the Internet. Ortega-Barón et al. (2016) have shown that victims of moderate to severe cyberbullying have significantly lower academic self-esteem than non-victimized adolescents, as well as a significantly lower sense of peer affiliation. In fact, as highlighted by Payne and Hutzell (2017), victims of any form of bullying are prone to avoidance behaviors towards school settings compared to students who have not experienced such victimization.

Despite the increased knowledge about the problem, numerous myths have spread, often unfoundedly, such as those analyzed by Sabella et al. (2013). For example, everyone knows what cyberbullying is; cyberbullying is a direct cause of suicide; or to avoid cyberbullying, all you have to do is turn off your computer or mobile phone. This last myth can contribute to the misguided decisions of some parents, teachers and guardians, who may be less familiar with information technologies and may take a markedly protective approach, such as the mere removal of the mobile phone, without considering other more effective measures (Hinduja and Patchin 2009).

It is necessary that families and teams of teachers understand what cyberbullying really is, and what measures are best suited to prevent and intervene in each case. It is also important to bear in mind that the reasons for the negative impact of intimidation vary according to the type of harassment, so coping strategies need to be adapted (Slonje et al. 2017).

At the international level, harassment has been a core area of research that has aroused concern as reflected in studies such as those by Baek and Bullock (2014), Cassidy et al. (2013) or Jimerson et al. (2010). In the national context, the first research on this topic was published at the beginning of the 21st century, coordinated by Ombudsman-UNICEF (2000). Since then, different works have drawn attention to a common concern: prevention, detection, intervention and management of this problem and its consequences. Thus, clear lines of intervention have been defined (Orjuela et al. 2013).

In a recent report by the Minors Ombudsman from the Andalusian Parliament (Parliament of Andalusia 2017), the importance of having teachers who take responsibility for prevention and response in cyberbullying situations is emphasized. They must act coordinated with health and social service professionals. In order to do this effectively, a strong initial training and continuous professional development dealing with cyberbullying is fundamental.

In our context, Álvarez et al. (2010a) analyze the lack of training displayed by teachers in initial training in their last year of studies at the University of Oviedo, in the face of school violence. The perception that they are not sufficiently prepared to respond effectively to bullying was widespread among pre-service teachers, coinciding with previous research findings (Ryan and Kariuki 2011), even 
observing a greater degree of ignorance than in other studies, and depending on the educational level for which these future teachers are being trained.

Both undergraduate and graduate education students display deficiencies that are evidenced when they are questioned about their acquired competencies to deal with cyberbullying as well as when discussing their degree of satisfaction with the training received (Álvarez et al. 2010b; Bauman and Del Río 2005; Yanes and Ries 2014). Therefore, a review of education university degree programs is necessary to include harassment, bullying and cyberbullying in initial training (Patchin and Hinduja 2006; Ryan et al. 2011).

However, this training should extend beyond the initial stages of teacher education. In this sense, the Ministry of Education, Culture and Sports, in coordination with autonomous communities, institutions, organizations, and a team of experts, launched the Strategic Plan for School Coexistence in 2015, in line with the current law that regulates education in Spain. This is an attempt to make schools safe and non-violent spaces. One of the pledges that schools must make is to become a place of respect. It is imperative to create a climate where students can only grow and coexist safely, without shadows, frustration or suffering. In order to do this, teacher training is highlighted as a key element for achieving this goal. For this reason, there is an incentive to promote teacher professional development in this area (in collaboration with universities, schools and other stakeholders that constitute educational communities) through the dialogue-based construction of knowledge.

As Boulton et al. (2013) point out, teachers have a vital role. And the reality is that victims do not consider teachers as capable of solving harassment situations (Gradinger et al. 2010; Ortega-Barón et al. 2016). Also, teachers have a limited perception of their ability to resolve conflicts (Abreu and Kenny 2017). DeSmet et al. (2015) confirmed that the large majority of teachers do not appropriately handle cyberbullying.

In recent times, research studies have centered on teachers' view of cyberbullying: how they see this phenomenon, what strategies they consider most useful to prevent it, their agreement with response measures, etc. The growing interest in their understanding arises, among other reasons, because differences in students' perceptions of the problem have been detected. These differences could further explain the gaps and dissatisfactions in their performance. There are discrepancies beyond their conceptualization of cyberbullying (Compton et al. 2014). Baraldsnes (2015) evidenced that even teachers' and pupils' perceptions regarding cyberbullying frequency are quite different. As a result, there have been successive studies, although they are scarce today, involving in-service teachers and pre-service teachers.

In-service teachers are concerned about cyberbullying (Eden et al. 2013). The most common type of cyberbullying they perceive is the circulation of embarrassing content (Huang and Chou 2013). Teachers disagree with the disregard of cyberbullying when it occurs inside the school and are more determined towards the following prevention strategies: reinforcing the role of bystanders, enriching classrooms with anti-bully lessons, and building character (Ghamrawi et al. 2016). Moreover, the strategies teachers perceive as most helpful in addressing cyberbullying (Stauffer et al. 2012) include increasing parental involvement and warning students about consequences for cyberbullying.

Pre-service teachers also display awareness of cyberbullying (Monks et al. 2016). They believe that cyberbullying is a problem in schools that affects students and teachers (Ryan et al. 2011). They are aware of the negative effects of cyberbullying on student lives (Yilmaz 2010). Although in the study carried out by Craig et al. (2011), taking as a sample teachers in the first years of initial training, a different way of understanding bullying is observed, and therefore of facing it, considering bullying of the homophobic, relational and cybernetic type to be less serious and problematic than physical bullying at school. These discrepancies seem to be related to issues such as the greater/lesser evidence of harassment, the lack of preparation of teachers in training to deal with this type of problem, and their previous harassment experiences.

Lester et al. (2018) was concerned with analyzing the incidence of age in perceptions. Age had not been taken into consideration in previous studies. They found distinct differences between pre-service 
teachers under and over 25 years of age. Specifically, pre-service teachers over the age of 25 have more favorable attitudes towards preventing bullying in schools, using proactive and less punitive incident management strategies and are more likely to believe students can change their behavior.

In contrast, gender has been understood as a source of variation regarding perceptions of teachers in training in different studies. From them we know that female pre-service teachers perceive bullying and cyberbullying in general as more serious than male ones and are more persuaded about the effects of cyberbullying (Craig et al. 2011; Yilmaz 2010). The only study, however, that yields extensive results is that of Yilmaz (2010). It states that gender also affects the perception of training. Male pre-service teachers feel more confident in identifying and managing cyberbullying as opposed to their female counterparts.

Generally, pre-service teachers report they are not skilled to identify and manage cyberbullying (Lester et al. 2018) and not prepared adequately (Ryan and Kariuki 2011; Ryan et al. 2011). However, there are studies that question generalization. In the work of Spears et al. (2015) pre-service teachers demonstrate high levels of self-efficacy with regard to addressing bullying and cyberbullying and are well prepared. In the same way, there are others that raise doubts about the real degree of awareness among teachers in training. According to Li (2008), preservice teachers are not aware the significance of this problem. In Li's study, although pre-service teachers display an understanding of the significant effects of cyberbullying on children and are concerned about cyberbullying, they do not think it is a problem in our schools.

After a thorough review of literature, we find that the research done is insufficient. We observe that findings about this topic are not conclusive and more research is warranted to answer numerous questions. Efforts should be made to differentiate teachers in training according to their perceptions. It is also important to clarify the incidence of gender and to analyze if the age or the specific degree pursued influences perceptions. This last variable has not been considered in previous studies and in our context it is relevant because the training that teachers receive is differentiated according to whether they are teachers of early childhood, primary or secondary education. But we must also overcome the descriptive character of the analyses and pause to examine the interaction between perceptions.

\section{Objectives and Research Problems}

With this study we intend to approach the perspective of teachers in training about cyberbullying in schools. We will address their perceptions about the relevance of the problem and the appropriateness of the response. We will ascertain, on the one hand, whether pre-service teachers see themselves prepared to act against cyberbullying as future professionals and, on the other hand, the assessment they make of the training they have received and they would like to receive. We will analyze whether perceptions of cyberbullying in educational settings expressed by teachers in training vary according to gender, age and degree pursued. We will examine pre-service teacher clusters related to their perceptions.

Thus, our research questions are the following:

1. Do teachers in training recognize cyberbullying as a current problem in education? Are they concerned by it?

2. How prepared do teachers in training feel to identify and manage cyberbullying situations? Are they willing to intervene? Does their level of preparation determine their intentions?

3. What is the degree of agreement of teachers in training with the response to cyberbullying in schools? Are pre-service teachers sensitized to act in coordination with families?

4. Do they feel that cyberbullying plays a role in their training programs? Are they interested in cyberbullying as academic content?

5. Do these perceptions of teachers in training change according to gender, age or degree pursued? Do their perceptions relate to each other? 
6. Are there different teacher in training profiles according to their perceptions towards cyberbullying?

In particular, the objectives set out in this research study were:

- To inquire about the perceptions of teachers in training about:

Their recognition of cyberbullying in schools and their concern for it.

Their ability to identify and respond to cases of cyberbullying, as well as their interest in intervening.

Their agreement with the measures to prevent, detect and respond to cyberbullying in schools.

Their initial training and their perceived need for specialization in the subject.

- To analyze whether the pre-service teachers' perceptions differ according to gender, age and degree pursued.

- To determine whether the perceptions of teachers in training correlate.

- To establish different profiles of teachers in training according to their manifested perceptions.

\section{Method}

\subsection{Participants}

A total of 408 teachers in training participated in the study by answering a questionnaire. Of these, $85.8 \%$ are women. $35.5 \%$ are under the age of 20 and $47.5 \%$ are between the ages of 21 and $25.45 .8 \%$ study at the University of Huelva and $32.8 \%$ at the University of Malaga. In this regard, it is worth noting that all participants are enrolled in different Andalusian public universities (Seville, Granada and Cadiz, as well as Huelva and Malaga), except for $9.8 \%$ who belong to the University of Castilla la Mancha. $51 \%$ of the participants are pursuing the undergraduate program in Primary Education, $34.3 \%$ the Early Childhood Education program and 14.5\% are enrolled in the Secondary Education Master's program. $28.2 \%$ of the students are attending the first year of one of the two undergraduate degree programs, $10 \%$ the second year and $23 \%$ are enrolled in the third year, and $22.1 \%$ in the fourth year of the program.

\subsection{Research Instrument}

The research was conducted using a quantitative survey approach. Data collection consisted of a survey validated and reused in other contexts besides Spain. The instrument was developed by Li (2008), based on a prior survey on teachers' attitudes towards bullying (Siu 2004) and applied in other studies, such as those by Ryan et al. (2011) or Eden et al. (2013).

In this study, the 22 items from the original survey were maintained, adapting them to the Spanish educational context as instructed by qualified educational experts. Thus, for example, the reference in one of the items to surveys as an information collection instrument for those affected by cyberbullying was substituted by the interview technique. Also, explicit allusions to the School Board or the Coexistence Commission are included in various items. Also, the 5-point Likert scale was used to assess the suitability of each item.

Li (2008) had already submitted the instrument to a multidisciplinary panel of experts. Five reviewers rated the appropriateness of items by assigning values of relevant, unable to decide or not relevant. In light of the findings, Li determined that the content validity was good. However, university professors specialized in educational research methodology and the subject matter reviewed our adaptation and translation of the survey from English.

After its review, the improvements suggested by the reviewers were incorporated. The instrument was uploaded to the online poll application "Opina", a platform available to University of Seville's teaching and research personnel. It was directly distributed to student representative at the different 
universities, for their distribution to the rest of the student body. The sample was thus non-probabilistic and accidental.

The "Survey on cyberbullying in education and perceptions of teachers in initial training" was comprised by a first series of demographic questions (gender, age, degree enrolled and year, university degree if any, and university where one attended), which were used to collect descriptive information from the sample, and a total of 22 items that had to be evaluated by those polled, using a 5 point Likert scale (from 1, or completely disagree, to 5, completely agree), plus the additional response option of Do not know / No response (see Appendix A). The Alpha coefficient of internal reliability for the instrument in our study was 0.74. With Li (2008) and Eden et al. (2013), the coefficient reached 0.88.

The instrument was internally organized into four indexes according to the adaptation of Eden et al. (2013) to gather information from in-service teachers. The four indexes were:

A. Concern about cyberbullying. The first 3 items allow us to inquire about the impression and degree of concern that students have about the problem. For example: "I believe that cyberbullying is a current educational problem", or "I am concerned about cyberbullying in education".

B. Self-confidence and intention to act when faced with cyberbullying. The students' perception of their current ability to identify and respond to cyberbullying cases and their interest in intervening is reflected in 3 items. Among them: "I am able to manage cyberbullying situations".

C. Agreement with action measures against cyberbullying. The opinion on the required actions at school and classroom level and the handling of cyberbullying by families and society is addressed with 13 items. Among them: "I think that the schools should sensitize families on the importance of the role they play in the prevention of cyberbullying" or "I consider it necessary to devote efforts to the professional development of teachers favoring their training in cyberbullying".

D. Assessment of initial training. Finally, 3 items collect the students' assessment of the attention given to the problem in initial teacher training and their perceived need for specialization. Among them: "In my studies (Early Childhood Education Degree, Primary Education Degree or Secondary Education Masters as appropriate) I am being trained to manage cyberbullying situations".

\subsection{Data Analysis Procedure}

The data was exported directly from the polling service "Opina" into an Excel spreadsheet, which was imported into IBM SPSS Statistics for analysis. In SPSS, the data set was purged, eliminating unsuccessful response attempts and correcting the type of variable and measure assigned by default to each of the items.

After analyzing the responses given to each of the items, based on a basic recount of the frequencies, a one-way analysis of variance (ANOVA) was conducted to detect possible differences according to the different categorical values. These were: gender, age and degree pursued. When homoscedasticity was not found (with Levene's test), the corresponding non-parametric tests were used (Mann-Whitney U test and Kruskal-Wallis H test).

Afterwards, four new variables were created, each one responding to the indexes (Concern about cyberbullying, Confidence and intention to act when faced with cyberbullying, Agreement with the action measures when facing cyberbullying, Assessment of the initial training), calculating them on the basis of the responses provided to the items that comprised each particular index. The variables in question were designated as: Concern, Confidence, Agreement and Assessment. In order to determine if these variables correlated bilaterally with each other, Pearson's correlation coefficient was calculated. Also, the different items in the indexes "Concern about cyberbullying", "Confidence and intention to act when faced with cyberbullying", "Assessment of the initial training" and a selection of them were also correlated with "Agreement with the measures of action when facing cyberbullying". 
Lastly, a k-means cluster analysis was performed taking into account the four variables related to the indexes and the entire sample. That is, no case was removed from analysis. The iterate and classify method was used. The number of case clusters was fixed at three, according to a hierarchical cluster analysis performed previously with the Ward method. Convergence was achieved in the eighth iteration because no further representative change in cluster centers was possible. The minimum distance between the initial centers was 3.853 .

\section{Results}

\subsection{Perceptions of the Teachers in Training}

Almost $80 \%$ of teachers in training $(79.4 \%)$ strongly agree and are concerned about cyberbullying in education. Significant differences were found between men and women (sig. 0.000). While $82.6 \%$ of women are absolutely alarmed, $60.3 \%$ of men display this level of concern. Women report greater concern.

The large majority of future teachers $(87.5 \%)$ agree that cyberbullying is a current problem in education, although only $55.9 \%$ of them are fully convinced of this. $63.2 \%$ completely agree and are certain and $24.8 \%$ are aware that victims of cyberbullying can now be found in classrooms. The perception of both issues differs with age (sig. 0.046; sig. 0.032). Most of the subjects in the different age groups strongly agree with them except those aged between 36 and 40 (see Table 1). Also, according to the degree program, there are differences with respect to the last perception. Thus, compared to $55.7 \%$ of students in the Early Childhood Education undergraduate degree who completely agree that in schools centers there are students suffering cyberbullying, $76.3 \%$ of those in the Secondary Master's degree share the same perception.

The results shed light on the solid agreement that exists on the ideal nature of prevention and intervention measures when faced with cyberbullying $(\mathrm{M}=4.57)$. Polled participants stated that they agree or completely agree with almost all the cyberbullying prevention and management actions in school (see Appendix B). Among them, we find the statement "I think that all teachers should know the protocol of action in cases of bullying" is regarded as the most important $(2.7 \%$ agree and $96.6 \%$ completely agree). However, it is interesting to note that only $67.6 \%$ of the teachers in training completely agree (although $24.8 \%$ were in agreement) with the statement "I believe that teachers should integrate into the curriculum how to make responsible use of technologies and what their risks are" or that only $65.9 \%$ completely agree (with an additional $30 \%$ in agreement) with the statement "I believe that teachers should organize specific classroom activities to raise awareness and provide training in cyberbullying".

The interpretation of these three measures differs with respect to gender (sig. 0.002; sig. 0.011; sig. 0.27). While $97.7 \%$ of the women were completely convinced about the first measure, $89.7 \%$ of the men were. As compared to the $70 \%$ and $68.3 \%$ of women who completely believed in the need of the second and third action, respectively, $53.4 \%$ and $51.7 \%$ of the men found themselves in the same position.

There are two items for which participants tend towards a neutral valuation, which is why we consider further studies necessary to understand this trend. These referred to the statement "I understand that interviews are a useful tool for students to express themselves about their cyberbullying experiences" ( $2.7 \%$ did not answer, and $27.5 \%$ were placed in intermediate values of the scale) and the statement "I value positively that in institutions the Coexistence Commission should be informed of situations of cyberbullying and the disciplinary measures taken" (24.5\% did not answer, and $29.9 \%$ were found in intermediate values of the scale). With respect to the first, differences were found in relation to the degree program (sig. 0.18). As observed in Table 2, the students enrolled in the Early Childhood Education Degree and the Primary Education Degree were less convinced as compared to those in the Master's in Secondary School Education. 
Soc. Sci. 2019, 8, 21

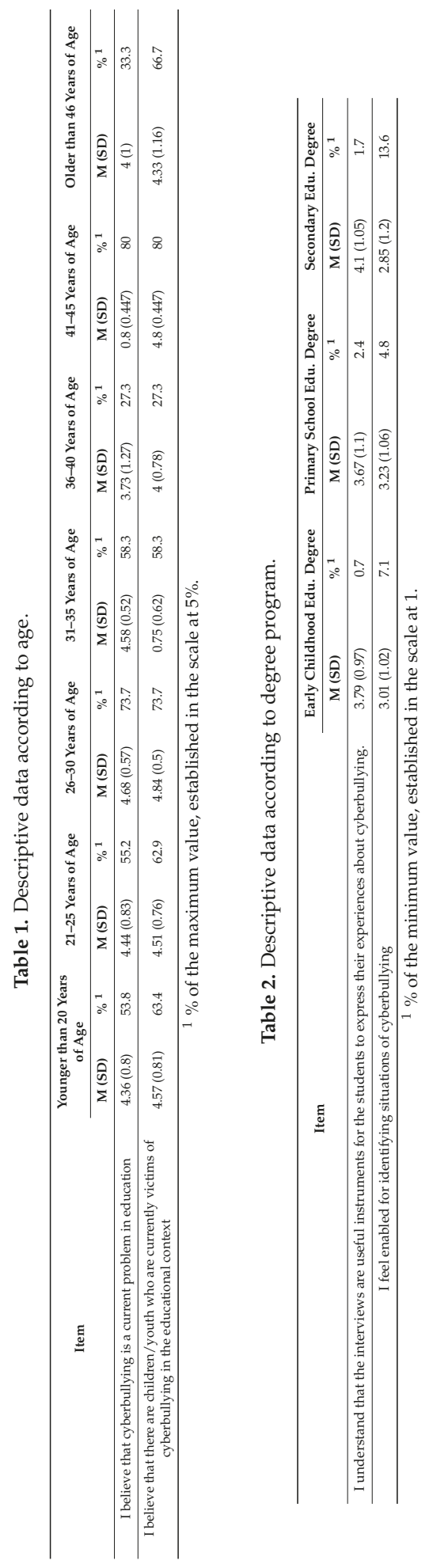


In terms of self-confidence, the results reveal that teachers in training don't consider themselves qualified. Only $7.4 \%$ completely agree with the statement "I feel qualified to identify situations of cyberbullying" and $3.7 \%$ of them completely agree with the statement "I am able to manage cyberbullying situations". Meanwhile, $42.6 \%$ and $42.9 \%$ respectively are at the mid-point of the scale. The self-perception of their ability to detect cyberbullying situations differs based on the degree pursued (sig. 0.030). Those enrolled in the Secondary Education Master's perceive themselves as the least qualified (see Table 2).

The average value of the index that measures satisfaction with the training they are receiving in the subject as future teachers, and the one they would like, demonstrates that it is low $(\mathrm{M}=3.23)$ (see Table 3). Data shows that $54.2 \%$ and $20.6 \%$ of the subjects either disagree or completely disagree that in their studies they are being prepared to manage cyberbullying situations. Moreover, $16.7 \%$ stated that cyberbullying is not the content to which they give the greatest importance among those that they would like to see addressed (or would have liked to develop) in their degree program. Only $7.4 \%$ completely agree with this. The general perception of cyberbullying in the set of contents that they would like to study in depth is not the same based on gender (sig. 0.042). 15.5\% of men completely disagree that this is the topic they would most like to address compared to $3.7 \%$ of women. Similarly, compared to $3.4 \%$ of men, $8 \%$ of women do agree strongly with the statement.

Table 3. Descriptive statistics of the different indexes and correlations.

\begin{tabular}{ccccccc}
\hline \multirow{2}{*}{ Index } & \multirow{2}{*}{$\mathbf{M}$} & SD & \multicolumn{4}{c}{ Pearson } \\
\cline { 4 - 7 } & & & Concern & Confidence & Agreement & Assessment \\
\hline Concern & 4.57 & 54 & - & & & \\
Confidence & 3.56 & 0.74 & $0.125^{*}$ & & & \\
Agreement & 4.57 & 0.36 & $0.438^{* *}$ & $0.142^{* *}$ & & \\
Assessment & 3.23 & 0.69 & $0.119^{*}$ & $0.283^{* *}$ & $0.1499^{* *}$ & \\
\hline & & & $* 0.05^{* *} p<0.01$.
\end{tabular}

\subsection{Links between the Perceptions of the Teachers in Training}

As observed on Table 3, between concern about cyberbullying and agreement with the action measures, there is a moderate linear relationship. The more recognition cyberbullying got as a current problem that required the school's attention, the greater the appreciation was for the measures of prevention, diagnosis, intervention and monitoring, which could be promoted in the education sphere. The correlations between the other possible index combination pairs were low but significant.

The differences shown by subjects in the item that specifically asks them to state agreement or concern about cyberbullying account for $9.06 \%$ of the differences in the intention expressed by subjects to intervene immediately if they knew that cases of cyberbullying were occurring $(r=0.301)$; and $13.25 \%$ of the differences in the desire for their training programs to address cyberbullying in depth $(r=0.364)$ (see Table 4$)$.

The intention to respond to cyberbullying correlates with virtually all the measures included in the questionnaire. The one that is most strongly related is the one that alludes to the fact that the educational community must be involved and committed in the fight against cyberbullying in schools, although the relationship is moderate $(r=0.301 p<0.01)$.

The correlation of the intention to act with the perception of the ability to identify situations of cyberbullying and the ability to manage them is significant but low. The coefficients of determination $\left(r^{2}\right)$ are: 0.015 and 0.02 , respectively. The bilateral relationship of the intention to act in cyberbullying situations is also low with the belief that cyberbullying is a current problem and with the perception that children and youth are currently suffering cyberbullying in the networks. Moreover, both abilities $(r=0.509)$ and both beliefs $(r=0.467)$ were moderately correlated. 


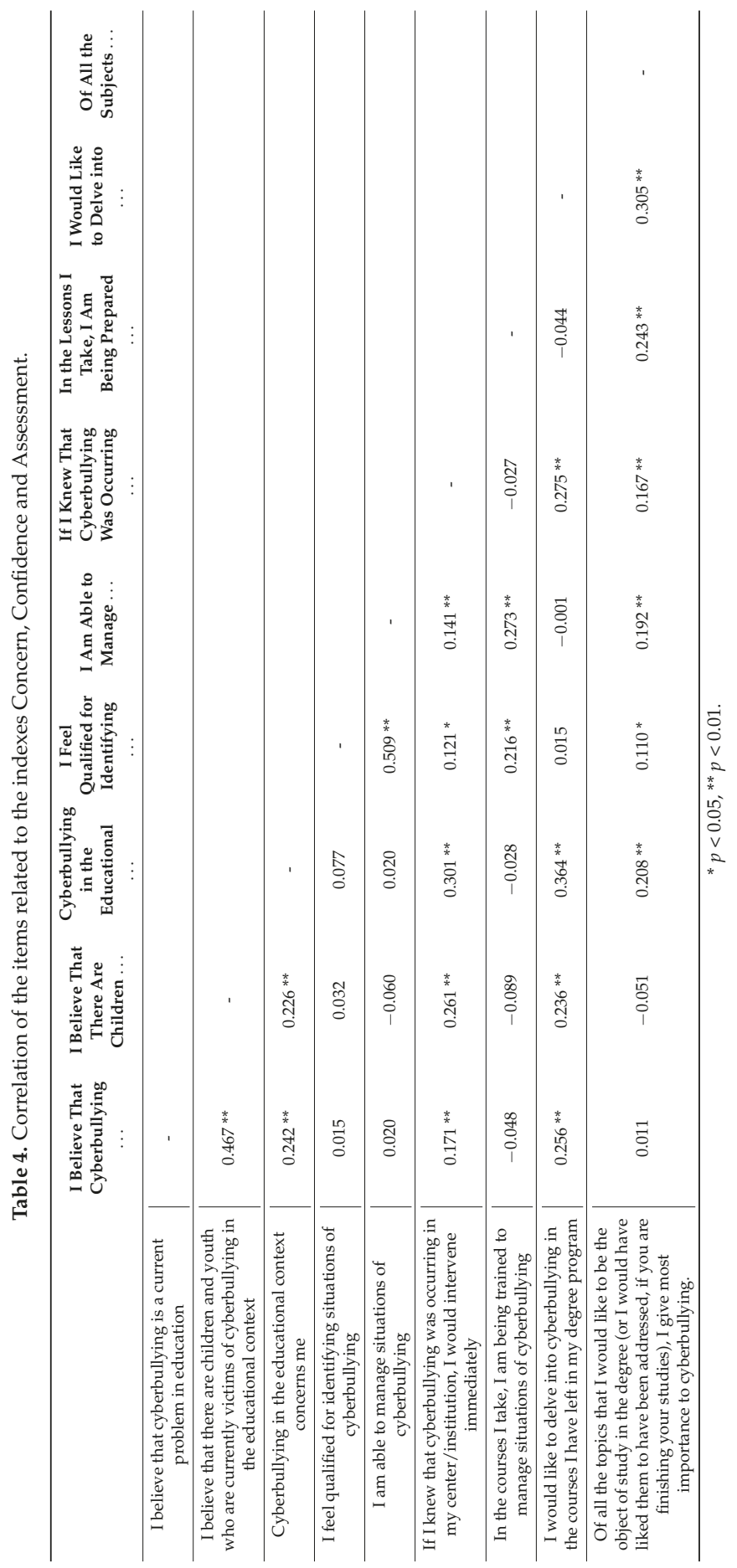




\subsection{Profiles of Teachers in Training}

Three profiles could be differentiated among the teachers in training, which were identified as (see Table 5):

Table 5. Descriptive statistics of the indexes according to profile.

\begin{tabular}{ccccccccc}
\hline & \multicolumn{2}{c}{ Index A } & \multicolumn{2}{c}{ Index B } & \multicolumn{2}{c}{ Index C } & \multicolumn{2}{c}{ Index D } \\
\cline { 2 - 9 } & M & SD & M & SD & M & SD & M & SD \\
\hline Trained & 4.58 & 0.5 & 3.9 & 0.52 & 4.62 & 0.32 & 4.06 & 0.43 \\
Competent & 4.64 & 0.46 & 3.89 & 0.49 & 4.57 & 0.33 & 2.92 & 0.42 \\
Aware & 4.45 & 0.66 & 2.64 & 0.46 & 4.5 & 0.44 & 2.89 & 0.51 \\
\hline
\end{tabular}

Profile 1. Trained. They represent $27.8 \%$ of future teachers. They are highly concerned about cyberbullying. They decidedly recognize the appropriateness of measures to approach cyberbullying in educational contexts. They perceive themselves as qualified and willing to respond to cyberbullying situations. They display satisfaction with their initial training in the subject and would even like to delve deeper into it.

Profile 2. Competent. They are $45.7 \%$ of the participants. They are highly concerned about cyberbullying. They decidedly recognize the appropriateness of measures to approach cyberbullying in educational contexts. They perceive themselves as qualified and willing to respond to cyberbullying situations in school contexts, but they are not satisfied with their initial training.

Profile 3. Aware. They constitute the smallest conglomerate (26.5\%). They are highly concerned about cyberbullying, they decidedly recognize the appropriateness of measures to approach cyberbullying in educational contexts. But they do not feel qualified to respond to a cyberbullying situation nor satisfied with their training in this subject.

\section{Discussion and Conclusions}

Bullying and cyberbullying perceptions held by both teachers in initial training and in-service teachers, has been an object of study in the last few years (Craig et al. 2011; Eden et al. 2013; Ghamrawi et al. 2016; Gorsek and Cunningham 2014; Huang and Chou 2013; Marczak and Coyne 2016; Ryan and Kariuki 2011), which makes it possible to compare the results obtained.

The need for the academic community to assess the awareness of educators regarding their responsibility and role in cyberbullying situations justifies the increasing interest to analyze their perceptions related to this issue. Research points to high levels of awareness alongside quality training as a fundamental basis to achieve effective prevention and management performances in cyberbullying situations (Ayas and Horzum 2011; Campbell et al. 2018).

Our study is based on the work of Li (2008) in Canada and Yilmaz (2010) in Turkey. But, with it, we advance the understanding on the perceptions of teachers in training regarding cyberbullying in educational contexts. We have delved into their perceptions, inquiring about the effects of variables such as gender (in line with findings from previous research), age and degree pursued. This last variable had not been previously considered. We have also analyzed the existing interactions between different participants' perceptions. Finally, three different profiles were identified and described based on four indexes. These were concern about cyberbullying, self-confidence and intention to act when faced with cyberbullying, agreement with action measures, and finally assessment of initial training.

In-service teachers see bullying as a serious problem (Craig et al. 2011) and recognize its negative impact on students (Ghamrawi et al. 2016). Similarly, teachers in training perceive cyberbullying as a current problem in schools (Ryan and Kariuki 2011; Ryan et al. 2011). In our study this perception is confirmed as well as it is corroborated that future teachers perceive that there are children and young people who are victims of cyberbullying in classrooms. According to our findings, these perceptions correlate and differ with the age variable, with younger participants exhibiting higher levels of concern. 
Degree pursued is another variable that correlates with their awareness of cyberbullying situations, with a higher awareness in participants from secondary education programs. These findings could be explained by subjects taking into account the age of their future students and their proportion of use of technological devices, by means of which they could experience cyberbullying situations. Along the same line, Eden et al. (2013) concluded that student age affected the teachers' level of concern about cyberbullying.

Yilmaz (2010) found that among teachers in training, female teachers displayed a higher awareness than their male counterparts regarding cyberbullying as an educational problem today. Our analysis does not support these findings. Moreover, in the present study, regardless of gender all participants exhibit concern, with female participants displaying higher levels of concern than male participants.

Previous studies have shown, among other things, the lack of teacher knowledge regarding the possible cyberbullying prevention strategies (Ghamrawi et al. 2016) or the hesitation they have when managing incidents (Huang and Chou 2013) and the inability of properly managing situations of cyberbullying (DeSmet et al. 2015). By extension, the future teachers in our study, just as the ones from Ryan and Kariuki (2011), have displayed self-doubt in their abilities to detect and manage cyberbullying. In spite of this, the surveyed subjects would attempt to take action when faced with this problem. We cannot firmly argue from our analysis that the greater the capacity, the greater the intention to intervene, or vice versa. Intention is related, in part, to concern. The other factors that would explain intention to intervene should be addressed in subsequent studies.

However, what we can point out the need to incorporate (or reinforce) training opportunities in this area in initial teacher training. In our context, teachers in training believe that within their curricula they are not being prepared to prevent or deal with cyberbullying (Álvarez et al. 2010a). Thus, according to Redmond et al. (2018), within the framework of each degree, the intentional design of authentic learning experiences must be undertaken in order to favor a deeper understanding of the subject, improve the competencies of future teachers with regard to their approach to cyberbullying situations, and increase their confidence. And, in the words of these authors, as their trainers, it is our responsibility to bring them closer to educational practices that reduce cyberbullying. An important formative strategy would be the establishment of networks between in-training teachers and experienced ones where they can share and exchange viewpoints, reflect on measures, analyze shared proposals, etc. (Yilmaz 2010).

Let us bear in mind that, as Ho et al. (2017) point out, increasing the knowledge of children and adolescents about the risks of social networks, they become more prudent in their social network activity and more aware of the negative consequences that can derive from inappropriate behavior. Also, if they develop as resilient young people, we mitigate the harmful effects of possible intimidation (Hinduja and Patchin 2017). Thus, among others, schools must promote awareness of the consequences of cyberbullying and encourage empathy towards those affected (Notar et al. 2013). And, specifically from the curriculum viewpoint, students must be empowered in the use of information and communication technologies and their digital competence (Cassidy et al. 2013).

Let us return to a question highlighted by our results. Not all pre-service teachers are completely convinced of the need to incorporate into the curriculum the responsible and safe use of technologies or to implement learning activities to raise awareness of the problem. Teacher educators must lead to improve the perception of these measures, about which women are most in favour. In the designated line, these measures may not be put in doubt.

Huang and Chou (2013) found that only a small percentage of in-service teachers offer anti-cyberbullying instruction and guidance before or after cyberbullying happens to curtail future acts of cyberbullying. According to these authors, this is due to the fact that teachers lack the knowledge on how to approach it. Our study's findings support this assumption. A small part of participants do not feel qualified to deal with cyberbullying situations (profile 3). In addition, a high number of future teachers are not satisfied with their training on the issue (profiles 2 and 3). The reasons for that perception will have to be approached in future studies. 
Participants from the Master's in Secondary Education exhibit the lowest levels in perceived self-confidence. These findings reflect a scarce training in the topic of cyberbullying that may be related to the issues raised by Montoro and Ballesteros-Moscosio (2016) regarding the design of the program itself. These authors describe how the promotion of school coexistence and conflict resolution were considered among the competencies, but none of them directly referred to bullying, and less if it took place in a virtual context. This emphasizes the importance of reviewing current teacher education programs to include the subject in the initial training of future education professionals.

Likewise, it is necessary to diagnose pre-service teachers' learning needs and know in depth their interests. Let us bear in mind that, according to the pre-service teachers of our study, not only cyberbullying is not being currently addressed in their programs but that also teachers do not consider it as priority academic content. Unlike the found by Ryan and Kariuki (2011), future teachers in our study do not perceive cyberbullying as the issue that most would like to see addressed (or would have wanted to address) in their degree. This perception is more characteristic of men than of women. Women are more concerned than men about cyberbullying and also are more in favour of cyberbullying as academic content. Concern correlates positively with the desire to learn about cyberbullying. Eden et al. (2013) also showed that there is interaction between the importance of learning about cyberbullying and in-service teachers' concern.

Precisely, the determining factors that allow us to differentiate up to three profiles of the teachers in training are the posture they adopt about their initial training, and the self-evaluation they make about their abilities. DeSmet et al. (2015) defined four secondary school educator clusters, on the basis of teachers' perceptions but also their practices.

In our case, three profiles of pre-service teachers have been differentiated. No other previous study has advanced knowledge in this line. This is, therefore, the first classification of teacher-in-training profiles available.

There are practically no differences between the profiles with regard to the degree of agreement with the measures adopted in schools (and cited in our data collection instrument). Among these, it is worth highlighting an action with which the future teachers completely agree. This refers to the fact that schools must make families aware of the importance they play in the prevention of cyberbullying. To prevent and deal with cyberbullying, teachers and families need to understand the nature of the problem and recognize their role. Educational measures to deal with cyberbullying include providing education to the students about the responsible use of the technologies, promoting professional development for teachers on the issue and supporting families so that they could also contribute to it (Beale and Hall 2007).

Teachers recognize that the involvement of parents in prevention must be encouraged, and for this to happen, families must be made aware of the problem. According to Stauffer et al. (2012), schools and parents should be encouraged to band together as a united force in preventing and addressing student cyberbullying. The creation of collaborative work between families and educators is needed, to overcome any type of bullying, either using the information technologies or not, inside as well as outside the school. Efforts should also be coordinated with students (Giménez Gualdo et al. 2018). Teachers, students and parents need to discuss in each school what constitutes cyberbullying and how to combat it (Compton et al. 2014).

Eden et al. (2013) found strong correlations between school commitments and in-service teachers' concern about cyberbullying. In relation to in-training teachers, our analysis confirms the existence of this correlation. The degree of agreement with prevention, detection, and intervention measures increases as their perception that cyberbullying is an educational problem increases, as well as their intention to seek an answer to the problem increases, also if their intention to seek an answer to the problem increases.

Of all the measures included in our questionnaire, there are two on which teachers do not position themselves. These are concerned with the usefulness of interviews as a means of gathering information 
from students suffering from cyberbullying and the importance of the role of Coexistence Commissions in centers to address cyberbullying situations.

Both measures are promoted in our country. On the one hand, interviews serve to collect direct information and assess the situation of cyberbullying. Their usefulness has been observed by Luengo Latorre (2014). In the Save the Children's protocol model for action against harassment and cyberbullying (Sastre 2016), its functionality is clearly defined. On the other hand, the role of Coexistence Commissions is considered decisive in promoting the design and development of information and awareness actions in the educational community (Luengo Latorre 2011). Based on the findings of our study, it is worth questioning whether these are due to the pre-service teachers' lack of knowledge, which would be further evidence of the need to improve initial training.

May this work serve to promote reflection. The perceptions of future teachers have been addressed in depth. We have defined a classification of professionals that allows us to highlight the presence of a group of future teachers who do not consider themselves trained. The suggestions point to the urgency of revising the training. We hope that teacher educators and university leaders will become aware of this.

It should be indicated that this study requires a greater deepening from a more qualitative and global perspective of the objectives; not only focusing on the perceptions that exclusively rely on self-reports, but also through interviews or discussion groups and also encompassing other sectors such as in-service teachers, families, social services, and other health professionals.

Author Contributions: Conceptualization, C.Y.-D. and M.D.G.F. and A.D.H.; methodology, C.Y.-D. and M.D.G.F.; formal analysis, C.Y.-D.; writing-original draft preparation, C.Y.-D. and M.D.G.F.; writing-review and editing, M.D.G.F. and A.D.H.; supervision, M.D.G.F. and A.D.H.

Funding: This work is supported by the R+D+I Project entitled Media competences of citizens in emerging digital media (smartphones and tablets): Innovative practices and educational strategies in multiple contexts, EDU2015-64015-C3-1-R (MINECO/FEDER), financed by the European Regional Development Fund (ERDF) and Ministry of Economy and Competitiveness of Spain.

Acknowledgments: The authors would like to express their appreciation to their colleagues who made suggestions for modification of the questionnaire and all respondents who participated in the survey. English Edition done by Daniela Jaramillo Dent.

Conflicts of Interest: The authors declare no conflict of interest.

\section{Appendix A}

Inventory on cyberbullying in education and perceptions of teachers in initial training.

A1. I believe that cyberbullying is a current educational problem.

A2. I believe that there are children and young people who are currently victims of cyberbullying in the educational context.

A3. I am concerned about cyberbullying in education

B1. I feel qualified to identify situations of cyberbullying

B2. I am able to manage cyberbullying situations

B3. If I knew that cyberbullying was taking place in my center/institution, I would intervene immediately.

C1. I think that all teachers should know the protocol of action in cases of bullying.

C2. I think it is necessary to devote efforts to the professional development of teachers, fostering their training in cyberbullying.

C3. I believe that teachers should integrate into the curriculum how to make responsible use of technologies and what their risks are.

C4. I believe that teachers should organize specific classroom activities to raise awareness and provide training in cyberbullying.

C5. I am sure that the Coexistence Commissions promote the continued development of information and awareness-raising activities in cyberbullying at school level. 
C6. I understand that interviews are a useful tool for students to express themselves about their cyberbullying experiences.

C7. I value positively that in institutions the Coexistence Commission should be informed of situations of cyberbullying and the disciplinary measures taken.

C8. I think that from the schools, families should be made aware of the importance they play in the prevention of cyberbullying.

C9. I think that centers should coordinate with community resources (social services, health services, nongovernmental organizations, etc.) to address cyberbullying.

$\mathrm{C} 10$. I believe that the educational community must be involved and committed in the fight against cyberbullying in schools.

C11. I think that television and other media should discuss and take action on cyberbullying.

C12. I think that students should receive advice on how to deal with cyberbullying.

C13. I believe that schools should organize their spaces and resources to help teachers cope with cyberbullying.

D1. In my current studies (Early Childhood Education undergraduate degree program, Primary Education undergraduate degree program or Secondary Master as appropriate) I am being prepared to manage cyberbullying situations.

D2. I would like to further delve into cyberbullying in the remaining part of the studies I am pursuing

D3. Of all the topics that I would like to see as objects of study in the degree (or I would have liked to see, if you are finishing your studies), I give most importance to cyberbullying.

\section{Appendix B}

\begin{tabular}{|c|c|c|c|c|}
\hline Item & Minimum & Maximum & $\mathbf{M}$ & SD \\
\hline A1. & 1 & 5 & 4.42 & 0.81 \\
\hline A2. & 1 & 5 & 4.56 & 0.76 \\
\hline A3. & 1 & 5 & 4.75 & 0.57 \\
\hline B1. & 1 & 5 & 3.1 & 1.07 \\
\hline B2. & 1 & 5 & 2.92 & 1.21 \\
\hline B3. & 1 & 5 & 4.68 & 0.72 \\
\hline $\mathrm{C} 1$. & 1 & 5 & 4.95 & 0.34 \\
\hline $\mathrm{C} 2$. & 1 & 5 & 4.76 & 0.52 \\
\hline C3. & 1 & 5 & 4.59 & 0.69 \\
\hline C4. & 2 & 5 & 4.57 & 0.66 \\
\hline $\mathrm{C} 5$. & 1 & 5 & 3.92 & 1.47 \\
\hline C6. & 1 & 5 & 3.78 & 1.03 \\
\hline C7. & 2 & 5 & 4.64 & 0.71 \\
\hline C8. & 1 & 5 & 4.82 & 0.49 \\
\hline C9. & 2 & 5 & 4.7 & 0.59 \\
\hline C10. & 2 & 5 & 4.81 & 0.45 \\
\hline C11. & 1 & 5 & 4.47 & 0.79 \\
\hline $\mathrm{C} 12$. & 1 & 5 & 4.8 & 0.48 \\
\hline C13. & 1 & 5 & 4.6 & 0.64 \\
\hline D1. & 1 & 5 & 1.88 & 1.2 \\
\hline D2. & 1 & 5 & 4.45 & 0.78 \\
\hline D3. & 1 & 5 & 3.34 & 1.03 \\
\hline
\end{tabular}

Minimum and maximum values mean and standard deviation per item. 


\section{References}

Abreu, Roberto Luis, and Maureen C. Kenny. 2017. Cyberbullying and LGBTQ youth: A systematic literature review and recommendations for prevention and intervention. Journal of Child \& Adolescent Trauma, 1-17. [CrossRef]

Álvarez, David, Celestino Rodríguez, Paloma González-Castro, José C. Núñez, and Luis Álvarez. 2010a. La formación de los futuros docentes frente a la violencia escolar. Revista de Psicodidáctica 15: 35-56.

Álvarez, David, Celestino Rodríguez, Paloma González-Castro, José C. Núñez, and Luís Álvarez. 2010b. La formación inicial de los futuros maestros en recursos para la convivencia escolar y el manejo del aula. European Journal of Education and Psychology 3: 187-98. [CrossRef]

Álvarez, David, José Carlos Núñez Pérez, Luís Álvarez Pérez, Alejandra Dobarro González, Celestino Rodríguez Pérez, and Paloma González-Castro. 2011. Violencia a través de las tecnologías de la información y la comunicación en estudiantes de secundaria. Anales de Psicología 27: 221-31.

Athanasiades, Christina, Anna Costanza Baldry, Theocharis Kamariotis, Marialena Kostouli, and Anastasia Psalti. 2016. The "net" of the Internet: Risk Factors for Cyberbullying among Secondary-School Students in Greece. European Journal on Criminal Policy and Research 22: 301-17. [CrossRef]

Ayas, Tuncay, and Mehmet Barış Horzum. 2011. Exploring the Teachers' Cyber Bullying Perception in terms of Various Variables. International Online Journal of Educational Sciences 3: 619-40.

Baek, Jieun, and Lyndal M. Bullock. 2014. Cyberbullying: A cross-cultural perspective. Emotional and Behavioural Difficulties 19: 226-38. [CrossRef]

Baraldsnes, Dziuginta. 2015. The Prevalence of Cyberbullying and the Views of 5-12 Grade Pupils and Teachers on Cyberbullying Prevention in Lithuanian Schools. Universal Journal of Educational Research 3: 949-59. [CrossRef]

Bauman, Sheri, and Adrienne Del Río. 2005. Knowledge and beliefs about Bullying in schools: Comparing pre-service teachers in United States and the United Kingdom. School Psychology International 26: 428-42. [CrossRef]

Beale, Andrew V., and Kimberly R. Hall. 2007. Cyberbullying: What school administrators (and parents) can do? The Clearing House: A Journal of Educational Strategies, Issues and Ideas 81: 8-12. [CrossRef]

Boulton, Michael J., Katryna Hardcastle, James Down, John Fowles, and Jennifer A. Simmonds. 2013. A Comparison of Preservice Teachers' Responses to Cyber versus Traditional Bullying Scenarios: Similarities and Differences and Implications for Practice. Journal of Teacher Education 65: 145-52. [CrossRef]

Buelga, Sofía, Begoña Iranzo, María-Jesús Cava, and Eva Torralba. 2015. Psychological profile of adolescent cyberbullying aggressors. Revista de Psicología Social 30: 382-406. [CrossRef]

Campbell, Marilyn, Chrystal Whiteford, and Johanna Hooijer. 2018. Teachers' and parents' understanding of traditional and cyberbullying. RevisJournal of School Violence. [CrossRef]

Cappadocia, M. Catherine, Wendy M. Craig, and Debra Pepler. 2013. Cyberbullying: Prevalence, Stability, and Risk Factors during Adolescence. Canadian Journal of School Psychology 28: 171-92. [CrossRef]

Cassidy, Wanda, Chantal Faucher, and Margaret Jackson. 2013. Cyberbullying among youth: A comprehensive review of current international research and its implications and application to policy and practice. School Psychology International 34: 575-612. [CrossRef]

Compton, Louise, Marilyn A. Campbell, and Amanda Mergler. 2014. Teacher, parent and student perceptions of the motives of cyberbullies. Social Psychology of Education 17: 383-400. [CrossRef]

Craig, Katrina, David Bell, and Alan Leschied. 2011. Pre-service Teachers' Knowledge and Attitudes Regarding School-Based Bullying. Canadian Journal of Education 34: 21-33.

DeSmet, Ann, Nathalie Aelterman, Sara Bastiaensens, Katrien Van Cleemput, Karolien Poels, Heidi Vandebosch, Greet Cardon, and Ilse De Bourdeaudhuij. 2015. Secondary school educators' perceptions and practices in handling cyberbullying among adolescents: A cluster analysis. Computers E Education 88: 192-201. [CrossRef]

Eden, Sigal, Tali Heiman, and Dorit Olenik -Shemesh. 2013. Teachers' perceptions, beliefs and concerns about cyberbullying. British Journal of Educational Technology 44: 1036-52. [CrossRef]

Finkelhor, David, Healther Turner, and Richard Ormrod. 2010. Poly-Victimization in a National Sample of Children and Youth. American Journal of Preventive Medicine 38: 323-30. 
Garaigordobil, Maite. 2011. Prevalencia y consecuencias del cyberbullying: Una revisión. International Journal of Psychology and Psychological Therapy 11: 233-54.

Ghamrawi, Najah A. R., Norma Ghamrawi, and Tarek Shal. 2016. Teachers' Perception of Cyberbullying in Lebanese Public School. Open Journal of Leadership 5: 95-109. [CrossRef]

Giménez Gualdo, Ana M., Simon C. Hunter, Kevin Durkin, Pilar Arnaiz, and Javier Maquilon. 2015. The emotional impact of cyberbullying: Differences in perceptions and experiences as a function of role. Computers $\mathcal{E}$ Education 82: 228-35. [CrossRef]

Giménez Gualdo, Ana M., Pilar Arnaiz Sanchez, Fuensanta Cerezo Ramirez, and Elaine Prodócimo. 2018. Teachers' and students' perception about cyberbullying. Intervention strategies in Primary and Secondary education. Comunicar 56: 29-38. [CrossRef]

Gorsek, Abby K., and Melissa M. Cunningham. 2014. A Review of Teachers' Perceptions and Training Regarding School Bullying. Pure Insights 3: 6.

Gradinger, Petra, Dagmar Strohmeier, and Christiane Spiel. 2010. Definition and Measurement of Cyberbullying. Cyberpsychology: Journal of Psychosocial Research on Cyberspace 4: 1.

Hinduja, Sameer, and Justin W. Patchin. 2009. Bullying beyond the Schoolyard: Preventing and Responding to Cyberbullying. Thousand Oaks: Sage Publications (Corwin Press).

Hinduja, Sameer, and Justin W. Patchin. 2017. Cultivating youth resilience to prevent bullying and cyberbullying victimization. Child Abuse and Neglect 73: 51-62. [CrossRef]

Ho, Shirley S., Liang Chen, and Angelica P. Y. Ng. 2017. Comparing cyberbullying perpetration on social media between primary and secondary school students. Computers $\mathcal{E}$ Education 109: 74-84. [CrossRef]

Huang, Yun-Yin, and Chien Chou. 2013. Revisiting cyberbullying: Perspectives from Taiwanese teachers. Computers \& Education 63: 227-39. [CrossRef]

Jimerson, Shane R., Susan M Swearer, and Dorothy L Espelage. 2010. Handbook of Bullying in Schools: An International Perspective. New York: Routledge.

Kowalski, Robin, Gary W. Giumetti, Amber Schroeder, and Micah R. Lattanner. 2014. Bullying in the digital age: A critical review and metaanalysis of cyberbullying research among youth. Psychological Bulletin 140: 1073-137. [CrossRef]

Larrañaga, Elisa, Santiago Yubero, Anastasio Ovejero, and Raúl Navarro. 2018. Socio-cognitive and emotional factors on perpetration of cyberbullying. Comunicar 56: 19-28. [CrossRef]

Lester, Leanne, Stacey Waters, Natasha Pearce, Barbara Spears, and Sarah Falconer. 2018. Pre-service Teachers: Knowledge, Attitudes and their Perceived Skills in Addressing Student Bullying. Australian Journal of Teacher Education 43: 30-45. [CrossRef]

Li, Quin. 2008. Cyberbullying in schools: An examination of preservice teachers' perception. Canadian Journal of Learning and Technology 34: 75-90. [CrossRef]

Luengo Latorre, José Antonio. 2011. Cyberbullying. Guía de Recursos para Centros en Casos de Ciberacoso. Madrid: Oficina del Defensor del Menor.

Luengo Latorre, José Antonio. 2014. Ciberbullying: Prevenir y Actuar. Hacia una Ética de las Relaciones en las Redes Sociales. Madrid: Colegio Oficial de Psicólogos de Madrid.

Marczak, Magda, and Iain Coyne. 2016. English Teachers and Cyberbullying: A Qualitative Exploration of the Stakeholders' Perceptions and Experience of the Phenomenon. In A Social-Ecological Approach to Cyberbullying. Edited by Michelle F. Wright. Hauppauge: Nova Publishing, pp. 197-224.

Monks, Claire P., Jess Mahdavi, and Katie Rix. 2016. The emergence of cyberbullying in childhood: Parent and teacher perspectives. Psicología Educativa 22: 39-48. [CrossRef]

Montoro, Elisabet, and Miguel Ángel Ballesteros-Moscosio. 2016. Competencias docentes para la prevención del ciberacoso y delito de odio en Secundaria. RELATEC. Revista Latinoamericana de Tecnología Educativa 15: 131-43. [CrossRef]

Muñoz, Josefa. 2016. Factores de riesgo en el acoso escolar y el ciberacoso: Implicaciones educativas y respuesta penal en el ordenamiento jurídico español. Revista Criminalidad 58: 71-86.

Musalem, B. Ricardo, and O. Paulina Castro. 2015. Qué se sabe de bullying. Revista Médica Clínica Las Condes 26: 14-23. [CrossRef]

Navarro, Raúl, Santiago Yubero, Elisa Larrañaga, and Verónica Martínez. 2012. Children's cyberbullying victimization: Associations with social anxiety and social competence in a Spanish sample. Child Indicators Research 5: 281-95. [CrossRef] 
Navarro, Raúl, Elisa Larrañaga, and Santiago Yubero. 2018 Differences between Preadolescent Victims and Non-Victims of Cyberbullying in Cyber-Relationship Motives and Coping Strategies for Handling Problems with Peers. Current Psychology 37: 116-27. [CrossRef]

Notar, Charles E., Sharon Padgett, and Jessica Roden. 2013. Cyberbullying: A Review of the Literature. Universal Journal of Educational Research 1: 1-9. [CrossRef]

Ombudsman-UNICEF. 2000. Informe Sobre Violencia Escolar: El Maltrato Entre Iguales en la Educación Secundaria Obligatoria. Madrid: Publicaciones del Defensor del Pueblo.

Orjuela, Liliana, Belkis Cabrera de los Santos, Juan Calmaestra, Joaquin Mora-Merchan, and Rosario Ortega-Ruiz. 2013. Acoso Escolar y Ciberacoso: Propuestas para la Acción. Informe. Madrid: Save the Children.

Ortega-Barón, Jessica, Sofía Buelga, and María Jesús Cava. 2016. The Influence of School Climate and Family Climate among Adolescents Victims of Cyberbullying. Comunicar 46: 57-65. [CrossRef]

Parliament of Andalusia. 2017. Informe especial del Defensor del Menor de Andalucía relativo a acoso escolar y ciberacoso: Prevención, detección y recuperación de las víctimas. BOPA. Parliament of Andalusia 407: 2-186.

Patchin, Justin W., and Sameer Hinduja. 2006. Bullies move beyond the schoolyard: A preliminary look at cyberbullying. Youth Violence \& Juvenile Justice 4: 148-69. [CrossRef]

Payne, Allison Ann, and Kirsten L. Hutzell. 2017. Old Wine, New Bottle? Comparing Interpersonal Bullying and Cyberbullying Victimization. Youth \& Society 49: 1-30. [CrossRef]

Redmond, Petrea, Jennifer V. Lock, and Victoria Smart. 2018. Pre-service teachers' perspectives of cyberbullying. Computers \& Education 119: 1-13. [CrossRef]

Ryan, Thomas, and Mumbi Kariuki. 2011. A Two-Year Comparative Analysis of Cyberbullying Perceptions of Canadian (Ontario) Pre-Service Educators. Journal of the Research Center for Educational Technology 7: 100-11.

Ryan, Thomas, Mumbi Kariuki, and Harun Yilmaz. 2011. A comparative analysis of cyberbullying perceptions of preservice educators: Canada and Turkey. The Turkish Online Journal of Educational Technology 10: 1-12.

Sabella, Russell A., Justin W. Patchin, and Sameer Hinduja. 2013. Cyberbullying myths and realities. Computers in Human Behavior 29: 2703-11. [CrossRef]

Sastre, Ana. 2016. Yo a Eso No Juego. Bullying y Ciberbullying en la Infancia. Anexo 4. Madrid: Save the Children.

Siu, Carol K. 2004. Pre-service teachers' attitudes about school bullying: A new perspective. Master's thesis, University of Calgary, Calgary, AB, Canada.

Slonje, Robert, Peter K. Smith, and Ann Frisén. 2017. Perceived reasons for the negative impact of cyberbullying and traditional bullying. European Journal of Developmental Psychology 14: 295-310. [CrossRef]

Sourander, Andre, Anat Brunstein Klomek, Maria Ikonen, Jarna Lindroos, Terhi Luntamo, Merja Koskelainen, Terja Ristkari, and Hans Helenius. 2010. Psychosocial Risk Factors Associated With Cyberbullying Among Adolescents. A Population-Based Study. Archives of General Psychiatry 67: 720-28. [CrossRef]

Spears, Barbara, Marilyn A. Campbell, Donna J. Tangen, Phillip Slee, and Donna Cross. 2015. Australian pre-service teachers' Knowledge and understanding of cyberbullying: Implications for school climate. Les Dossiers des Sciences de L'éducation 33: 109-30. [CrossRef]

Stauffer, Sterling, Melissa Allen Heath, Sarah Marie Coyne, and Scott Ferrin. 2012. High school teachers' perceptions of cyberbullying prevention and intervention strategies. Psychology in the Schools 49: 353-67. [CrossRef]

Yanes, Cristina, and Francis Ries. 2014. Liderando el cambio: Estudio sobre las necesidades formativas de los futuros docentes de secundaria. Revista Fuentes 14: 105-24.

Yilmaz, Harun. 2010. An Examination of Preservice Teachers' Perceptions about Cyberbullying. Eurasia Journal of Mathematics, Science \& Technology Education 6: 263-70. [CrossRef]

(C) 2019 by the authors. Licensee MDPI, Basel, Switzerland. This article is an open access article distributed under the terms and conditions of the Creative Commons Attribution (CC BY) license (http:/ / creativecommons.org/licenses/by/4.0/). 


\title{
Mothers' Perceptions of the Phenomenon of Bullying among Young Children in South Korea
}

\author{
Hyun-jung Ju and Seung-ha Lee * \\ Department of Early Childhood Education, Chung-Ang University, 84 Heukseok-ro, Dongjak-gu, Seoul 712-749, \\ Korea; jhj834@cau.ac.kr \\ * Correspondence: seungha94@cau.ac.kr; Tel.: +82-2-820-5882
}

Received: 1 November 2018; Accepted: 2 January 2019; Published: 8 January 2019

\begin{abstract}
This study aimed to investigate mothers' different perspectives on bullying in early childhood. Twelve mothers having children under eight years old were interviewed in South Korea. All the interviews were transcribed in Korean and analyzed using Nvivo. The constant comparison method was used to analyze the data. The results showed six themes consisting of categories: (1) concept of bullying (2) difficulty in defining bullying in early childhood, (3) difficulty in telling other mothers about bullying, (4) children who do not reveal their experiences, (5) ways to be aware of bullying, and (6) mothers' concern. Categories were sometimes divided into subcategories. Findings showed that mothers seemed to view bullying differently, and that relationships among them contributed to differences in their perspectives on bullying. Mothers' relationships also interacted with children's relationships. Children were unlikely to tell their victimization experiences, due to certain reasons. These findings can contribute to understanding the nature of bullying in early childhood, increasing the social awareness of bullying among young children, and emphasizing the need for intervention/prevention programs.
\end{abstract}

Keywords: bullying; young children; wang-ta; mothers; aggression

\section{Introduction}

Bullying is a pervasive problem that can occur at any point from early childhood to adulthood. Bullying is usually defined as a subtype of aggressive behaviors that are repeated over time, toward an individual who is unable to defend oneself (i.e., imbalance of power) (Olweus 1993). This aggression could be physical (e.g., hitting), verbal (e.g., name calling), relational (e.g., exclusion), or cyber (e.g., sending nasty messages through electronic media). The characteristics of bullying in early childhood (Lee et al. 2016; Monks et al. 2003; Monks and Smith 2006) differ from those in middle childhood and adolescence. Young children are less likely than older groups to perceive imbalances of power, and repetition of actions; which may reflect that bullying is less targeted toward one child (Monks and Smith 2006).

Whether the three criteria that are used to define bullying - intentional harm-doing, repetition, and imbalance of power-should be included in the context of young children is a controversial topic. Young children begin engaging in goal-directed behavior, and start perceiving others' intentional behaviors at around the age of four. This is also the age at which they are able to recognize power imbalances between people (Williams et al. 2016). However, due to the instability of the victim's role among young children (Monks et al. 2002), it is unclear whether the repetition of behavior is a necessary aspect of the definition of bullying (Vlachou et al. 2011; Williams et al. 2016). Because of these reasons, some researchers use the terms "precursory bullying" (Levine and Tamburrino 2014) or "unjustified aggression" (Monks et al. 2002).

Despite the controversy regarding the definition of bullying in early childhood, studies have identified aggressive behaviors in early childhood that can be categorized as bullying. Using Olweus' 
definition of bullying, Kirves and Sajaniemi (2012) reported that 7.1\% of three to six-year-olds in their study were bullies, $3.3 \%$ were victims, and $2.2 \%$ were bully-victims. Additionally, participant roles such as bully, victim, or defenders, were clear, even among three-year-old children and among children under seven years old (Lee et al. 2016; Monks et al. 2002; Perren and Alsaker 2006; Repo and Sajaniemi 2015).

Identifying bullying in the early years is vital to prevent children's social and emotional problems. Experiences of bullying in early childhood were related to difficulties in peer relationships, and they resulted in adjustment problems, as well as internalizing and externalizing behaviors. Young children who bullied others showed low social competence, and were less likely to positively interact with peers (Camodeca et al. 2015). Additionally, their bullying behaviors were often related to victimization (Lee et al. 2016; Perren and Alsaker 2006). Longitudinal studies showed the causality more clearly. Relationally victimized children in kindergarten exhibited high levels of adjustment problems; greater loneliness, frequent school avoidance, and low level of school liking. They were also found to be negatively correlated to school academic achievement (Kochenderfer and Ladd 1996). Arseneault et al. (2006) conducted a cohort study among 2232 children over a five-year period. In their study, earlier pure victims exhibited more internalizing behavior and unhappiness compared to the control group two years later. Earlier bully-victims exhibited more internalizing and externalizing behaviors, compared to the control group and pure victims, two years later. Further, victimization experiences in the first, third, and fifth grades in elementary school predicted a decrease in popularity, an increase in aggressive behaviors, inattention, delinquency, and symptoms of anxiety and depression for five years (Hanish and Guerra 2002).

Parental perceptions of bullying have been explored in several studies. A common finding is that parents are unlikely to be aware of bullying or victimization experiences by their children (Mishna et al. 2006). Generally, children do not tell their parents about being bullied (Mishna 2004), because they think that it would aggravate the situation, and result in the termination of friendships. Furthermore, even when parents are aware of the existence of a problem, they find it difficult to determine whether the situation involves bullying; they are unsure of whether the incident is a common conflict among peers; or whether the problem is the fault of their child or of other children (Mishna 2004).

Identifying bullying is important, as it influences how parents manage the situation (Sawyer et al. 2011). If adults do not act on children's reports of bullying or victimization experiences, children may feel that there is no way to obtain help to escape bullying, exposing them to more bullying and increasing their fear (Clarke and Kiselica 1997). Furthermore, some adults are not even aware that indirect relational aggression or social exclusion are regarded as bullying (Harcourt et al. 2014; Sawyer et al. 2011). Therefore, adults' accurate awareness of what constitutes bullying is necessary. However, among young children, it can be difficult to distinguish bullying from the general negative interactions that can frequently occur among friends, posing a further hindrance for adults in addressing bullying among children (Purcell 2012; Sawyer et al. 2011).

Considering the characteristics described above, defining and recognizing bullying is more difficult in early childhood compared to other age ranges. The few existing studies on the perceptions of young children's bullying are based on the Western world, although the features of bullying may vary across different cultures (Smith et al. 2002).

\subsection{Bullying in South Korea}

The phenomenon of bullying differs across cultures, and the differences may be particularly stark between Western and Eastern countries, which are often compared in terms of collectivistic or individualistic perspectives. South Korea is a collectivistic culture in which people are interdependent with their in-group members, and where harmony among them is prioritized (Hofstede and Hofstede 2005). In South Korea, there are several terms that indicate phenomena similar to bullying: gipdan-ttadolim (group isolation), gipdan-goerophim (group bullying or group teasing), hakkyo-pokryuk (school violence), and wang-ta (social exclusion or excluded/victimized person). These terms have been used interchangeably, although there are some differences between them (Lee et al. 2012). For instance, 
the term wang-ta indicates social exclusion: literally, a socially excluded person. The term wang-ta usually include other aggressive behavior (physical or verbal), as well as social exclusion (Lee et al. 2011, 2012). During the late 1990s to the early 2000s, the terms gipdan-ttadolim (group isolation) or gipdan-goerophim (group bullying or group teasing) were relatively frequently used, whereas the term hakkyo-pokryuk has been widely used more recently. The term hakkyo-pokryuk includes a wide range of aggressive behavior that may occur among school pupils, and is often used by the formal system. The term wang-ta has been more popularized among school pupils (Lee et al. 2012). Koreans do not interpret each term in the same way, although these terms have some similarities. There is no academic agreement on the term that is most likely to correspond to the term bullying in English. Furthermore, there are no studies on the most appropriate Korean term to represent bullying in early childhood. Some studies investigating bullying in early childhood borrow the term hakkyo-pokryuk (e.g., Kwak and Kim 2016), because there is no academic agreement or discussion on the term issue. Bullying in early childhood in South Korea has been rarely researched: only a few studies have investigated its prevalence. In Song and Lee (2014) study, 53\% of kindergarten teachers observed ttadolim among children over the course of a year, and most of them reported that they noticed social exclusion (92\%), followed by verbal aggression (37\%), and instrumental aggression (30\%). Similarly, Kwak and Kim (2016) reported that $63 \%$ of teachers in both kindergarten and daycare centers observed hakkyo-pokryuk among young children, and considered it to be serious and to warrant specialized education for its management.

However, few studies have directly questioned young children about bullying or victimization experiences. Lee et al. (2016) found that $8-13 \%$ of four- to six-year-olds participating in their study reported victimization experiences. Although children and teachers have reported bullying or victimization among young children, studies on the subject are still very few. Furthermore, studies of bullying in early childhood focused on teachers or children, rather than parents. There have hardly been any studies on how parents perceive bullying among young children in South Korea. Generally, mothers seem to be more sensitive to their children's bullying experiences compared to fathers, and they offer an effective solution to eradicate bullying (Georgiou 2008; Lester et al. 2017). Mothers in South Korea are more likely to be closely involved in the care and education of their children, compared to fathers (Hong and Lee 2019). Therefore analyzing mothers' thoughts on bullying among children will be useful in examining bullying in South Korea.

This study aimed to investigate mothers' perceptions of bullying among young children in South Korea, focusing on whether their children had experienced bullying, and their thoughts on these situations.

\subsection{Early Childhood Education System in South Korea}

In South Korea, children aged five years and below are educated in two types of educational institutions: kindergarten, where children aged three to five years are enrolled, and daycare centers, where zero to five-year-olds are cared for and educated. Parents can choose either of the two types of institutions. Most children (90\%) aged three to five are educated/cared for at either kindergartens or daycare centers (Park et al. 2015). Children between the ages of six and eleven are enrolled in elementary schools, and the attendance rate of elementary schools in South Korea is $97.3 \%$ (Department of Education, Korean Educational Development Institute 2017). In keeping with government instructions, these institutions watch over children from roughly 9:30 a.m. to 1:30 p.m., working additional hours if necessary. If parents are unable to pick their children up in the afternoon, these institutions take care of the children until 5 p.m. or longer. Thus, young children spend most of their waking hours in one place with the same peers.

\section{Method}

This study used qualitative methods to explore the perspectives and experiences of bullying among mothers of young children. 


\subsection{Recruitment and Consent}

Participants were recruited through snowball sampling. Mothers who were already familiar with the authors were interviewed first, and then asked to introduce other mothers with similar experiences. This study adhered to all ethical guidelines of the institution to which authors belonged to. There was no need for IRB approval for this research, as it does not involve any medical action nor cause harm. Before the interview began, the participants were informed of the research purpose, procedures, and data collection methods. A list of interview questions was also shown to them before the interview, so they were able to make an informed decision regarding their participation. Mothers who agreed to be interviewed also filled and submitted a consent form. Most participants were openly receptive and interested in this study, because they hardly had opportunities to talk about the issue of bullying or victimization among their children. Measures were taken to ensure that the collected data did not expose personal information such as the names of mothers and their children's educational institutions and areas of residence. The children's names quoted in the results section were indicated as alphabet initials (i.e., $A, B, C$ and so on) with the exception of the child labelled M11, who divulged a verbal bullying incident that called for an indication of the child's name: in this case, a child's pseudonym was used. Further, participants were indicated as initials (i.e., M1: Mother 1, M2: Mother 2 ... ).

\subsection{Participants}

Twelve mothers living in Seoul or Gyeonggi Province in South Korea, participated in this study. The participants were aged between 35 and 44 years, and were all married. Among the participants, six were not employed, three were part-time workers, two were full-time workers, and one was a postgraduate student. They had one to three children, and at least one of their children was between three and eight years old. The mothers were all college or university graduates. The information of the participants is described in Table 1. This study regarded early childhood as a development stage: from birth to eight years old (OECD 2015), in which children in kindergarten, day care center, and lower elementary school level were included. These children were exposed to bullying, but their bullying experiences were hardly investigated. Additionally, mothers whose children had joined elementary school recently were expected to give relatively richer information on their experiences related to bullying both in kindergarten and elementary school.

Table 1. Information of participants and their children.

\begin{tabular}{|c|c|c|c|c|}
\hline Mother & Number of Children & Child's Age (year) & Child's Gender & Child's Educational Institution Type \\
\hline \multirow{2}{*}{ M1 } & \multirow{2}{*}{2} & 1 & Male & No school \\
\hline & & 4 & Female & Daycare \\
\hline \multirow{2}{*}{ M2 } & \multirow{2}{*}{2} & 3 & Female & Daycare \\
\hline & & 6 & Female & Elementary \\
\hline \multirow{2}{*}{ M3 } & \multirow{2}{*}{2} & 5 & Female & Elementary \\
\hline & & 10 & Male & Daycare \\
\hline M4 & 1 & 5 & Female & Kindergarten \\
\hline \multirow{2}{*}{ M5 } & \multirow{2}{*}{2} & 5 & Female & Kindergarten \\
\hline & & 7 & Female & Elementary \\
\hline \multirow[b]{2}{*}{ M6 } & \multirow{2}{*}{2} & 5 & Female & Kindergarten \\
\hline & & 7 & Female & Elementary \\
\hline \multirow{2}{*}{ M7 } & \multirow[b]{2}{*}{2} & 3 & Male & Daycare \\
\hline & & 5 & Female & Daycare \\
\hline \multirow{2}{*}{ M8 } & \multirow[b]{2}{*}{2} & 4 & Female & Daycare \\
\hline & & 4 & Female & Daycare \\
\hline
\end{tabular}


Table 1. Cont.

\begin{tabular}{ccccc}
\hline Mother & Number of Children & Child's Age (year) & Child's Gender & Child's Educational Institution Type \\
\hline \multirow{2}{*}{ M9 } & 2 & 0.5 & Male & No School \\
& \multirow{2}{*}{ M10 } & 5 & Female & Kindergarten \\
\hline \multirow{3}{*}{ M11 } & \multirow{2}{*}{3} & 3 & Female & Elementary \\
& & 5 & Female & Daycare \\
& & 7 & Female & Daycare \\
M12 & 1 & 7 & Female & Elementary \\
\hline
\end{tabular}

\subsection{Interviews}

Semi-structured interviews were conducted. All interviews were conducted by the first author of this study. Prior to the in-depth interview, preliminary interviews were administered to two mothers of four-year-old children to check the appropriateness of the interview questions and to confirm whether mothers of young children had experiences relevant to the research topic. Parents clearly indicated that their young children often experienced bullying from their peers or friends, and reported difficulties related to the incidents. They tried to solve them, but they did not know how to go about it. The preliminary interview showed that the mothers were aware of bullying and its specific features in early childhood, and that it was different from bullying experienced in other ages. The two mothers who were interviewed preliminarily were not included as participants in the main interviews. The main interviews were carried out either individually, or through a focus group, depending on the participants' schedule or their familiarity with each other. Seven individual interviews (M1, M2, M3, M7, M8, M9, M10), and two focus groups (Group 1: M4, M5, M6; Group2: M11, M12) were conducted.

Given the fact that several terms used in South Korea corresponded to bullying in western cultures, and that each term represented a slightly different meaning, the researchers did not use South Korean specific terms such as wang-ta or goerophim in the initial interview, in order to avoid the prejudice or preconception that mothers might have about the terms. These terms were used only after they were mentioned by the participants. Instead, cartoons describing several types of aggressive behaviors were shown to participants. Then, they were asked about their thoughts on them. The cartoons were developed by Smith et al. (2002), and they have been widely and effectively used to elicit the concept of bullying (Lee et al. 2011, 2012; Monks and Smith 2006; Smith et al. 2002). In this study, six cartoons, each describing different types of aggressive behaviors, were used: (1) an individual's physical aggression (hitting a smaller person), (2) verbal aggression (saying nasty things), (3) indirect physical aggression (breaking another's ruler), (4) group physical aggression (several children hitting a child), (5) direct/relational aggression (not allowing someone to play with others), and (6) indirect/relational (spreading a rumor) (A cartoon engaging in an individual's physical aggression is shown in Appendix A).

Mothers were shown the cartoons and asked,

- What do you think about these behaviors (expressed by the cartoons) among children?

- Has your child ever experienced (or have you ever heard about) these behaviors? If so, please tell me about the situation in detail.

- What did you do when your child had an experience related to these behaviors?

Interviews were carried out in cafes or the participants' homes, where the mothers felt most comfortable. The interviews lasted approximately 60-120 min, and were audio-recorded.

\subsection{Qualitative Analysis}

All interviews were transcribed into Korean. Nvivo 12 software was used to analyze the data, and the constant comparative method, based on the grounded theory, was used (Strauss and Corbin 1998). Basic concepts in open coding were identified. The categories and subcategories were named 
by using words that represent and comprise the basic concepts. Some categories had subcategories as participants generated richer information and detailed perceptions on certain categories. The core categories were selected, and the relevance of the other categories based on elaboration were confirmed. Through this process, six major themes were identified and categorized. The authors independently conducted coding, created categories, and held discussions. Whenever there were differences in analysis, especially in categories or subcategories, the authors returned to the data, reviewed the analysis, and discussed it until they were in agreement.

\section{Results}

Six major themes emerged: (1) the concept of bullying (2) difficulty in defining bullying in early childhood (3) difficulty in communicating with other mothers about bullying (4) children who do not reveal their experiences (5) ways to be aware of bullying and (6) mothers' concern. Each theme consisted of categories that were sometimes divided into subcategories. Table 2 shows the hierarchy of themes and categories (and subcategories).

Table 2. Themes and categories (subcategories) that emerged from the analysis of mothers' interviews.

\begin{tabular}{|c|c|c|c|c|c|c|}
\hline Theme & $\begin{array}{l}\text { Theme 1. Concept } \\
\text { of bullying }\end{array}$ & $\begin{array}{l}\text { Theme 2. Difficulty of } \\
\text { defining bullying in early } \\
\text { childhood }\end{array}$ & $\begin{array}{l}\text { Theme 3. Difficulty in } \\
\text { communicating with } \\
\text { other mothers about } \\
\text { bullying }\end{array}$ & $\begin{array}{l}\text { Theme } 4 \text {. Children } \\
\text { who do not reveal } \\
\text { their experiences }\end{array}$ & $\begin{array}{l}\text { Theme } 5 \text {. Ways to } \\
\text { be aware of } \\
\text { bullying }\end{array}$ & $\begin{array}{l}\text { Theme } 6 . \text { Mothers' } \\
\text { concern }\end{array}$ \\
\hline $\begin{array}{l}\text { Category } \\
\text { (Subcategory) }\end{array}$ & $\begin{array}{l}\text { Categories 1-1. } \\
\text { Criteria of } \\
\text { bullying } \\
\text { (Subcategories: } \\
\text { Physical, } \\
\text { psychological } \\
\text { harm, } \\
\text { repetition, power, } \\
\text { intention, } \\
\text { victim-centeredness }\end{array}$ & $\begin{array}{l}\text { Category 2-1. Ambiguity } \\
\text { of situation } \\
\text { (Subcategories: Severity, } \\
\text { repetition, } \\
\text { self-defense, peer } \\
\text { interaction) } \\
\text { Category 2-2. Different } \\
\text { standpoints of mothers } \\
\text { (Subcategory: } \\
\text { Aggressor's mothers vs. } \\
\text { victim's mother, } \\
\text { Mothers' personal } \\
\text { characteristics) }\end{array}$ & $\begin{array}{l}\text { Category 3-1. } \\
\text { Relationship among } \\
\text { others (Subcategories: } \\
\text { Closeness, } \\
\text { afraid of being } \\
\text { wang-ta) } \\
\text { Category 3-2. } \\
\text { Links between } \\
\text { mothers' and } \\
\text { children's } \\
\text { relationships }\end{array}$ & $\begin{array}{l}\text { Category } 4-1 \text {. Fear } \\
\text { Category } 4-2 . \\
\text { Introversion, } \\
\text { Category } 4-3 \text {. } \\
\text { Desire to play with } \\
\text { aggressor } \\
\text { Category } 4-4 \text {. } \\
\text { Limited language } \\
\text { ability }\end{array}$ & $\begin{array}{l}\text { Category 5-1. } \\
\text { Online and offline } \\
\text { network among } \\
\text { mothers } \\
\text { Category 5-2. } \\
\text { Witness } \\
\text { Category 5-3. } \\
\text { Children's reports }\end{array}$ & $\begin{array}{l}\text { Category 6-1. } \\
\text { Worries of being } \\
\text { bullies or victims } \\
\text { Category 6-2. } \\
\text { Consistency } \\
\text { Category 6-3. } \\
\text { Lack of coping } \\
\text { strategies } \\
\text { Category 6-4. } \\
\text { Trust/distrust of } \\
\text { teacher }\end{array}$ \\
\hline
\end{tabular}

Due to the limited space, only the quotes that were most representative of each category (or subcategory) were shown. In some categories, more than one quote were displayed, while in other categories, only one quote was indicated if it carried the meaning of the category (or subcategory) efficiently.

\section{Theme 1. Concept of bullying.}

The theme concept of bullying explains how mothers conceptualized bullying, and what criteria they used to define bullying among young children. This was further explained by the category "criteria of bullying" and its subcategories.

Category 1-1. Criteria of bullying. (Subcategories: Physical/psychological harm, repetition, power, intention, and victim-centeredness).

Mothers' concepts of bullying were similar to those defined by academic researchers: They used the criteria of physical/psychological harm, repetition, power, and intention. Additionally, mothers focused on defining young children's bullying from victims' perspectives.

"Of course, hitting is goerophim, but psychological suffering also often occurs among girls" (M4). (Subcategory: physical/psychological harm).

"If this goes on for long, it is goerophim" (M2). (Subcategory: repetition).

"A child can once in a while engage in these behaviors for fun, but if those are repeated, they can be harmful" (M3). (Subcategory: repetition).

"The child (aggressor) does not consider his/her friend an equal" (M5). (Subcategory: power). 
"If they know that they commit goerophim, then it is goerophim: even if they do not know what they do. If someone is victimized, that is goerophim regardless of whether the children are aware of the meaning of their actions" (M2). (Subcategory: intention).

"If the child (victim) is so distressed that he/she cannot sleep, then their experience is goerophim" (M6). (Subcategory: victim-centeredness).

"If an individual feels pain from an action directed at them, that is goerophim" (M4). (Subcategory: victim-centeredness).

Mothers often mentioned that stress or pain from the victims' perspective was an important criterion for defining bullying, rather than the use of relatively more objective standards (repetition, intention, power).

The subcategory "victim-centeredness" may have resulted from the ambiguity of the bullying situation in early childhood, which leads to difficulties in defining bullying in early childhood.

\section{Theme 2. Difficulty in defining bullying in early childhood.}

The theme difficulty in defining bullying in early childhood leads to obstacles that interfere in judging certain aggressive episodes as bullying or not. It consisted of the categories "ambiguity of situation," and "different standpoints of mothers", and subcategories of each category.

Category 2-1. Ambiguity of situation. (Subcategories: Severity, repetition, self-defense, and peer interaction).

Mothers have difficulty in defining bullying, although they are aware of the basic criteria (harmfulness, repetition, power, intention, and victim-centeredness), because of the ambiguity of the aggressive situation. This was further explained by subcategories such as severity, repetition, self-defense, and peer interaction. When aggressive behaviors occurred, it was difficult to decide to what extent these subcategories were involved (whether the aggressive behavior was severe, how many times it was repeated, whether it was done in self-defense, and whether it was negative peer interactions or general peer conflicts rather than bullying).

" $X$ says nasty words and hits others. Are these behaviors that have resulted from having experienced humiliation? It is not clear whether $X$ hit $Y$ though $Y$ has done nothing to him/her $\ldots$ or if $X$ swears at $Y$, and $Y$ hits $X$, which behavior is more punishable?" (M5). (Subcategory: severity, self-defense).

"A teacher told children not to report an aggressive behavior until it had happened seven times. This is the solution provided by a teacher. The teacher said there was nothing wrong with the accounts of either of the children (the aggressor and the victim). Each had reasonable explanation for their behavior. Children only consider their own views. There is a gap between the children, which the teacher may have difficulty balancing ... It may be strange from an adult's perspective, but children feel victimized" (M1). (Subcategory: peer interaction).

Mothers and teachers were all confused by the boundary between bullying and other negative interactions (such as fighting and joking). Mothers were confused about what behavior was worse among several types of aggressive behaviors. Even more confusing was aggressive behaviors that occurred in response to others' provocation. Mothers stated that teachers regarded the aggressive behaviors among children as general conflicts rather than as bullying. It seems to be the reason why teachers did not react to every single conflict among children, and told children to report only when an aggression was repeated many times (such as seven times in the example above). In contrast, children were clear about these concepts: if they were at the receiving aggressive behavior, it was regarded as being bullied or victimized whereas if they were the aggressors, it was just for fun. Teachers' views were different from those of mothers, which caused mothers to distrust teachers, and explained the category of trust/distrust of the teacher under the sixth theme, mothers' concern.

Category 2-2. Different standpoints of mothers. (Subcategory: Aggressors' mothers versus victims' mothers, and mothers' personal characteristics). 
Mothers had different perspectives, depending on whether their children were the victims or the aggressors. Their responses also depended on their personal characteristics. Some mothers, when their children were involved in bullying behavior, apologized to the victim's mother, which was regarded as reasonable and understandable by other mothers. However, some mothers of aggressive children reacted aggressively toward the victim's mother and did not admit their children's wrongdoing. Participants perceived that these different responses resulted from the mothers' personal characteristics. These could make them reluctant to tell other mothers about their children's victimization.

"My girl could not sleep and did not want to go to kindergarten. However, because it was not her girl who was victimized, she perceived the situation as simple and downplayed it, and that hurt me ... They said my girl is too sensitive and fussy" (M6). (Subcategory: aggressors' mothers versus victims' mothers).

Mothers reported that aggressors' mothers tended to regard the incident not as bullying but a misunderstanding among children.

“They (aggressors' mothers) are not humble enough to apologize to victims or their mothers. They think there is something wrong with the other child (victim), or that there has simply been a misunderstanding between children" (M5). (Subcategory: aggressors' mothers versus victims' mothers).

"I told her frankly that I felt bad about her girl's careless words. $H$ cries whenever $H$ is reminded of the incident. It was hurting $H$. . I I know she was not at fault, her girl was ... but she didn't take this situation as seriously as I did" (M8). (Subcategory: aggressors' mothers versus victims' mothers).

There were a lot of comments regarding these different points of view. Not all aggressive mothers justified their children's mistakes. Mothers' personal characteristics played a part in how they reacted upon hearing that their children were bullies. This is important, because their own nature makes the victims' mothers unlikely to tell aggressors' mothers about their children's bullying, which in turn, makes it difficult to stop such incidents.

"The first type, mother says, "No matter what, hitting is wrong and I apologize." This is normal. The second type says, "Oh, I will apologize ... but maybe there is some issue among the children." This is still a mild reaction; the third is pushy, "No, there must be something wrong" and, ask her child. The child could be lying, but the mother chooses to only believe her child's words. This is what poses a problem" (M5). (Subcategory: mothers' personal characteristics).

\section{Theme 3. Difficulty in communicating with other mothers about bullying.}

The theme difficulty in communicating with other mothers about bullying represents mothers' reluctance and worries of telling or sharing bullying-related experiences of their children. The category "relationships among mothers" was deeply involved with the difficulties in communicating. Further, the category "links between mothers" and "children's relationships" explained that the relationships among mothers and those among children were connected and influenced each other, which made mothers more careful about talking about their or other children's experiences of bullying.

Category 3-1. Relationships among mothers. (Subcategories: Closeness, fear of being wang-ta).

Mothers found it difficult to directly talk to the aggressor's mother or to other mothers uninvolved in the bullying situation. They were afraid of damaging of their relationships with other mothers after telling experiences of their children.

The subcategory "closeness among mothers" can either make it easier or more difficult to tell other mothers of their children's bullying. In one way, closeness can easily solve this problem.

"If I know the aggressor and the aggressor's mother, I can approach her more easily, such as, 'Hey, your girl hits my girl, could you ask your girl about this?' However, if I do not know the mother, I would already be upset before asking her and would be ready for an argument" (M12). (Subcategory: closeness). 
However, mothers of victims could also be unlikely to speak to aggressors' mothers about the situation if the two share a close relationship.

"She was not at fault, but we may be uncomfortable because of the children's matter. I pretended and tried to be fine because no one was (physically) harmed, but I am not actually ... (fine)" (M6). (Subcategory: closeness).

Victims' mothers were unable to gauge how aggressors' mothers would react upon hearing of their children's behavior. Unless the aggressor's mother was sensible and empathized with the victimized child, the friendship between the mothers would end, or at least become uncomfortable.

The subcategory "fear of being wang-ta" explains that mothers could not tell victimization experiences of their children because they were afraid of being isolated if the victimization did not elicit other mothers' empathy. Mothers were worried about how the victimization of their child would be perceived, and whether other mothers could understand the situation.

"If I react very strongly even though it was the other child's fault, they might think that I overreact and regard me as a violent and stubborn person. I would become a cause for alarm'" (M5). (Subcategory: fear of being wang-ta).

Another mother's interview clearly demonstrated this worry.

"I have lived in this town for eight years, so I know the aggressor who makes trouble here ... One child was victimized by this aggressor. The victim's mother is not one to remain silent; she made sure the whole school knew, sending instant messages directly even to her child's teacher. She opened a chat room for mothers, so that they could be aware of what happened among the children" (M2). (Subcategory: fear of being wang-ta).

M2 did not show a positive attitude toward the victim's mother; she seemed to think the situation could have been handled in other ways.

Generally, mothers know both aggressor and victim, because they live in the same town, and their children usually go to the same school in the district. Thus, their relationships are complicated: sometimes they may be close to aggressor's mother, in that case, they might tend not to blame aggressor too much.

Category 3-2. Links between mothers' and children's relationships.

Mothers' and children's relationships are related. Children's peer relations can be influenced by mothers' relationships. If mothers had conflicts, their children are not allowed to play together by their mothers.

"It is very common. Mothers' relationships directly affect those of the children. Children can recover their relationship, but they cannot play anymore because their mothers' relationship has been severed" (M7).

Sometimes, mothers can contribute to making a child or a child's mother wang-ta intentionally or unintentionally; they can stigmatize a child who has trouble with other children in the town, and the child and his/her mother can be socially excluded.

"If some mothers say that a child is weird, he/she is socially excluded, rumors spread implicitly around mothers; they overreact even over very trivial things ... Mothers only think about their own children." (M9).

Mothers' selfishness in thinking only of their own children can be detrimental to the reputations of other children, contributing to making certain children wang-ta. In contrast, when an aggressive child bullied other children and his/her mother ignored the situation, other mothers were distressed by the mother and the child.

"If a child (aggressor) lacks self-control. He/she fights with others, then his/her mother should say 'it is your fault, you should have behaved better' but she responds, 'Um ... I see' and that is the end of it. Then the boy would think 'Whatever I do is okay' Then, the mother gets in trouble with the other mothers, and she is socially excluded by the other mothers" (M6). 


\section{Theme 4. Children who do not reveal their experiences.}

The fourth theme, children who do not reveal their experiences to, explained why children were unlikely to tell their bullying-related experiences to parents. The categories "fear", "introversion," and "desire to play with aggressor" were related to the psychological reasons for the children's difficulty in determining victimization. "limited language ability" was regarded as a cognitive factor that contributed to children's difficulty in reporting incidences of bullying to their parents.

Category 4-1. Fear.

If children were threatened or dominated by someone who is physically or socially more powerful, they felt fear, which made them difficult to report the bullying.

"The boys drank soap bubbles because they were frightened of the aggressor. There were 10 boys in the class, and five of them drank the bubbles" (M2).

"X commanded $A$ to put up her hands and reflect upon her faults. I was speechless ... The teacher told $X$ that they must not do it" (M1).

The order of a dominant child seems to be undeniable in the children's social world. Children seem to panic, and are unable to think about what to do and how to cope with the dominant child's behavior.

Category 4-2. Introversion.

Some mothers worried that their children's introverted characteristics led to their being unaware of events in kindergarten.

" $X$ is not weak nor tender like my girl ... A is not talkative; usually she doesn't speak about what happens at the daycare center ... She was so tender, she couldn't react to it" (M1).

Also, when a dominant child meets one who is tender and introverted, bullying is more likely to occur, as the introverted child is unlikely to directly express their displeasure to the aggressor.

" $O$ is a dominant child, if there are children who are younger than $O, O$ snatches what they are doing, and uses it" (M10).

Category 4-3. Desire to play with the aggressor.

Quite often, children seemed to think that if they reported the situation, they would be unable to continue playing with the aggressor.

This makes mothers frustrated.

"I told E not to play with the other girl, but she wants to, and I can't stop her, which really disappoints me" (M5).

Children seemed to want to play with aggressor, because they attracted characteristics that the aggressor had

"I asked B 'Why do you want to play with her?' and B said. 'Because she dresses like a princess and other children like her' ..." (M2).

Category 4-4. Limited language ability.

Children have difficulty in expressing their victimization experiences, because their language ability restricts them from expressing their victimization experiences appropriately and in a timely manner. This was very frequently mentioned by mothers.

" $C$ is a child of my friend. $C$ has been suffering from atopic eczema since she was a baby, when she joined first grade in elementary school, she told her mother that she had had a very difficult time in kindergarten. Other kids used to tease her because of her skin. At the time, she had told her mother that she did not want to go to kindergarten, but her mother did not know the reason for this and pushed her to go kindergarten. Her mother had regarded her complaint as general or infantile behavior. She could not express what she was going through at that time because she was too young but she is mature enough now ..." (M3). 
"J was not able to speak in detail because she was four years old. She said "Mom, $O$ is really bad" I asked 'Why?, then ' $O$ is nice when teacher is hanging around, but she does whatever she wants when the teacher disappears' I said to $J$ 'Children are like that ... you also do whatever you want' ... I did not think of it as important" (M10).

"A child cannot refute point-by-point when another child says that he/she has done something that he/she has not. He/she just cries and says, 'I didn't, I didn't.' The other children just see him/her crying; they don't listen to what he/she actually did, and it turns into a bad situation" (M11).

Young children's expressions are likely to be simple as the above (e.g., 'she is bad' 'I don't want to go kindergarten'). This can cause mothers to tend to disregard the importance of their expressions, and other children in the same class are not able to understand the situation.

Also, children were often unaware of whether the bad events that they experienced were bullying. Although they felt bad, it seemed to be difficult for them to tell at the time, which could be a result of their limited language ability, and their desire to play with the aggressor.

This did not mean that they were fine and not hurt; but rather, that they had buried the hurt within themselves for a long time, telling adults much later. This reflects on the fact that children do not forget their victimization. Instead, it seems that they can tell of when their cognitive or language development has reached a level where they are able to explain their experience.

Furthermore, young children could express non-aggressive behaviors which they received from others as aggressive behaviors, due to their limited language abilities, which might have been caused by their cognitive developmental stage in interpreting others' intensions and behaviors.

"I intentionally teach my boy to improve his language skills because he should be able to express himself if he is victimized, but that backfired. One day, a teacher called me and said that my boy told her I hit him. I was shocked, 'Did I hit him?' . . I just patted him to put him to bed ... " (M7).

Children's simple and delayed expressions of their victimization, or wrong expression of non-victimization experiences renders mothers unlikely to identify bullying incidents correctly. Also, as the incidents described by their children might have occurred months or even years ago, it is difficult for them to discern exactly what happened.

\section{Theme 5. Ways to be aware of bullying.}

The fifth theme, ways to be aware of bullying, outlines diverse ways in which mothers were informed of bullying incidents: the categories "online and offline networks among mothers," "witness," and "children's reports" further explained the theme.

Category 5-1. Online and offline networks among mothers.

Mothers heard of bullying incidents among children through group chat rooms, or from other mothers who were close to them.

"I didn't know at first, but I have heard from other mothers ... They talked seriously about what had happened, and I asked them whose child had done it" (M2).

"The mum heard from another mum whose child is in the same class as her son" (M4).

Online chats among mothers were useful for obtaining information related to the children, but also had negative effects. Some mothers reported the following disadvantages of group chat rooms: "Group chat, especially among the mothers of all the children in one class, causes many problems" (M11).

"I only use it for class-related notices." (M12).

In spite of the negative effects of an online network among mothers, it is not easy for mothers to be logged-out from the online chat room, because some important messages or notices related to the school class are announced online.

Category 5-2. Witness.

Sometimes mothers witnessed what happened among the children, which often made them surprised or angry. 
" $Z$ commands my girl to obey her when they play together, and my girl cannot command as $Z$ does. This happens consistently and it makes me so upset." (M8).

Category 5-3. Children's reports.

Children told their mothers about their victimization experiences, sometimes on the day of the incident, and other times, a while later.

"Usually, B does not tell me what happened in school. However, after that incident (victimization), she said, 'Mum, I dislike going to school a bit,' so I was aware that something was wrong" (M2).

"J does not tell me in detail, but she tells me when she is bullied. When she washes her hair, she says it ... Children are like that, suddenly they are reminded of previous happenings" (M10).

\section{Theme 6. Mothers' concern.}

The last theme, mothers' concern, showed mothers' worries related to bullying. This theme consisted of the categories "worries of being bullies or victims," "consistency," "lack of coping strategies," and "trust/distrust of teacher".

Category 6-1. Worries of being bullies or victims.

The mothers worried about whether their children could be bullies or victims.

" $B$ can be an aggressor, not a victim, so I warn her when she says something bad. Sometimes she says nasty words. I tell her that she should not say bad things to friends" (M2).

Category 6-2. Consistency.

From early ages, bullying happened frequently, and mothers were afraid that it would be consistent throughout mid-childhood or adolescence.

"I thought these things don't happen at early ages. However, such incidents occur even among first and second graders in elementary school. I worry about what will happen when they grow up" (M6).

"They met when they were very young. It happened sometimes but disregarded at that time. It continued in elementary school, and now $S$ slaps $T^{\prime}$ 's face" (M3).

As M3 mentioned, mothers perceived that a failure to intervene in children's problematic peer relations from an early age could cause the behaviors to become severe.

Category 6-3. Lack of coping strategies.

Mothers were embarrassed and surprised when they heard that their children were being bullied. Generally, they did not know what to do. They told teachers, or asked their children how to react, but were unsure of whether their interventions were appropriate and effective.

"I was so embarrassed when I heard of it. I did not know what to do" (M4).

"I did not know what to do, and to what extent I could intervene in a child's matter ... Even when I say something, I cannot blame or tell the boy off ... he may say 'I just call Oh-e to Oh-ri,' boys are not afraid (of my words)" (M11).

The mothers' responses reflected that they did not have many options for coping. M11's daughter (Oh-e) was verbally bullied because her name had similar pronunciation to Oh-ri (in Korean this means "duck"). M11 expected that the aggressor would not listen to her words, as he knew that she could not speak assertively to him. Thus, he justified or trivialized his behavior, rather than admitted it as bullying.

Category 6-4. Trust/distrust of teacher.

Mothers expected that the teacher would be able to solve bullying incidents. Sometimes their expectations were fulfilled, but sometimes they were not. Depending on teachers' reactions or coping mechanisms, mothers built trustful/distrustful relationships with the teachers. Some mothers formed trustful relationships with teachers while experiencing and dealing with their children's victimization. 
"Last year, the teacher was very helpful. The teacher told me to ask $A$ if she had said bad things. The teacher said that children tend to disclose only specific parts of stories, where they appeared to be the victims. So, I needed to find out what exactly my child's role had been in the matter" (M1).

In contrast, some mothers were disappointed by teachers' passive responses to their children's experiences of victimization. Although they understood the teachers' stance, they were frustrated by the fact that the matter was not dealt with adequately.

"I told Oh-e to ask for help from the teacher. However, the teacher told children not to complain, but to try solving their issues independently. The teacher considered children's reporting as tattling. The teacher has difficulty with looking into every report because children complain about even the most trivial things on a daily basis. The boundary between tattling and reporting is not clear. "I do not know to what extent I have to tell Oh-e 'you have to report to the teacher if bad things happen to you.' She was hurt, cried, and felt she was being bullied and that no one could help ... " (M11).

"I talked through the phone with teacher, the teacher did not consider seriously ... The teacher just seemed to think 'Um ... another mother phones me'" (M10).

As mentioned in the subcategory "peer interaction" under category 2-1. Ambiguity of situation, teachers and mothers have different views. Mothers desired the teachers' help in their children's victimization; however, from the mothers' viewpoints, teachers were perceived to handle general conflicts and victimization in the same way, even though they should be treated differently.

\section{Discussion}

This study showed that bullying among young children occurred explicitly, and in a very sophisticated way. The difficulty in defining bullying among young children arises from the various perspectives on the matter, which hinders communication between people, eventually making the situation difficult to solve.

\subsection{Mothers' Definition of Bullying among Young Children}

Mothers defined the phenomenon of bullying in early childhood as being similar to bullying in middle childhood and adolescence, including the concepts of aggressive behavior, repetition, and an imbalance of power (Olweus 1993). However, one more concept-victim centeredness-was emphasized in the context of early childhood bullying.

The victim-centered aspect of defining bullying is related to the issues of repetition, harm, and the severity of aggression. One physical attack can be categorized as bullying if the child on the receiving end is frightened and damaged by it (Arora 1996), and it does not necessarily need to last a long time. According to Rigby, saying "You weren't bullied. You will never meet the guy again" (Rigby 2006, 32) is not practical. Furthermore, young children's language ability, and the relationships among mothers emphasize the need for victims' perspectives on defining bullying. Due to their limited language ability, children's bullying or victimization situations were less likely to be described accurately. Also, mothers had different perceptions on bullying, depending on whether their children were bullies or victims. These are specified in detail in the following section.

\subsection{Relationship among Mothers and Its Link to Children's Relationships}

Mothers had difficulty in talking about or reporting bullying/victimization incidents, because of their own relationships. Mothers had different perspectives toward bullies and victims, and their personal characteristics contributed to this dichotomy. Their difficulty in ascertaining whether a certain behavior was counted as "bullying" or "general conflict", was consistent in previous studies (Mishna et al. 2006; Purcell 2012). This study provides further reasons for the diverse perspectives on bullying.

Different perspectives toward bullying resulted in anxieties that other mothers, who might judge the situation differently, may not understand or empathize with them. They were afraid of being excluded from mothers' social circles. 
Mothers' and children's social exclusion or bullying were interrelated, and they influenced each other. This was an interesting finding in this study. On one hand, a child's bullying can result in a mother's social exclusion. If the aggressor's mother does not admit that her child's behavior constitutes bullying and instead blames the victim, other mothers may avoid or socially exclude her. On the other hand, a victimized child can cause his/her mother to be excluded. If the victim's mother strongly puts forth her opinions on the victimization of her child, other mothers might think she has gone too far. This is in the similar line with a previous finding; parents were reluctant to be open about the victimization of their child, because they were afraid of being labeled as overprotective, which could influence their child's reputation in kindergarten (Crisp and Humphrey 2008).

Regardless of whether their children are aggressors or victims, mothers can be isolated if they do not accommodate others' perspectives, and are adamant about their own stance. Mothers' group chats can contribute to children's and mothers' bullying. These group chats are not only useful for obtaining information related to children and school work, and for communicating with other mothers, but they make it easy to manipulate relationships, or to spread rumors about happenings among children. Owing to this reason, some kindergartens and schools in South Korea discourage mothers' group chats. In this way, early childhood bullying can be connected to cyberbullying and bullying among mothers.

This implies that it is imperative for mothers to be educated about cyber and traditional bullying. Mothers in group chats could intentionally or unintentionally reveal information that is related to other children, and the other participants of the chat may then become prejudiced toward the children and their mothers.

Mothers were in a dilemma over whether or not to tell others about bullying incidents. If they revealed the incident, they were afraid of being misunderstood by other mothers, and if they did not, their children could be victimized again.

Therefore, mothers generally tried to solve the problem themselves by teaching their children coping strategies, or speaking to the teachers. Sometimes they told the mother of the aggressor, but this was regarded as a risky move, because it could either solve the problem or make it worse.

\subsection{Children's Difficulties}

Children can have difficulty in expressing their victimization experiences, because of their psychological traits (introversion) emotional status (fear), desire to play with the aggressor, and limited language abilities.

Introverted or shy children may be distressed by extroverted or dominant children who strongly express themselves. Socially excluded girls seemed to try not to ruin other children's moods, and to fit in, rather than dwelling on how being excluded made them feel. They might have been under the impression that their relationships will end if they express their negative feelings. Although it was not reported whether the victimized children blamed themselves or not, this may be risky because it allows bullying to continue, negatively affecting the victim's mental health by lowering their self-worth.

Furthermore, the aggressor does not always play that role: he/she could also be a cheerful mate during play. Due to the desire to keep the aggressor as a playmate, children might overlook their victimization experiences in spite of their unpleasant feelings. This does not mean that they forget their victimization: these experiences remain in their memory for a long time, which reflects that the experiences were hurtful for their emotional and mental health. They just might not have known how to express themselves, or how to deal with the unpleasant feelings at the time. This implies that young children must be taught coping strategies and emotion management skills.

Most mothers reported being surprised at the occurrence of bullying at young ages, and worried about its persistence until adolescence. Mothers reported that they did not know what to do when they heard of the victimization of their children. They expected teachers' active involvement in the issues, but this was not always the case. This is the same line with previous findings in that parents were upset and surprised by their children's victimization, and upon seeking help from the school, they were disappointed by the school's responses and felt helplessness about the situation (Brown 2010). 


\subsection{Suggestions for Interventions in Early Childhood Bullying}

Given the findings in this study, it is necessary to develop prevention/intervention programs for bullying in early childhood. While at the school level, there are strict and explicit instructions for what to do in the event of bullying, no such instructions exist in educational institutions for young children. Intervention programs should include the following aspects.

First, education on the concept of bullying should be implemented for mothers, teachers, and children. Helping them to conceptualize the behaviors that can constitute bullying could help to fill the gaps in their perspectives. Then, it can be possible for mothers to discuss the wrong behaviors of children without damaging their relationships. It would also be helpful for teachers to understand that bullying can be defined differently among parents, children, and themselves, and to try to empathize with mothers' and children's perspectives. Although defining bullying is complicated, this procedure is necessary for recognizing bullying, and intervening (Sawyer et al. 2011). Parents' involvement (i.e., information for parents, parents' training) in intervention was found to be an important component in anti-bullying programs (Ttofi and Farrington 2011). However, there are very few studies on education for parents on the concept of bullying in early childhood. This should be considered while developing an intervention program for bullying among young children.

Second, it is important for children to learn to express their experiences in an appropriate way. Young children may have difficulty objectively describing certain situations or experiences, because of their language development levels, as well as self-centric thoughts. Adults can support them in expressing their needs and expectations in appropriate ways. It is essential to educate young children to understand others' intentions.

To define bullying from victims' perspectives (victim-centeredness) appropriate expressions related to their bullying or victimization experiences is necessary. At the same time, mothers and teachers need to be aware that even one incident can count as bullying for young children, whether the incident is severe or not. Adults need to be sensitive and pay attention to what children say and how they behave. Adults may dismiss what children say to them, because they may often regard children's words as being neither severe nor important (e.g., a child kept saying "I don't want to go to kindergarten" but her mother ignored it). However, young children's perceptions of the severity of the incident may differ from that of adults.

It is also imperative to teach children coping strategies: bullied children must learn how to react, and express and report their victimization; and aggressors must learn about how others may feel regarding their behavior, and ask for their needs in a socially appropriate way. Social and emotional skills have been included in intervention programs for young children. For example, 'Second step: A bullying prevention program' focused on developing social skills among children who are four to eight years old. As preventive strategies, controlling impulsive behavior, anger management, and perspective-taking skills were practiced by children (Committee for Children 2014). The program improved children's social emotional competence, and reduced peer problems (Low et al. 2015).

Third, social efforts are necessary to establish a sound cyber culture among mothers. This has not been elucidated in any intervention program; however, given the findings in this study, this should be included in intervention programs for families or parents. Education on cyber goerophim (cyberbullying) for mothers should be implemented. It can prevent connecting bullying among children to bullying or cyberbullying among mothers, thereby improving mothers' sensitivity toward cyberbullying. The power of mothers' cyber communities can be used in a positive way. They can be bystanders who pay attention to the incidents that occur among mothers or children, and judge whether certain behaviors can be regarded as bullying or not. They could encourage the mothers of victims and protect the children whose rumors are being spread.

This study has limitations. First, it investigated mothers' perceptions only, and not those of fathers, and most mothers in this study were relatively highly educated. Parents may show different perceptions on bullying. For example, fathers may be more likely to think that bullying can happen 
while children grow up. Thus, one need to be careful when generalizing the results of this study. Perceptions of mothers who come from more diverse demographic backgrounds are needed.

Second, teachers' voices were not investigated in this study. According to mothers' reports, teachers seem to have more generous views on bullying. Further study is necessary about how teachers' perspectives differ from those of mothers.

Third, it is not known whether relationships among mothers are important in understanding the phenomenon of young children's bullying in other cultures. The replication of this study in other cultures would be helpful in comparing the similarities and differences of mothers' (or parents') perceptions of bullying across cultures.

Last, the expectations from the interventions should be studied further. This study analyzed only mothers' responses to their children's bullying experiences, rather than the need for intervention programs.

\section{Conclusions}

This study shows that understanding bullying among young children is quite complicated. The ambiguity involved in defining bullying, the diverse perspectives among mothers on bullying, the relationships among mothers, and the relationships between mothers and children lead to both mothers' and children's difficulties in speaking of and sharing the victimization experience. Sharing one's victimization experience is important in solving the problem by empathizing and understanding each other. This does not show that bullying among young children is not severe; rather, its severity has not been disclosed nor shared among people. The South Korean government and society must pay attention to bullying among young children. It may contribute to emphasizing parental involvement in bullying studies, though this study was conducted by using a South Korean sample.

Finally, this study can contribute to understanding the nature of bullying in early childhood, improve the attention paid to bullying among young children, and emphasize the need for intervention/prevention programs.

Author Contributions: Conceptualization, H.-j.J.; Data curation, H.-j.J. and S.-h.L.; Formal analysis, H.-j.J. and S.-h.L.; Funding acquisition, S.-h.L.; Investigation: H.-j.J.; Methodology, S.-h.L.; Resources, S.-h.L.; Writing original draft: S.-h.L.; Writing-review \& editing: H.-j.J. and S.-h.L.

Funding: This research was supported by the Chung-Ang University Research Grants in 2018.

Acknowledgments: We deeply appreciated the mothers who were willing to participate in, and shared their experiences for this study.

Conflicts of Interest: The authors declare no conflict of interest. The funders had no role in the design of the study; in the collection, analyses, or interpretation of data; in the writing of the manuscript, or in the decision to publish the results.

\section{Appendix A}

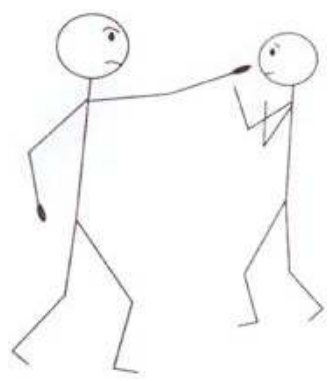

Figure A1. A cartoon: Individual physical aggression. 


\section{References}

Arora, Tiny. 1996. Defining bullying: Towards a clearer general Understanding and More Effective Intervention Strategies. School Psychology International 17: 317-29. [CrossRef]

Arseneault, Louise, Elizabeth Walsh, Kali Trzesniewski, Rhiannon Newcombe, Avshalom Caspi, and Terrie E. Moffitt. 2006. Bullying victimization uniquely contributes to adjustment problems in young children: A nationally representative cohort study. Pediatrics 118: 130-38. [CrossRef] [PubMed]

Brown, James Roger. 2010. Trajectories of Parents' Experiences in Discovering, Reporting, and Living with the Aftermath of Middle School Bullying. Ph.D. dissertation, Indiana University, Bloomington, IN, USA.

Camodeca, Marina, Simona C. S. Caravita, and Gabrielle Coppola. 2015. Bullying in preschool: The associations between participant roles, social competence, and social preference. Aggressive Behavior 41: 310-21. [CrossRef] [PubMed]

Clarke, Elizabeth A., and Mark S. Kiselica. 1997. A systemic counseling approach to the problem of bullying. Elementary School Guidance \& Counseling 31: 310-25.

Committee for Children. 2014. Second Step. Social-Emotional Skills for Early Learning. Available online: http: //www.secondstep.org/Portals/0/common-doc/DECA_SS_alignment.pdf (accessed on 7 January 2019).

Crisp, Beth R., and Gary Humphrey. 2008. Bullying affects us too: Parental responses to bullying at kindergarten. Australian Journal of Early Childhood 33: 45-49.

Department of Education, Korean Educational Development Institute. 2017. Statistical Yearbook of Education. Available online: https://kess.kedi.re.kr/publ/view;jsessionid= IJNOt0tFC4nC64eDrrTCPQIRrKZeGuaM2gOA6xqsX3vAL3puU5hdQuJsmtlDYqt0?survSeq=2017\& publSeq $=2 \&$ menuSeq=3894\&itemCode=02\&language=en\# (accessed on 7 January 2019). (In Korean)

Georgiou, Stelios N. 2008. Bullying and victimization at school: The role of mothers. British Journal of Educational Psychology 78: 109-25. [CrossRef] [PubMed]

Hanish, Laura D., and Nancy G. Guerra. 2002. A longitudinal analysis of patterns of adjustment following peer victimization. Development and Psychopathology 14: 69-89. [CrossRef] [PubMed]

Harcourt, Susan, Marieke Jasperse, and Vanessa A. Green. 2014. We were sad and we were angry: A systematic review of parents' perspectives on bullying. Child \& Youth Care Forum 43: 373-91.

Hofstede, Geert, and Gert Jan Hofstede. 2005. Cultures and organisations: Software of the mind. In Revised and Expanded, 2nd ed. New York: McGillHill.

Hong, Yea-Ji, and Kangyi Lee. 2019. The effect of parenting stress on social interactive parenting with a focus on Korean employed mothers' parenting support from ecological contexts. Children and Youth Services Review 96 : 308-15. [CrossRef]

Kirves, Laura, and Nina Sajaniemi. 2012. Bullying in early educational settings. Early Child Development and Care 182: 383-400. [CrossRef]

Kochenderfer, Becky J., and Gary W. Ladd. 1996. Peer victimization: Cause or consequence of school adjustment? Child Development 67: 1305-17. [CrossRef] [PubMed]

Kwak, Hyun Joo, and Myung Ha Kim. 2016. An Analysis of Early Childhood Teachers' Perceptions and Demands on Teacher Education Programs for School Violence-related Training. The Korean Society for Early Childhood Teacher Education 20: 217-36.

Lee, Seung-ha, Peter K. Smith, and Claire P. Monks. 2011. Perceptions of bullying-like phenomena in South Korea: A qualitative approach from a lifespan perspective. Journal of Aggression, Conflict and Peace Research 3: 210-21. [CrossRef]

Lee, Seung-ha, Peter K. Smith, and Claire P. Monks. 2012. Meaning and usage of a term for bullying-like phenomena in South Korea: A lifespan perspective. Journal of Language and Social Psychology 31: 342-49. [CrossRef]

Lee, Seung-ha, Peter K. Smith, and Claire P. Monks. 2016. Participant roles in peer-victimization among young children in South Korea: Peer-, self-, and teacher-nominations. Aggressive Behavior 42: 287-98. [CrossRef] [PubMed]

Lester, Leanne, Natasha Pearce, Stacey Waters, Amy Barnes, Shelley Beatty, and Donna Cross. 2017. Family involvement in a whole-school bullying intervention: Mothers' and fathers' communication and influence with children. Journal of Child and Family Studies 26: 2716-27. [CrossRef] 
Levine, Emily, and Melissa Tamburrino. 2014. Bullying among young children: Strategies for prevention. Early Childhood Education Journal 42: 271-78. [CrossRef]

Low, Sabina, Clayton R. Cook, Keith Smolkowski, and Jodie Buntain-Ricklefs. 2015. Promoting social-emotional competence: An evaluation of elementary version of Second Step. Journal of School Psychology 53: 463-77. [CrossRef]

Mishna, Faye. 2004. A qualitative study of bullying from multiple perspectives. Children E Schools 26: $234-47$.

Mishna, Faye, Debra Pepler, and Judith Wiener. 2006. Factors associated with perceptions and responses to bullying situations by children, parents, teachers, and principals. Victims and Offenders 1: 255-88. [CrossRef]

Monks, Claire P., and Peter K. Smith. 2006. Definitions of bullying: Age differences in understanding of the term, and the role of experience. British Journal of Developmental Psychology 24: 801-21. [CrossRef]

Monks, Claire P., Rorasio Ortega Ruiz, and Elena Torrado Val. 2002. Unjustified aggression in preschool. Aggressive Behavior: Official Journal of the International Society for Research on Aggression 28: 458-76. [CrossRef]

Monks, Claire P., Peter K. Smith, and John Swettenham. 2003. Aggressors, victims, and defenders in preschool: Peer, self-, and teacher reports. Merrill-Palmer Quarterly 49: 453-69. [CrossRef]

OECD. 2015. Early Learning and Development: Common Understanding. Available online: http:/ /www.oecd.org/ education/school/ECEC-Network-Common-Understandings-on-Early-Learning-and-Development.pdf (accessed on 24 December 2018).

Olweus, Dan. 1993. Bullying at School: What We Know and What We Can Do. Oxford: Blackwell.

Park, Jin ah, Chang Hyun Park, and Ji-won Eom. 2015. Mid-to-Long Term Forecasts of the Demand and Fiscal Spending for Early Childhood Education and Childcare. Research Report. Seoul: Korean Institute of Child Care and Education, Available online: http:/ / www.kicce.re.kr/kor/publication/02.jsp? mode=view\&idx=18986\& startPage=20\&listNo=95\&code=report01\&search_item $=\&$ search_order=\&order_list=10\&list_scale=10\& view_level=0 (accessed on 24 December 2018). (In Korean)

Perren, Sonja, and Françoise D. Alsaker. 2006. Social behavior and peer relationships of victims, bully-victims, and bullies in kindergarten. Journal of Child Psychology and Psychiatry 47: 45-57. [CrossRef] [PubMed]

Purcell, Anita. 2012. A qualitative study of perceptions of bullying in Irish primary schools. Educational Psychology in Practice 28: 273-85. [CrossRef]

Repo, Laura, and Nina Sajaniemi. 2015. Prevention of bullying in early educational settings: Pedagogical and organisational factors related to bullying. European Early Childhood Education Research Journal 23: 461-75. [CrossRef]

Rigby, Ken. 2006. Bullying in Schools: And What to Do about It. London: Jessica kingsley.

Sawyer, Jami-Leigh, Faye Mishna, Debra Pepler, and Judith Wiener. 2011. The missing voice: Parents' perspectives of bullying. Children and Youth Services Review 33: 1795-803. [CrossRef]

Smith, Peter K., Helen Cowie, Ragnar F. Olafsson, and Andy P. D. Liefooghe. 2002. Definitions of bullying: A comparison of terms used, and age and gender differences, in a Fourteen-Country international comparison. Child Development 73: 1119-33. [CrossRef]

Song, Eun Young, and Kyung Min Lee. 2014. An Analysis on the Status and Kindergarten Teachers' Awareness of Bullying Occurring in Kindergarten. Journal of Future Early Childhood Education 21: 289-315.

Strauss, Anselm, and Juliet Corbin. 1998. Basics of Qualitative Research: Procedures and Techniques for Developing Grounded Theory. Thousand Oaks: Sage.

Ttofi, Maria M., and David P. Farrington. 2011. Effectiveness of school-based programs to reduce bullying: A systematic and meta-analytic review. Journal of Experimental Criminology 7: 27-56. [CrossRef]

Vlachou, Maria, Eleni Andreou, Kafenia Botsoglou, and Eleni Didaskalou. 2011. Bully/victim problems among preschool children: A review of current research evidence. Educational Psychology Review 23: 329-58. [CrossRef]

Williams, Amanda J., Danielle Smith, and Rebecca Winters. 2016. Applying Olweus' conceptualization of bullying to early childhood. In Contemporary Perspectives on Research on Bullying and Victimization in Early Childhood Education. Edited by Olivia N. Saracho. Charlotte: Information Age Publishing.

(C) 2019 by the authors. Licensee MDPI, Basel, Switzerland. This article is an open access article distributed under the terms and conditions of the Creative Commons Attribution (CC BY) license (http:/ / creativecommons.org/licenses/by/4.0/). 


\title{
Article \\ What Parents Can Do to Prevent Cyberbullying: Students' and Educators' Perspectives
}

\author{
Wanda Cassidy ${ }^{1}$, Chantal Faucher ${ }^{2, *}$ and Margaret Jackson ${ }^{3}$ \\ 1 Faculty of Education, Simon Fraser University, Burnaby, BC V5A 1S6, Canada; cassidy@sfu.ca \\ 2 Centre for Education, Law and Society, Simon Fraser University, Surrey, BC V3T 0A3, Canada \\ 3 School of Criminology, Simon Fraser University, Burnaby, BC V5A 1S6, Canada; margarej@sfu.ca \\ * Correspondence: cfaucher@sfu.ca; Tel.: +1-778-782-8045
}

Received: 30 October 2018; Accepted: 26 November 2018; Published: 28 November 2018

\begin{abstract}
This article presents findings related to the role parents can play in the prevention of cyberbullying and the promotion of cyber-kindness. The findings are drawn from a study conducted at a private school in Western Canada, involving 177 student survey participants in Grades 8 through 10 (including both day students and boarding students) and interviews with 15 educators employed at the same school. Findings relate to parental supervision of computer usage, students' willingness to inform parents about cyberbullying, and how students and educators view the role of parents in relation to the prevention of cyberbullying and the promotion of cyber-kindness. Education, dialogue, relationship strengthening, computer usage monitoring, and partnerships between schools and parents are emphasized as solutions, which are highly consistent with the existing research literature on this topic. Additionally, the study reveals the particular vulnerability of boarding students to cyberbullying victimization and perpetration.
\end{abstract}

Keywords: cyberbullying; prevention; cyber-kindness; parents; K-12; private school; boarding students; information and communication technology

\section{Introduction}

Parents, educators, and students alike have concerns related to the cyberbullying that affects youth in Canada and around the world. Most Canadian teenagers today cannot recall a world without the Internet, nor would they wish to do so. The Internet has brought new opportunities in terms of education, idea exchange, and socializing to levels earlier generations could not have imagined. However, the benefits have also brought with them some problems, cyberbullying among them, to which solutions are sought by all concerned.

For some time, researchers have been examining the nature and extent of cyberbullying behaviors and the impacts such online interactions have in order to develop solutions that are based on a greater awareness and understanding of the issue.

In this article, we examine data from a survey of students at a private school in Western Canada, and interviews with educators from the same school about the issues of cyberbullying and cyber-kindness. In particular, we consider the data that relates to family variables and what parents can and should do to prevent cyberbullying and promote cyber-kindness.

\section{Literature Review}

Cyberbullying has been the predominant term used by Canadian (and other) researchers to refer to online behaviors that are offensive, derogatory, exclusionary, unwanted, and hurtful (Beran et al. 2015; Cassidy et al. 2013; Deschamps and McNutt 2016; Li 2010; Mishna et al. 2014), and self-reports have been the primary means through which researchers have been able to learn about 
this problem (Beran et al. 2015; Cassidy et al. 2009; Li 2010; Mishna et al. 2012). Specific operational definitions of cyberbullying vary and no universal tool for measuring cyberbullying prevalence has been adopted. As a result, prevalence rates vary. For example, several Canadian studies report cyberbullying victimization rates ranging from $14 \%$ to $50 \%$ of youth surveyed and self-reported cyberbullying perpetration rates ranging from 25\% to 36\% (Beran et al. 2015; Cassidy et al. 2009; Cénat et al. 2015; Li 2010; Mishna et al. 2010, 2012; Wade and Beran 2011).

Cyberbullying can, nonetheless, be said to impact a considerable number of young people, including those who are targets, perpetrators, both, and/or witnesses or bystanders. Reported impacts on cyberbullying victims include a wide range of mental and physical health effects, school problems, and impacts on relationships (Beran et al. 2012, 2015; Cassidy et al. 2009, 2017; Mishna et al. 2014).

Parents' awareness of their children's involvement in cyberbullying, whether as perpetrator or victim, is relatively low (Cassidy et al. 2012), as is the awareness among school authorities and staff (Cassidy et al. 2012). Parents may have the expectation that schools will deal with cyberbullying, while schools may counter that the problem is within the families' responsibilities if the cyberbullying was conducted outside of school hours on a device in the home.

Regardless of where the responsibilities lie, a range of responses have been consistently supported by research participants in studies on cyberbullying among children and youth: cyberbullying education for all concerned (students, parents, school staff), cyberbullying policies that are clear and well implemented, better reporting mechanisms, more support for victims, improving school climate and culture, and role modeling (Cassidy et al. 2011, 2012, 2012, 2013; Ryan et al. 2011). Zero-tolerance and punishment-based approaches do not appear to hold much promise, despite the apparent popularity of such "tough stance" approaches. Such approaches do little to repair the harm caused by cyberbullying and to prevent further harm. An ethic of care approach that is inclusive and respectful of all involved, values relationships and community building (Noddings 2002, 2005, 2006) offers more long-term promise.

What makes carving out appropriate responses and solutions to the problem of cyberbullying among children and youth more pressing is that the problem does not end at high school graduation (Faucher et al. 2015). Cyberbullying has also been documented as a significant challenge in post-secondary education (Cassidy et al. 2019; Cowie and Myers 2015) as well as in the workplace (Baruch 2005; Coyne et al. 2017; D'cruz and Noronha 2013; Privitera and Campbell 2009). Cyberbullying occurs on platforms that feature prominently in the everyday life of post-secondary students, faculty, and other workers. These (adult) individuals report similar impacts from the cyberbullying as those reported by children and youth: physical and mental health impacts, impacts on relationships, and impacts on performance and motivation. As such, early intervention is imperative.

\section{Materials and Methods}

In 2011, the first and third authors were approached by the principal of a private school (School A) in Western Canada, to conduct a study of cyberbullying at the school. The name and exact location of the school has been withheld in order to protect the anonymity of all participants. Some relatively serious incidents of cyberbullying had occurred involving members of the school community, which had raised the concerns of school staff as well as parents. The principal was aware of the first and third authors' previous work and asked for a study similar to what they had done in other schools. They were looking for a better understanding of the issue at the local level in order to enact change based on the research results and recommendations informed by those specific results, as would be consistent with participatory research principles (Cornwall and Jewkes 1995). While the research drew from past work of the first and third authors, it also incorporated specific local concerns (day versus boarding students, particular issues that had arisen at that school, etc.).

The authors surveyed 177 students at School A and interviewed 15 teachers and other school staff about the issues of cyberbullying and how to promote cyber-kindness. The school received comprehensive reports of the findings from the student surveys and from the educator interviews. 
These are available online at http:/ / www.sfu.ca/education/cels/research/publications---reports.html or upon request from the corresponding author. A review of the full range of findings is beyond the scope of this paper.

In keeping with the theme of this special issue, the focus of this article is students' and educators' views on what parents can do to prevent cyberbullying and promote cyber-kindness. In this study, cyberbullying was defined as the use of various formats of electronic communication (Facebook, email, text messages, camera phones, blogs, websites, YouTube, chat rooms, etc.) to convey messages that are mean, hurtful, nasty, derogatory, vulgar, untrue, or generally unkind. In contrast to face-to-face bullying, electronic messages can reach a far wider audience, exist in perpetuity, and the perpetrators' identity can more easily remain unknown.

In contrast, cyber-kindness is understood to mean the use of those same modes of communication for the purpose of expressing care, kindness, and thoughtfulness in ways that may bolster self-esteem in the recipient.

The study protocol was submitted to ethics review by the SFU Office of Research Ethics and categorized as "Minimal Risk" (file 2011s0661). Participation in the student survey at School A was completely voluntary and respondents were assured that their responses would remain anonymous. Parental consent and participant consent were secured prior to distribution of the student surveys. Participants in the educator interviews were also assured their anonymity would be protected and all documentation referred to interview participants through pseudonyms. Participation in the interviews was completely voluntary and participant consent was secured prior to each interview.

After parental and participant consent were obtained, the research team distributed paper surveys to student participants during a series of school assemblies scheduled for this purpose. The researchers assured students that their responses were anonymous and remained on site to answer any questions that arose during the completion of the surveys. The surveys contained 177 closed- and open-ended questions asking respondents about their demographic variables (grade level, gender, age, whether they were day students or boarding students, first language and main language spoken at home, race/ethnicity), home and school life, information and communication technology (ICT) access and usage, beliefs and opinions, experiences with cyber-kindness and cyberbullying as victim, witness, and/or perpetrator, and thoughts on solutions to cyberbullying. A total of 177 surveys were completed and analyzed using IBM SPSS (U.S. version 21.0) descriptive statistics for the closed-ended questions and thematic analysis for the open-ended responses.

Educators (administrators, teachers, counsellors, house parents) at the school were invited to participate in semi-structured individual interviews with one of the researchers. In total, 15 educators volunteered to be interviewed. The interviews were held in a private setting at the school. After securing consent from the participants, the interviews were audio-recorded and later transcribed in full. The interviews lasted between 20 and $60 \mathrm{~min}$ and covered a range of topics related to the interviewees' own familiarity levels with various forms of on-line exchanges, their degree of concern with and awareness of cyberbullying that happens, the importance of cyberbullying prevention and cyber-kindness, their awareness of school policies and curriculum that specifically address cyberbullying, ideas about how best to address and/or prevent cyberbullying, roles that parents and educators can play in that regard. The researchers conducted a thematic analysis of the interview transcripts using a grounded theory process (Merriam and Tisdell 2016) where the themes were determined on the basis of interaction with the data (Miles and Huberman 1994). Certain themes recurred in most of the interviews, while others (though less prevalent) were emphasized particularly strongly by some of the participants. 


\section{Findings}

\subsection{Participants}

The student survey participants were in grades 8 to 10 at School A (21\% from Grade 8, 43\% from Grade 9, and 36\% from Grade 10), 60\% were female, and $72 \%$ were day students while the remainder were boarding students living in the residences at School A. The majority identified English as their first language learned (69\%) and the main language currently spoken in their home (72\%). Most of the student participants were born in Canada $(60 \%)$ and identified their racial/ethnic group as Caucasian $(50 \%)$ or Asian $(24 \%)$.

The educator interview participants included men and women who had been working at School A for an average of 12 years (between two and 23 years), and in the field of education more broadly for an average of 24 years of experience (between 11 and 38 years). They occupied a variety of roles within School A including teachers, house parents, administrators, counsellors, IT workers, advisors, coaches, and individuals involved in organizing extra-curricular activities.

\subsection{Parental Supervision of Computer Use and Cyberbullying}

Most students, whether day students or boarding students, had access to at least three computers on a daily basis and more than half of them tended to use computers in a private setting such as their bedroom or a home office, suggesting that parental or guardian supervision of online activities would be unlikely. The predominant time of day during which they went online was between the time school ended and the time they went to bed, however one third of participants indicated that they used their computer in the late evening or at night time, particularly those who were boarding and were communicating with friends and family in a different time zone.

Despite times and places of computer usage that suggest limited adult supervision, when asked whether cyberbullying behaviors tended to start at home or school, the vast majority responded that cyberbullying was more likely to start at school and continue once they got home or to their residence $(71 \%)$, rather than starting in the home environment and continuing once they got to school $(27 \%)$.

Boarding students were slightly more likely to report being cyberbullied overall, including being cyberbullied by someone they considered a friend as well as being cyberbullied by a classmate or acquaintance they did not know very well. For instance, as shown in Table 1, 33.1\% of day student respondents indicated they had never been cyberbullied by a friend, classmate, or acquaintance, compared to $18.8 \%$ of boarding students. Meanwhile, $42.5 \%$ of day students and $52.1 \%$ of boarding students indicated they had been cyberbullied "often" by one or more of these groups of students. Boarding students were also more likely to report having themselves engaged in cyberbullying another student ( $47.9 \%$ once or twice and $2.1 \%$ often, compared to $26.8 \%$ and $0.8 \%$ respectively for day students) and slightly more likely to report having cyberbullied a teacher or school principal (22.9\% of boarding students admitted to doing this once or twice and $2.1 \%$ often, compared to $17.3 \%$ of day students admitting to doing this once or twice and $2.1 \%$ often).

Table 1. Comparison of day and boarding students' involvement with cyberbullying.

\begin{tabular}{lcc}
\hline Behavior & Day Students (\%) & Boarding Students (\%) \\
\hline Cyberbullied by another student-Never & 33.1 & 18.8 \\
Cyberbullied by another student (or students)_Often & 42.5 & 52.1 \\
Engaged in cyberbullying another student_Once or twice & 26.8 & 47.9 \\
Engaged in cyberbullying another student-Often & 0.8 & 2.1 \\
Engaged in cyberbullying a teacher or principal-Once or twice & 17.3 & 22.9 \\
Engaged in cyberbullying a teacher or principal-Often & 2.1 & 2.1 \\
\hline
\end{tabular}




\subsection{Informing Parents about Cyberbullying}

Just over half of respondents said that if they were victims of cyberbullying, they would tell their parents or guardians about it. Female students, younger students, boarding students, students who have never been cyberbullied, and students who have never cyberbullied someone else (student or school staff) were more likely to respond in this way than their respective counterparts. On the other hand, boarding students were much more likely than day students to keep cyberbullying victimization to themselves and tell no one at all (31.3\% of boarding students responded in this way compared to $15 \%$ of day students). The overall rate of students who stated that they would tell their parents if they were victims of cyberbullying $(53.7 \%)$ was higher than the rate of those who said they would tell a member of the school staff $(40.1 \%)$, but lower than the rate who said they would tell their friends if they were being cyberbullied $(72.9 \%)$.

Students were also asked who, if anyone, they would tell if they witnessed someone else being cyberbullied and less than half said they would tell their parents. Again, female students were more likely to respond positively as were younger students, students who had been cyberbullied often and those who had never cyberbullied someone else. As well, boarding students were more likely than day students to keep it to themselves when they witnessed someone else being hurt ( $16.7 \%$ compared to $7.1 \%)$. Students overall were less likely to tell their parents (47.5\%) than school staff $(54.2 \%)$ or their friends $(67.8 \%)$ if they witnessed someone else being cyberbullied.

\subsection{What Should Parents Do-Students' Views}

Two of the open-ended questions asked student respondents to comment on what parents should do (1) to encourage kind, thoughtful, and caring online interactions (cyber-kindness) and (2) to prevent cyberbullying. The two sets of responses overlapped quite significantly, such that they are presented here as a group. The main themes that emerged from the responses to these two questions included: education approaches, role modeling and building strong relationships, technology monitoring and restrictions, and punishment if needed. These themes are summarized in Table 2 and explored in greater depth through participants' responses below.

Table 2. Summary of key themes.

- Teach about cyberbullying, cyber-kindness, online privacy, long-term effects of cyber-behaviors

Education approaches

- Parents, teachers, and students to educate themselves in order to participate in meaningful dialogue

\begin{tabular}{|c|c|}
\hline Role modeling & - Model desirable behavior online and offline, especially kindness \\
\hline Relationship building & $\begin{array}{l}\text { - } \quad \text { Kind and supportive home } \\
\text { - } \quad \text { Close parent-child relationships } \\
\text { - Take an interest in child's life }\end{array}$ \\
\hline Technology & $\begin{array}{ll}\text { - } & \text { Monitor usage } \\
\text { - } & \text { Limit time online } \\
\text { - } & \text { Restrict access if necessary }\end{array}$ \\
\hline Punishment & $\begin{array}{l}\text { - None specified other than removing access to certain sites } \\
\text { or devices }\end{array}$ \\
\hline
\end{tabular}


The predominant theme among the responses for how best to prevent cyberbullying and promote cyber-kindness focused on education. Students said parents should teach their children about bullying, cyberbullying, online privacy, and the kinds of long-term effects that may come from posting certain types of messages online. They suggested it was important to remind children often about these things, but not lecturing about the topic: "don't have a super serious talk, its ${ }^{1}$ awkward" (15-year-old female day student). Rather, they favoured an open conversation about cyberbullying, that would educate about the consequences and use personal stories and concrete examples in order to be more relatable.

Explain to them that what they say can never be permanently "deleted" off the internet. This is why my brother deleted his facebook when he decided to go to law school. Future employers or schools can see everything, so you have to think of the long term effects of your posts (15-year-old female day student)

Put it into perspective by talking to their children: Ask them how it would feel if someone randomly posted something nice to brighten their day on their facebook wall, and how they should do it, too. (15-year-old female day student)

learn about it, talk to child every once \& a while $1 /$ month MAX or we tune out. (14-year-old female day student)

Remind their kids to be more kind, thoughtful and caring everyday. (15-year-old male boarding student)

Parents should explain to their children that online harassment is not acceptable and they should be kind to one another online and even offline. (16-year-old male day student)

The second theme of responses suggested that, in order to prevent cyberbullying and promote cyber-kindness, parents should model the desirable behaviors they wished to see in their children, whether that be appropriate online interactions or kindness more broadly.

Set the example; be kind to one another and stay friends with your child. If they see you as a friend as well as their parents, they will see that their friend is kind, therefore they may be more kind. (15-year-old female day student)

Be an example of kindness when they themselves are using technology to communicate. (14-year-old female day student)

Be kinder to each other and set a good example, be nice to the child, monitor the child's internet sometimes. (14-year-old male boarding student)

The theme of role modeling was also closely tied to the idea of building strong relationships between parents and their children. The student respondents stated that parents should talk to their children more generally (not specifically about cyberbullying). They should be aware what is going on with their children. One student expressed the idea that a kind and supportive home based on close parent-child relationships was most conducive to the promotion of cyber-kindness and elimination of cyberbullying:

If there is to be peace between neighbours (e.g., students), there must be peace in the home. If there is to be peace in the home, there must be peace in the heart. To attack the root problem, perhaps parents being kind to their children and try to support them. Don't nag, don't pry too much and don't sugarcoat your words most important, it only annoys. Be calm and make your home a relaxing haven to try and achieve peace in the heart and in the home. (15-year-old female day student)

1 Note: Students' comments are reproduced as written by the students. 
Another student said cyberbullying could be prevented: "By being caring, loving parents and not forget about their kids" (14-year-old female day student).

Simply talk with their children and find out the reason and care of why they did it. Explain the whole situation and help find a suitable solution. (13-year-old female day student)

Compliment, help with school. (14-year-old female day student)

Ask their kids how their day went etc., don't accept "it's fine" as an answer. If it was bad, be aware of their online standing. Ask caring questions. (13-year-old male day student)

The third theme among the responses emphasized that access to technology is at least part of the problem when it comes to cyberbullying. Many student survey respondents stated that parents should impose restrictions on technology usage, limit time spent online, and monitor what their children are doing online. Some went as far as to say that access to technology should be taken away when a child is found to be engaging in cyberbullying, however, other respondents argued that this approach does not work.

Moniter their childs computer hours (as a child growing up) and useage. (For ex..: My dad only lets us use the family computer in the livingroom) in that case because my dad was around I was very cautious of what I was doing and still am that way even when he isn't monitoring me. (15-year-old female boarding student)

Parents should pay attention to what their children do online, they should also encourage good behavior (14-year-old male day student)

Set consequences. If their children cyberbully, the cellphone is taken away or their FB account deleted. Also, put it in perspective and talk about why they shouldn't do it, because if it were done to them, they wouldn't like it. (15-year-old female day student)

Parents should limit computer time and maybe once in a while check what their child is actually doing online. They should regularly remind them that cyberbullying is bad and can drive kids to hurt or even kill themselves, and that they should never take part in it. (13-year-old female day student)

Limit how much technology they can use. Lots of kids have FB and don't realize what they should or shouldn't be posting. (15-year-old male boarding student)

Let their children to have less time on the internet (14-year-old male boarding student)

Have parents able to access some of the ongoings of social networking of their children. Have computer in the living room where parents could watch over. (15-year-old female day student)

However, it should be noted that other respondents argued that this approach of restricting access to technology tools does not work.

But, the problem is, they will always find some other device unknown by parents; either a friend's or at school. (15-year-old female day student)

They also raised concerns about their privacy and not wanting parents to be intrusive into their online interactions.

The final theme identified among the student survey responses, though far less prevalent than the previous four, was that punishment should be imposed when online misbehavior occurred. The student survey also offered a set of potential solutions for students to rate and punishment was not among the highest rated solutions. However, $29.8 \%$ of day students and $16.7 \%$ of boarding students identified punishment of students who participate in cyberbullying among their top three choices in the suggested solutions. 


\subsection{What Should Parents Do-Educators' Views}

Not surprisingly, the educators interviewed also favoured educational approaches above all else, education for students, educators, as well as parents. On the topic of parental education, the educators placed a great deal of emphasis on its importance in preventing cyberbullying. Interview participants considered that many parents lack awareness of their children's online behavior, activities, and social media presence, of the on-line risks youth face, and of the school's policy and rules related to appropriate use of information technology. According to those interviewed, parents provide their children with access to technology, but fail to monitor their online presence and behaviors.

The respondents, many of whom are parents themselves, discussed how education and awareness served to increase parents' abilities to engage in meaningful conversations about technology with their children. Since the majority of students surveyed claimed they would tell their parents if they were being cyberbullied, it is imperative that parents be adequately prepared to engage in these conversations in an informed manner. Some participants mentioned that School A had offered workshops for parents, which they felt was a positive contribution to parental education, but, of course, this would only be of benefit to those parents who lived locally.

The building of strong parent-child relationships was also raised by the educators. They placed a great deal of emphasis on parents' availability and presence in their children's lives, noting that parents' roles in raising healthy, confident, and responsible children cannot be understated, and that they should lead by example and model the behaviors they wish to see in their children.

Interview participants also discussed the roles of parents in terms of the idea that schools and parents are partners in the prevention of cyberbullying. Some suggested that the diversity of perspectives (and varying degrees of realism) among parents about the role and place of information technology in their children's lives and on what are appropriate restrictions to impose led to some difficulty for implementing policies and discipline around the issue of cyberbullying. They argued that raising awareness among parents of the nature and extent of cyberbullying would help to promote collaboration between the parents and the school, as well as engaging all stakeholders (including students) in a community conversation about this issue.

The common wisdom at the time of data collection was that children's online behaviors could best be monitored by giving them access to computers only in open areas that parents could easily monitor (Sakellariou et al. 2012; Ybarra and Mitchell 2004). The educators interviewed also raised this perspective. They were concerned over unsupervised computer usage that occurred behind closed doors or late at night when parents were not monitoring the behavior. They felt parents could take on a greater role in setting limits on usage (time and place), monitoring that usage, and modelling the online behaviors for their children to emulate. Since then, the increasing proliferation of smart phones and other portable electronic devices that can easily access the Internet has perhaps made this idea obsolete. If that is the case, then the need for education of both parents and children is further reinforced. Monitoring computer usage may now require more inventiveness than restricting times and places in which computers and other electronic devices can be used. A panoply of applications have been developed to allow parents remote access to their children's devices, restricting times of day when the Internet can be accessed, total time online per day, and/or types of sites to be accessed. Such approaches may be useful for monitoring time spent online and cyber-behaviors, however, they do seem to be premised on a lack of trust. More consistent with the study's findings would be to maintain an open conversation between parents and children where online behaviors are examined and discussed with confidence.

\section{Discussion}

During the time the researchers spent at School A, school staff mentioned that they were satisfied to see the approach taken in this study. They were pleased that educators' voices were included in order to give context for the student survey findings and that the role of family was being given consideration. There was also an appreciation of the fact that the focus of the study was on how to 
promote cyber-kindness, rather than only on the negative conduct, or cyberbullying. One educator being interviewed even mused that it might be better to call this research cyber-kindness research so as to not worry the parents about the possibility of cyberbullying occurring at the school they pay money to for their child to attend.

In following up with the principal of School A after the research reports had been delivered (over six months after the survey had been administered), the third author enquired as to whether any new incidents of cyberbullying had arisen since the survey. The principal reported only one incident related to the use of mimes (involving two boarding students). Emphasis was placed on several positive aspects in that case: a bystander became involved, tried to intervene with the perpetrator (although without success), then told his or her parents who reported it to the school. Such responses were deemed appropriate by the principal who felt that the reaction may have been aided by the participation in the survey and ensuing discussions about cyberbullying.

Although this study cannot properly be termed participatory research, some principles of participatory research can be seen in the initiation of the study as well as in the follow-up with the local community. Research results were used to direct action and decisions for addressing cyberbullying and related problems within the school community.

The school organized a presentation to inform the parents about the study findings, but the meeting was very poorly attended, with only a handful of families showing up. This turnout was contrasted with the previous year's presentation following a serious cyberbullying incident at the school in which families had turned out in very large numbers. Although anecdotal, such a contrast does highlight a tendency for parents to be more reactive than proactive in their approach to the issue of cyberbullying. For both the researchers and the principal, it was a clear indication of the need to develop parental education about cyberbullying, particularly among the generation of parents who are not intimately familiar with technology or with how technology might be used to cyberbully.

The school also organized a discussion with the students and sought suggestions for creating a more positive school environment. Twelve students volunteered to participate in a focus group about positive aspects of their school and what could be improved. Some positive aspects were highlighted, but also what the principal termed a sort of "fear factor" — students behave due to fear of punishment, suspension, expulsion, etc. Disciplinary actions were seen by the principal as fairly limited in terms of their potential to address the issue, although such actions were mentioned by both students and educators in this study as a means of responding to online misbehavior.

Whereas the findings in this study are limited to students and educators from one school, they are highly consistent with findings from a larger earlier study conducted by two of the authors involving students, teachers, and parents from five schools in the same province. For instance, student survey respondents in the larger study (Cassidy et al. 2009) also predominantly felt that cyberbullying starts in the school context and continues in the home setting. The rates of reporting to parents, school personnel, and friends when one is a victim or witness of cyberbullying are nearly identical between the two studies, as are the rates for telling no one at all.

Educators interviewed in the earlier study (Cassidy et al. 2012) were similarly concerned about parents' relative lack of awareness about their children's online behavior and lack of knowledge about ICT in general. The need for parental monitoring of ICT usage was emphasized as well as the need for the school and parents to collaborate with students in identifying solutions to this problem.

The earlier study also included a parent survey (Cassidy et al. 2012), which demonstrated that parents' ideas about the solutions to cyberbullying are consistent with the views of students and educators. Role modelling, open dialogue, and education stood out among parents' views on solutions. Stricter controls over ICT usage were also mentioned, though with less frequency and importance to the overall solution. 


\section{Conclusions}

Therefore, from our analyses, it is apparent that there is a range of perspectives on the role parents can play in the solution to cyberbullying that is fairly consistent between students, educators, and parents. Education and awareness about cyberbullying and cyber-kindness is needed for all concerned parties. Education is the key for accessing a dialogue that is fruitful and positive and serves as a foundation for building strong relationships between students and their parents. Role modelling of appropriate online and offline behaviors is important, as is the monitoring of students' online interactions.

Further, the present study brought added attention to the particular vulnerabilities of boarding students, compared to day students as far as cyberbullying. On the one hand, these students are in some ways a captive audience in terms of ICT usage. They may be staying up late to communicate with their family overseas and ICT may be their principal means of communication. As such, they are particularly vulnerable to cyberbullying victimization at a higher rate than day students. On the other hand, their ICT usage (and behavior more generally) may be less closely monitored than day students', which may be a factor in accounting for their greater involvement in the perpetration of cyberbullying behavior.

Future research should be undertaken to examine the public/private divide more closely, such as with government oversight and the public coffers for public schools, as opposed to those more proximally concerned about this kind of behavior in the private schools, that is, parents and private donors. Such a discrepancy might well affect the type of responses put in place. Similarly, educators in public schools may experience differing pressures compared to educators in private schools. These pressures may also be exerted when dealing with cyberbullying, thus producing a different approach and focus of intervention.

\section{Limitations}

This study did not purport to be able to produce widely generalizable findings as its purpose was to examine the issue of cyberbullying and the potential for cyber-kindness at the local level for the benefit of one specific school community. Although some principles of participatory research were followed, it should be noted that the local community was not involved in the data collection, interpretation, and analyses phases, which would have been consistent with a true participatory research process (Cornwall and Jewkes 1995). The findings of this study are based on a relatively small non-random sample of students and educators and are, therefore, not generalizable to other schools or locations.

Author Contributions: Conceptualization, W.C. and M.J.; Data curation, C.F.; Formal analysis, W.C., C.F. and M.J.; Investigation, W.C. and M.J.; Methodology, W.C. and M.J.; Project administration, W.C. and M.J.; Supervision, W.C. and M.J.; Writing-original draft, C.F.; Writing—review \& editing, W.C. and M.J.

Funding: This research was funded through the Centre for Education, Law and Society.

Acknowledgments: The authors wish to acknowledge the Assistant Director, Student Life at School A for her contribution and support of this research, as well as Karen Brown for her assistance in designing and administering the survey and conducting some of the interviews.

Conflicts of Interest: The authors declare no conflict of interest.

\section{References}

Baruch, Yehuda. 2005. Bullying on the net: Adverse behavior on e-mail and its impact. Information \& Management 42: 361-71. [CrossRef]

Beran, Tanya, Lauren Stanton, Ross Hetherington, Faye Mishna, and Shaheen Shariff. 2012. Development of the bullying and health experiences scale. Interactive Journal of Medical Research 1. [CrossRef] [PubMed]

Beran, Tanya, Faye Mishna, Lauren B. McInroy, and Shaheen Shariff. 2015. Children's experiences of cyberbullying: A Canadian national study. Children $\mathcal{E}$ Schools 37: 207-14. [CrossRef] 
Cassidy, Wanda, Karen Brown, and Margaret Jackson. 2011. Moving from cyber-bullying to cyber-kindness: What do students, educators and parents say? In Youth Culture and Net Culture: Online Social Practices. Edited by E. Dunkels, G.-M. Franberg and C. Hallgren. Hershey: IGI Global Press, pp. 256-77. ISBN 9781609602093.

Cassidy, Wanda, Karen Brown, and Margaret Jackson. 2012. "Making kind cool": Parents' suggestions for preventing cyber bullying and fostering cyber kindness. Journal of Educational Computing Research 46: 415-36. [CrossRef]

Cassidy, Wanda, Karen Brown, and Margaret Jackson. 2012. "Under the radar": Educators and cyberbullying in schools. School Psychology International 33: 520-32. [CrossRef]

Cassidy, Wanda, Chantal Faucher, and Margaret Jackson. 2013. Cyberbullying among youth: A comprehensive review of current international research and its implications and application to policy and practice. School Psychology International: Special Issue on Cyberbullying 34: 575-612. [CrossRef]

Cassidy, Wanda, Chantal Faucher, and Margaret Jackson. 2017. Adversity in university: Cyberbullying and its impacts on students, faculty and administrators. International Journal of Environmental Research and Public Health 14: 888-906. [CrossRef] [PubMed]

Cassidy, Wanda, Chantal Faucher, and Margaret Jackson, eds. 2019. Cyberbullying at University in International Contexts. London: Routledge, ISBN 9781138730397.

Cassidy, Wanda, Margaret Jackson, and Karen Brown. 2009. Sticks and stones can break my bones, but how can pixels hurt me? Students' experiences with cyber-bullying. School Psychology International 30: $383-402$. [CrossRef]

Cénat, Jude Mary, Martin Blais, Martine Hébert, Francine Lavoie, and Mireille Guerrier. 2015. Correlates of bullying in Quebec high school students: The vulnerability of sexual-minority youth. Journal of Affective Disorders 183: 315-21. [CrossRef] [PubMed]

Cornwall, Andrea, and Rachel Jewkes. 1995. What is participatory research? Social Science E Medicine 41: 1667-76. [CrossRef]

Cowie, Helen, and Carrie-Anne Myers, eds. 2015. Bullying among University Students: Cross-National Perspectives. London: Routledge, ISBN 9781138809260.

Coyne, Iain, Samuel Farley, Carolyn Axtell, Christine Sprigg, Luke Best, and Odilia Kwok. 2017. Understanding the relationship between experiencing workplace cyberbullying, employee mental strain and job satisfaction: A dysempowerment approach. The International Journal of Human Resource Management 28: 945-72. [CrossRef]

D'cruz, Premilla, and Ernesto Noronha. 2013. Navigating the extended reach: Target experiences of cyberbullying at work. Information and Organization 23: 324-43. [CrossRef]

Deschamps, Ryan, and Kathleen McNutt. 2016. Cyberbullying: What's the problem? Canadian Public Administration 59: 45-71. [CrossRef]

Faucher, Chantal, Wanda Cassidy, and Margaret Jackson. 2015. From the sandbox to the inbox: Comparing the acts, impacts, and solutions of bullying in K-12, higher education, and the workplace. Journal of Education and Training Studies 3: 111-25. [CrossRef]

Li, Qing. 2010. Cyberbullying in high schools: A study of students' behaviors and beliefs about this new phenomenon. Journal of Aggression, Maltreatment \& Trauma 19: 372-92. [CrossRef]

Merriam, Sharan B., and Elizabeth J. Tisdell. 2016. Qualitative Research: A Guide to Design and Implementation, 4th ed. San Francisco: Jossey-Bass, ISBN 9781119003618.

Miles, Matthew B., and A. Michael Huberman. 1994. Qualitative Data Analysis, 2nd ed. Thousand Oaks: Sage Publications, ISBN 0803946538.

Mishna, Faye, Charlene Cook, Tahany Gadalla, Joanne Daciuk, and Steven Solomon. 2010. Cyber bullying behaviors among middle and high school students. American Journal of Orthopsychiatry 80: 362-74. [CrossRef] [PubMed]

Mishna, Faye, Mona Khoury-Kassabri, Tahany Gadalla, and Joanne Daciuk. 2012. Risk factors for involvement in cyber bullying: Victims, bullies and bully-victims. Children and Youth Services Review 34: 63-70. [CrossRef]

Mishna, Faye, Kaitlin J. Schwan, Rachael Lefebvre, Payal Bhole, and David Johnston. 2014. Students in distress: Unanticipated findings in a cyber bullying study. Children and Youth Services Review 44: 341-48. [CrossRef]

Noddings, Nel. 2002. Educating Moral People: A Caring Alternative to Character Education. New York: Teachers College Press, ISBN 9780807741689 
Noddings, Nel. 2005. The Challenge to Care in Schools: An Alternate Approach to Education, 2nd ed. New York: Teachers College Press, ISBN 9780807746097.

Noddings, Nel. 2006. Educational leaders as caring teachers. School Leadership \& Management 26: 339-45. [CrossRef] Privitera, Carmel, and Marilyn Anne Campbell. 2009. Cyberbullying: The new face of workplace bullying? Cyberpsychology \& Behavior: The Impact of the Internet, Multimedia and Virtual Reality on Behavior and Society 12: 395-400. [CrossRef]

Ryan, Thomas, Mumbi Kariuki, and Harun Yilmaz. 2011. A comparative analysis of cyberbullying perceptions of preservice educators: Canada and Turkey. Turkish Online Journal of Educational Technology 10: 1-12.

Sakellariou, Tass, Annemaree Carroll, and Stephen Houghton. 2012. Rates of cybervictimization and bullying among male Australian primary and high school students. School Psychology International 33: 533-49. [CrossRef]

Wade, Ann, and Tanya Beran. 2011. Cyberbullying: The new era of bullying. Canadian Journal of School Psychology 26: 44-61. [CrossRef]

Ybarra, Michele L., and Kimberly J. Mitchell. 2004. Online aggressors/targets, aggressors, and targets: A comparison of associated youth characteristics. Journal of Child Psychology and Psychiatry 45: 1308-16. [CrossRef] [PubMed]

(C) 2018 by the authors. Licensee MDPI, Basel, Switzerland. This article is an open access article distributed under the terms and conditions of the Creative Commons Attribution (CC BY) license (http:/ / creativecommons.org/licenses/by/4.0/). 
Article

\title{
Parents' Responses to Coping with Bullying: Variations by Adolescents' Self-Reported Victimization and Parents' Awareness of Bullying Involvement
}

\author{
Elisa Larrañaga, Santiago Yubero and Raúl Navarro * \\ Department of Psychology, University of Castilla-La Mancha, Cuenca 16071, Spain; \\ elisa.larranaga@uclm.es (E.L.); santiago.yubero@uclm.es (S.Y.) \\ * Correspondence: raul.navarro@uclm.es; Tel.: +34-969-179100 (ext. 4330)
}

Received: 29 June 2018; Accepted: 24 July 2018; Published: 25 July 2018

\begin{abstract}
Bullying has been recognized as an important risk factor for mental health. A growing number of researchers have encouraged parents to work collaboratively with schools to prevent and intervene in bullying situations. This study explores the relationship between parents' awareness of bullying involvement, adolescents' self-reported victimization, and six possible parents' responses to their child's victimization. The participants were 1044 seventh-tenth grade students and their parents. Logistic regressions analyses were applied to determine if parents' awareness of victimization and adolescents' self-reporting of victimization were associated with parents' responses to bullying victimization. The results showed that parents' awareness of bullying and adolescents' self-reported victimization were only associated with the "defends herself/himself" and "talks to bully" response. In other words, the parents who believe their child has been bullied are less likely to encourage their children to talk with the bully, and when children are victimized, it is less likely that their parents will encourage them to defend themselves or talk with the bully.
\end{abstract}

Keywords: bullying; cyberbullying; family; parents; bullying awareness; coping strategies

\section{Introduction}

Bullying is an intentional and aggressive behavior that is repeatedly performed by one or several individuals against someone unable to defend him/herself (Smith 2016). Bullying can be verbal (e.g., name calling, threats), physical (e.g., punching, kicking hitting, harming personal belonging), and can include social-relational aggression (e.g., rumor spreading, social exclusion). Other more recent forms of bullying attacks are made using the internet and information-communication technologies (ICT), known as cyberbullying (e.g., posting the victim's private photos online).

Although the last two decades have witnessed a significant decrease in bullying in many countries, bullying is still a major problem among young people. Prospective longitudinal and cross-sectional studies indicate that victims of bullying are more likely than non-victimized youth to report emotional distress, low self-esteem, symptoms of depression, social isolation, anxiety, and lower life satisfaction, as well as poor academic performance, school absenteeism, and suicidal ideation (Moore et al. 2017; Wolke 2017). Given these risks, it is necessary to make effective intervention and prevention efforts to work with and attend to victimized students. Parents are encouraged to work collaboratively with schools to intervene and prevent bullying by increasingly more researchers (Rigby 2017; Zych et al. 2017). Therefore, it is necessary to know parents' perceptions of bullying and how they respond to bullying victimization. The current study focuses on parents' awareness of bullying and adolescent's self-reported victimization as potential factors that are related to how parents respond to their child's victimization. 


\subsection{Parents and Their Awareness of Bullying Victimization}

Parents play an important role in intervening and preventing bullying situations. Previous research has indicated that parents' responsiveness to a child's victimization is related to the child's ability to cope with bullying (Lester et al. 2017). Nevertheless, parents are not normally aware of the child's victimization, because children are quite often reluctant to reveal anything to their parents about their bullying experiences (Bjereld et al. 2017). Youth may hide that they are bullied, because they feel shame, they think it is not serious enough, they believe that informing their parents could make their problem worse, or they attempt to solve the problem themselves. If they are victims of cyberbullying, youths may fear their parents will control or limit their internet or cellphone use (Yubero et al. 2018; Stavrinides et al. 2015).

Previous research has shown that parents believe that bullying is a serious problem and estimate higher rates of victimization than do teachers (Gradinger et al. 2017). However, very few studies have analyzed parent/child agreement on bullying involvement. An investigation with American children has shown that parents report fewer cases of bullying than do youths, but parents tend to perceive their child being bullied when the child has never reported this (Holt et al. 2008). Along the same lines, a study analyzing cyberbullying in Amsterdam conducted by Dehue et al. (2008) found that the percentage of parents who reported that their children are being cyberbullied is much lower than the percentage of children who report being cyberbullied.

\subsection{Parents and Their Response to Bullying Victimization}

Research findings suggest that the quality of relationships with parents is closely related to bullying/cyberbullying. In particular, previous research suggests that parents being available and open to communicate with children are in a better position to help avoid bullying and protect children from its negative consequences. In the United States of America (USA), the research conducted by Wang et al. (2009) reported that parental behaviors involving positive communication to understand adolescents' concerns and problems, or skills to make upset adolescents feel better, actually protect them from bullying. Elgar et al. (2014), also in the USA, reported that family communication and contact can help adolescents to be protected from the harmful effects of bullying. Despite the fact that such positive communication per se does not prevent suffering from bullying, it helps to create trust and allows youths to be aware that they can rely on family members to help them and to provide adaptive ways to cope with bullying. Moreover, previous research has indicated that parental warmth is consistently associated with lower cyberbullying victimization (Elsaesser et al. 2017).

When parents become aware of their child's victimization or when a child discloses bullying, numerous parents do not know how to help their child to cope with bullying. However, parents' responses to bullying may differ (e.g., contacting the school administrator or school teacher, contacting the bully or his/her parents (Hale et al. 2017; Waasdorp et al. 2011)). Practitioners and researchers suggest that parents first help by carefully listening to their child, not making decisions on the spur of the moment or adopting responses that do not contemplate the child's opinion, because rushed decisions can worsen victimization or model unsuitable response strategies (Buelga et al. 2017; Cross et al. 2018). Researchers encourage parents to notify schools and to work collaboratively with schools to overcome bullying. Previous research conducted with parents of victimized youth from elementary, middle, and high schools has revealed that most parents respond by talking to their child about victimization and contacting the administrator or teacher (Waasdorp et al. 2011).

\subsection{The Present Study}

The present study was designed to extend previous research to help explain the association between adolescents' self-reported victimization, parents' awareness of bullying, and their responses to bullying victimization. Therefore, the primary aims of this study were as follows: (a) to evaluate the degree of agreement between parent/child reports of bullying/victimization involvement; (b) 
to examine parents' responses to bullying victimization; (c) to explore whether some demographic variables (child's age and gender) were related to parents' responses to their child's victimization; and (d) to investigate the associations between parents' awareness of bullying involvement, adolescents' self-reported victimization, and six possible parents' responses to their child's victimization.

Based on previous research documenting that parents tend to report lower bullying rates than do students, the hypothesis was that parents/children's agreement on bullying victimization would not be high. It was also expected that parents who are aware of their child's victimization would be more likely to use any responses included in this study to cope with the victimization. Likewise, parents whose children report being bullied would also be more likely to use any responses included in the study. Finally, it was hypothesized that it would be more likely that parents with younger children would contact schools and talk to the bully or his/her parent rather than encourage their children to defend themselves and/or ignore the problem.

\section{Method}

\subsection{Participants}

A total of 1044 adolescents from four public secondary schools and their parents participated in this study. The adolescents were students in four public secondary schools in the Castilla-La Mancha region (Spain). A total of $24 \%$ were in grade $7,24.3 \%$ were in grade $8,24.9 \%$ in grade 9 , and $26.8 \%$ in grade 10 . A total of $45.5 \%$ participants were males, and $54.5 \%$ participants were females. The ages ranged from $12-17$ years old $(\mathrm{M}=14.39$; $\mathrm{SD}=1.54)$. On average, the parents were 42.95 years old (range: $34-52$ years). A total of $700(67.1 \%)$ of the parents were female, and $344(32.9 \%)$ of the parents were male.

\subsection{Procedure}

Students in the four secondary schools were asked to participate $(\mathrm{N}=1258)$. The students took part in the study if they returned a form in which their parents had to give their parental consent (32 parents did not give parental consent). The parents or legal guardians who gave parental consent received a questionnaire to assess parents' awareness of bullying involvement and their responses to bullying victimization. The parents' questionnaire had a code in order to pair data with their child's. A total of $85.08 \%$ of the parents returned the questionnaire to the school. In $50.3 \%$ of cases, mothers filled in the questionnaire alone, fathers completed it in $16.4 \%$ of cases, and mothers and fathers worked together in $33.3 \%$ of cases.

The adolescents completed the 20-min questionnaire in groups of approximately 25 students at school under the supervision of at least one of the researchers. The participants were assured that their individual responses would remain anonymous and would not be seen by their parents, peers, or teachers.

\subsection{Measurement Variables and Instruments}

First, the adolescents gave information about their age, gender, and grade. After that, they filled out a battery of questions regarding self-reported bullying victimization. The parents had to report if they knew their child was being victimized and indicate how they responded or will respond to bullying.

\subsubsection{Self-reported Bullying Victimization}

The scale used was the Bullyharm (Hall 2016), a 14-item self-reported measure to self-report different bullying behaviors in the real world and on the internet occurring during the last month. The items were scored on a 3-point scale $(0=$ never; $1=1$ or 2 times in the past month; $2=$ about 1 time a week; or 3 = twice a week or more). Examples of items are "said something to scare or intimidate me" and 
"sent me a mean email, instant message, or text message". In the present study, Cronbach's alpha reliability coefficient was 0.86 .

\subsubsection{Parents' Awareness of Bullying Involvement}

Following Holt et al. (2008), the parents responded "Yes" or "No" to a single question: "have you ever suspected or found out that your child might be bullied by other children?"

\subsubsection{Parents' Responses to Bullying.}

The parents' responses to bullying were assessed by a single question ("What have you done when your child told you about being bullied, or you noticed that she/he was being bullied?") to which they could endorse up to six possible responses: "encourage my child to defend himself/herself", "tell my child to ignore/do nothing", "contact the school", "control his/her internet access and cellphone use", "talk to the bully", and "talk to the bully's parents". The parents had to select three responses that described their behavior when they discovered that their child was being bullied.

\section{Results}

\subsection{Overview of the Analyses}

Percentages of the adolescents' self-reported victimization were first computed. Second, the parents/adolescents concordance was examined using the parents' beliefs and the adolescents' self-reports of bullying involvement. Third, percentages of the parents who endorsed each possible response to their child's victimization were computed. Fourth, differences in each parent's response according to the adolescents' self-reported victimization and the parents' beliefs about their child's victimization status were examined using a chi-square test. Finally, the extent to which gender, age, the parents' beliefs, and the child's self-reports related to each parent's response was evaluated through a logistic regression analysis. SPSS 20.0 statistical software was used for all the analyses.

\subsection{Self-Reported Victimization and Parent/Child Concordance}

The participants were considered victims of bullying if they reported having suffered one or more of the behaviors included in the questionnaire at least once a week during the last month. That is, the participants indicated experience of any of the 14 behaviors included in the questionnaire "about 1 time a week" in the last month. This criterion fits the emphasis placed on bullying as a repetitive behavior. According to this condition, 979 adolescents (93.8\%) indicated that they had not been a victim of bullying, while $65(6.2 \%)$ of the participants in the sample indicated that they had been victims of bullying at least once a week in the last month. Among the participants, $6.7 \%$ of females $(n=38)$ were bullied and $5.7 \%$ of males were bullied $(n=27)$. There were no sex differences $\left(\chi^{2}(\right.$ d.f.: 1$)=0.438$; $p=0.523)$ or age differences $\left(\chi^{2}\right.$ (d.f.: 1$\left.)=0.590 ; p=0.445\right)$ in the victims' frequency. The distribution of the participants according to gender and age group in the victim and non-victim groups is reported in Table 1. Regarding the type of bullying, 41 (3.9\%) of the participants were victims of traditional bullying, $12(1.1 \%)$ of the participants were victims of cyberbullying, and $12(1.1 \%)$ of the participants were victims of both traditional bullying and cyberbullying. 
Table 1. Characteristics of the participants by victimization status.

\begin{tabular}{ccc}
\hline & Not Victimized \% $(n)$ & Victimized \% (n) \\
\hline Overall & $93.8(979)$ & $6.2(65)$ \\
\hline Adolescent's gender & $94.3(448)$ & $5.7(27)$ \\
Male & $93.3(531)$ & $6.7(38)$ \\
Female & & \\
Student's age & $50.8(530)$ & $3.1(32)$ \\
12-14 years old & $43(449)$ & $3.2(33)$ \\
15-17 years old &
\end{tabular}

Note: Values represent the percentages of adolescents with the number of adolescents in parentheses.

Overall, $22.3 \%$ of the parents indicated that their child had been bullied. When considering the agreement rates for the entire sample (see Table 2), the results indicated than approximately $1.6 \%$ of the sample, both the child and their parents, reported bullying involvement, and for rest of the $73 \%$ of the sample, both the child and the parents did not report bullying involvement. In only approximately $4.5 \%$ of the sample did a child report being bullied when their parents did not report that the child had been bullied. However, there was a tendency for parents to think that their child had been bullied when the child did not report this $(20.7 \%)$.

Table 2. Agreement between the student reports of being bullied and the parents' awareness of their child being bullied.

\begin{tabular}{ccc}
\hline & \multicolumn{2}{c}{ Parents' Awareness } \\
\hline & $\begin{array}{c}\text { Parents believe their child } \\
\text { had been bullied }(n=233)\end{array}$ & $\begin{array}{c}\text { Parents believe their child had } \\
\text { not been bullied }(n=811)\end{array}$ \\
\hline $\begin{array}{c}\text { Adolescents reported being } \\
\text { bullied }(n=65)\end{array}$ & $17(1.6 \%)$ & $48(4.6 \%)$ \\
\hline $\begin{array}{c}\text { Adolescents reported not } \\
\text { being bullied }(n=979)\end{array}$ & $216(20.7 \%)$ & $763(73.1 \%)$ \\
\hline
\end{tabular}

\subsection{Characteristics of Parents' Responses}

The percentages of parents who endorsed each possible response to bullying were first examined (see Table 3). The most common response was contacting a teacher/administrator from the schools, followed by controlling internet access and talking to the bully's parents. The least common response was encouraging their child to defend herself/himself.

Table 3. Parents' responses to bullying victimization.

\begin{tabular}{cc}
\hline Response & Total \% (n) \\
\hline Defends herself/himself & $15.7 \%(164)$ \\
Ignore/do nothing & $30.7 \%(320)$ \\
Contact the school & $75.7 \%(790)$ \\
Control internet access and cellphone use & $55.5 \%(579)$ \\
Talk to bully & $17.2 \%(180)$ \\
Talk to the bully's parents & $54.4 \%(568)$
\end{tabular}

Note: The data represents the percentage and numbers of parents who endorsed the response (i.e., answered "Yes").

Second, differences in each parents' response according to the adolescents' self-reported victimization and the parents' awareness of their child's victimization status were examined (see Tables 4 and 5). Regarding the parents' awareness, as indicated in Table 4, the parents who believed 
that their child had not been bullied were more likely to indicate that they would use any of the responses significantly more frequently than the parents who believed that their child had been bullied.

Table 4. Percentages of the parents' responses according to the parents' awareness of bullying involvement.

\begin{tabular}{ccc}
\hline Response & $\begin{array}{c}\text { Parents Believe Their Child Had } \\
\text { Been Bullied }(\boldsymbol{n}=\mathbf{2 3 3})\end{array}$ & $\begin{array}{c}\text { Parents Believe Their Child Had } \\
\text { Not Been Bullied }(\boldsymbol{n}=\mathbf{8 1 1})\end{array}$ \\
\hline Defends herself/himself & $30(2.9 \%)$ & $134(12.8 \%)^{* * *}$ \\
Ignore/do nothing & $73(7.0 \%)$ & $247(23.7 \%)^{* * *}$ \\
Contact the school & $184(17.6 \%)$ & $606(58.0 \%)^{* * *}$ \\
Control internet access and cell-phone use & $146(14.0 \%)$ & $433(41.5 \%)^{* * *}$ \\
Talk to bully & $41(3.9 \%)$ & $139(13.3 \%)^{* * *}$ \\
Talk to bully's parents & $123(11.8 \%)$ & $445(42.6 \%)^{* * *}$ \\
\hline
\end{tabular}

Note: only includes the parents who reported that they used or would use any of the responses. ${ }^{* * *} p<0.001$.

Table 5. Percentages of the parents' responses according to the adolescents' self-reported victimization.

\begin{tabular}{ccc}
\hline Response & Not Victimized $(\boldsymbol{n}=\mathbf{9 7 9 )}$ & Victimized $(\boldsymbol{n}=\mathbf{6 5})$ \\
\hline Defends herself/himself & $145(13.9 \%)^{* * *}$ & $18(1.8 \%)$ \\
Ignore/do nothing & $306(29.3 \%)^{* * * *}$ & $14(1.3 \%)$ \\
Contact the school & $737(70.6 \%)^{* * *}$ & $53(1.4 \%)$ \\
Control internet access and cellphone use & $541(51.8 \%)^{* * *}$ & $38(3.6 \%)$ \\
Talk to bully & $162(15.5 \%)^{* * *}$ & $18(1.7 \%)$ \\
Talk to the bully's parents & $538(51.5 \%)^{* * *}$ & $30(2.9 \%)$ \\
\hline
\end{tabular}

Note: only includes the parents who reported using or would use any of the responses. ${ }^{* * *} p<0.001$.

With respect to the adolescents' self-reported victimization, as shown in Table 5, the parents of those who were not bullied would use any of the responses significantly more frequently that the parents of those who were actually bullied.

\subsection{Relationships Linking Parents' Awareness, Adolescents' Self-Reported Victimization, and Parents' Coping Strategies}

Table 6 provides the results of the odds ratios (OR) for each examined factor in the logistic regression analysis. The data indicated that gender only increased the likelihood of the "ignore/do nothing" response. That is, parents were more likely to tell their children to ignore the problem or do nothing when children were female. Regarding age, the data showed that age increased the likelihood of the "contact the school" and "control internet access" responses but decreased the likelihood of the "defends himself/herself" and "talk to bully" responses. That is, when children were younger, parents were more likely to contact a teacher/administrator at school or control internet access or cellphone use. However, when children were older, their parents were more likely to encourage them to defend themselves or talk to the bully. 
Table 6. Logistic regression model predicting the associations among the parents' responses, gender, age, the parent's awareness of bullying involvement, and self-reported victimization. OR: odds ratio.

\begin{tabular}{|c|c|c|c|c|c|c|c|c|c|}
\hline \multirow[b]{2}{*}{ Independent Variable } & \multicolumn{3}{|c|}{ Defend } & \multicolumn{3}{|c|}{ Ignore } & \multicolumn{3}{|c|}{ School } \\
\hline & $B$ & OR & $95 \% \mathrm{CI}$ & $B$ & OR & $95 \% \mathrm{CI}$ & $B$ & OR & $95 \% \mathrm{CI}$ \\
\hline Gender & 0.10 & 1.12 & $(0.79-1.56)$ & 0.27 & $1.32 *$ & $(1.01-1.72)$ & 0.05 & 1.05 & $(0.79-1.40)$ \\
\hline $\begin{array}{l}\text { Parent believes child has } \\
\text { been bullied }\end{array}$ & 0.30 & 1.34 & $(0.84-2.06)$ & -0.05 & 0.94 & $(0.68-1.29)$ & -0.27 & 0.79 & $(0.56-1.13)$ \\
\hline Self-reported victimization & -0.87 & $0.41^{* *}$ & $(0.23-0.73)$ & 0.50 & 1.64 & $(0.89-3.02)$ & -0.38 & 0.68 & $(0.36-1.30)$ \\
\hline Independent variable & $B$ & OR & $95 \%$ CI & $B$ & OR & $95 \% \mathrm{CI}$ & $B$ & OR & $95 \% \mathrm{CI}$ \\
\hline Gender & -0.19 & 0.82 & (0.64-1.05) & -0.17 & 0.84 & $(0.60-1.17)$ & -0.19 & 0.82 & $(0.64-1.05)$ \\
\hline Age & 0.24 & $1.27 *$ & (0.99-1.63) & -0.34 & 0.71 * & $(0.51-0.98)$ & 0.06 & 1.06 & $(0.98-1.14)$ \\
\hline $\begin{array}{c}\text { Parent believes child has } \\
\text { been bullied }\end{array}$ & -0.01 & 0.97 & (0.66-1.43) & -0.37 & 0.69 * & $(0.51-0.93)$ & 0.08 & 1.08 & $(0.80-1.45)$ \\
\hline
\end{tabular}

Note: Gender was coded as girls $=1$. Age was coded as $12-14=1 .{ }^{*} p<0.05 ;{ }^{* *} p<0.01$.

Regarding the parents' awareness of bullying involvement, the parents' perceptions only lowered the likelihood of the "talk to bully" response. The parents who believe their child had been bullied were less likely to encourage their children to talk with the bully. Regarding self-reported victimization, actual bullying lowered the likelihood of the "defends herself/himself" and "talk to bully" responses. That is, when children were victimized, it was less likely that their parents would encourage them to defend themselves or talk with the bully.

\section{Discussion}

The present study examined adolescents' self-reported victimization and parents' awareness of and their responses to bullying victimization. Contrary to what was expected, the parents' reported bullying victimization rates were higher than those informed by the adolescents. Moreover, the parents' awareness of bullying and the adolescents' self-reported victimization were not related with the six parents' examined responses.

\subsection{Degree of Agreement between Child's and Parents' Reports of Bullying Victimization}

Consistently with the hypothesis, a low degree of concordance between the child's and the parents' reports of bullying was found. Specifically, among the adolescents who reported being bullied, approximately $2 \%$ of the parents reported this same problem, whereas approximately $5 \%$ of the parents did not report that their child had been victimized. Contrary to previous research, the parents reported higher bullying victimization rates than did their children (Holt et al. 2008). It is likely that parents are more inclined to consider bullying to be present in mild or moderate cases of peer victimization, whereas adolescents may be reluctant to inform adults about their bullying experiences, consider some aggressive events to not be serious enough, or only consider bullying to be present in cases where peer victimization is more intense. However, in line with previous research, the results showed that the parents tend to think that their child had been bullied when the child did not reported this (Holt et al. 2008). Future studies should address how parent/child differences in defining bullying may affect parent/child concordance about bullying victimization rates.

\subsection{Parents Responses to Victimization}

The majority of parents reported responding to their child's victimization by contacting a teacher/administrator from the school, followed by controlling internet access and cellphone use. This last response may be related with parents' growing concern about cyberbullying, an evolved manifestation of traditional bullying performed through electronic and digital media (Wright 2018). Nevertheless, a high percentage of parents also recommended maladaptive strategies for coping or 
responding to bullying, such as ignoring bullying or encouraging their child to defend herself/himself. Researchers have shown that talking to children about victimization and contacting the school are more appropriate responses than ignoring the problem or contacting the bully, as these responses can have negative corollaries for the victimized child (Garnett et al. 2015; Navarro et al. 2018). Indeed, system theories suggest that family responses are likely to influence children's responses. This theoretical framework is useful when considering how family responses to bullying can contribute to mitigate the problem or to make the problem worse. Concretely, the family system theory suggests that a youth's strategies for coping with bullying are likely to be shaped by the way their family system has coped with the problem (Cross and Barnes 2014). If the family is unable to cope adaptively with bullying, this may further reinforce the use of maladaptive behaviors among young people experiencing difficulty in coping with bullying. For example, parental overprotective or permissive responses have been linked with bullying victimization (Georgiou and Stavrinides 2013).

It was hypothesized that the parents' responses would vary according to the parents' awareness of bullying and the adolescent's self-reported victimization. Contrary to our expectations, parents reporting that their children had been victimized and parents whose children reported being victimized reported a lower use of any of the coping responses than parents who did not report that their child had been victimized and those whose children reported not being victimized. This difference may be related to the fact that the number of non-victimized adolescents and the number of parents not reporting bullying victimization is much larger than the victimized adolescents and the parents reporting bullying victimization. However, parents whose children had not been victimized might have indicated a great number of coping responses guided by a social desirability bias according to which parents ought to cope with bullying in any possible way to show that they are always responsive to their children's needs (Hale et al. 2017). Another possibility is that the parents with non-victimized children are not sure how to suitably respond to bullying, and they have difficulties selecting the most effective strategy to protect their children (Harcourt et al. 2014). Conversely, the parents whose children are victimized could have acquired previous experience from coping with bullying and are more selective with the used coping responses, or alternatively, they believe that the offered responses in the study are not effective in stopping bullying. Further research should explore how previous experiences dealing with bullying may impact parents' responses to bullying victimization.

The primary aim of this study was to explore the association between adolescents/parents' bullying reports and parents' responses to their children's victimization. Contrary to what was expected, the parents' awareness of bullying victimization was related only with the parents' likelihood of opting for the "talk with the bully" response. The parents with victimized children were not as likely to encourage their child to talk with their bully. In the same way, the adolescents' reports of bullying victimization lowered the likelihood of the parents encouraging their children to defend themselves. This suggests that parents of victimized youth may feel that talking with the bully is not an effective response to stop the bullying and may believe that this response could make the victimization worse (Mishna et al. 2006). Prior research has indicated that parents' attitudes to bullying and their perception of school might be more associated with parents' responses to bullying than their awareness of victimization (Waasdorp et al. 2011).

Some variation in the parents' responses to bullying was found according to the students' demographic factors. Specifically, the findings suggest that there may be some developmental differences in the parents' responses (e.g., parents with younger children are not likely to encourage their children to defend themselves or talk to bullies but would more probably contact schools and control internet access). Consistent with previous research (Waasdorp et al. 2011), parents with younger children were more likely to more directly intervene in response to their children's victimization by contacting schools or restricting the use of technology to deal with bullying, whereas parents with older children may encourage their child to solve the bullying themselves. The parents were also more likely to tell their female children to ignore the problem or do nothing about it. This last result may be related to parents still holding gender stereotypes, which means that they may see males as being 
more aggressive, courageous, independent, and assertive and females as more emotional, sensitive, people-oriented, and reliant. Accordingly, the parents who hold these views may believe that females will not be prepared to deal with bullying (Morales et al. 2016). The parents might also view female bullying as being less serious because females do not normally engage as much in physical bullying as males (Stubbs-Richardson et al. 2018). Further research should inquire how the internalization of specific feminine or masculine stereotypical traits could differently affect parents' responses to bullying victimization.

\subsection{Limitations}

This study has several limitations that should be noted. First, the analyses in this study are cross-sectional and correlational and, therefore, inferences cannot be made about causality or directionality. Second, this study collected only self-reported data, and the relationships that we observed here could be influenced by a response bias. Third, our study sample comprised adolescents and their parents from a given region in Spain. The associations in other samples could differ. Moreover, it might be that the parents who completed surveys were different from the parents who did not complete surveys in ways that could have influenced the study findings. Fourth, the time frame used for the adolescents' and parents' reports of bullying victimization was different. The students were asked about their bullying experiences during the last month, whereas the parents were asked one open question without a specific time frame. This may explain the differences in parents and student ratings of bullying. Fifth, different types of bullying were analyzed together, and the parents' responses could vary according with the bullying nature: physical, verbal, social, or cyber. Further studies should analyze differences in parents' responses according to the type of bullying. Finally, we analyzed only parents' awareness and their responses to bullying victimization. Further research should examine parents' awareness and responses to bullying perpetration.

\subsection{Practical Implications}

The results of this study highlight the importance of cultivating parent-adolescent relationships to deal with bullying victimization processes. Previous research has documented that parents play a key role providing support and listening about children's worries and problems, but also guiding their children to prevent or stop the bullying. The present findings point out that it is crucial to promote open communication between parents and children to disclose victimization and to offer social support (Larrañaga et al. 2016; Scott et al. 2016). Parents should be aware about the negative effects of maintaining a poor relationship with their children and learn how a relationship based on affection and open communication can help to offer support and emotional security when children face any problem. Moreover, given that many adolescents do not report bullying to their parents, practitioners should encourage parents to talk with their children about bullying and cyberbullying victimization to make children aware that they are there to listen and help cope with problems. Research has shown that parents providing emotional warmth facilitate adolescents' disclosure of bullying involvement (Elsaesser et al. 2017).

Previous studies emphasize the importance of parents actively participating in bullying prevention and intervention programs in order to be most effective (Gradinger et al. 2017). The present results have shown that the parents seem to have high pro-bullying coping intentions. Indeed, the majority of the parents indicated that they would contact the school in order to deal with bullying. School administrators and teachers should use these intentions to foster the willingness to participate in a whole-school prevention program. Along the same lines, parents should be encouraged not only to talk with their children about bullying but also to notify schools about bullying and to work collaboratively with teachers to cope with bullying situations. 


\section{Conclusions}

This study analyzed the associations among parents' awareness of bullying victimization, their responses to their child's victimization, and adolescents' self-reported victimization. The findings highlight how relevant it is to improve parent-child relationships and communication about bullying and to continue reinforcing parents' role in intervening in bullying situations and preventing them.

Author Contributions: Data curation, E.L.; Formal analysis, E.L. and R.N.; Funding acquisition, E.L. and S.Y.; Methodology, E.L. and R.N.; Project administration, S.Y.; Resources, S.Y.; Writing-Original Draft, R.N.; Writing-Review \& Editing, E.L., S.Y. and R.N.

Funding: This research was financed by the Spanish Ministry of Economy and Competitiveness under the National Program of Research and Innovation (I + D + i 2015): PSI2015-70822-R

Conflicts of Interest: The authors declare no conflict of interest.

\section{References}

Bjereld, Ylva, Kristian Daneback, and Max Petzold. 2017. Do bullied children have poor relationships with their parents and teachers? A cross-sectional study of Swedish children. Children and Youth Services Review 73: 347-51. [CrossRef]

Buelga, Sofí, Belén Martínez-Ferrer, and María Jesús Cava. 2017. Differences in family climate and family communication among cyberbullies, cybervictims, and cyber bully-victims in adolescents. Computers in Human Behavior 76: 164-73. [CrossRef]

Cross, Donna, and Amy Barnes. 2014. Using systems theory to understand and respond to family influences on children's bullying behavior: Friendly Schools Friendly Families Program. Theory into Practice 53: $293-99$. [CrossRef]

Cross, Donna, Leanne Lester, Natasha Pearce, Amy Barnes, and Shelley Beatty. 2018. A group randomized controlled trial evaluating parent involvement in whole-school actions to reduce bullying. The Journal of Educational Research 111: 255-67. [CrossRef]

Dehue, Francine, Catherine Bolman, and Trijntje Völlink. 2008. Cyberbullying: Youngsters' experiences and parental perception. Cyberpsychology Behavior 11: 217-23. [CrossRef] [PubMed]

Elgar, Frank, Anthony Napoletano, Grace Saul, Melanie Dirks, Wendy Craig, Paul Poteat, Melissa Holt, and Brian Koenig. 2014. Cyberbullying victimization and mental health in adolescents and the moderating role of family dinners. JAMA Pediatrics 168: 1015-22. [CrossRef] [PubMed]

Elsaesser, Caitlin, Beth Russell, Christine McCauley Ohannessian, and Desmond Patton. 2017. Parenting in a digital age: A review of parents' role in preventing adolescent cyberbullying. Aggression and Violent Behavior 35: 62-72. [CrossRef]

Garnett, Bernice, Katherine Masyn, Bryn Austin, David Williams, and Kasisomayajula Viswanath. 2015. Coping styles of adolescents experiencing multiple forms of discrimination and bullying: Evidence from a sample of ethnically diverse urban youth. Journal of School Health 85: 109-17. [CrossRef] [PubMed]

Georgiou, Stelios, and Panayiotis Stavrinides. 2013. Parenting at home and bullying at school. Social Psychology of Education 16: 165-79. [CrossRef]

Gradinger, Petra, Dagmar Strohmeier, and Christiane Spiel. 2017. Parents' and teachers' opinions on bullying and cyberbullying prevention: The relevance of their own children's or students' involvement. Zeitschrift Für Psychologie 225: 76-84. [CrossRef]

Hale, Rebecca, Claire Fox, and Michael Murray. 2017. As a parent you become a tiger": Parents talking about bullying at school. Journal of Child and Family Studies 26: 2000-15. [CrossRef] [PubMed]

Hall, William. 2016. Initial development and validation of the bullyharm: The bullying, harassment, and aggression receipt measure. Psychology in the Schools 53: 984-1000. [CrossRef] [PubMed]

Harcourt, Susan, Marieke Jasperse, and Vanessa Green. 2014. "We were sad and we were angry": A systematic review of parents' perspectives on bullying. Child Youth Care Forum 43: 373-91. [CrossRef]

Holt, Melissa, Glenda Kaufman-Kantor, and David Finkelhor. 2008. Parent/child concordance about bullying involvement and family characteristics related to bullying and peer victimization. Journal of School Violence 8: 42-63. [CrossRef] 
Larrañaga, Elisa, Santiago Yubero, Anastasio Ovejero, and Raúl Navarro. 2016. Loneliness, parent-child communication and cyberbullying victimization among Spanish youths. Computers in Human Behavior 65: 1-8. [CrossRef]

Lester, Leanne, Natasha Pearce, Stacey Waters, Amy Barnes, Shelley Beatty, and Donna Cross. 2017. Family Involvement in a Whole-School Bullying Intervention: Mothers' and Fathers' Communication and Influence with Children. Journal of Child and Family Studies 26: 2716-27. [CrossRef]

Mishna, Faye, Debra Pepler, and Judith Wiener. 2006. Factors associated with perceptions and responses to bullying situations by children, parents, teachers, and principals. Victims and Offenders 1: 255-88. [CrossRef]

Moore, Sophie, Rosana Norman, Shuichi Suetani, Hannah Thomas, Peter Sly, and James Scott. 2017. Consequences of bullying victimization in childhood and adolescence: A systematic review and meta-analysis. World Journal of Psychiatry 7: 60-76. [CrossRef] [PubMed]

Morales, Francisco, Santiago Yubero, and Elisa Larrañaga. 2016. Gender and bullying: Application of a three-factor model of gender stereotyping. Sex Roles 74: 169-80. [CrossRef]

Navarro, Raúl, Elisa Larrañaga, and Santiago Yubero. 2018. Differences between preadolescent victims and non-victims of cyberbullying in cyber-relationship motives and coping strategies for handling problems with peers. Current Psychology 37: 116-27. [CrossRef]

Rigby, Ken. 2017. How Australian parents of bullied and non-bullied children see their school responding to bullying. Educational Review 1-16. [CrossRef]

Scott, Emma, Jeremy Dale, Rachel Russell, and Dieter Wolke. 2016. Young people who are being bullied-do they want general practice support? BMC Family Practice 17: 116. [CrossRef] [PubMed]

Smith, Peter. 2016. Bullying: Definition, Types, Causes, Consequences and Intervention. Social and Personality Psychology Compass 10: 519-32. [CrossRef]

Stavrinides, Panayiotis, Militsa Nikiforou, and Stelios Georgiou. 2015. Do mothers know? Longitudinal associations between parental knowledge, bullying, and victimization. Journal of Social and Personal Relationships 32: 180-96. [CrossRef]

Stubbs-Richardson, Megan, Colleen Sinclair, Rebecca Goldberg, Chelsea Ellithorpe, and Suzanne Amadi. 2018. Reaching out versus lashing out: Examining gender differences in experiences with and responses to bullying in high school. American Journal of Criminal Justice 43: 39-66. [CrossRef]

Waasdorp, Tracy Evan, Catherine Bradshaw, and Jeffrey Duong. 2011. The link between parents' perceptions of the school and their responses to school bullying: Variation by child characteristics and the forms of victimization. Journal of Educational Psychology 103: 324-35. [CrossRef]

Wang, Jing, Ronald Iannotti, and Tonja Nansel. 2009. School bullying among adolescents in the United States: Physical, verbal, relational, and cyber. Journal of Adolescent Health 45: 368-75. [CrossRef] [PubMed]

Wolke, Dieter. 2017. Prevalence and consequences of bullying: What could healthcare services do for intervention? European Psychiatry 41: S25. [CrossRef]

Wright, Michelle. 2018. Cyberbullying Victimization through Social Networking Sites and Adjustment Difficulties: The Role of Parental Mediation. Journal of the Association for Information Systems 19: 113-23. [CrossRef]

Yubero, Santiago, Elisa Larrañaga, Raúl Navarro, and María Elche. 2018. Padres, hijos e internet. Socialización familiar de la red. Universitas Psychologica 17: 1-13. [CrossRef]

Zych, Izabela, David Farrington, Vicente Llorent, and Maria Ttofi. 2017. Protecting Children Through Anti-bullying Interventions. In Protecting Children against Bullying and Its Consequences. Cham: Springer, pp. 57-68.

(C) 2018 by the authors. Licensee MDPI, Basel, Switzerland. This article is an open access article distributed under the terms and conditions of the Creative Commons Attribution (CC BY) license (http:/ / creativecommons.org/licenses/by/4.0/). 
Article

\title{
Psychometric Properties of the CYBVICS Cyber-Victimization Scale and Its Relationship with Psychosocial Variables
}

\author{
Sofía Buelga ${ }^{1, *}$, Belén Martínez-Ferrer ${ }^{2}$, María-Jesús Cava ${ }^{1}$ and Jessica Ortega-Barón ${ }^{3}$ \\ 1 Department of Social Psychology, Faculty of Psychology, University of Valencia, Valencia 46010, Spain; \\ Maria.J.Cava@uv.es \\ 2 Department of Education and Social Psychology, University Pablo Olavide, Sevilla 41013, Spain; \\ bmarfer2@upo.es \\ 3 Department of Psychology of Education and Psychobiology, Faculty of Education, \\ International University of la Rioja (UNIR), Logroño 26006, Spain; Jessica.Ortega@uv.es \\ * Correspondence: sofia.buelga@uv.es
}

Received: 23 November 2018; Accepted: 3 January 2019; Published: 9 January 2019

\begin{abstract}
The main goal of the present study was to analyze the psychometric properties of the revised version of the Adolescent Cyber-Victimization Scale (CYBVICS). This scale is composed of 18 items that assess direct and indirect cyber-victimization. Two subsamples participated in the present study. Sample 1 included 1318 adolescents ( $47.4 \%$ boys) from 12 to 16 years old ( $M=13.89$, $S D=1.32)$. Sample 2 was composed of 1188 adolescents (51.5\% girls) from 12 to 16 years old $(M=14.19, S D=1.80)$. First, an exploratory factor analysis was conducted on sample 1 . Results yielded a bifactor structure: direct cyber-victimization and indirect cyber-victimization. To confirm the structure of the CYBVICS, we selected sample 2 to perform confirmatory factor analysis and test its convergent validity with theoretically related measures. The results supported the reliability and validity of the two-factor model. In addition, measurement invariance was established. Related to convergent validity, positive correlations between cyber-victimization and peer victimization, depressive symptoms, and offensive communication with the mother and the father were found. Moreover, negative correlations were found between cyber-victimization and open communication with the mother and the father and family self-esteem.
\end{abstract}

Keywords: cyber-victimization; scale development; psychometric properties; adolescence

\section{Introduction}

Cyberbullying is defined as an intentional, aggressive, and repetitive behavior, where a person or group uses electronic devices (mainly the Internet and the smartphone) to bully a person who cannot defend him/herself (Aboujaoude et al. 2015; Buelga et al. 2017). The prevalence of this technological bullying by peers ranges between $5 \%$ and $72 \%$ (Athanasiou et al. 2018; Kowalski et al. 2014), with an average incidence rate of cyber-victimization of $23 \%$ in the adolescent population (Hamm et al. 2015). Therefore, there is considerable divergence in the results obtained in different scientific studies, probably due to the use of different methodological measures and strategies to evaluate cyberbullying and cyber-victimization (Buelga et al. 2012; Vivolo-Kantor et al. 2014). In recent years, cyberbullying has clearly become a growing problem among youth in every country in the world (Antoniadou et al. 2016; Lee and Shin 2017; Yubero et al. 2017; Zych et al. 2016).

As Lee and Shin (2017) suggest, this increase and spread of cyberbullying among youth can be attributed to numerous factors. One of the main reasons is the increasing availability and massive use of smartphones in adolescence (Ortega-Baron et al. 2017; Lee and Shin 2017). This tendency is 
confirmed in many countries. In Korea, more than $80 \%$ of students have a smartphone that they use daily to actively connect to a large number of smartphone apps (Lee and Lee 2013). In the United States, 95\% of adolescents between 13 and 17 years old have a smartphone, and $45 \%$ of them claim to be online almost continually (Anderson and Jiang 2018). Of the European countries, Spain has the largest number of smartphones in the general population. In fact, $70 \%$ of young Spaniards have a smartphone at the age of 12 , and $98 \%$ at the age of 14 , and they use them to connect to popular social networks (Ditrendia Digital Marketing Trends 2016; Protégeles 2014).

Therefore, the smartphone is currently a key essential element in people's daily lives, especially among adolescents (Del Río et al. 2017; Garaigordobil 2017; Navarro et al. 2016). Due to their comfortable and fast connectivity to immediate messaging services (e.g., WhatsApp) and social networks (e.g., Instagram, Facebook), these digital platforms can be used by young people not only to communicate positively with others, but also to easily harass peers publicly and virally.

The consequences of cyberbullying are so serious for the victim that it is considered a worldwide public health problem (Aboujaoude et al. 2015; Ferrara et al. 2018). Moreover, 20\% of adolescent cyber-victims have expressed suicidal ideations (Van Geel et al. 2014). In many cases, the experience of cyber-victimization produces intense emotional distress in the victim (Larrañaga et al. 2016). In addition, unlike traditional victimization, parents frequently do not know about the victimization experienced by their child, which increases the victim's feeling of loneliness (Buelga et al. 2016; Nocentini et al. 2018). Thus, authors such as Thompson et al. (2012) suggest that the accumulation of adverse life events (cumulative lifetime adversities) in adolescence is closely related to suicidal ideation (see Serafini et al. 2015).

Certainly, continuous technological advances promote the modification and appearance of new forms and modalities of cyberbullying behavior (Cross et al. 2015; Cohen-Almagor 2018) that should be evaluated through updated and validated tools with methodological rigor, in order to prevent and intervene in this social problem (Kowalski et al. 2014). For instance, recent studies have pointed out that cyberbullying behaviors could be classified into direct and indirect cyber-victimization behaviors (Antoniadou et al. 2016; Lohbeck and Petermann 2018). Direct cyber-victimization includes verbal-type behaviors and attacks directed toward the person (e.g., sending insulting messages directly to the victim). Indirect cyber-victimization includes behaviors and attacks oriented indirectly toward the person through the manipulation of photos and videos (e.g., gossiping behind the victim's back).

From this perspective, taking into account the need to detect new expressions of cyberbullying in order to improve intervention in this field, the main purpose of this study is to validate the psychometric properties of the revised version of CYBVICS. This scale is a revised version of the CYBVIC scale (Buelga et al. 2012), which uses Willard's classification (Willard 2007) to evaluate the frequency with which the adolescent is a target of cyber-victimization behaviors related to harassment, belittlement, invasion of privacy, identity theft, and social exclusion through the Internet, on the one hand, and through the smartphone, on the other.

The CYBVICS scale is a two-dimensional scale on the use of the smartphone and includes these cyber-aggressions and other new ones, grouped in two cyber-victimization modalities, direct and indirect. Direct cyber-victimization includes experiences of being victimized that involve direct attacks (e.g., "Someone insulted me or ridiculed me on social networks") and social-type behaviors (e.g., "Someone removed or blocked me from groups so that I wouldn't have any friends"). Indirect cyber-victimization includes experiences of being victimized that involve the manipulation of images (e.g., "Someone created or manipulated videos or photos of me"), identity theft (e.g., "Someone created a false profile with my personal data on the Internet"), or hacking (e.g., "Someone changed my password to social networks so I could not access them"; see Appendix A).

The structural validity of the instrument was analyzed through exploratory and confirmatory factor analyses, the multi-group analysis of two independent samples of adolescents, and an analysis to test its convergent validity with several indicators of psychosocial adjustment and wellbeing. This study will allow us to acquire up-to-date instruments for scientific investigation in order to prevent 
and intervene in this serious cyber-bullying problem among adolescents. Furthermore, this scale would be a useful tool for detecting cyber-victims in the school context.

\section{Method}

\subsection{Participants}

In this cross-sectional study, the participants were 2506 adolescents enrolled in Obligatory Secondary Education. They were distributed in two independent samples, from Andalucía and the Valencian Community (Spain). To select the participants, stratified cluster sampling was carried out. The sampling units were semi-private and public schools from Andalusian Region (sample 1) and the Valencian Community (sample 2). Previous analysis showed that the two samples were equivalent in terms of gender and academic grade.

Sample 1 was composed of 1318 adolescents (age range: $12-16$ years, $M=13.89, S D=1.32$ ) of both sexes (52.6\% girls). The sample distribution by academic grade in Secondary Education was as follows: $24.58 \%$ Grade 7, 27.39\% Grade 8, 23.75\% Grade 9, and 24.28\% Grade 10.

Sample 2 was composed of 1188 adolescents (age range: $12-16$ years, $M=14.19, S D=1.80$ ) of both sexes (48.5\% boys). The sample distribution by academic grade was as follows: $30 \%$ Grade 7 , $25.10 \%$ Grade 8, 21.5\% Grade 9, and 23.40\% Grade 10.

\subsection{Measures}

\subsubsection{Cyber-Victimization Scale (CYBVICS)}

This scale is an adaptation of the Adolescent Victimization through Mobile Phone and Internet Scale (CYBVIC; Buelga et al. 2010, 2012). This new scale is an updated version of the previous scale, given that, with the use of the smartphone, the distinction between the cellphone and Internet currently makes no sense. Moreover, in addition to the items on the original scale, this new scale includes eight other items. Thus, the Cyber-Victimization Scale consists of 18 self-reported items (see Appendix A) rated on a 5-point Likert-type scale ranging from 1 (never) to 5 (always). This scale measures the adolescent's experience as a victim of cyberbullying in the past 12 months. A self-report measure was elaborated due to its greater capacity to recognize adolescents' cyber-victim behaviors.

First, to adapt the questionnaire, we started with the items on the CYBVIC validated scale, and, after reviewing the literature and other scales used in the past three years (Antoniadou et al. 2016), a list of 23 cyber-victimization behaviors was elaborated. This initial questionnaire was administered to an experimental sample of 48 adolescents between 12 and 16 years old. The aim was to explore possible difficulties in comprehending the items and find out whether the adolescents would add to or eliminate any of the cyber-victimization behaviors from the questionnaire. Some adolescents thought one item from the list was difficult to understand, and that another item referred to a behavior that was not currently performed. At the same time, three experts in adolescence and cyber-bullying also examined the items' clarity and thoroughness, coinciding with the adolescents. These judges also suggested suppressing another item, and so the questionnaire was composed of 20 items. Finally, two items that presented a saturation inferior to 0.20 in the Exploratory Factor Analysis (EFA) were eliminated, so that the final questionnaire contained 18 items.

\subsubsection{Multidimensional Self-Concept Scale AF5 (AF5)}

The AF5 (García and Musitu 1999) is a self-reported scale composed of 30 items that evaluate 5 dimensions of self-esteem: Academic, social, emotional, family, and physical. In this study, the Family Self-concept subscale was used, which is composed of 6 items that measure aspects related to adolescents' perceptions of their affective and relational bonds with their families (e.g., "I feel loved by my parents"). Cronbach's alpha reliability coefficient in this study was 0.73 . 


\subsubsection{The Parent-Adolescent Communication Scale (PACS)}

The PACS (Barnes and Olson 1982; Spanish Adaptation by Estévez et al. 2005) is a self-reported scale composed of 20 items rated on a 5-point Likert-type scale ranging from 1 (never) to 5 (always). Items measure the adolescent's perception of the communication with his/her father and mother separately. This scale has three subscales for the father and three for the mother: Openness in Father/Mother Communication; Offensive Communication with Father/Mother, and Avoidant Communication with Father/Mother. In this study, the subscales of Openness in Father/Mother Communication (11 items) and Offensive Communication with Father/Mother (4 items) were used. The Cronbach's alpha reliability coefficients in this study were: 0.91 and 0.90 for openness communication with the mother and father, respectively; and 0.71 and 0.78 for Offensive communication with the father and mother, respectively.

\subsubsection{Center for Epidemiological Studies Depression Scale (CES-D)}

The CES-D (Radloff 1977; Spanish Adaptation and Short form by Herrero and Meneses 2006) is a self-reported scale that consists of 7 items rated on a Likert-type scale ranging from 1 (never) to 4 (always) to assess the presence of depressive symptomatology in the past month. Cronbach's alpha reliability coefficient in this study was 0.80 .

\subsubsection{Victimization Scale among Peers}

This instrument is a self-reported scale consisting of 20 items rated from 1 (never) to 4 (always) that evaluate situations of direct and indirect victimization experienced by the adolescent in school (Mynard and Joseph 2000). Cronbach's alpha reliability coefficient in this study was 0.79 .

\subsection{Procedure}

The same procedure was followed in both samples. First, a letter was sent to the principals of the selected schools. Second, a seminar was held for the teachers to explain the research objectives and request parent authorization. Next, a letter describing the study was sent to the parents, asking for active authorization if they wanted their child to participate in the study ( $96 \%$ of the parents authorized their children's participation in the study). Questionnaires were administered during a regular class period (55 min) with the supervision of trained researchers. Participation was voluntary and anonymous, and privacy was guaranteed. Few students refused to participate in the study $(<2 \%)$. This study met the ethical requirements for research with human beings according to the fundamental principles established in the Declaration of Helsinki, and it was approved by the Ethics Committee of the University of Valencia (Protocol Number: H1456762885511).

\subsection{Data Analysis}

Exploratory Factor Analysis (EFA) and Confirmatory Factor Analysis (CFA) were carried out separately in the two samples in order to obtain cross-validation of the scale's factor structure (Izquierdo et al. 2014; Worthington and Whitttaker 2006). First, EFA was performed with the first sample, and the factors' reliabilities were calculated. Previously, the suitability of this analysis was explored through the Bartlett sphericity test and the Kaiser-Mayer-Olkin (KMO) sample adequacy test. To extract the factors, the Principal Components method with Oblimin rotation was used. This rotation is used when it is estimated that the factors obtained are correlated. To select the factors, a self-value higher than 1 and a decrease in the Cattell sedimentation graphic were taken into account. The SPSS program (23) was used.

Next, CFA was carried out to contrast the factor structure obtained with the second sample, using the QS 6.1 program (Bentler and Wu 2005). The maximum robust verisimilitude estimation method was used for all the analyses, due to the lack of multivariate normality in the data (Mardia coefficient = 1573.56). Several fit indicators were used, in addition to the Satorra-Bentler chi-square: the comparative fit index (CFI), the Bentler-Bonett non-normative fit index (NNFI)—also called the Tucker-Lewis index 
(TLI) - and the Root Mean Square Error of Approximation (RMSEA). Values of CFI and TLI above 0.95 are considered a good fit, as well as RMSEA values below 0.50. Regarding the Chi-square, a proposed model is considered to fit the data well when the ratio between the Chi-square and the degrees of freedom is less than 3 (Bentler and Bonett 1980).

\section{Results}

\subsection{Item Analysis}

Table 1 presents the distribution of the item responses. The item with the highest mean score was item 2 ("They called me on my smartphone and hung up to bother or frighten me"), whereas the item with the lowest mean was item 9 ("They put my cellphone number on the Internet and said bad or false things about me so people would call me and get me into trouble."). Kolmogorov-Smirnoff test results indicated that the items did not fit a normal distribution. The scores obtained on the asymmetrical and kurtosis indexes showed that all the items were distributed in a positive and leptokurtic way. Finally, the item-total correlation was positive and significant; therefore, all the items contribute in the same direction.

\subsection{Factor Structure of the CYBVICS}

First, Exploratory Factor Analysis was carried out in order to obtain the resulting factor structure. The results of the Kaiser-Meyer-Olkin test (0.95) and the Bartlett test $\left(\chi^{2}=109048.45 ; \mathrm{gl}=153, p<0.001\right)$ performed with the data from sample 1 indicated that the factor model was adequate to explain the data. The principal components analysis with oblimin rotation showed a two-factor structure that explained $53.08 \%$ of the variance.

Based on the semantic analysis of the items distributed in the factors and each item's saturation in the factor (see Table 2), the following factor structure can be observed, coherent with theoretical arguments linked to cyber-victimization behaviors. The first factor ( $43.85 \%$ of the variance) refers to behaviors that involve the cyber-aggressor directing electronic communication towards the victim and provoking an immediate negative effect (e.g., phone calls, instant messaging, text, or multimedia messages etc.). Therefore, and following the proposal by Langos (2012), this factor has been referred to as direct cyber-victimization. The second factor (9.24\% of the explained variance) contains items that refer to behaviors through which the cyberbully does not directly manage the communication and even avoids being identified. In addition, these behaviors involve greater premeditation. According to Langos (2012), this factor is referred to as indirect cyber-victimization. The correlation between the two factors is high and significant $(\mathrm{r}=0.63, p<0.001)$.

To confirm this structure, CFA was conducted in the second sample (see Table 2). The fit indexes for the proposed model indicated a good fit of the model and confirmed the scale's factor structure $\left(\chi^{2}=159.91, \mathrm{gl}=134, p>0.05, \mathrm{CFI}=0.97, \mathrm{TLI}=0.97 ; \mathrm{RMSEA}=0.013\right.$ [0.00-0.02] $)$. The internal consistency coefficients (Cronbach's $\alpha$ ) of these factors in the second sub-sample were also above 0.70 . Furthermore, high and significant correlations were obtained between the two factors (see Table 3). 


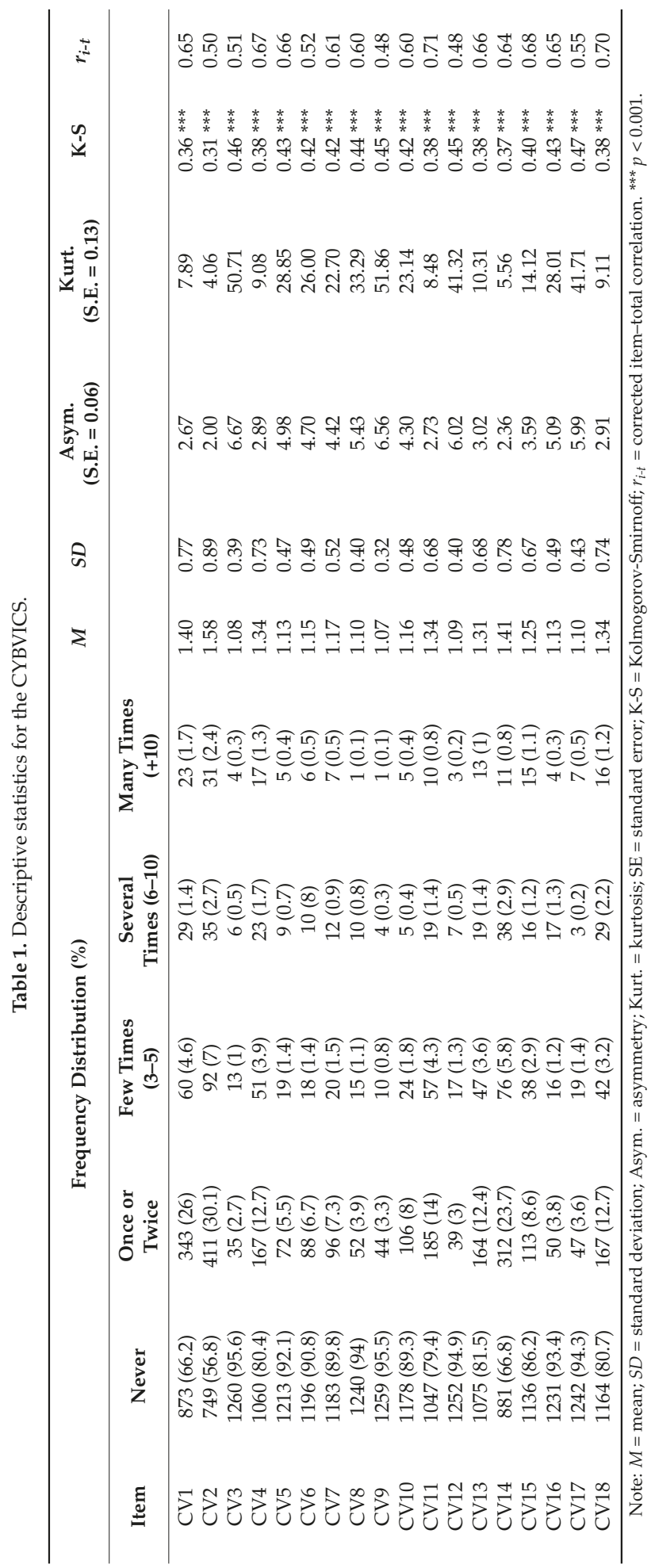


Table 2. Factor loadings for the EFA and CFA.

\begin{tabular}{ccccc}
\hline Item & \multicolumn{2}{c}{ EFA } & \multicolumn{2}{c}{ CFA } \\
\hline & F1 & F2 & $\begin{array}{c}\text { F1 } \\
\text { DCV }\end{array}$ & $\begin{array}{c}\text { F2 } \\
\text { ICV }\end{array}$ \\
\hline CV1 & 0.76 & 0.45 & 0.66 & \\
CV2 & 0.60 & 0.37 & 0.50 & \\
CV3 & 0.42 & 0.64 & & 0.71 \\
CV4 & 0.75 & 0.53 & 0.68 & \\
CV5 & 0.58 & 0.73 & & 0.69 \\
CV6 & 0.41 & 0.68 & & 0.63 \\
CV7 & 0.52 & 0.70 & & 0.67 \\
CV8 & 0.52 & 0.70 & & 0.75 \\
CV9 & 0.34 & 0.67 & & 0.72 \\
CV10 & 0.53 & 0.68 & & 0.69 \\
CV11 & 0.79 & 0.54 & 0.75 & \\
CV12 & 0.33 & 0.69 & & 0.69 \\
CV13 & 0.77 & 0.45 & 0.73 & \\
CV14 & 0.77 & 0.43 & 0.77 & \\
CV15 & 0.76 & 0.54 & 0.73 & \\
CV16 & 0.56 & 0.74 & & 0.70 \\
CV17 & 0.40 & 0.74 & & 0.65 \\
CV18 & 0.83 & 0.47 & 0.77 & \\
\% Explained Variance & 43.85 & 9.24 & & \\
\hline
\end{tabular}

Note: DCV = Direct Cyber-Victimization; ICV = Indirect Cyber-Victimization; EFA = Exploratory Factor Analysis; $\mathrm{CFA}=$ Confirmatory Factor Analysis.

Table 3. Descriptive statistics, factor correlations, and Cronbach's alpha (in parentheses) for the 2-factor model.

\begin{tabular}{ccccc}
\hline & $\boldsymbol{M}$ & $\boldsymbol{S D}$ & $\mathbf{D C V}$ & ICV \\
\hline DCV & 1.23 & 0.60 & $(0.92)$ & \\
ICV & 1.37 & 0.75 & $0.66^{* *}$ & $(0.89)$ \\
\hline
\end{tabular}

Note: DCV = Direct Cyber-Victimization, ICV = Indirect Cyber-Victimization; $M=$ mean; $S D=$ Standard Deviation. Alpha Global Scale $=0.88 .{ }^{* *} p<0.01$.

\subsection{Test of Invariance}

To evaluate the scale's factor invariance, a multi-group analysis was carried out to confirm that the number of factors, the items' saturations, and the correlations between the items were invariant in the two adolescent samples. Different nested models were estimated: (1) a first model without restrictions in which there is no imposed equality between the saturations and the correlations between the factors (model without restrictions); and (2) a second model that imposes equality between all the saturations and the correlations between the factors (model with restrictions) in the groups. These models were compared using the $\chi^{2}$ difference test (See Table 4). The results showed that the two models differed on one restriction. Once it was freed, the two models were equivalent.

Table 4. Tests of measurement invariance across two samples for the two-factor model.

\begin{tabular}{cccccccr}
\hline Model & Description & \multirow{2}{*}{$\chi^{2}$} & df & $\begin{array}{c}\text { Comparison of } \\
\text { Nested Models }\end{array}$ & $\begin{array}{c}\text { Difference } \\
\text { S-B } \chi^{2}\end{array}$ & $\begin{array}{c}\text { Difference } \\
\text { df }\end{array}$ & $p$ \\
\hline M1 & Restricted model & 362.0577 & 284 & & - & - & - \\
M2 & Model without restrictions & 343.3642 & 268 & M1-M2 & 18.69 & 16 & $>0.05$ \\
Ma & 1 restriction unconstrained & 352.7305 & 283 & Model 1a-Model 2 & 9.37 & 15 & $>0.05$ \\
\hline
\end{tabular}

\subsection{Convergent Validity}

Finally, the scale's convergent validity was analyzed by considering the correlations between the global cyber-victimization index obtained with the CYBVICS scale and other theoretically related constructs, such as: open communication with the father and the mother, offensive communication with the father and the mother, family self-esteem, depressive symptomatology, and peer victimization (see Table 5). 
Table 5. Correlations among cyber-victimization, family communication, family self-esteem, depressive symptomatology, and peer victimization.

\begin{tabular}{ccccccccc}
\hline & Cyber-Victimization & OpCM & OfCM & OpCF & OfCF & FS-E & $\begin{array}{c}\text { Depres } \\
\text { Sympt. }\end{array}$ & $\begin{array}{l}\text { Peer } \\
\text { Vict. }\end{array}$ \\
\hline Cyber victimization & 1 & $-0.19^{* *}$ & $0.28^{* *}$ & $-0.18^{* *}$ & $0.23^{* *}$ & $-0.21^{* *}$ & $0.46^{* *}$ & $0.42^{* *}$ \\
\hline
\end{tabular}

Note: OpCM = Open Communication with the Mother; OfCM = Offensive Communication with the Mother;

$\mathrm{OpCF}=$ Open Communication with the Father; OfCF = Offensive Communication with the Father; FS-E = Family

Self-Esteem; Depres Sympt. = Depressive Symptoms; Peer Vict. $=$ Peer Victimization. ${ }^{* *} p<0.01$.

The results showed significant positive and moderate correlations between cyber-victimization and offensive communication with the mother $(\mathrm{r}=0.28, p<0.01)$ and with the father $(\mathrm{r}=0.23, p<0.01)$. As expected, a strong and positive correlation was found between cyber-victimization and peer victimization $(\mathrm{r}=042, p<0.01)$ and depressive symptomatology $(\mathrm{r}=0.46, p<0.01)$. Furthermore, cyber-victimization showed significant and low negative correlations with open communication with the mother $(\mathrm{r}=-0.19, p<0.01)$ and with the father $(\mathrm{r}=-0.18, p<0.01)$, and moderate negative correlations with family self-esteem $(\mathrm{r}=-0.21, p<0.01)$.

\section{Discussion}

The technological changes, along with the appearance and modification of new cyber-victimization behaviors, as well as the severe consequences of cyber-bullying for the victim's psychological wellbeing (Ortega-Barón et al. 2016; Nocentini et al. 2018), suggest the need for updated and reliable instruments that allow its adequate measurement. In this regard, this study has found empirical evidence that supports the scale's validity, factor structure, internal consistency, and convergent validity with theoretically related external variables.

Thus, regarding the CYBVICS' factor structure, the results of the current study show a structure formed by two factors. This two-factor structure was also found for the original scale, which measures bullying through the smartphone, on the one hand, and bullying through the Internet, on the other. On the new scale, the two factors measure, in this case, direct cyber-victimization and indirect cyber-victimization, and they explain $53.08 \%$ of the variance. The first factor refers to cyber-aggressions oriented directly toward the victim, both verbal (i.e., insults on forums) and social (i.e., social exclusion from online groups) bullying. The second factor focuses more on indirect or instrumental cyber-aggressions that use tools to cause harm to the victim, such as creating a false profile of the victim, identity theft, or hacking his/her personal account.

These results are consistent with the two-factor structure of the CBVEQ-G scale by Antoniadou et al. (2016), who also classify their items as indirect aggressions and direct aggressions. These results are also congruent with previous literature on traditional bullying that points to the existence of these two dimensions of peer violence, referred to as direct or manifested aggressions and indirect or relational aggressions (Martínez-Ferrer et al. 2018; Mynard and Joseph 2000; Little et al. 2003).

Furthermore, the confirmatory factor analysis through the sample cross-validation procedure confirmed the scale's validity. This two-factor structure was found to be the model that best fit the data, also verifying the factor invariance of the CYBVICS scale in two independent samples of adolescents. In addition, the items showed adequate reliability in terms of internal consistency, both by factor and in the total scale. The reliability of the scale with the addition of the new items, therefore, presents sufficient psychometric guarantees, also found for the original scale. Evidence was also obtained of our new instrument's construct validity, given that significant correlations were found between the CYBVICS scale and the external variables considered: family communication with the mother and the father, family self-concept, depressive symptomatology, and traditional victimization.

Regarding these relationships between variables, our results show that cyber-victimization and traditional victimization are closely related, which was also found with the original scale and in previous literature (Alonso and Romero 2017; Cava and Buelga 2018; Mitchell and Jones 2015; Ortega-Baron et al. 2017). As Tokunaga (2010) and Kowalski et al. (2014) indicate, adolescents' 
problems in the school context are transferred to and continue in Internet. Thus, for example, Hinduja and Patchin (2008) found that adolescents who had suffered from traditional bullying in the previous 6 months were 2.5 times more likely to experience cyberbullying as well. In addition, as in the original scale, the existence of a high relationship between cyber-victimization and depressive symptomatology can be observed. This result supports the large number of studies that show the negative consequences of victimization on the wellbeing and adjustment of the victim (Garaigordobil 2017; Navarro et al. 2018; Serafini et al. 2015; Yubero et al. 2017). In this victimization situation, the family plays an essential role in helping their child to get out of this situation (Garaigordobil and Machimbarrena 2017; Navarro et al. 2015; Nocentini et al. 2018). A problem arises when the family has no family resources to protect or help their child, making him/her more vulnerable to being cyber-victimized by his/her peers. Consistently, a close link has been found between a negative family atmosphere and a reduction in adolescents' social and individual resources, which makes them an easier target for their peers' aggressions (Cava et al. 2018; Lereya et al. 2013). In fact, our data show that the quality of the family climate is inversely related to cyber-bullying. Thus, a negative family climate with problematic communication patterns with the mother/father is related to cyber-victimization. However, when the communication patterns with the mother/father are open and the child feels valued and respected in the family, these variables are negatively associated with cyber-victimization, which seems to indicate that they play a protective role. Parents need to talk to their children to find out their worries, concerns, and motivations when navigating through the Internet (Buelga et al. 2016; Navarro et al. 2018). The children have to perceive that their parents are a source of unconditional social support that can help them to face any problem in the Internet. Some adolescents do not tell their parents they are being bullied because they are afraid of their reaction; of being punished because they performed risky behaviors in Internet, such as talking to strangers or sending photos with sexual content (sexting). Thus, it is essential for parents to foment family communication so that the child perceives that his/her parents provide their support in difficult situations. Therefore, the quality of the family climate, that is, the family emotional bond with relationships of parent-child trust and patterns of family communication, is one of the most important measures for preventing cyberbullying (Buelga et al. 2017; Moreno-Ruiz et al. 2019).

The current study also has some limitations. First, even though the sample used in this investigation is adequate for the analyses carried out (Cava et al. 2018; Kline 2015), it would be advisable to carry out subsequent validation analyses with larger samples of Spanish adolescents, as well as adolescent samples from other countries in the world, in order to take into account possible cultural differences in the instrument's measurement. Moreover, the questionnaire's validation was carried out in an urban population, so that it would be advisable to verify the results in a rural population, given that the conditions and the adolescents' life style would differ. In addition, although this study provides evidence about important psychometric properties of the instrument (factor validity, convergent, and reliability), other psychometric aspects such as test-retest reliability were not considered and should be analyzed in future studies.

However, and despite these limitations, the current study guarantees the CYBVICS scale's suitability, recommending its application in the adolescent population. The serious consequences of cyber-bullying for adolescents supports the need for in-depth studies with reliable instruments to prevent this serious worldwide problem. In this context, the family is still a fundamental socializing agent in promoting children's healthy development and psychosocial adjustment.

Author Contributions: All the authors of the manuscript contributed equally to the research and writing of the present study.

Funding: This research was funded by the Ministry of Economy and Competitiveness of Spain, and the European Union though the European Regional Development Fund "A way of making Europe" [PSI2015-65683-P (MINECO/FEDER, UE)].

Conflicts of Interest: The authors declare no conflict of interest. 


\section{Appendix A CYBVICS. A}

\section{Adolescent Cyber-Victimization Scale}

Below, you will see some behaviors that some boys and girls might do to intimidate or really bother you (not as a joke), through the cellphone, Internet, social networks, tablets, or WhatsApp in the past year.

\begin{tabular}{|c|c|c|c|c|}
\hline & 2: Once or twice & & & \\
\hline \multicolumn{5}{|c|}{$\begin{array}{l}\text { 1. Someone insulted or ridiculed me in social networks or groups like WhatsApp to really hurt me. [Me han } \\
\text { insultado o puesto en ridículo en redes sociales o en grupos como el WhatsApp para hacerme daño de verdad] }\end{array}$} \\
\hline \multicolumn{5}{|c|}{$\begin{array}{l}\text { 2. Someone called my cellphone and hung up to bother or frighten me. [Me han llamado al móvil y no han } \\
\text { contestado para fastidiarme o asustarme] }\end{array}$} \\
\hline \multicolumn{5}{|c|}{$\begin{array}{l}\text { 3. Someone used threats to make me do things on the Internet or smartphone that I did not want to do (like } \\
\text { recording myself on video, giving money, doing bad things). [ Me han obligado con amenazas a hacer cosas } \\
\text { que no quería en Internet o por el móvil (como grabarme en video, dar dinero, hacer cosas malas)] }\end{array}$} \\
\hline \multicolumn{5}{|c|}{$\begin{array}{l}\text { 4. Someone told my secrets or revealed personal things about me in social networks or groups (WhatsApp, } \\
\text { snapchat ... ). [Han contado secretos míos o revelado cosas personales mías sin mi permiso en redes sociales o } \\
\text { en grupos (Whatsapp, snapchat ... )] }\end{array}$} \\
\hline \multicolumn{5}{|c|}{$\begin{array}{l}\text { 5. To make fun of me, someone made or manipulated videos or photos of me and uploaded or distributed } \\
\text { them on social networks or by smartphone. [Para burlarse de mí, han creado o manipulado videos o fotos } \\
\text { mías, y las han subido o distribuido en redes sociales o por el móvil]. }\end{array}$} \\
\hline \multicolumn{5}{|c|}{$\begin{array}{l}\text { 6. Someone logged into my profile or accor } \\
\text { cuentas sin que yo pueda hacer nada] }\end{array}$} \\
\hline \multicolumn{5}{|c|}{$\begin{array}{l}\text { 7. Someone pretended to be me saying or doing bad things on the Internet. [Se han hecho pasar por mí para } \\
\text { decir o hacer cosas malas en Internet] }\end{array}$} \\
\hline \multicolumn{5}{|c|}{$\begin{array}{l}\text { 8. Someone purposely created a webpage, a forum, or a group just to make fun of me and criticize me in front } \\
\text { of everyone. [Han creado adrede una página, un foro o un grupo solo para meterse conmigo y criticarme } \\
\text { delante de todos] }\end{array}$} \\
\hline \multicolumn{5}{|c|}{$\begin{array}{l}\text { 9. Someone put my cellphone number on the Internet and said bad or false things about me so that people } \\
\text { would call me and get me into trouble. [Han puesto mi número de teléfono móvil en Internet diciendo cosas } \\
\text { malas o falsas de mí para que me llamen y meterme en líos] }\end{array}$} \\
\hline \multicolumn{5}{|c|}{$\begin{array}{l}\text { 10. Someone took my smartphone and used it to send photos, videos, or mean messages to others to get me } \\
\text { into trouble with them. [Me han cogido mi teléfono y desde mi móvil han enviado fotos, videos o mensajes } \\
\text { malos a otros para meterme en problemas con los demás] }\end{array}$} \\
\hline \multicolumn{5}{|c|}{$\begin{array}{l}\text { 11. Someone criticized me or made fun of comments, photos, or videos I uploaded to social networks or } \\
\text { groups like WhatsApp. [Han criticado o se han burlado de comentarios, fotos o videos que yo he subido en } \\
\text { redes sociales o en grupos como el WhatsApp] }\end{array}$} \\
\hline \multicolumn{5}{|c|}{$\begin{array}{l}\text { 12. Someone created a false profile on the Internet with my personal data in order to impersonate me saying or } \\
\text { doing bad things. [Han creado en Internet un perfil falso con mis datos personales para decir o hacer cosas } \\
\text { malas, haciéndose pasar por mí] }\end{array}$} \\
\hline \multicolumn{5}{|c|}{$\begin{array}{l}\text { ed and did not answer messages or things I shared in groups or social networks, just to } \\
\text { [Me han ignorado y no han contestado a mensajes o cosas que yo he puesto en grupos o en } \\
\text { hacerme sentir mal] }\end{array}$} \\
\hline \multicolumn{5}{|c|}{$\begin{array}{l}\text { 14. Someone provoked me in social networks or groups by insulting or taunting me to make me angry and } \\
\text { cause a big argument. [Me han provocado en redes sociales o en grupos con insultos y burlas para que yo me } \\
\text { enfade mucho y que haya una gran discusión] }\end{array}$} \\
\hline \multicolumn{5}{|c|}{$\begin{array}{l}\text { 15. Someone eliminated or blocked me from groups to leave me without any friends. [Me han eliminado o } \\
\text { bloqueado de grupos para dejarme sin amigos] }\end{array}$} \\
\hline \multicolumn{5}{|c|}{$\begin{array}{l}\text { 16. Someone stole my photos, videos, or private conversations and uploaded them or sent them to others. } \\
\text { [Me han robado fotos, videos, conversaciones privadas, y las han subido o enviado a otros] }\end{array}$} \\
\hline \multicolumn{5}{|r|}{ han cambiado la } \\
\hline & & & & \\
\hline
\end{tabular}




\section{References}

Aboujaoude, Elias, Matthew Savage, Vladan Starcevic, and Wael Salame. 2015. Cyberbullying: Review of an old problem gone viral. Journal of Adolescent Health 57: 10-18. [CrossRef]

Alonso, Cristina, and Estrella Romero. 2017. Aggressors and Victims in Bullying and Cyberbullying: A Study of Personality Profiles using the Five-Factor Model. The Spanish Journal of Psychology 20: E76. [CrossRef]

Anderson, Monica, and Jingjing Jiang. 2018. Report Teens, Social Media \& Technology. Washington: Pew Research Center. Available online: www.pewinternet.org/2018/05/31/teens-social-media-technology-2018 (accessed on 18 November 2018).

Antoniadou, Nafsika, Constantinos M. Kokkinos, and Angelos Markos. 2016. Development, construct validation and measurement invariance of the Greek cyber-bullying/victimization experiences questionnaire (CBVEQ-G). Human Behavior 65: 380-90. [CrossRef]

Athanasiou, Kalliope, Eirini Melegkovits, Elisabeth K. Andrie, Charalampos Magoulas, Chara K. Tzavara, Clive Richardson, and Artemis K. Tsitsika. 2018. Cross-national aspects of cyberbullying victimization among 14-17-year-old adolescents across seven European countries. BMC Public Health 18: 800. [CrossRef]

Barnes, Howard, and David H. Olson. 1982. Parent adolescent communication scale. In Family Inventories: Inventories Used in a National Survey of Families across the Family Life Cycle. Edited by David H. Olson, Hamilton I. McCubbin, Howard Barnes, Andrea Larsen, Marla Muxen and y Marc Wilson. St. Paul: University of Minnesota Press, pp. 33-48.

Bentler, Peter M., and Douglas G. Bonett. 1980. Significance tests and goodness of fit in the analysis of covariance structures. Psychological Bulletin 88: 588-66. [CrossRef]

Bentler, Peter M., and Eric J. C. Wu. 2005. EQS 6.1 for Windows. Encino: Multivariate Software INC, pp. 1-26, ISBN 1-885898-03-7.

Buelga, Sofía, María Jesús Cava, and Gonzalo Musitu. 2010. Cyberbullying: Victimización entre adolescentes a través del teléfono móvil y de Internet. Psicothema 22: 784-89.

Buelga, Sofía, María Jesús Cava, and Gonzalo Musitu. 2012. Validación de la escala de victimización entre adolescentes a través del teléfono móvil y de Internet. Revista Panamericana de Salud Pública 32: 36-42. [CrossRef]

Buelga, Sofía, Belén Martínez-Ferrer, and Gonzalo Musitu. 2016. Family relationships and cyberbullying. In Cyberbullying across the Globe: Gender, Family and Mental Health. Edited by Raúl Navarro, Santiago Yubero and Elisa Larrañaga. Basel: Springer International Publishing, pp. 94-114, ISBN 978-3-319-25552-1.

Buelga, Sofía, Belén Martínez-Ferrer, and María-Jesús Cava. 2017. Differences in family climate and family communication among cyberbullies, cybervictims, and cyber bully-victims in adolescents. Computers in Human Behavior 76: 164-73. [CrossRef]

Cava, María-Jesús, and Sofía Buelga. 2018. Propiedades psicométricas de la Escala de Victimización Escolar entre Iguales (VE-I). Revista Evaluar 18: 40-53.

Cava, María-Jesús, Sofía Buelga, and Inés Tomás. 2018. Peer Victimization and Dating Violence Victimization: The Mediating Role of Loneliness, Depressed Mood, and Life Satisfaction. Journal of Interpersonal Violence. Advance online publication. [CrossRef]

Cohen-Almagor, Raphael. 2018. Social responsibility on the Internet: Addressing the challenge of cyberbullying. Aggression and Violent Behavior 39: 42-52. [CrossRef]

Cross, Donna, Amy Barnes, Alana Papageorgiou, Kate Hadwen, Lydia Hearn, and Leanne Lester. 2015. A social-ecological framework for understanding and reducing cyberbullying behaviours. Aggression and Violent Behavior 23: 109-17. [CrossRef]

Del Río, María Isabel, Santiago Mendo, Benito del Barco, and Elena Felipe. 2017. Abuso del Móvil en Estudiantes Universitarios y Perfiles de victimización y agresión. Adicciones 29: 245-55. [CrossRef] [PubMed]

Ditrendia Digital Marketing Trends. 2016. Informe Mobile en España y en el Mundo 2015. Available online: https:/ / goo.gl/AGi5JF (accessed on 15 October 2018).

Estévez, Estefanía, Gonzalo Musitu, and Juan Herrero. 2005. El rol de la comunicación familiar y del ajuste escolar en la salud mental del adolescente. Salud Mental 28: 81-89.

Ferrara, Pietro, Francesca Ianniello, Alberto Villani, and Giovanni Corsello. 2018. Cyberbullying a modern form of bullying: Let's talk about this health and social problem. Italian Journal of Pediatrics 44. [CrossRef] 
Garaigordobil, Maite. 2017. Antisocial behavior: Connection with bullying/cyberbullying and conflict resolution. Psychosocial Intervention 26: 47-54. [CrossRef]

Garaigordobil, Maite, and Juan M. Machimbarrena. 2017. Stress, competence, and parental educational styles in victims and aggressors of bullying and cyberbullying. Psicothema 29: 335-40. [CrossRef] [PubMed]

García, Fernando, and Gonzalo Musitu. 1999. AF5: Autoconcepto Forma 5. Madrid: Tea.

Hamm, Michele P., Amanda S. Newton, Annabritt Chisholm, Jocelyn Shulhan, Andrea Milne, Purnima Sundar, and Lisa Hartling. 2015. Prevalence and effect of cyberbullying on children and young people: A scoping review of social media studies. JAMA Pediatrics 169: 770-77. [CrossRef] [PubMed]

Herrero, Juan, and Julio Meneses. 2006. Short Web-based versions of the perceived stress (PSS) and Center for Epidemiological Studies-Depression (CESD) Scales: A comparison to pencil and paper responses among Internet users. Computers in Human Behavior 22: 830-46. [CrossRef]

Hinduja, Sameer, and Justin W. Patchin. 2008. Cyberbullying: An exploratory analysis of factors related to offending and victimization. Deviant Behavior 29: 129-56. [CrossRef]

Izquierdo, Isabel, Julio Olea, and Francisco José Abad. 2014. Exploratory factor analysis in validation studies: Uses and recommendations. Psicothema 26: 395-400. [CrossRef]

Kline, Rex B. 2015. Principles and Practice of Structural Equation Modelling. New York: Guilford Publications, pp. 154-96, ISBN 9781462523344.

Kowalski, Robin M., Gary W. Giumetti, Amber N. Schroeder, and Micah R. Lattanner. 2014. Bullying in the digital age: A critical review and meta-analysis of cyberbullying research among youth. Psychological Bulletin 140: 1073-137. [CrossRef]

Langos, Colette. 2012. Cyberbullying: The challenge to define. Cyberpsychology, Behavior, and Social Networking 15: 285-89. [CrossRef]

Larrañaga, Elisa, Santiago Yubero, Anastasio Ovejero, and Raúl Navarro. 2016. Loneliness, parent-child communication and cyberbullying victimization among Spanish youths. Computers in Human Behavior 65: 1-8. [CrossRef]

Lee, Chang Ho, and Keyong S. Lee. 2013. Exploration of the impact of social media use on youths' cyberbullying: Focusing on network characteristics. Studies on Korean Youth 24: 259-85.

Lee, Chang Ho, and Namin Shin. 2017. Prevalence of cyberbullying and predictors of cyberbullying perpetration among Korean adolescents. Computers in Human Behavior 68: 352-58. [CrossRef]

Lereya, Suzet Tanya, Muthanna Samara, and Dieter Wolke. 2013. Parenting behavior and the risk of becoming a victim and a bully/victim: A meta-analysis study. Child Abuse \& Neglect 37: 1091-108.

Little, Tood D., Christopher C. Henrich, Stephanie M. Jones, and Patricia. H. Hawley. 2003. Disentangling the "whys" from the "whats" of aggressive behaviour. International Journal of Behavioral Development 27: 122-33. [CrossRef]

Lohbeck, Annette, and Franz Petermann. 2018. Cybervictimization, self-esteem, and social relationships among German secondary school students. Journal of School Violence 17: 472-86. [CrossRef]

Martínez-Ferrer, Belén, David Moreno, and Gonzalo Musitu. 2018. Are adolescents engaged in the problematic use of social networking sites more involved in peer aggression and victimization? Frontiers in Psychology 9. [CrossRef]

Mitchell, Kimberly J., and Lisa M. Jones. 2015. Cyberbullying and bullying must be studied within a broader peer victimization framework. Journal of Adolescent Health 56: 473-74. [CrossRef]

Moreno-Ruiz, David, Belén Martinez-Ferrer, and Francisco García-Bacete. 2019. Parenting styles, cyberaggression, and cybervictimization among adolescents. Computers in Human Behavior 93: 252-59. [CrossRef]

Mynard, Helen, and Stephen Joseph. 2000. Development of the multidimensional peer-victimization scale. Aggressive Behavior 26: 169-78. [CrossRef]

Navarro, Raúl, Roberto Ruiz-Oliva, Elisa Larrañaga, and Santiago Yubero. 2015. The impact of cyberbullying and social bullying on optimism, global and school-related happiness and life satisfaction among 10-12-year-old schoolchildren. Applied Research in Quality of Life 10: 15-36. [CrossRef]

Navarro, Raúl, Santiago Yubero, and Elisa Larrañaga, eds. 2016. Cyberbullying Across the Globe: Gender, Family and Mental Health. Switzerland: Springer International Publishing. [CrossRef]

Navarro, Raúl, Santiago Yubero, and Larrañaga Elisa. 2018. Cyberbullying victimization and fatalism in adolescence: Resilience as a moderator. Children and Youth Services Review 84: 215-21. [CrossRef] 
Nocentini, Annalaura, Giada Fiorentini, Ludovica Di Paola, and Ersilia Menesini. 2018. Parents, family characteristics and bullying behavior: A systematic review. Aggression and Violent Behavior. [CrossRef]

Ortega-Barón, Jessica, Sofía Buelga, and María Jesús Cava. 2016. The Influence of School Climate and Family Climate among Adolescents Victims of Cyberbullying. Comunicar 24: 57-65. [CrossRef]

Ortega-Baron, Jessica, Sofía Buelga, María Jesús Cava, and Eva Torralba. 2017. School violence and attitude toward authority of student perpetrators of cyberbullying. Journal of Psychodidactics 22: 14-23. [CrossRef]

Protégeles. 2014. Menores de Edad y Conectividad en España: Tablets y Smartphones. Available online: https://goo.gl/K4cvH9 (accessed on 21 November 2018).

Radloff, Leonore S. 1977. The CES-D scale: A self report depression scale for research in the general population. Applied Psychological Measurement 1: 385-401. [CrossRef]

Serafini, Gianluca, Caterina Muzio, Giulia Piccinini, Eirini Flouri, Gabriella Ferrigno, Maurizio Pompili, Paolo Girardi, and Mario Amore. 2015. Life adversities and suicidal behavior in young individuals: A systematic review. European Child \& Adolescent Psychiatry 24: 1423-46. [CrossRef]

Thompson, Richard, Alan J. Litrownik, Mark, D. Everson, Diana J. English, Howard Dubowitz, Laura Proctor, and Emalee G. Flaherty. 2012. Adverse experiences and suicidal ideation in adolescence: exploring the link using LONGSCAN samples. Psychology of Violence 2: 211-25. [CrossRef]

Tokunaga, Robert S. 2010. Following you home from school: A critical review and synthesis of research on cyberbullying victimization. Computers in Human Behavior 26: 277-87. [CrossRef]

Van Geel, Mitch, Paul Vedder, and Jenny Tanilon. 2014. Relationship between peer victimization, cyberbullying, and suicide in children and adolescents: A meta-analysis. JAMA Pediatrics 168: 435-42. [CrossRef]

Vivolo-Kantor, Alana M., Brandi N. Martell, Kristin M. Holland, and Ruth Westby. 2014. A systematic review and content analysis of bullying and cyber-bullying measurement strategies. Aggression and Violent Behavior 19: 423-34. [CrossRef]

Willard, Nancy E. 2007. The authority and responsibility of school officials in responding to cyberbullying. Journal of Adolescent Health 41: S64-S65. [CrossRef]

Worthington, Roger L., and Tiffany A. Whitttaker. 2006. Scale development research: A content analysis and recommendations for best practices. The Counseling Psychologist 34: 806-38. [CrossRef]

Yubero, Santiago, Raúl Navarro, María Elche, Elisa Larrañaga, and Anastasio Ovejero. 2017. Cyberbullying victimization in higher education: An exploratory analysis of its association with social and emotional factors among Spanish students. Computers in Human Behavior 75: 439-49. [CrossRef]

Zych, Izabela, Rosario Ortega-Ruiz, and Inmaculada Marín-López. 2016. Cyberbullying: A systematic review of research, its prevalence and assessment issues in Spanish studies. Psicología Educativa 22: 5-18. [CrossRef]

(C) 2019 by the authors. Licensee MDPI, Basel, Switzerland. This article is an open access article distributed under the terms and conditions of the Creative Commons Attribution (CC BY) license (http:/ / creativecommons.org/licenses/by/4.0/). 
Article

\title{
The Relationship between Parental Control and High-Risk Internet Behaviours in Adolescence
}

\author{
David Álvarez-García *, Trinidad García and Zara Suárez-García \\ Department of Psychology, University of Oviedo, Plaza Feijóo, s/n, 33003 Oviedo, Spain; \\ garciatrinidad@uniovi.es (T.G.); uo186794@uniovi.es (Z.S.-G.) \\ * Correspondence: alvarezgardavid@uniovi.es; Tel.: +34-985-103-278
}

Received: 29 April 2018; Accepted: 30 May 2018; Published: 1 June 2018

\begin{abstract}
One of the main predictors of being a victim of cyber-aggression is engaging in high-risk behaviours on the internet. The main objective of this research is to analyse the relationship between two types of parental control (restriction and supervision) and engagement in high-risk internet behaviours during adolescence. To that end, and as a secondary objective, we designed and validated the High-risk Internet Behaviours Questionnaire for adolescents, used in this study. We analysed the responses of 946 adolescents aged between 12 and 18 to the High-risk Internet Behaviours Questionnaire and the Questionnaire on Parental Control of Internet Use in Adolescence. The results show that the questionnaire has appropriate metrics of reliability and validity, and show the existence of a statistically significant negative relationship, albeit small, between supervision and engaging in high-risk internet behaviours. We discuss the practical implications of these results.
\end{abstract}

Keywords: parental control; restriction; supervision; high-risk behaviours; internet; adolescence

\section{Introduction}

The internet can be a very positive tool for an adolescent. It may be of great use for learning and sharing knowledge, taking part in social initiatives, and keeping in touch with family and friends. However, careless internet use can produce certain risks, such as excessive internet use, exposure to potentially harmful content, orbeing the victim of cyber-aggression. Cyber-aggression refers to those behaviours or omissions through information and communication technologies that is intended to harm or offend (Corcoran et al. 2015). These aggressions can take various forms, such as written or verbal cyber-aggression, visual cyber-aggression, online exclusion, and impersonation (Nocentini et al. 2010).

Certain adolescent behaviours related to mobile phone or internet use can make it easier for people to fall victim to cyber-aggression. Previous research has shown that these high-risk behaviours include allowing others to upload one's videos or images to the internet, adding people to social networks who are not known personally, communicating online with strangers, publishing personal information on social networks, meeting up with someone face-to-face who has only previously been known online, giving out one's telephone number to people that have just been met or are not known well, sending compromising photos of oneself or others via mobile phones or the internet, and exchanging personal information with people only known online (Gómez et al. 2017; Liau et al. 2005; Mesch 2009; Sasson and Mesch 2017).

The family has an important role to play in preventing these high-risk behaviours. Parents are often advised to exercise some control over their children's internet use. Occasionally, families set limits or restrictions on internet use (time, content, activities, etc.), either establishing rules or using specific software. Or they may supervise the adolescents' activity, covertly or overtly, either during or following the activity. Some studies maintain that parental control over internet use is a protective factor, albeit limited, for these high-risk behaviours (Lee 2013; Lee and Chae 2012; Liau et al. 2005) as well as for being a victim of 
cyberbullying (Elsaesser et al. 2017; Giménez et al. 2017; Navarro et al. 2013). Some studies have been more specific, finding a significantly larger effect for supervision than for restriction (Khurana et al. 2015). However, there is research which suggests the existence of a positive relationship between parental internet control and engaging in high-risk internet behaviours (Duerager and Livingstone 2012) or being the victim of cyberbullying (Sasson and Mesch 2017). This result was interpreted as indicating that parental control was more likely when the parents knew or suspected that their child was engaging in high-risk behaviours or being on the receiving end of cyberbullying.

Faced with these inconsistent results from previous research, the main objective of this study is to analyse the relationship between parental control of internet use and high-risk internet behaviours in a sample of Spanish adolescents. In order to achieve that, and as a secondary objective, we undertook the design and validation of the High-Risk Internet Behaviours Questionnaire for adolescents, which was used in this study.

\section{Method}

\subsection{Participants}

The participants in this study were students in compulsory secondary education in six schools in Asturias (Spain). Before performing a statistical analysis, we selected the students who reported that they owned their own mobile phone, used instant messaging (e.g., WhatsApp), participated in social networks, and surfed the internet for non-homework purposes. The final sample was made up of 946 adolescents aged between 12 and $18(\mathrm{M}=14.29 ; \mathrm{SD}=1.37), 50.7 \%$ girls. The distribution of students over the four years of compulsory secondary education (ESO) was: 20.5\% in first year, $25.3 \%$ in second year, $26.6 \%$ in third year, and $27.6 \%$ in fourth year.

\subsection{Measuring Instruments}

\subsubsection{High-Risk Internet Behaviours Questionnaire}

This is a self-report designed and tested for this study (Appendix A). It is made up of 8 items, each of which describes a high-risk behaviour on the internet. The respondent indicates the extent to which they think it is true that they engage in each of the behaviours through a Likert-type scale with four alternatives ( 1 = completely false, $2=$ somewhat false, $3=$ somewhat true, $4=$ completely true). In the Results section, we give the psychometric properties of the questionnaire.

\subsubsection{Questionnaire on Parental Control of Internet Use during Adolescence}

This questionnaire (Álvarez-García et al. 2018) is made up of 7 items. For each item, the respondent indicates the extent to which they think the corresponding statement about possible control of their internet use by their parents is true. The questionnaire measures two types of control: restriction (e.g., "My parents limit when I can use the internet (either by telling me or by configuring the computer)") and supervision (e.g., "My parents know who is in my list of contacts"). The responses are in a Likert-type format with four alternatives $(1=$ completely false, $2=$ somewhat false, $3=$ somewhat true, $4=$ completely true). High scores indicate high levels of either restriction or supervision. The internal consistency of each factor in the sample in this study is adequate ( $\alpha=0.71$ for the restriction factor and $\alpha=0.79$ for the supervision factor).

\subsection{Procedure}

Once the participating schools and the questionnaires had been decided on, we sought permission from each school's management to carry out the study. We informed them of the research objectives and the process, and the fact that it was voluntary and anonymous, and that the results would be treated confidentially. Before completing the questionnaire, the students were also informed of the 
same information. The instrument was applied by the research team to all of the groups in each of the schools during school hours.

\subsection{Data Analysis}

Firstly, we analysed the statistical guarantees from the High-Risk Internet Behaviours Questionnaire, then we analysed the relationship between parental control and high-risk internet behaviours in adolescence. For the former, we analysed the psychometric properties of the items using SPSS 24.0 software. Following that, we performed a confirmatory factor analysis using EQS 6.2 software, starting from the polychoric correlation matrix, using the robust maximum likelihood method of estimation given the non-normally distributed scores. Finally, we calculated the reliability for the questionnaire in terms of internal consistency via Cronbach's alpha. For the analysis of the relationship between parental control and high-risk internet behaviours we calculated Spearman correlation coefficients, partial correlation coefficients, and multiple linear regression, using SPSS 24.0 software.

\section{Results}

\subsection{Validation of the High-Risk Internet Behaviours Questionnaire}

\subsubsection{Item Analysis}

The proportion of participants who failed to answer each item, or gave invalid responses is relatively insignificant (between $0.2 \%$ and $0.7 \%$ ) as Table 1 shows. All of the alternatives were chosen by some participants for each item. The standard deviations show that there was variability between participants' scores. According to the results of the Kolmogorov-Smirnov test (Table 1), the scores for each item were not normally distributed. All of the items, except item 1, demonstrated positive asymmetry, which means that the students tended to score the lower values in the scale (few high-risk internet behaviours).

Table 1. Descriptive statistics for the application of the High-Risk Internet Behaviours Questionnaire to the sample $(N=946)$.

\begin{tabular}{|c|c|c|c|c|c|c|c|c|c|c|c|}
\hline \multirow{2}{*}{ Item } & \multicolumn{5}{|c|}{ Scale Scores $(\%)$} & \multirow{2}{*}{$\mathbf{M}$} & \multirow{2}{*}{$S D$} & \multirow{2}{*}{$\begin{array}{c}\text { Asym. } \\
(\mathrm{SE}=0.08)\end{array}$} & \multirow{2}{*}{$\begin{array}{c}\text { Kurt. } \\
(\mathrm{SE}=0.16)\end{array}$} & \multirow{2}{*}{$Z$} & \multirow{2}{*}{$r_{i-t}$} \\
\hline & 1 & 2 & 3 & 4 & NA & & & & & & \\
\hline 1 & 23.3 & 21.5 & 35.5 & 19.5 & 0.3 & 2.51 & 1.05 & -0.13 & -1.19 & $7.02 *$ & 0.32 \\
\hline 2 & 31.0 & 30.4 & 25.6 & 12.6 & 0.4 & 2.20 & 1.02 & 0.32 & -1.05 & $5.90 *$ & 0.55 \\
\hline 3 & 46.6 & 20.7 & 20.3 & 11.6 & 0.7 & 1.97 & 1.07 & 0.64 & -0.96 & $8.76^{*}$ & 0.50 \\
\hline 4 & 32.9 & 29.8 & 23.8 & 13.2 & 0.3 & 2.17 & 1.03 & 0.37 & -1.06 & $6.18^{*}$ & 0.41 \\
\hline 5 & 76.1 & 8.7 & 9.5 & 5.5 & 0.2 & 1.44 & 0.88 & 1.83 & 2.04 & 13.98 * & 0.52 \\
\hline 6 & 47.4 & 25.5 & 18.3 & 8.7 & 0.2 & 1.88 & 1.00 & 0.77 & -0.63 & $8.80 *$ & 0.55 \\
\hline 7 & 85.9 & 8.9 & 3.6 & 1.3 & 0.3 & 1.20 & 0.55 & 3.10 & 9.74 & 15.37 * & 0.34 \\
\hline 8 & 77.1 & 13.3 & 6.2 & 3.0 & 0.4 & 1.35 & 0.73 & 2.18 & 4.06 & 13.98 * & 0.52 \\
\hline
\end{tabular}

Scale scores: $1=$ completely false; $2=$ somewhat false; $3=$ aomewhattrue; $4=$ completely true; NA= no answer or null answer; $M=$ mean; $S D=$ standard deviation; Asym. = asymmetry; Kurt. = kurtosis; $\mathrm{SE}=$ standard error; $\mathrm{Z}=$ Kolmogorov-Smirnov $\mathrm{Z} ; r_{i-t}=$ corrected item-total correlation. ${ }^{*} p<0.001$.

The corrected item-total correlation $\left(r_{i-t}\right)$ was positive in all items, with values between 0.32 and 0.55 , which indicates that they all contributed to measuring what the test measured, in the same direction. The correlations between each of the questionnaire items were positive and statistically significant in all cases, with values ranging between 0.11 and 0.46 . Therefore, all of the items were related, but not redundant.

\subsubsection{FactorAnalysis}

In order to examine the theoretical model fit to the empirical data, we performed a confirmatory factor analysis. The model being tested is made up of a single factor (high-risk internet behaviours). Each item in the questionnaire would be explained by this factor. The results indicate that this 
single-factor model adequately represents the data we obtained $\chi_{S B}^{2}=111.96 ; d f=20 ; \chi^{2} / d f=5.60$; $\mathrm{NFI}=0.960 ; \mathrm{CFI}=0.967 ; \mathrm{RMSEA}=0.070$ (90\% CI: 0.057-0.082). The factorial weightings for each item in the factor are moderate or high (Figure 1).

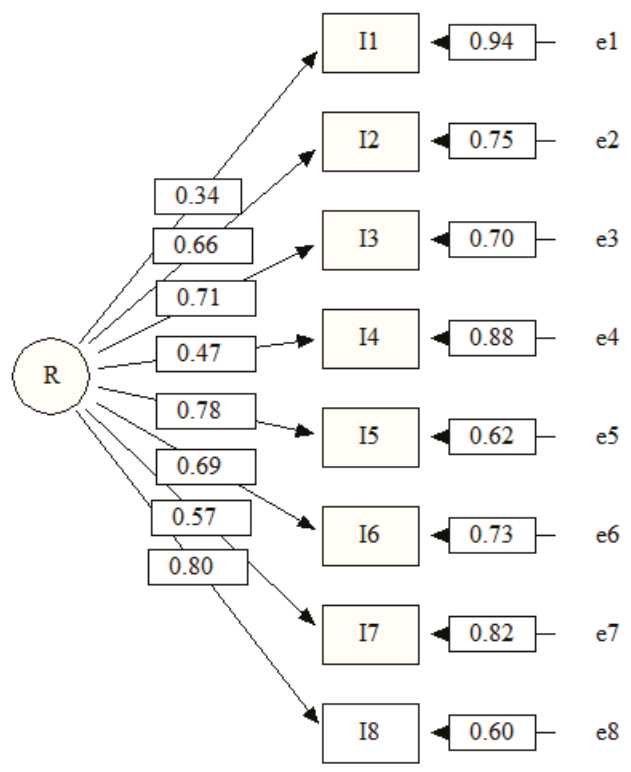

Figure 1. Factorial structure of the High-Risk Internet Behaviours Questionnaire ( $R=$ high-risk internet behaviours).

\subsubsection{Reliability}

Test reliability, as measured by internal consistency, was adequate. Cronbach's alpha for the overall scale was 0.84 .

\subsection{Relationship between Parental Control and High-Risk Internet Behaviours}

The obtained Spearman correlation coefficients (Table 2) seem to show that the extent to which adolescents report that their parents or guardians restrict or supervise their internet use is statistically significantly negatively correlated with the extent to which the adolescentsrecognise their own high-risk internet behaviours. This association, however, is relatively weak.

Table 2. Correlation between scores for parental internet restriction and supervision and adolescent high-risk Internet behaviours $(N=946)$.

\begin{tabular}{cccc}
\hline & \multicolumn{3}{c}{ High-Risk Internet Behaviours } \\
\cline { 2 - 4 } & $r_{S}$ & $r_{a b . c}$ & $\beta$ \\
\hline Restriction & $-0.12^{* * *}$ & $-0.08^{*}$ & 0.003 \\
Supervision & $-0.16^{* * *}$ & $-0.14^{* * *}$ & $-0.141^{* * *}$ \\
\hline
\end{tabular}

$r_{s}=$ Spearman correlation; $r_{a b . c}=$ partial correlation, controlling for the effect of age; $\beta=$ standardized regression coefficients, including age, restriction, and supervision in the model. ${ }^{*} p<0.05 ;{ }^{* *} p<0.01$; ${ }^{* * *} p<0.001$.

In the sample being analysed, age correlated negatively with parental rules $\left(r_{S}=-0.29 ; p<0.001\right)$ and supervision $\left(r_{S}=-0.28 ; p<0.001\right)$ of internet use, and correlated positively with adolescents' high-risk internet behaviours $\left(r_{S}=0.19 ; p<0.001\right)$. In order to show that the relationship between 
parental control and high-risk behaviours was not spurious, and explained by the relationship between the two variables and age, we analysed the partial correlation between high-risk internet behaviours and the two types of parental control, statistically controlling for the effect of age. As Table 2 shows, the results are very similar to the zero order correlations.

However, multiple linear regression including age, restriction, and supervision in the model shows that supervision, but not restriction, is significantly associated withadolescent high-risk internet behaviours (Table 2). Restriction isstatistically significantly positively correlated with supervision $\left(r_{S}=0.60 ; p<0.001\right)$.

\section{Discussion}

The main objective of this study was to analyse the relationship between parental control over internet use (restriction or supervision) and high-risk internet behaviours in a sample of Spanish adolescents. The results support the hypothesised negative relationship, but only for supervision.

This result fits with the idea that the family has a significant, although limited, influence over the prevention of adolescent high-risk behaviours. Various possible reasons have been identified for this limited influence (Navarro et al. 2013). One is that adults often do not understand the content of the apps their children use, or how they work. The adolescents may have strategies to get around the rules without leaving traces of their activities on their devices, which makes it more difficult to control. As the children get older, they may also spend more time with their friends rather than family, and if their friends encourage these behaviours, there is a higher risk that the adolescent will engage in them (Sasson and Mesch 2014).

In this study, engaging in high-risk internet behaviours demonstrated a stronger (negative) relationship with supervision than with restriction, as in previous research (Khurana et al. 2015). It may suggest that control is more effective if the adolescents' behaviour is monitored, rather than just announcing a restriction or using a specific piece of software. Nonetheless, it is important to remember that parental control over internet use tends to have positive effects, especially in open, affective contexts which support adolescent autonomy, and negative effects in inconsistent and controlling contexts (Gómez-Ortiz et al. 2015; Valkenburg et al. 2013).

A secondary objective in this study, essential to fulfil the main objective, was to design and validate the High-Risk Internet Behaviours Questionnaire for adolescents. The results demonstrate that the indicators chosen to measure the construct are appropriate, and that the test has adequate psychometric properties of reliability and validity for the use it was designed for.

This study, therefore, represents a contribution to the field of research, in so far as it provides a new tool for measuring high-risk internet behaviours in adolescence, and contributes to the clarification of the relationship between parental control of internet use and engaging in high-risk internet behaviours in adolescence. In order to prevent high-risk behaviours and, in turn, prevent their children from becoming victims of cyber-aggression in adolescence, it is important for families to have some control over their children's internet activity. To be effective and not counterproductive, that control must adapt to the adolescent's maturity and need for autonomy (Ang 2015). The objective should be to encourage a responsible autonomy, and not to impose restrictions on it. The control should be exercised in an affective context, in which adolescents are encouraged to think critically about positive, responsible Internet use.

While this research is a contribution to the field, it is not without limitations. In the first place, this research was carried out with an incidental sample, extracted from a specific population limited to certain ages and geographical areas. Therefore, any generalisation of the conclusions to other ages or regions should be made with caution. In the second place, the research used adolescents' self-reports. It would be useful in future to gather information from the families as well. Finally, we used a correlational methodology, which means that the direction of the relationship cannot be determined. The conclusions are made as a hypothesis for confirmation in the future using other methodologies (such as longitudinal studies). 
Author Contributions: Conceptualization, D.A.; Investigation, D.A., T.G., and Z.S.-G.; Data Curation, T.G., and Z.S.-G.; Methodology, D.A.; Writing-Original Draft Preparation, D.A., T.G., and Z.S.-G.; Writing-Review \& Editing, D.A., T.G., and Z.S.-G.; Supervision, D.A.

Funding: This research was funded by the Consejería de Economía y Empleo del Principado de Asturias [Council of Economy and Employment of the Princedom of Asturias] (Spain). Grant number: FC-15-GRUPIN14-053.

Acknowledgments: The authors thank all pupils, teachers, and principals of the respective schools for their participation in this study.

Conflicts of Interest: None of the authors of this paper has a financial or personal relationship with other people or organizations that could inappropriately influence or bias the content of the paper.

\section{Appendix A. High-Risk Internet Behaviours Questionnaire}

Mark a cross $(X)$ to indicate the extent to which you think each of the following statements are true. Please only choose one answer from the four options available. Try to respond to all of the statements.

\begin{tabular}{|c|c|c|c|c|}
\hline & 1 & 2 & 3 & 4 \\
\hline \multicolumn{5}{|l|}{$\begin{array}{l}\text { 1. Permito que otras personas suban fotos o videos míos a Internet [I let } \\
\text { other people upload my photos or videos to the internet]. }\end{array}$} \\
\hline \multicolumn{5}{|l|}{$\begin{array}{l}\text { 2. Agrego a mis redes sociales a gente que no conozco personalmente [I } \\
\text { add people to my social networks who I don't know personally]. }\end{array}$} \\
\hline \multicolumn{5}{|l|}{$\begin{array}{l}\text { 3. Me he comunicado alguna vez on-line con extraños (por ejemplo, } \\
\text { chateando) [I have communicated online with strangers (e.g., in chats)]. }\end{array}$} \\
\hline \multicolumn{5}{|l|}{$\begin{array}{l}\text { 4. Suelo publicar información personal en mis redes sociales: qué voy a } \\
\text { hacer, dónde y con quién; fotos o vídeos personales o familiares;.. [I usually } \\
\text { publish personal information on my social networks: what I am going to } \\
\text { do, where, and who with; personal or family photos or videos ... ]. }\end{array}$} \\
\hline \multicolumn{5}{|l|}{$\begin{array}{l}\text { 5. He quedado alguna vez con alguien en persona que conocía sólo de } \\
\text { Internet [I have met up with someone in person who I had only previously } \\
\text { known online]. }\end{array}$} \\
\hline \multicolumn{5}{|l|}{$\begin{array}{l}\text { 6. Doy mi número de teléfono a chicos o chicas a los que acabo de conocer } \\
\text { o conozco poco [I give my telephone number to boys or girls who I have } \\
\text { just met or who I don't know very well]. }\end{array}$} \\
\hline \multicolumn{5}{|l|}{$\begin{array}{l}\text { 7. He enviado alguna foto comprometida mía a otras personas a través del } \\
\text { teléfono móvil o Internet [I have sent compromising photos (mine or } \\
\text { belonging to someone else) by mobile phone or internet]. }\end{array}$} \\
\hline $\begin{array}{l}\text { 8. He intercambiado información personal mía con personas a las que solo } \\
\text { conozco de Internet [I have exchanged my personal information with } \\
\text { people who I have only known online]. }\end{array}$ & & & & \\
\hline
\end{tabular}
1 = completely false; 2 = somewhat false; 3 = somewhat true; 4 = completely true.

\section{References}

Álvarez-García, David, Trinidad García, Marisol Cueli, and José Carlos Núñez. 2018. Control parental del uso de Internet durante la adolescencia: Evolución y diferencias de género. Manuscript submitted for publication.

Ang, Rebecca P. 2015. Adolescent cyberbullying: A review of characteristics, prevention and intervention strategies. Aggression and Violent Behavior 25: 35-42. [CrossRef]

Corcoran, Lucie, Conor Mc Guckin, and Garry Prentice. 2015. Cyberbullying or Cyber Aggression? A Review of Existing Definitions of Cyber-Based Peer-to-Peer Aggression. Societies 5: 245-55. [CrossRef]

Duerager, Andrea, and Sonia Livingstone. 2012. How Can Parents Support Children's Internet Safety? London: EU Kids Online.

Elsaesser, Caitlin, Beth Russell, Christine McCauley Ohannessian, and Desmond Patton. 2017. Parenting in a digital age: A review of parents' role in preventing adolescent cyberbullying. Aggression and Violent Behavior 35: 62-72. [CrossRef] 
Giménez, Ana M., José A. Luengo, and M. José Bartrina. 2017. What are young people doing on Internet? Use of ICT, parental supervision strategies and exposure to risks. Electronic Journal of Research in Educational Psychology 15: 533-52. [CrossRef]

Gómez, Patricia, Sion Kim Harris, Carmen Barreiro, Manuel Isorna, and Antonio Rial. 2017. Profiles of Internet use and parental involvement, and rates of online risks and problematic Internet use among Spanish adolescents. Computers in Human Behavior 75: 826-33. [CrossRef]

Gómez-Ortiz, Olga, Rosario Del Rey, Eva María Romera, and Rosario Ortega-Ruiz. 2015. Los estiloseducativospaternos y maternos en la adolescencia y surelación con la resiliencia, el apego y la implicación en acoso escolar. Anales de Psicología 31: 979-89. [CrossRef]

Khurana, Atika, Amy Bleakley, Amy B. Jordan, and Daniel Romer. 2015. The Protective Effects of Parental Monitoring and Internet Restriction on Adolescents' Risk of Online Harassment. Journal of Youth and Adolescence 44: 1039-47. [CrossRef] [PubMed]

Lee, Sook-Jung. 2013. Parental restrictive mediation of children's internet use: Effective for what and for whom? New Media \& Society 15: 466-81. [CrossRef]

Lee, Sook-Jung, and Young-Gil Chae. 2012. Balancing Participation and Risks in Children's Internet Use: The Role of Internet Literacy and Parental Mediation. Cyberpsychology, Behavior, and Social Networking 15: 257-62. [CrossRef] [PubMed]

Liau, Albert Kienfie, Angeline Khoo, and Peng Hwaang. 2005. Factors Influencing Adolescents Engagement in Risky Internet Behavior. CyberPsychologyEBehavior 8: 513-20. [CrossRef]

Mesch, Gustavo S. 2009. Parental Mediation, Online Activities, and Cyberbullying. CyberpsychologyEBehavior 12: 387-93. [CrossRef]

Navarro, Raúl, Cristina Serna, Verónica Martínez, and Roberto Ruiz-Oliva. 2013. The role of Internet use and parental mediation on cyberbullying victimization among Spanish children from rural public schools. European Journal of Psychology of Education 28: 725-45. [CrossRef]

Nocentini, Annalaura, Juan Calmaestra, Anja Schultze-Krumbholz, Herbert Scheithauer, Rosario Ortega, and Ersilia Menesini. 2010. Cyberbullying: Labels, behaviours and definition in three European countries. Australian Journal of Guidance \& Counselling 20: 129-42.

Sasson, Hagit, and Gustavo Mesch. 2014. Parental mediation, peer norms and risky online behavior among adolescents. Computers in Human Behavior 33: 32-38. [CrossRef]

Sasson, Hagit, and Gustavo Mesch. 2017. The Role of Parental Mediation and Peer Norms on the Likelihood of Cyberbullying. The Journal of Genetic Psychology 178: 15-27. [CrossRef] [PubMed]

Valkenburg, Patti M., Jessica Taylor Piotrowski, Jo Hermanns, and Rebecca De Leeuw. 2013. Developing and Validating the Perceived Parental Media Mediation Scale: A Self-Determination Perspective. Human Communication Research 39: 445-69. [CrossRef]

(C) 2018 by the authors. Licensee MDPI, Basel, Switzerland. This article is an open access article distributed under the terms and conditions of the Creative Commons Attribution (CC BY) license (http:/ / creativecommons.org/licenses/by/4.0/). 

MDPI

St. Alban-Anlage 66

4052 Basel

Switzerland

Tel. +41 616837734

Fax +41 613028918

www.mdpi.com

Social Sciences Editorial Office

E-mail: socsci@mdpi.com

www.mdpi.com/journal/socsci

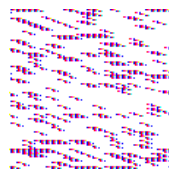



MDPI

St. Alban-Anlage 66

4052 Basel

Switzerland

Tel: +41 616837734

Fax: +41 613028918

www.mdpi.com 